\title{
Studies into the structural basis of the DNA uridine endonuclease activity of exonuclease III homolog Mth212
}

\author{
Dissertation \\ zur Erlangung des Doktorgrades \\ der Mathematisch-Naturwissenschaftlichen Fakultäten \\ der Georg-August Universität zu Göttingen
}

Vorgelegt von

Khaliun Tseden

aus Greifswald, Deutschland 
D7

Referent:

Prof. Dr. Hans-Joachim Fritz

Korreferent:

PD Dr. Wilfried Kramer

Tag der mündlichen Prüfung:

02. Mai 2011 


\section{Table of Contents}

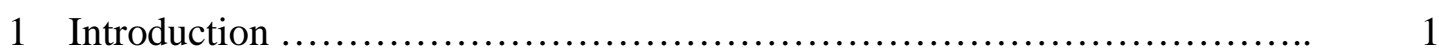

1.1. Background to the study …............................................ 1

1.1.1. Necessity of mutation avoidance.................................. 1

1.1.2. Mutations arising in DNA during replication ...................... 1

1.1.3. Exogenous sources of DNA damage .............................. 2

1.1.4. Endogenous sources of DNA damage .............................. 2

1.1.4.1. Hydrolytic DNA deamination ................................. 4

1.1.5. Repair of uracil in DNA .........................................

1.1.5.1. Uracil-initiated base excision repair ......................... 5

1.1.5.2. Uracil-initiated nucleotide incision repair ................. $\quad 7$

1.2. Objective and methodology of the study .............................. 9

1.2.1. Objective of the study......................................... 9

1.2.2. Methodology of the study ...................................... 9

1.2.2.1. Necessity of screening or selection methodology in 11 directed evolution of enzymes

1.2.2.2. Selection of a protein with acquired DNA uridine 11 endonuclease activity

2. Materials and Methods ................................................. 13

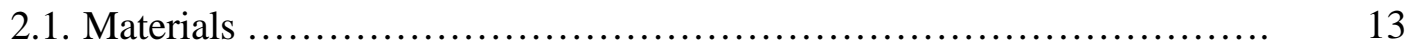

2.1.1. Bacterial strains …............................................ 13

2.1.1.1. Escherichia coli .......................................... 13

2.1.1.2. Bacillus subtilis .......................................... 14

2.1.2. Bacteriophage strains ............................................. 14

2.1.3. Plasmid vectors ................................................... 15

2.1.4. 2' Desoxyriboseoligonucleotides ................................. 17

2.1.5. Molecular ladders and markers ................................... 21

2.1.6. Enzymes and proteins ............................................ 22

2.1.7. Chemicals and reagents .......................................... 22

2.1.8. Molecular biology kits ........................................ 24

2.1.9. Buffers and solutions ............................................ 24 
2.1.10. Bacterial growth media ............................................ 29

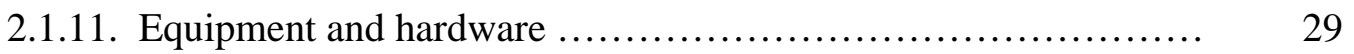

2.1.12. Other materials ...................................................... 31

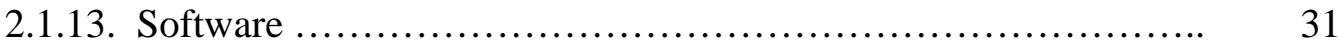

2.1.14. Databanks .......................................................... 32

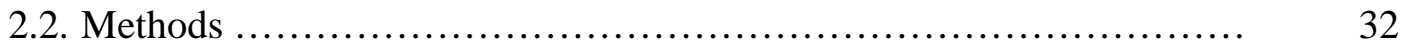

2.2.1. Microbiological methods ......................................... 32

2.2.2. Molecular biological methods .................................. $\quad 37$

2.2.3. Protein biochemical methods ..................................... 47

3. Results and Discussion ............................................... 53

3.1. Production and characterization of ExoA from Bacillus subtilis........... 53

3.1.1. Production and purification of ExoA …........................ 54

3.1.2. Biochemical characterization of ExoA …......................... 55

3.2. Attempted genetic selection of a protein carrying DNA uridine 57 endonuclease activity with the use of PBS1 bacteriophage

3.2.1. Design of a selection procedure …............................. 57

3.2.2. Construction of a mutant gene library ............................. 58

3.2.2.1. Optimisation of error-prone PCR conditions 59

3.2.2.2. Cloning of the library and transformation of E. coli 61

3.2.2.3. Investigation of transformation efficiencies of different $B$. 62 subtilis strains

3.2.3. Investigation of PBS1 bacteriophage .............................. 63

3.2.3.1. Verification of presence of uridine residues in PBS1 63 bacteriophage genome

3.2.3.1.1. Processing of PBS1 DNA in vivo .................. 65

3.2.3.2. Experiments to obtain clear-plaque mutant of PBS1 67 bacteriophage

3.3. Attempted genetic selection of a protein carrying U-Endo activity with 71 the use $E$. coli bacteriophage

3.3.1. Design of a selection procedure ................................... 71

3.3.2. Construction of a mutant gene library .............................. 72

3.3.3. Construction of E. coli mutant strains C1a Aung and C520 Aung .. $\quad 73$ 
3.3.4. Cloning of an amber-suppressor tRNA gene ................... 74

3.3.5. Cultivation of bacteriophage P2vir1Ram3 on dut- ung- strain ... 75

3.3.6. Survey of inability of P2vir1Ram3 bacteriophage to finish 76

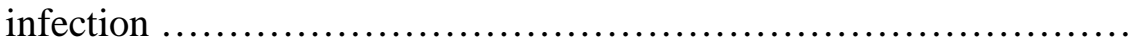

3.4. Attempted genetic selection based on heteroduplex DNA of phagemid 80 pBluescriptII with uracil containing mismatch

3.4.1. Construction of mutant gene library ........................ 81

3.4.2. Construction of heteroduplex DNA ........................... 81

3.5. ExoA triple mutant and selection of its stable variant by genetic 88 complementation.

3.5.1. Generation and purification of the ExoA S110G_R111K_R120K triple and R120K single mutants

3.5.2. Activity assays with ExoA variants

3.5.3. Attempts to optimize production of ExoA triple mutant protein ... 95

3.5.4. ExoA quadruple (S110G_R111K_D145N_R120K) mutant 96 production, purification and activity assays

3.5.5. Design of selection procedure of a stable variant of ExoA triple mutant

3.5.6. E. coli $\triangle x t h A$ strain and cytotoxicity of overproduced proteins .... 99

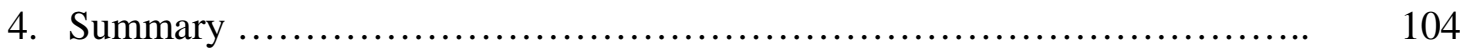

5. Abbreviations ....................................................... 106

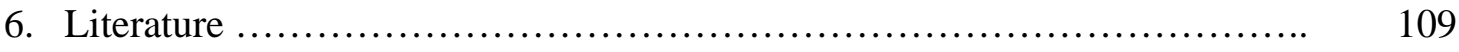

7. Appendix.............................................................. 121

7.1. Sequences (attached CD)

Acknowledgements

Curriculum vitae 


\section{Introduction}

\subsection{Background to the study}

\subsubsection{Necessity of mutation avoidance}

DNA, the carrier of genetic information in all cells and many viruses, is a dynamic molecule, subject to changes that alter this information (Lindahl, 1993). This genetic variability is essential for the adaptation and survival processes and drives the evolution. At the same time, an organism requires the correct functioning of lots of genes, damaging each of whose could have fatal consequences. Mutations in DNA can arise from natural cellular functions, like replication and recombination. In addition, the chemical instability of DNA under physiological conditions and susceptibility to reaction with various endogenous and exogenous compounds contribute to mutation pool. These mutations affect the structure of the genetic material and are considered to be DNA damage (Friedberg et al., 2006). Much of these mutations change the coding properties of DNA, leading to expression of defect proteins; some modifications alter the efficiency of transcription, stall the replication fork, which at large can lead to cell death. Therefore, existence of DNA damage recognition and removal processes is of crucial importance in mutation avoidance and viability. In the following subsections sources of DNA mutations are briefly discussed.

\subsubsection{Mutations arising in DNA during replication}

DNA replication is a highly precise process with fidelity of about one error per $10^{9}-10^{10}$ nucleotides (Kunkel, 1992). This high fidelity of DNA synthesis is achieved through cooperative action of DNA polymerase, exonucleolytic proofreading and post-replicative mismatch repair processes. DNA polymerase synthesizes the DNA with only one mistake per $10^{4}-10^{5}$ nucleotides as a result of a tight control on the stability of the newly formed hydrogen bonds in the active center of the enzyme. However, bias in the nucleotide pool and base tautomerisation can lead to various misincorporations (Roberts and Kunkel, 1996). In addition, polymerases are prone to "strand slippage" when copying sections of DNA that contain a large number of repeating nucleotides or repeating sequences which leads to deletions or insertions (Bichara et al., 2006). 3'-5' exonucleolytic proofreading activity associated with replicative polymerases usually increases the fidelity of DNA synthesis 100-fold (Benkovic and Cameron, 1995). Replication errors that were not corrected by the proofreading process are 
subject to post-replicative mismatch repair (MMR) thus increasing the fidelity of DNA synthesis by around three orders of magnitude (Friedberg et al., 2006).

\subsubsection{Exogenous sources of DNA damage}

DNA damage causing physical and chemical agents that are generated outside of the cell are covered in this sub-section. Physical mutagens are primarily radiation sources, including UVand ionizing radiation. Cyclobutane pyrimidine dimers (CPD) are the most common lesions produced in DNA when irradiated with UV. If not repaired, these lesions lead to replication arrest (Yoon et al., 2000). Ionizing radiation generates reactive oxygen species (ROS) which cause a variety of DNA lesions among of which hazardous DNA strand breaks are prevalent (Rastogi et al., 2010). Generally, enzymes involved in nucleotide excision repair (NER) pathway recognize and repair these DNA damages. Alkylating agents are the most abundant exogenous chemical mutagens. Abnormal base methylation, or AP-site formation are the results of their interaction with DNA. In addition, bifunctional alkylating agents can react with two different nucleophilic centers in DNA causing DNA cross-links. Chemicals, such as bleomycin and calicheamicin, cause DNA breaks or base modifications (Friedberg, 2006).

\subsubsection{Endogenous sources of DNA damage}

Normal metabolic processes also generate ROS, which, in addition to single-strand break formations, can modify DNA bases by oxidation (De Bont and van Larebeke, 2004). Both purine and pyrimidine bases are subject to oxidation. One of the most prevalent lesions in DNA is guanine oxidized to 8-oxo-7,8-dihydroguanine, which is capable of base pairing with adenine, resulting in a $\mathrm{G} \rightarrow \mathrm{T}$ transversion mutation following the replication (Ruiz-Laguna et al., 2000). Products of unsaturated lipids oxydation can react with bases in DNA resulting in exocyclic etheno adducts such as etheno-dC or etheno-dA. Generally, base alterations produced by oxidizing agents are substrates of the base excision repair (BER).

Intracellular S-adenosylmethionine (SAM), which is a methyl group donor in enzymatic methylation reactions, is known as a weak non-enzymatic DNA-methylating agent (Lindahl, 1993). One of the products of its reaction with DNA bases is $\mathrm{O}^{6}$-methylgunine $\left(\mathrm{O}^{6}-\mathrm{MeG}\right)$ which base pairs with thymine rather than with cytosine. This point mutation is repaired by 
damage reversal system by recruiting $\mathrm{O}^{6}-\mathrm{MeG}$ DNA methyltransferase, which removes the methyl group (E. C. Friedberg et al., 2006).

Another principal source of DNA damage is spontaneous hydrolysis reaction (Figure 1.1). Especially susceptible is the N-glycosidic bond of the purines. Depyrimidination also occurs, but about 30 times slower. The resulting apurinic/apyrimidinic (AP) sites, if not repaired, can lead to DNA chain rupture. It was estimated that 10000 depurination events occur daily in a diploid mammalian cell (Friedberg, 2006). Not only glycosidic bonds, but also DNA bases suffer from hydrolytic attacks. The exocyclic amino groups of the bases are labile and readily undergo reactions of hydrolytic deamination (Lindahl, 1993). Formation and repair of these DNA damages, especially of cytosine deamination, will be described in more details as it has direct relation to this work.

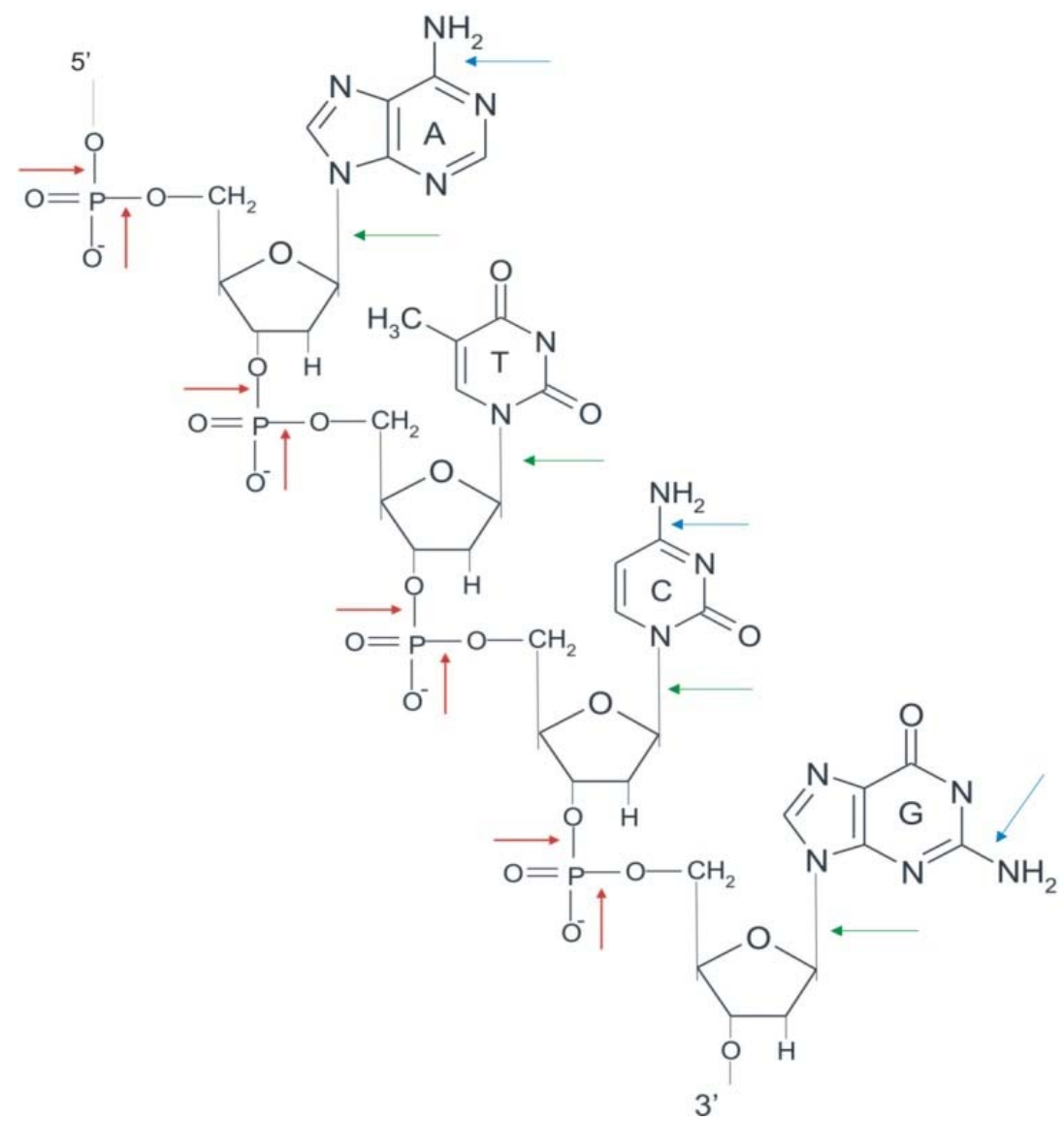

Figure 1.1: DNA primary structure with four principal DNA bases and major sites of spontaneous hydrolytic attack. Green arrows indicate N-glycosidic bonds; red arrows: phosphodiester bonds; blue arrows: bonds with exocyclic amino groups. Adapted from T. Lindahl, 1993. 


\subsubsection{Hydrolytic DNA deamination}

In the course of the hydrolytic deamination, purines adenine and guanine are converted into the hypoxanthine and xanthine residues, respectively. Xanthine is unable to pair stably with either cytosine or thymine and thus may result in arrested DNA synthesis, whereas hypoxanthine generates a pre-mutagenic lesion as it preferentially base pairs with cytosine (Friedberg, 2006). But as rates of purines deamination are low (for instance, conversion of adenine into hypoxanthine in single-stranded DNA occurs at about $2 \%$ of the rate of the conversion of cytosine to uracil (Lindahl, 1979)) and the resulting products are repaired efficiently, no real threat to the integrity of the genetic information is considered.

Hydrolytic deamination occurs most rapidly at 5-methylcytosine (5-meC) sites (Lindahl, 1993). 5-meC is produced by site-specific DNA (cytosine-5)-methyltransferase which transfer methyl group from S-adenosylmethionine to the C-5 position of cytosine in double-stranded DNA (Chen et al. 1994). Cytosine methylation has important functions such as modification of DNA as a defense against the invasion of the foreign DNA species in prokaryotes (Palmer and Marinus, 1994) and involvement in the regulation of gene expression, embryogenesis, genomic imprinting, aging, and some other processes in eukaryotic cells (Jaenisch and Bird, 2003). Deamination of 5-meC in DNA results in the formation of thymine and hence of $\mathrm{T} / \mathrm{G}$ mispair. The subsequent replication rounds will generate a $\mathrm{GC} \rightarrow \mathrm{AT}$ transition mutation. Base excision repair initiated by several highly specialized enzymes, and a specific repair process in some bacteria termed very short patch repair (VSP) mechanism are responsible for the repair of T/G mismatches (Bhagwat and Lieb, 2002).

Hydrolytic cytosine deamination occurs about 50 times quicker than deamination of the purines (Lindahl and Nyberg, 1972). Resulting uracil is formed at high rates especially in the single stranded DNA during transcription, replication or recombination (Lindahl and Barnes, 2000). Although uracil is normally confined to RNA, the formation of uracil in DNA is mutagenic due to its preferential pairing with adenine residue. If not repaired, this will lead to $\mathrm{GC} \rightarrow \mathrm{AT}$ transition mutation in $50 \%$ of progeny when replication proceeds. E. coli strains that are defective in the removal of uracil from DNA have an increased spontaneous mutation rate, and $\mathrm{GC} \rightarrow \mathrm{AT}$ base pair transitions are observed at selected sites in such mutants (Duncan and Miller, 1980). Deamination of cytosine can be enhanced by a number of chemical alterations and steric factors, by the formation of UV-radiation induced cyclobutane pyrimidine dimers, by certain intercalating agents or by the positioning of a mismatched or alkylated base 
opposite cytosine. Deamination can also be promoted by reaction with nitrous acid or sodium bisulfate (Friedberg et al., 2006). Generation of uracil by gamma radiation-induced deamination of cytosine and sensitivity of E. coli cells deficient in Ung and Smug1 DNA glycosylases to gamma-radiation was reported (An et al., 2005). In eukaryotic cells, uracil can arise in DNA due to the enzymatic deamination of cytosine (Harris et al., 2002), by drug treatment or folate deficiency (Kavil et al., 2007). In addition, uracil can be incorporated into DNA during semiconservative replication and the extent of this incorporation is directly related to the size of intracellular dUTP pool. Presence of U/A base pairs rather than T/A base pairs, in general, does not change the coding information, but uracil-containing DNA possesses the altered binding affinities for the transcription factors or other regulatory proteins (Verri et al., 1990).

Uracil residues in DNA exist transiently since they are subject to removal by the multi-step uracil initiated DNA base excision repair (BER) process in most organisms and by nucleotide incision repair pathway (NIR) described to date only in M. thermautotrophicus (Georg et al., 2006; Schomacher et al., 2009).

\subsubsection{Repair of uracil in DNA}

\subsubsection{Uracil-initiated base excision repair}

Base excision repair (BER), which is the primary defence mechanism against major forms of DNA base damage, occurs in two stages: an initial, damage specific stage carried out by individual DNA glycosylases targeted to distinct base lesions, and a damage-general stage that restores the correct DNA base sequence (Mol et al., 1999). Figure 1.2 illustrates how damagegeneral stage of BER after removal of uracil by uracil-DNA glycosylase proceeds.

\section{Uracil-DNA Glycosylases}

The first UDG was discovered in E. coli by T. Lindahl in 1974 in a search for activities that would repair uracil in DNA. This also represented the discovery of BER (Krokan et al., 2002). Ung from E. coli later proved to be a representative of widespread and highly conserved family of UDGs - family 1 . At present, UDGs are classified into 5 families comprising the UDG-superfamily. Distribution of UDG family representatives in certain eubacteria, eukaryotes and archaea are summarized in Table 1.1. 


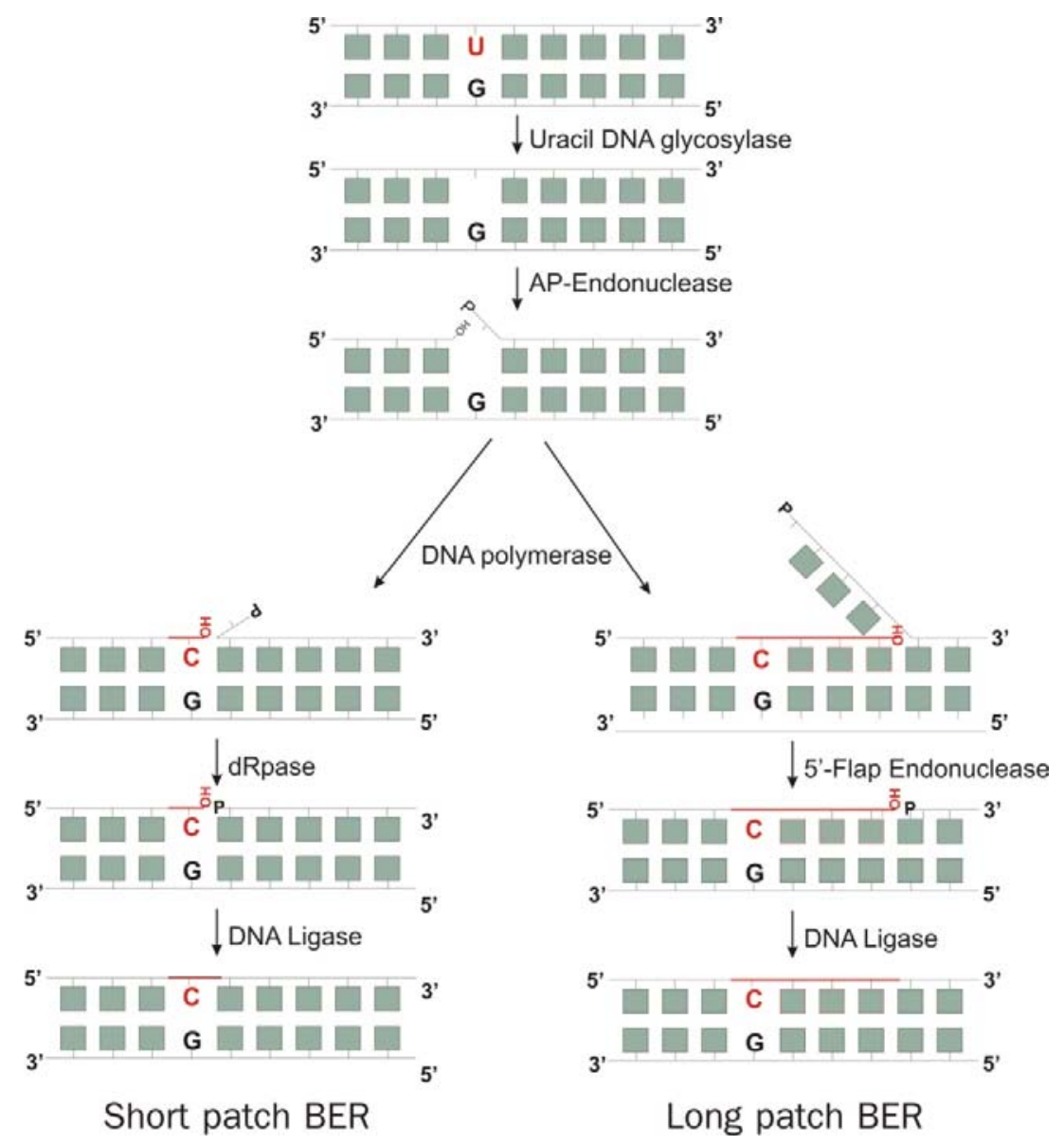

Figure 1.2: Schematic outline of uracil-initiated BER showing the separate steps. Uracil-DNA glycosylase recognises uracil base and cleaves the $\mathrm{N}-\mathrm{C} 1$ 'glycosidic bond between uracil base and deoxyribose sugar. Generated AP-site (apurinic/apyrimidinic site) is processed by an AP-Endonuclease by catalyzing the hydrolysis of sugar-phosphate backbone at the 5' side of AP-site and leaving 3'-OH and 5'-deoxyribose-phosphate (dRp) termini. In the short patch BER pathway 3'-OH serves as primer terminus for a DNA polymerase which replaces the AP-site by repair synthesis. dRp moiety is then removed by dRpase and the nick is ligated by a DNA ligase. In the long patch BER pathway strand displacement synthesis by DNA polymerase creates a 5' flap that is cleaved by 5 '-flap endonuclease to create a ligatable nick. Adapted from Friedberg et al., 2006 and Smolorz, 2009.

\begin{tabular}{|c|c|c|c|c|c|c|}
\hline & \multicolumn{2}{|c|}{ Eubacteria } & \multicolumn{2}{|c|}{ Eukaryotes } & \multicolumn{2}{|r|}{ Archaea } \\
\hline & E. coli & T. thermophilus & S. cerevisiae & H. sapiens & A. fulgidus & M. thermautotrophicus \\
\hline Family 1 (Ung) & + & + & + & + & - & - \\
\hline Family 2 (MUG/TDG) & + & + & - & + & - & + \\
\hline Family 3 (SMUG) & - & - & - & + & - & - \\
\hline Family 4 (tUDGa) & - & + & - & - & + & - \\
\hline Family 5 (tUDGb) & - & + & - & - & - & - \\
\hline
\end{tabular}

Table 1.1: Phylogenetic distribution of uracil-DNA glycosylases. +: encoded in genome; -: not detected; Ung Uracil N-Glycosylase, Mug/TDG - Mismatch specific Uracil-DNA-Gglycosylase/Mismatch-specific ThymineDNA-Glycosylase, SMUG - Single-strand-specific Monofunctional Uracil-DNA-Glycosylase, tUDGa and tUDGb - Thermostable Uracil-DNA Glycosylases. Adapted from Friedberg et al., 2006. 
Aside from enzymes from these 5 families, uracil in DNA is processed by DNA glycosylases which belong to structurally distinct "helix-hairpin-helix" $(\mathrm{HhH})$ superfamily. Mig.MthI from M. thermautotrophicus (Horst and Fritz, 1996), Pa-Mig from P. aerophilum (Yang et al., 2000), MBD4 from H. sapiens (Hendrich et al., 1999) belong to this class of enzymes. These enzymes remove uracil from $\mathrm{U} / \mathrm{G}$ and thymine from $\mathrm{T} / \mathrm{G}$ mismatches, and do not act on single-stranded DNA. However, uracil appears to be a minor substrate for these enzymes, since the uracil-excising activity is not robust in crude extracts (Sartori et al., 2001) and uracil can be removed only from certain sequence contexts (Horst and Fritz, 1996).

UDG activities corresponding to one family or other have been identified in organisms from all kingdoms, including the viruses, and many organisms have multiple examples. This distribution specifies the important role of uracil repair in the maintenance of genome integrity. The lack of UDGs which can be responsible for general uracil repair in some organisms, such as $M$. thermautotrophicus, can only stand for existence of alternative pathways to counteract the threat of uracil in DNA.

\subsubsection{Uracil-initiated nucleotide incision repair}

Nucleotide incision repair (NIR) is initiated through direct strand incision by an endonuclease resulting in 3'OH termini for DNA repair synthesis; the dangling damaged nucleotide is then a good substrate for flap endonuclease, DNA polymerase I or exonuclease (Ischenko and Saparbaev, 2002). Until Georg et al. (2006) identified Mth212 from M. thermautotrophicus to initiate the DNA uracil repair via NIR, E. coli Vsr-endonuclease was the only described enzyme to possess DNA uridine endonuclease activity. Vsr, however, incises the DNA strand only in the proper sequence context and processes only $\mathrm{U} / \mathrm{G}$ mismatches, therefore does not qualify as an initiator of general DNA uracil repair (Gläsner et al., 1995; Gabbara et al., 1994; Schomacher et al., 2009).

\section{Initiation of NIR by Mth212}

M. thermautotrophicus, as mentioned above, is devoid of genes encoding uracil-DNA glycosylases that can serve as initiators of general DNA uracil repair. Mismatch-specific glycosalyse Mig.MthII and $\mathrm{HhH}$ glycosylase Mig.MthI from this organism were found to be unable to initiate general DNA uracil repair as these enzymes excise uracil only within certain 
sequence contexts (Horst and Fritz, 1996; Starkuviene, 2001). To address the question to the DNA uracil repair in $M$. thermoautotrophicus $\Delta \mathrm{H}$ members of our laboratory fractionated the cell extract and searched for relevant activity. As result of their work Mth212, exonuclease III homolog, was discovered and characterized biochemically. Mth212, in addition to the numerous enzymatic activities inherent to exonuclease III homologs, recognises uridine in DNA and cleaves the phosphodiester backbone direct to the 5'side of the 2'deoxyuridine residue independently of the sequence context and the nucleotide juxtaposed to the uridine residue in the complementary strand (Georg et al., 2006).

Repair studies in vitro employing whole cell extracts demonstrated that in $M$. thermautotrophicus $\Delta \mathrm{H}$ general repair of DNA uracil residues is initiated by this direct strand incision catalyzed solely by Mth212 and this organism is completely dependent of this pathway (Schomacher et al., 2009). The presence of Mth212, DNA polymerase B (mthPolB), 5'-flap endonuclease (mthFEN) and DNA ligase (mthDNA_ligase), purified to apparent homogeneity, was sufficient for complete repair of DNA uracil residues in vitro (Schomacher et al., 2010).

If compared to BER (Figure 1.2), in this pathway Mth212 substitutes the two-step reaction achieved by consecutive action of UDG and AP-endonuclease in a single-step reaction by directly incising the DNA strand on 5' side of uridine residue. Following steps correspond to the long patch BER pathway: strand displacement synthesis by DNA polymerase (mthPolB) creates a 5 ' flap that is cleaved by 5 '-flap endonuclease (mthFEN) to create a ligatable nick which is processed by DNA ligase (mthDNA_ligase).

Besides direct damage reversal, this constitutes the simplest DNA repair pathway characterized so far. This simplicity naturally suggests that this mechanism should be widely spread phylogenetically. However, in most organisms BER is the "quarterback" to withstand the threat of uracil in DNA. This suggests that the evolution of DNA uracil repair had at least two alternative ways: (1) evolution of uracil specific DNA glycosylase activity in some protein, resulting in the foundation of the UDG-superfamily and (2) expanding the substrate spectrum of an AP-endonuclease such that it accepts, in addition, uracil as substrate, as is the case with Mth212. The possibility of another alternative is still open as there are organisms, 
such as M. kandleri AV19 and M. stadtmanae, devoid of both UDG genes and exonuclease III homolog genes (Schomacher et al., 2009).

\subsection{Objective and methodology of the study}

\subsubsection{Objective of the study}

What is the structural basis of the unique activity of Mth212? The finding of a new pathway of uracil repair for archaeal DNA raised this question along with a query regarding the molecular mechanism of uracil recognition, in particular how Mth212 discriminates against cytosine and thymine residues. Within all identified and characterized exonuclease III homologs Mth212 is the only known (to date) representative that recognizes uridine in the DNA and initiates the repair. However, multiple sequence alignment of exonuclease III homologs with Mth212 revealed no remarkable divergence from the conserved sequence that can be in charge of the unique activity. In X-ray crystallography studies of the enzyme, co-crystallised with DNA (in cooperation with the department of Prof. Dr. R. Ficner), enzyme invariably bound to the ends of substrate DNA duplexes thus precluding insight into its interaction with DNA uridine residue. To begin of this study, attempts to clarify the mechanism of uracil recognition by means of directed mutagenesis were met with little success.

In this study, it is attempted to elucidate the mechanism of uridine recognition of Mth212. As above mentioned conventional methods were insufficient in shedding light on this mechanism, another approach was employed. New route taken employs genetics, the idea being to take an exonuclease III homolog without DNA uridine endonuclease activity and to provide it with this activity by means of directed evolution.

\subsubsection{Methodology of the study}

Directed evolution of proteins is known to be a powerful tool for generating enzymes with properties such as improved catalytic activities, increased thermostability or new substrate specificities. At the same time, modifying protein function precedes understanding the molecular mechanisms underlying those modifications (Arnold, 1998). This means that a transformation of a protein, homologous to Mth212 but with no activity against uracil, into DNA uridine endonuclease will bring about the knowledge of which amino acid residues 
participate in the uridine recognition. Projecting these amino acids onto 3D structure of Mth212 will lead to the elucidation of structural peculiarities of Mth212 that lie underneath the unique activity and, at the same time, it is possible to shed light on the pathway taken by natural evolution that resulted on this activity. In addition, this knowledge can facilitate the discovery of other organisms, whose genomes are sequenced, that employ the same mechanism as $M$. thermautotrophicus for general DNA uracil repair.

When converting an enzyme into DNA uridine endonuclease, it is rational to remodel a protein scaffold which at most resembles Mth212. ExoA, exonuclease III homolog from B. subtilis, was chosen as an object for randomization. This protein, which shares $46 \%$ identity and $64 \%$ similarity with Mth212, was described as a multifunctional DNA-repair enzyme with APendonuclease, 3'-5' exonuclease, ribonuclease $\mathrm{H}$, and 3'-monoesterase activities (Shida et al., 1999). Crystal structure of this protein has not been solved yet. In addition, B. subtilis being host for PBS1 bacteriophage was decisive for choosing exonuclease III homolog from this organism for directed evolution (Results and Discussion, Section 3.2.1).

\section{Directed evolution of enzymes involved in DNA repair and synthesis}

The enzymes responsible for DNA repair and replication are in general highly conserved across diverse domains of life. And the question arising is whether such enzymes can tolerate changes in their amino acid sequence.

The nucleotide sequence of DNA polymerases is highly conserved within families and these enzymes demonstrate a remarkable conservation of structure, even in particularly divergent organisms. However, extensive studies on directed evolution carried out with T.aquaticus Pol I (Taq Pol I) revealed high mutability of the polymerase active site in vivo (Patel and Loeb, 2000). Moreover, Taq polymerase mutants that were able to efficiently synthesize long stretches of RNA from a DNA template were isolated. (Xia et al., 2002). In other study HSV-1 TK gene encoding thymidine kinase was mutagenized and the enzymes with altered substrate specifities were reported (Black et al., 1996). $\mathrm{O}^{6}$-Alkylguanine-DNA Alkyltransferase variants were evolved that show enhanced function, have altered substrate specifities or more resistant to inhibitors (Davidson et al., 2002). In every case the creation of large altered proteins has 
been achieved and the emerging picture is that even highly conserved proteins can tolerate wide-spread amino acid changes at the active site without substantial loss of activity.

\subsubsection{Necessity of screening or selection methodology in directed evolution of enzymes}

Directed evolution experiments consist of two major steps: first, the creation of genetic diversity in the target gene in the form of gene libraries; and second, an effective selection of the library for the desired catalytic activity. An array of methods has been developed to generate diversity: depending on the experiment, mutagenesis might entail degenerate oligonucleotide-directed or error-prone DNA synthesis, shuffling of mutant DNA fragments, combinatorial synthesis and other methods (for overview refer to Results and Discussion, Section 3.2.2 - 3.2.3). The bottleneck for most directed enzyme evolution endeavors is the availability of a genuinely high-throughput screen or selection for the target activity (Aharoni et al., 2005). The difference between screening and selection lies in screening being an active search performed on individual clones and requires some spatial organization of the screened variants on agar plates, microtiter plates, arrays or chips, whereas selection act simultaneously on the entire pool of genes. Thus, the main advantage of genetic selection over screening is that many more library members can be analyzed at once. In the best screening protocols, which take advantage of fluorogenic or chromogenic substrates, the maximum number of library members that can be assayed is about $10^{5}$ (Hilvert et al., 2002). In contrast, up to $10^{9}$ clones can be assessed using genetic selection in vivo in $E$. coli cells. The limit of the clones that can be surveyed is dependent, at least theoretically, on transformation efficiency. Therefore, genetic selection in bacteria other than E. coli, can be less efficient due to lower transformation efficiencies. It is challenging to develop suitable selection strategy for a particular catalytic activity. Coupling of the target reaction to survival in the selection step may require development of complex, non-trivial and intelligent assays (Hilvert et al., 2002). In fact, most of the experimental effort of directed evolution is devoted to devising, validating and implementing a suitable methodology (Arnold, 1998).

\subsubsection{Selection of a protein with acquired DNA uridine endonuclease activity}

As described above, in protein evolution experiment the most demanding step is the development of a selection strategy. Since it is intended to provide an enzyme with DNA 
uridine endonuclease activity, selection approach should meet following demands: (1) DNA uridine, the substrate for the new activity, must present in assay and (2) desired enzymatic activity must ensure the isolation of cells carrying this particular mutant from other cells. During this study three selection approaches for selecting ExoA mutant carrying DNA uridine endonuclease activity from the library were designed and tested.

\section{Further application of established methodology}

Once established, the selection approach can be employed in identifying enzymes responsible for the initiation of DNA uracil repair. Genomic libraries of organisms such as M. mazei, M. jannaschii, M. kandleri, M. maripaludis, where no UDG gene is available, can be constructed and enzymes responsible for general DNA uracil repair can be identified. 


\section{Materials and Methods}

\subsection{Materials}

\subsubsection{Bacterial strains}

\subsubsection{Escherichia coli}

BL21_UXX (Georg et al., 2006)

E. coli B, F-, ompT, hsdS (rB-mB-), dcm+, TetR, gal 1(DE3), endA, Hte [argU, ileY, leuW, $\mathrm{CmR}]$, sung

One Shot TOP10 (Invitrogen, Carlsbad, CA)

F- $m c r \mathrm{~A} \Delta(m r r-h s d \mathrm{RMS}-m c r \mathrm{BC}) \varphi 80 l a c \mathrm{Z} \Delta \mathrm{M} 15 \Delta$ lacX74 nup G recA1 araD139 $\Delta$ (araleu)7697 galE15 galK16 rpsL( $\left.\operatorname{Str}^{\mathrm{R}}\right)$ end $\mathrm{A} 1 \lambda^{-}$

DH5a (Invitrogen, Carlsbad, CA)

F-, $\Phi 80$ dlacZ M15, endA1, recA1, hsdR1 (rK-mK+), supE44, thi-1, gyrA96 (NalR), relA1, (lacZYA- $\arg F) \mathrm{U} 169$

TOP10F' (Invitrogen, Carlsbad, CA)

$\mathrm{F}^{\prime}\left[\right.$ lacl $^{q}$ Tn10(tet $\left.\left.{ }^{\mathrm{R}}\right)\right]$ mcrA $\Delta(m r r-h s d \mathrm{RMS}-m c r \mathrm{BC}) \quad \varphi 80 l a c \mathrm{Z} \Delta \mathrm{M} 15$ AlacX74 deoR nupG recAl araD139 $\Delta$ (ara-leu) 7697 galU galK $\operatorname{rpsL}\left(\mathrm{Str}^{\mathrm{R}}\right)$ endA1 $\lambda^{-}$

XL1-Red (Stratagene, USA)

F- endA1 gyrA96(nal $\left.{ }^{\mathrm{R}}\right)$ thi-1 relA1 lac $g \ln \mathrm{V} 44 h s d \mathrm{R} 17\left(\mathrm{r}_{\mathrm{K}}{ }^{-} \mathrm{m}_{\mathrm{K}}{ }^{+}\right)$mut $\mathrm{S}$ mut $\mathrm{T}$ mutD5 Tn10

CJ236 (New England Biolabs, Ipswich, MA)

F $\Delta\left(\right.$ HindIII)::cat $\left(\mathrm{Tra}^{+} \mathrm{Pil}^{+} \mathrm{Cam}^{\mathrm{R}}\right) /$ ung-1 relA1 dut-1 thi-1 spoTl mcrA

XL10-Gold Kan $^{\mathrm{r}}$ ultracompetent cells (Stratagene, USA)

$\operatorname{Tet}^{\mathrm{r}} \Delta(m c r A) 183 \Delta($ mcrCB-hsdSMR-mrrr) 173 endA1 supE44 thi-1 recA1 gyrA96 relA1 lac The [F' proAB lacl $^{q} \mathrm{Z} \Delta \mathrm{M} 15 \mathrm{Tn} 10\left(\mathrm{Tet}^{\mathrm{r}}\right) \mathrm{Tn} 5\left(\mathrm{kan}^{\mathrm{r}}\right)$ Amy]

C1a (Prof. G. E. Christie, Virginia Commonwealth University, USA), (Sasaki and Bertani, 1965)

F- prototrophic

C1a Aung (this study)

F- Aung::kan

C520 (Prof. G. E. Christie, Virginia Commonwealth University, USA), (Sunshine et al., 1971)

F- supD

C520 Aung (this study)

F- supD $\Delta u n g:: k a n$ 
NM522 (Promega, Madison, USA)

$\mathrm{F}^{\prime} \operatorname{proA}^{+} B^{+}$lacl $^{q} \Delta($ lacZ)M15/ $\Delta($ lac-proAB) glnV thi-1 $\Delta($ hsdS-mcrB $) 5$

NM522 Aung (Ber, 2009)

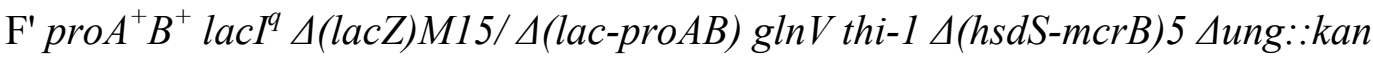

BW25113 $\Delta$ xthA (Ber, 2009)

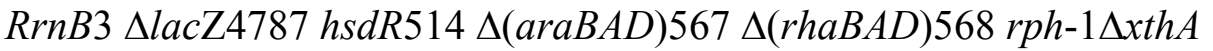

\subsubsection{Bacillus subtilis}

W168 (BGCS, The Ohio State University, USA)

$\operatorname{trp} \mathrm{C} 2$

SB19E (BGCS, The Ohio State University, USA)

ctrA1, ts-2, Erm ${ }^{\mathrm{R}}$

IH6140 (Dr. V. Kontinen collection of strains, National Institute for Health and Welfare, Helsinki, Finnland), (Palva et al., 1983)

Low exoprotease activity strain derived from strain IH6040: amyE aroI906 metB5 sacA321; obtained after multiple mutagenesis steps with NNG

IG-20 (BGSC, The Ohio State University, USA), (Bron et al, 1975)

$\operatorname{trp} \mathrm{C} 2, \mathrm{r}(-), \mathrm{m}(-)$

ISW1214 (Dr. J-H. Kim collection of strains, Gyeongsang National University, Korea), (Ishiwa and Shibahara-Sone, 1986)

Tetracycline sensitive strain derived from strain 1012: $\operatorname{trp} \mathrm{C} 2, h s r \mathrm{M} 1$, leuA8, metB5; obtained after mutagenesis with introsoguanidine

\subsubsection{Bacteriophage strains}

PBS1 (BGSC, The Ohio State University, USA), (Takahashi, 1963)

P2 vir1 (Prof. G. E. Christie, Virginia Commonwealth University, USA), (Bertani, 1957)

P2 vir1 Ram3 (Prof. G. E. Christie, Virginia Commonwealth University, USA), (Lindahl, 1971)

M13K07 helper phage (New England Biolabs, Ipswich, MA)

P1 (house collection) 


\subsubsection{Plasmid vectors}

Below are the schematic representations of vectors used in this study. Gene reading frames are colored blue and replication origins are colored grey. Arrows indicate transcription or replication directions. Restriction endonuclease recognition sites used for the cloning of DNA fragments are shown. All schemes are created using Vector NTI 11.5 Software (Invitrogen, Carlsbad, CA).

\subsubsection{1 pET_28a (Novagen, San Diego, CA)}

For the nucleotide sequence of the pET28a vector refer to Appendix 7.1.1.

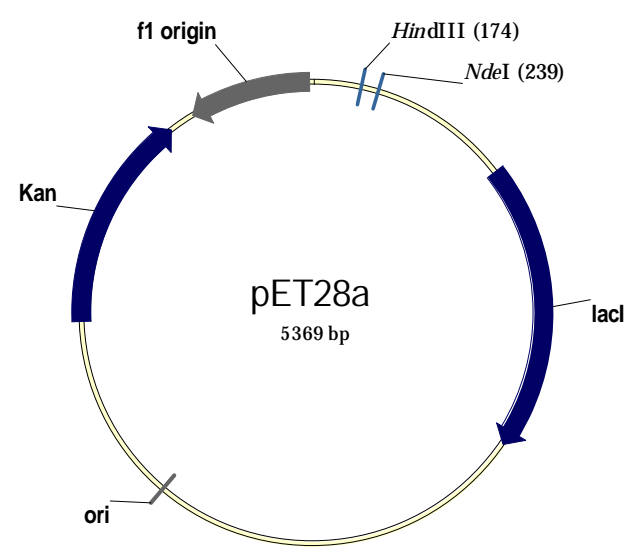

Figure 2.1: Schematic representation of pET_28a vector

Kan: neomycine phosphotransferase gene, provides kanamycine resistance. lacI: gene for Lac repressor.

\subsubsection{2 pJET 1.2 (Fermentas, Burlington, Ontario)}

For the nucleotide sequence of pJET1.2 vector refer to Appendix 7.1.2.

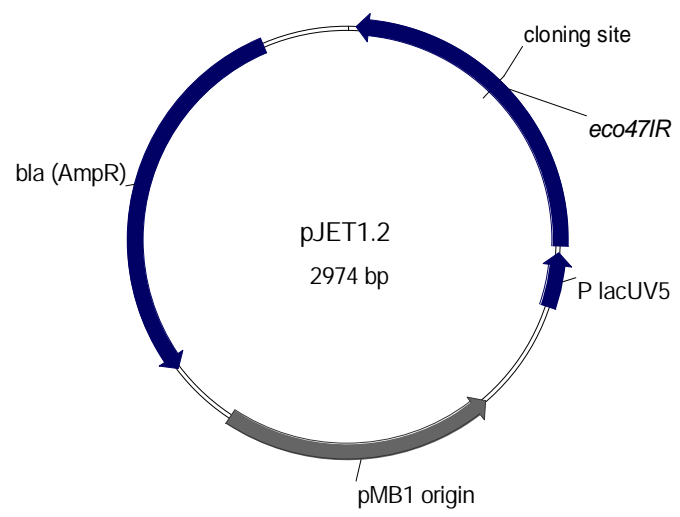

Figure 2.2: Schematic representation of pJET1.2 vector

bla: gene for $\beta$-lactamase, provides ampicilline resistance. Eco47IR: gene for a restriction endonuclease, lethal for $E$. coli when expressed

\subsubsection{3 pBQ200_BpiI (Prof. Dr. J. Stülke, Institute of Mocrobiology and Genetics,}

Göttingen) (Martin-Verstraete et al., 1994)

pBQ200_BpiI vector was obtained by introducing 2 BpiI (BbsI) restriction endonuclease sites via Site directed Quick-change ${ }^{\circledR}$ mutagenesis into pBQ200 vector DNA. For the nucleotide sequence of pBQ200_BpiI vector refer to Appendix 7.1.3. 


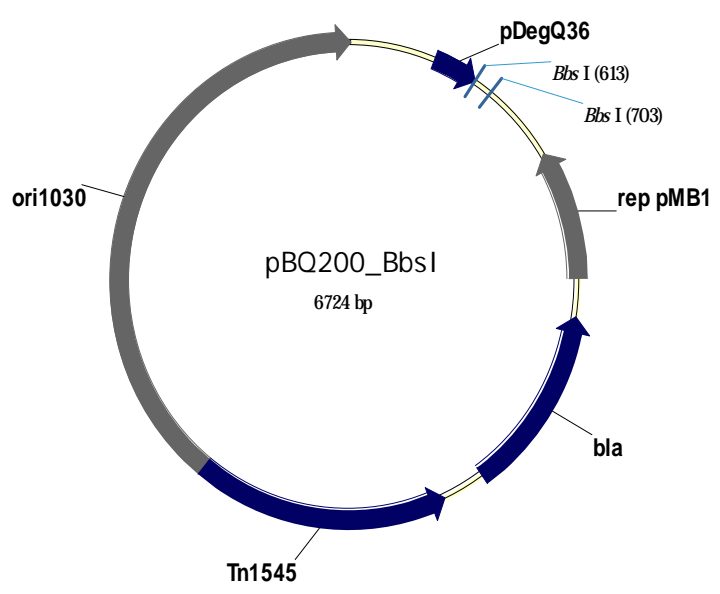

Figure 2.3: Schematic representation of pBQ200_BpiI vector

bla: gene for $\beta$-lactamase, provides ampicilline resistance. $\operatorname{Tn} 1545$ : transposon Tn1545 from Streptococcus pneumoniae carrying rRNA methylase gene, provides erythromycin resistance. Ori1030: B. subtilis replication origin. pDegQ36: mutagenized promoter of B. subtilis $\operatorname{deg} Q$ gene (Msadek et al., 1991).

\subsubsection{4 pASK-08 (IBA GmbH, Göttingen, Germany)}

pASK-08 vector was obtained from pASK_IBA3plus vector (B. Popova, unpublished). For the nucleotide sequence of pASK-08 vector refer to Appendix 7.1.4.

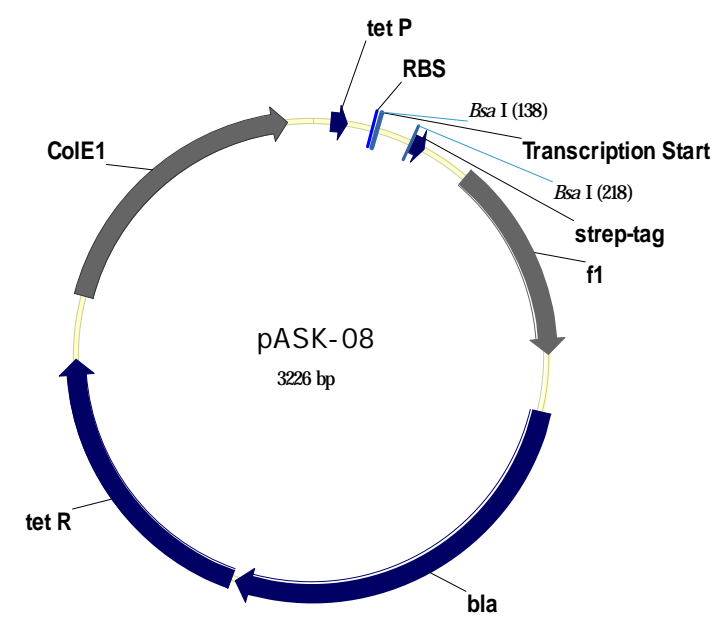

Figure 2.4: Schematic representation of pASK-08 vector

bla: gene for $\beta$-lactamase, provides ampicilline resistance. tetR: gene for repressor of tet promoter. tetP: tet promoter. RBS: ribosome binding site

\subsubsection{5 pTNA (Prof. Dr. R. Sterner, Biophysik und biophysikalische Chemie,}

\section{Universität Regensurg)}

pTNA vector was obtained from pDS56/RBSII/SphI (Qiagen, Hilden, Germany) vector, by exchanging the promoter region with E. coli Tryptophanase promoter (Henn-Sax, Disseration, 2001). For the nucleotide sequence of pTNA vector refer to Appendix 7.1.5.

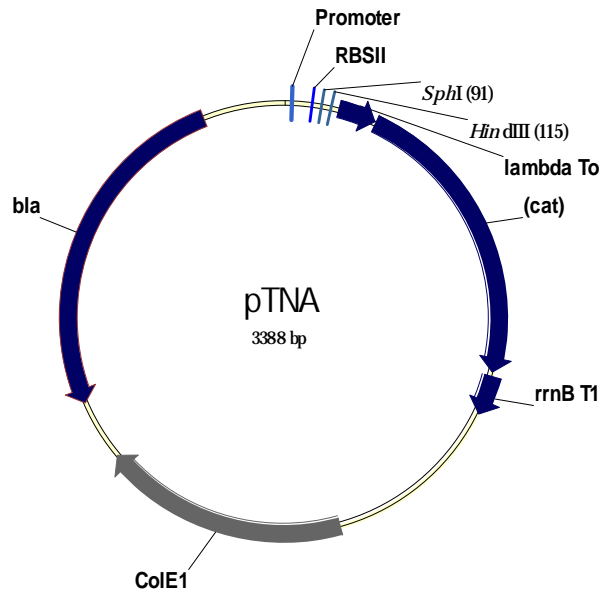

Figure 2.5: Schematic representation of pTNA vector

bla: gene for $\beta$-lactamase, provides ampicilline resistance. (cat): chloramphenicol acetyl transferase gene, protein is not expressed due to the lack of promoter. RBS II: synthetic ribosome binding site. lambda To, rrnB T1: terminator sequences. 


\subsubsection{6 pACYC177 (Chang and Cohen, 1978)}

For the nucleotide sequence of pACYC177 vector refer to Appendix 7.1.6.

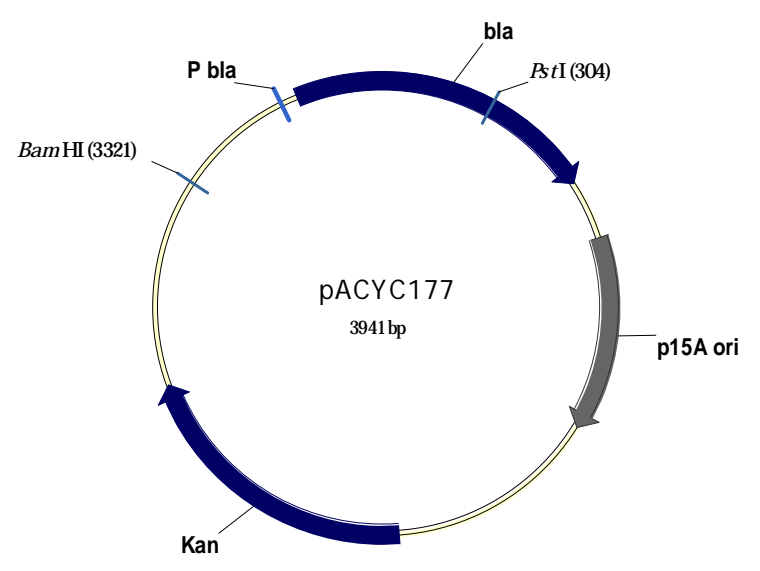

Figure 2.6: Schematic representation of pACYC177 vector

bla: gene for $\beta$-lactamase, provides ampicilline resistance. Kan: neomycine phosphotransferase gene, provides kanamycine resistance. $\mathrm{P}$ bla: promoter of bla gene

\subsubsection{7 pBluescipt II SK (+) (Fermentas, Burlington, Ontario)}

For the nucleotide sequence of pBluescript II SK $(+)$ vector refer to Appendix 7.1.7.

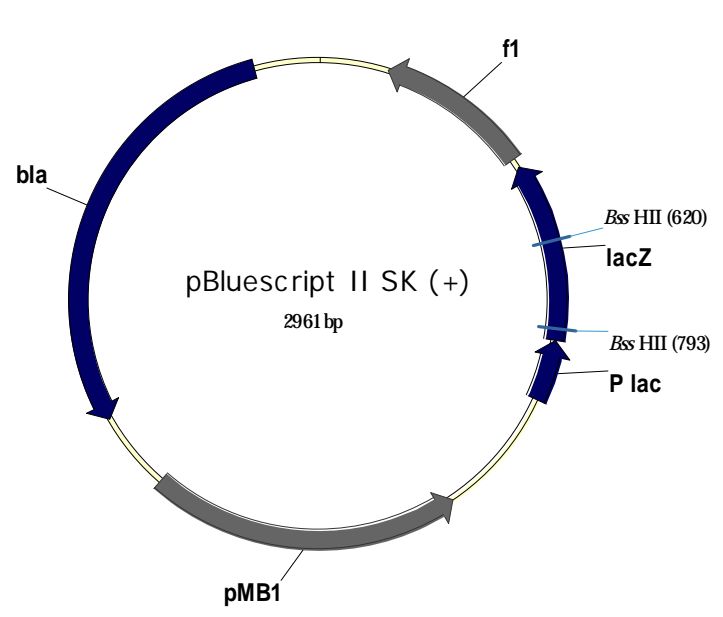

Figure 2.7: Schematic representation of pBluescript II SK (+) vector

bla: gene for $\beta$-lactamase, provides ampicilline resistance. lacZ: gene for $\mathrm{N}$-terminal fragment of $\beta$-galactosidase. Plac: promoter of lacZ gene. f1: bacteriophage $\mathrm{fl}$ intergenic (IG) region carrying the sequences required in cis for initiation and termination of phage f1 DNA synthesis and for packaging of DNA into bacteriophage particles. pBluescipt II SK $(+)$ is replicated such that the sense strand of $l a c Z$ gene is secreted within the phage particles.

\subsubsection{2' Desoxyriboseoligonucleotides}

All oligonucleotides were purchased from either Sigma (München) or PURIMEX (Gebenstein).

\subsubsection{Primers for polymerase chain reaction}

Primers for cloning of exoA into pET28a vector:

$$
\begin{array}{ll}
\text { ExoA_For } & \text { 5'AACATATGAAGTTGATTTCATGGAATG 3' } \\
\text { ExoA_Rev } & \text { 5' CGAAGCTTTCATATATTGATGATAAGTTC 3' }
\end{array}
$$


Primers for cloning of exo $A$ into pBQ200 vector:
ExoA_XbaI_F
5'TCTAGACTCACTTATTTAAAGGAGGAAA
CAATCATGAAGTTGATTTCATGGAATG 3'
$\begin{array}{ll}\text { ExoA_HindIII_R } & \text { 5'AAGCTTCTAAGCATGATGATGATGATGA } \\ & \text { TGTATATTGATGATAAGTTCAACCAC 3' }\end{array}$

Primers for cloning of $m t h 212$ into pBQ200 vector:
Mth212pbq200xbaIF
5' TCTAGACTCACTTATTTAAAGGAGGAAACAA TCATGACCGTGCTAAAAATAATA 3'
Mth212pbq200pstIR
5' CTGCAGCTAATGATGATGATGATGATGTAGTT CTATTTCCAGTCCTATGG 3'

Primers for cloning exo $A$ into pASK vector:
pASK_BsaI_exoA_F
5' GTGTGGTCTCAAATGAAGTTGATTTCATGGAA 3'
exoA_pASK_6His_2R
5' GTGGTCTCAGCTACTAATGATGATGATGATGA TGTATATTGATGATAAGTTC 3'

Primers for cloning exo $A$ into pTNA vector:

exoA_pTNA_F

ExoA_HindIII_3R
5'GTGCATGCTAAAGTTGATTTCATGGAATGTAAAC 3'

5' GTAAGCTTCTAAGCATGATGATGATGATGATGT

ATATTGATGATAAGTTCAACAGG 3'

Primers for verification of ung deletion:
KAN_SEN
5' CGGTGCCCTGAATGAACTGC 3'
KAN_ANT
5' CGGCCACAGTCGATGAATCC 3'
UNG_AUS_SEN
5' CATCAACTTATGCGGGTGTG 3'
UNG_AUS_ANT

Primers for cloning of serU132 into pACYC177 vector:
serU_EcoRI_F
5' TGGAATTCGTTTTGCTCGCAAACTCGTCAC 3'
serU_PstI_R
5' TGCTGCAGGtgtaAATCGTACAATGGtAAG 3'

Primers for cloning $c c d B$ into pBluescript II SK $(+)$ :
ccdB_BssHII_2F
5' GTGCGCGCAGTTTAAGGTTTACACC 3'
ccdB_BssHII_R
5' GTGCGCGCTTATATTCCCCAGAACATCAGG 3'

\subsubsection{Primers for Error-Prone PCR}

Cloning into $\mathrm{pBQ} 200$ vector:
Exoa_ep_bpii_F
5' TGTGCGTCTCAGTTCCTCACTTATTTAAAGG 3'
Ep_exoa_esp3i_newR
5' TGTGCGTCtCTAGCGCTAAGCATGATGATGATG 3'

Cloning into pASK-08 vector:

pASK_EP-PCR_F 5' GTGTGGTCTCAAATGAAG 3' 
pASK_EP-PCR_2R

5'GTGGTCTCAGCTACTAATGATGATGATGATGATG 3'

Cloning into pTNA vector:

exoA_pTNA_EP-PCR_F 5' GAGGAGAAATTAAGCATGC 3'

ExoA_ep_pbq200_R 5' AAGCTTCTAAGCATGATGATGATGATGATG 3'

\subsubsection{Primers for Site-Directed Mutagenesis}

Introduction of 2 BpiI restriction sites into $\mathrm{pBQ} 200$ vector:

0512before1 5' GTAACAGATCAAATACCGAAGACTCGTTCACCCGGGATC 3'

0512before2 5' GATCCCCGGGTGAACGAGTCTTCGGTATTTGATCTGTTAC 3'

0512after1 5' GTGAAATTGTTATCCGCTCAGTCTTCCACACAACAT ACGAGCC 3'

0512after2 5' GGCTCGTATGTTGTGTGGAAGACTGAGCGGATAACA ATTTCAC 3',

Removal of $S p h \mathrm{I}$ restriction site from exoA:

exoA_QC_F 5' GATTAGAGCGGATTGATTACCGTATGCAATGGGAAGA GGCTTTAC 3'

exoA_QC_R 5' GTAAAGCCTCTTCCCATTGCATACGGTAATCAATCCG CTCTAATC 3 ,

Overlap Extension Mutagenesis of $c c d B$ :

ccdB_overlapextension_1

5' GATCCCCCTGGCTAGCGCACGTCTGCTGTCAGATTAAGTCT CCCGTGAGCTCTACCCGGTGG 3'

ccdB_overlapextension_2

5'CCACCGGGTAGAGCTCACGGGAGACTTAATCTGACAGCAG

ACGTGCGCTAGCCAGGGGGATC 3'

ExoA R120K mutagenesis:

exoA_R120K_F 5'GATTAGAGCGGATTGATTACA

AGATGCAATGGGAAGAGG 3'

exoA_R120K_R 5' CCTCTTCCCATTGCATCTTGT

AATCAATCCGCTCTAATC 3'

ExoA S110_R111K_R120K mutagenesis:

exoA_3exchanges_F

5' GTTTACACGCCCAATGGCAAAAGGGGATTAGAGCGGAT

TGATTACAAGATGCAATGGGAAGAGG 3'

exoA_3exchanges_R

5'CCTCTTCCCATTGCATCTTGTAATCAATCCGCTCTAATCC

CCTTTTGCCATTGGGCGTGTAAAC 3' 
ExoA_D145N mutagenesis:

ExoA_D145N_1 5' CAGTGATTTTATGCGGTAATTTGAATGTAGCCCATC 3'

ExoA_D145N_2 5' GATGGGCTACATTCAAATTACCGCATAAAATCACTG 3'

\subsubsection{Primers for DNA sequencing analysis}

pJET1.2 vector sequencing primers:

pJET1.2 Forward 5' CGACTCACTATAGGGAGAGCGGC 3'

pJET1.2 Reverse 5' AAGAACATCGATTTTCCATGGCAG 3'

pASK vector sequencing primers:

pASK_seq_F 5' CCACTCCCTATCAGTGATAG 3'

pASK_seq_R 5' GTCGCACAATGTGCGCC 3'

pTNA vector sequencing primers:

$\begin{array}{ll}\text { pTNA_seq_2F } & 5, \text { AATAAACAAATAGGGGTTCC 3' } \\ \text { pTNA_seq_2R } & 5, \text { TATCCAGTGATTTTTTTCTC 3, }\end{array}$

pBluescript II SK $(+)$ sequencing primers

pBluescript_seq1 5' GAATAGACCGAGATAGGGTTG 3'

pBluescript_seq2 5' CTGCAAGGCGATTAAGTTGGG 3'

pBluescript_seq3 5' GGCACGACAGGTTTCCCGACTGG 3'

Primers for sequencing gpR region of $\mathrm{P} 2$ bacteriophage:

P2_gpR_seq_F 5' GCAGACGAACGGCGATTTAAG 3'

P2_gpR_seq_R 5' CTGCCGCAGACGTTTCGCCAG 3'

\subsubsection{Oligonucleotides for Endonuclease Assay}

40_Prince_AP: 5'(F) GGGTACTTGGCTTACCTGCCCTGAPGCAGCTGTGGGCGCAG3'

40_Prince_U: 5'(F) GGGTACTTGGCTTACCTGCCCTGUGCAGCTGTGGGCGCAG3'

40_Prince_C: 5'(F) GGGTACTTGGCTTACCTGCCCTGCGCAGCTGTGGGCGCAG3'

40_Prince_T: 5'(F) GGgTACTTGGCTTACCTGCCCTGTGCAGCTGTGGGCGCAG3'

40_Prince_G: 5'CCCACAGCTGCGCAGGGCAGGTAAGCCAAGTACCCTACGT3'

40_Prince_C: 5'CCCACAGCTGCCCAGGGCAGGTAAGCCAAGTACCCTAGCT3'

40_Prince_A: 5'CCCACAGCTGCACAGGGCAGGTAAGCCAAGTACCCTAGCT3'

40_Prince_T: 5'CCCACAGCTGCTCAGGGCAGGTAAGCCAAGTACCCTAGCT3'

35_Prince_G: 5' CTGCGCCCACAGCTGCGCAGGGCAGGTAAGCCAAG 3'

23-M (23mer): 5'(F)GGGTACTTGGCTTACCTGCCCTG 3'

Underlined nucleotides build a mismatch pair in substrate oligonucleotides used in enzymatic tests. F: fluorescein (6-isomer); AP: model of a stable AP site 


\subsubsection{Molecular Ladders and Markers}

\subsubsection{DNA size marker}
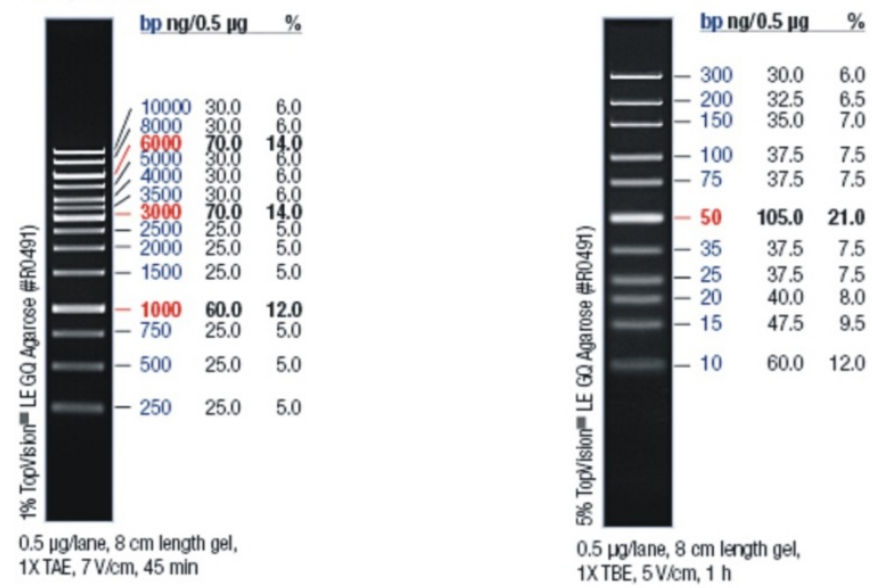

Figure 2.8: GeneRuler ${ }^{\mathrm{TM}} 1 \mathrm{~kb}$ DNA Ladder (left) and GeneRuler ${ }^{\mathrm{TM}}$ Ultra Low Range DNA Ladder (right) (Fermentas, Burlington, Ontario).

The DNA molecular length standards were adjusted with TE buffer (2.1.9) and 6x loading dye solution (Fermentas) to the DNA concentration of $0.1 \mu \mathrm{g} / \mu \mathrm{l}$ and stored at $4{ }^{\circ} \mathrm{C}$. Lengths are indicated in base pairs (bp).

\subsubsection{Protein size marker}

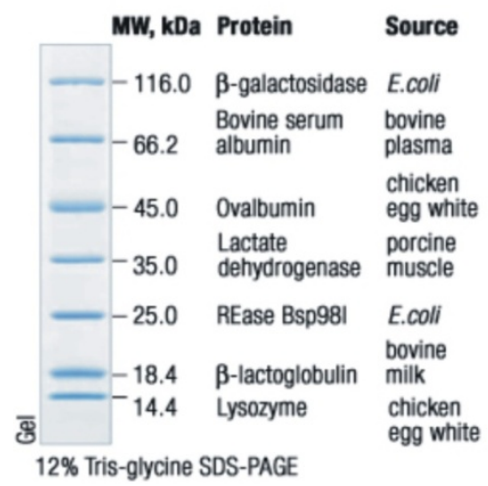

Figure 2.9: Unstained protein molecular weight marker (Fermentas, Burlington, Ontario) . This marker was used in all SDS-PAGE analyses.
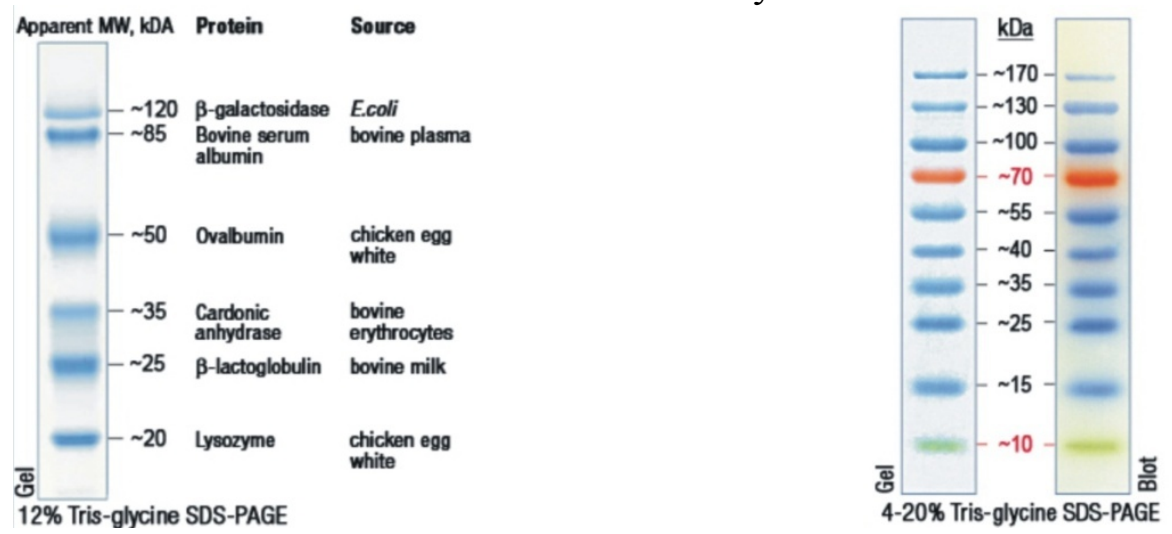

Figure 2.10: Prestained Protein Molecular Weight Marker (left) and PageRuler ${ }^{\mathrm{TM}}$ Prestained Protein Ladder (right) (Fermentas, Burlington, Ontario). These markers were used for Western blot analyses (2.2.3.2). 


\subsubsection{Enzymes und Proteins}

$\begin{array}{ll}\text { Boehringer (Mannheim) } & \text { Ribonuclease A (Rnase A). } \\ \text { Fermentas (Burlington, Ontario) } & \text { Restriction endonucleases } \\ & \text { Pfu-DNA-Polymerase (recombinant) } \\ & \text { T4-DNA-Ligase } \\ & \text { Calf Intestine Alkaline Phosphatase (CAP) } \\ \text { New England Biolabs Inc. (Ipswich, MA) } & \text { Restriction endonucleases } \\ & \text { Taq-DNA-Polymerase } \\ & \text { M. mazei } \text { tUDGa - produced in E. coli and } \\ \text { Own laboratory } & \text { purified (by S. Ber) } \\ & \text { Ugi from PBS2 bacteriophage, produced in E. } \\ & \text { coli and purified (by L. Schomacher) } \\ & \text { Mth212 from } M . \text { thermautotrophicus, } \\ & \text { produced in } E . \text { coli and purified (by E. } \\ & \text { Ciirdaeva) } \\ \text { Anti-Penta-His mouse monoclonal IgG1 } & \text { antibody (BSA free) } \\ \text { Proteinase K } \\ \text { Lysozyme } \\ \text { Anti-mouse IgG (whole molecule)-Alkaline } \\ \text { phosphatase conjugated, produced in goat } \\ \end{array}$

\subsubsection{Chemicals and reagents}

\section{AGS GmbH, Heidelberg:}

Qualex Gold Agarose

\section{AppliChem, Darmstadt:}

Acrylamid 4k - 30\% solution; Ampicillin (Sodium salt); Bisacrylamid

4K-2\% solution; Chloramphenicol; Erythromycin; Coomassie Brilliant Blue G250 und R250; Dithiothreitol (DTT); Methanol; Nickel (II)-Chloride;

\section{Fermentas:}

Isopropyl- $\beta$-D-Thio-Galactopyranosid (IPTG)

\section{Fluka, Neu-Ulm:}

Bromphenol blue; Dimethylsulfoxyd (DMSO); Glycerol, 87\%; Formamide; Polyethylene glycol (PEG) 6000; 


\section{GE Healthcare, Uppsala, Sweden:}

Chelating Sepharose ${ }^{\mathrm{TM}}$ Fast Flow

Invitek, Berlin:

dNTP (2'-Desoxyribosenucleosidtriphosphate)

\section{Merck, Darmstadt:}

2-Mercaptoethanol; Calcium chloride dehydrate; Formaldehyde; Magnesium chloride hexahydrat

\section{MJ Research, Waltham, MA:}

Chill-out ${ }^{\mathrm{TM}}$ liquid wax

\section{Oxoid, Cambridge, UK:}

Yeast extract; Tryptone; Bacteriological agar

\section{Pharmacia LKB, Uppsala, Sweden:}

Blue Dextran 2000

\section{Roche Diagnostics, Mannheim:}

"Complete, EDTA-free" Protease Inhibitor Cocktail Tablets

\section{Roth GmbH, Kalsruhe:}

Ammonium acetate, Ammonium chloride, Ammonium sulphate, Ampicillin sodium salt, Chloramphenicol, Citric acid monohydrate, Disodium phosphate, Ethanol, Ethidium bromide, Acetic acid, Urea, (4-(2-hydroxyethyl)-1-piperazineethanesulfonic acid (HEPES), 2-Propanol, Kanamycin, Potassium chloride, Potassium hydroxide, Methanol, Sodium acetate, Sodium chloride, Monosodium phosphate, Sodium hydroxide, Sodium thiosulfate, Phenol, Phosphoric acid, Rotiphorese ${ }^{\circledR}$ Gel30 (Acrylamide:Bisacrylamide 37.5:1), Sucrose, Hydrochloric acid (smoking), Tris (hydroxymethyl) aminomethane

\section{Scharlau Chemie, Barcelona, Spain:}

Ammonium persulfate, Chloroform, Boric acid, Imidazole

\section{Serva, Heidelberg:}

Ethylenediaminetetraacetic acid (EDTA), Glycine, Sodiumlaurylsulphate (SDS),

N,N,N',N'- Tetramethylethylenediamine(TEMED)

\section{Sigma, Steinheim:}

Lincomycin, Tetrasodium pyrophosphate, Triethanolamine, Triton X-100 (OctylphenolPolyethylenglycol), Polyethylenglycol-Sorbitan-Monolaurat $\left(\mathrm{TWEEN}^{\circledR} 20\right)$, Xylencyanol FF 


\subsubsection{Molecular biology Kits}

Fermentas, Burlington, Ontario

Genomed, Bad Oyenhausen

Macherey-Nagel, Düren

Roche Diagnostics, Mannheim

\subsubsection{Buffers and solutions}

\section{Common used buffers:}

ALF-marker

95\% Formamide, 20mM EDTA pH 8.0, 5

$\mathrm{mg} / \mathrm{ml}$ Dextran-Blue, stored at $4^{\circ} \mathrm{C}$

APS stock solution, $10 \%$

Ammonium persulfate in $\mathrm{H}_{2} \mathrm{O}$, stored in

aliquots at $-20^{\circ} \mathrm{C}$

dNTP stock solution

$10 \mathrm{mM}$ of each dNTP in $\mathrm{H}_{2} \mathrm{O}$, stored at $-20^{\circ} \mathrm{C}$

EDTA stock solution

$500 \mathrm{mM}$ EDTA dissolved in $\mathrm{H}_{2} \mathrm{O}$ with addition of solid $\mathrm{NaOH}$

DTT stock solution

1M DTT in $\mathrm{H}_{2} \mathrm{O}$, sterilised $(0.45 \mu \mathrm{m}$ pore size filter) and stored at $-20^{\circ} \mathrm{C}$

Ethidium bromide stock solution

$10 \mathrm{mg} / \mathrm{ml}$ Ethidium bromide

Isopropyl- $\beta$-D-thiogalactopyranosid

(IPTG) stock solution

$1 \mathrm{M}$ IPTG in $\mathrm{H}_{2} \mathrm{O}$, sterilised $(0.45 \mu \mathrm{m}$ pore size filter) and stored at $-20^{\circ} \mathrm{C}$

PBS-Buffer $(1 \mathrm{x})$

$10 \mathrm{mM} \mathrm{Na}_{2} \mathrm{HPO}_{4}, 1.8 \mathrm{mM} \mathrm{KH}_{2} \mathrm{PO}_{4} \mathrm{pH}$ 7.3, $140 \mathrm{mM} \mathrm{NaCl}, 2.7 \mathrm{mM} \mathrm{KCl}$

Phenol/Chloroform

25 vol. of phenol/TE, 24 vol. of Chloroform,

1 vol. of Isoamyl alcohol

Phenol/TE

Phenol, saturated with TE-Buffer, $0.1 \%$ (w/v)

8-Hydroxychinolin

SDS-PAGE Loading buffer (Hoechst) $\quad$ 98\% Formamide, 10 mM EDTA pH 8.0, 0.025\% Xylencyanol FF, 0.025\% Bromphenol blue

RNase A stock solution

$10 \mathrm{mg}$ RNaseA in $1 \mathrm{ml}$ of $10 \mathrm{mM}$ Tris/HCl $\mathrm{pH}$

$7.5,15 \mathrm{mM} \mathrm{NaCl}$. The mixture was preheated for $15 \mathrm{~min}$ at $100^{\circ} \mathrm{C}$ and cooled down at RT 
SSC-Buffer

Sucrose marker (DNA loading buffer)

50x TAE buffer

10x TBE buffer

T4-DNA-Ligase buffer

TE-buffer

Polymerase Buffers:

ThermoPol Reaction Buffer (10x)
$50 \mathrm{mM} \mathrm{NaCl}, 15 \mathrm{mM}$ Sodium citrate

$60 \%(\mathrm{w} / \mathrm{v})$ Sucrose, $0.05 \%(\mathrm{w} / \mathrm{v})$ Bromphenol blue, $0.05 \%(\mathrm{w} / \mathrm{v})$ Xylencyanol FF in TAE-

Buffer

2M Tris/Acetate, $50 \mathrm{mM}$ EDTA

0.89M Tris/Borate $\mathrm{pH} 7.9,25 \mathrm{mM}$ EDTA

$400 \mathrm{mM}$ Tris/ $\mathrm{HCl} \mathrm{pH} 7.8,100 \mathrm{mM} \mathrm{MgCl} 2$,

$100 \mathrm{mM}$ DTT, 5 mM ATP

$10 \mathrm{mM}$ Tris/HCl pH 8.0, 0.5 mM EDTA
$200 \mathrm{mM}$ Tris/HCl, $100 \mathrm{mM} \mathrm{KCl,20mM}$

$\mathrm{MgSO}_{4}, 100 \mathrm{mM}\left(\mathrm{NH}_{4}\right)_{2} \mathrm{SO}_{4}, 1 \%(\mathrm{v} / \mathrm{v})$ Triton

$\mathrm{X}-100, \mathrm{pH} 8.8$ at $25^{\circ} \mathrm{C}$

Pfu-Polymerase Buffer (10x) with $\mathrm{MgSO}_{4} \quad 200 \mathrm{mM}$ Tris/HCl pH 8.8, 100mM $\left(\mathrm{NH}_{4}\right)_{2} \mathrm{SO}_{4}$, $100 \mathrm{mM} \mathrm{KCl}, 1 \%(\mathrm{v} / \mathrm{v})$ Triton X-100, 1mg/ml BSA, 20mM $\mathrm{MgSO}_{4}$

\section{Antibiotic stock solutions:}

All stock solutions are sterilized by filtering $(0.45 \mu \mathrm{m}$ pore size $)$ and stored at $-20^{\circ} \mathrm{C}$.

Ampicillin stock solution

Chloramphenicol stock solution

Erythromycin stock solution

Kanamycin stock solution

Lincomycin stock solution

Tetracycline stock solution

\section{Buffers for chromatography:}

IMAC wash buffer

IMAC-elution buffer

Heparin column wash buffer

Wash buffer for making salt gradient
$100 \mathrm{mg} / \mathrm{ml}$ in $\mathrm{H}_{2} \mathrm{O}$

$25 \mathrm{mg} / \mathrm{ml}$ in Ethanol

$2 \mathrm{mg} / \mathrm{ml}$ in $\mathrm{H}_{2} \mathrm{O}$

$50 \mathrm{mg} / \mathrm{ml}$ in $\mathrm{H}_{2} \mathrm{O}$,

$25 \mathrm{mg} / \mathrm{ml}$ in $\mathrm{H}_{2} \mathrm{O}$

$25 \mathrm{mg} / \mathrm{ml}$ in $\mathrm{H}_{2} \mathrm{O}$

$25 \mathrm{mM}$ HEPES /KOH pH 7.6, 0.5M NaCl

$30 \mathrm{mM}, 60 \mathrm{mM}, 70 \mathrm{mM}, 80 \mathrm{mM}, 90 \mathrm{mM}$,

$100 \mathrm{mM}, 300 \mathrm{mM}$, and $500 \mathrm{mM}$ Imidazole in

IMAC wash buffer

20 mM HEPES/KOH pH 7.6,

$5 \mathrm{mM}$ 2-Mercaptoethanol (sterile filtrated)

$3 \mathrm{M} \mathrm{NaCl}$, sterile filtrated 
JETSTAR buffers (Genomed, Bad Oeynhausen):

E1

E2

E3

E4

E5

E6
$50 \mathrm{mM}$ Tris/HCl pH 8.0, $10 \mathrm{mM}$ EDTA

$200 \mathrm{mM} \mathrm{NaOH}, 1 \%$ (w/v) SDS

3.1M Potassium acetate $\mathrm{pH} 5.5$

$100 \mathrm{mM}$ Sodium acetate $\mathrm{pH}$ 5.0, $600 \mathrm{mM} \mathrm{NaCl}$,

$0.15 \%$ Triton $\mathrm{X}-100$

$100 \mathrm{mM}$ Sodium acetate $\mathrm{pH}$ 5.0, $800 \mathrm{mM} \mathrm{NaCl}$, $100 \mathrm{mM}$ Tris/ $\mathrm{HCl} \mathrm{pH} 8.5,1.25 \mathrm{M} \mathrm{NaCl}$

\section{Buffers for restriction endonucleases (1x, Fermentas, Burlington, Ontario):}

B+ buffer

$10 \mathrm{mM}$ Tris/ $\mathrm{HCl} \mathrm{pH} 7.5,10 \mathrm{mM} \mathrm{MgCl}{ }_{2}$,

$0.1 \mathrm{mg} / \mathrm{ml} \mathrm{BSA}$

G+ buffer

$10 \mathrm{mM}$ Tris/ $\mathrm{HCl} \mathrm{pH} 7.5,10 \mathrm{mM} \mathrm{MgCl}$, $50 \mathrm{mM} \mathrm{NaCl}, 0.1 \mathrm{mg} / \mathrm{ml} \mathrm{BSA}$

$\mathrm{O}+$ buffer

$50 \mathrm{mM}$ Tris- $\mathrm{HCl} \mathrm{pH} 7.5,10 \mathrm{mM} \mathrm{MgCl}$,

$100 \mathrm{mM} \mathrm{NaCl}, 1 \mathrm{mg} / \mathrm{ml}$ BSA

$\mathrm{R}+$ buffer

$10 \mathrm{mM}$ Tris/ $\mathrm{HCl} \mathrm{pH} 8.5,10 \mathrm{mM} \mathrm{MgCl}_{2}$,

$100 \mathrm{mM} \mathrm{KCl}, 0.1 \mathrm{mg} / \mathrm{ml} \mathrm{BSA}$

Buffer $\mathrm{Y}+/$ Tango $^{\mathrm{TM}}$

$33 \mathrm{mM}$ Tris/Acetate $\mathrm{pH}$ 7.9, $10 \mathrm{mM}$ magnesium acetate, $66 \mathrm{mM}$ pothassium acetate, $0.1 \mathrm{mg} / \mathrm{ml}$ BSA

BamHI-buffer

$10 \mathrm{mM}$ Tris/ $\mathrm{HCl} \mathrm{pH}$ 8.0, $5 \mathrm{mM} \mathrm{MgCl} 2,100 \mathrm{mM}$

$\mathrm{KCl}$, $0.02 \%$ Triton X-100, $0.1 \mathrm{mg} / \mathrm{ml}$ BSA

EcoRI-buffer $50 \mathrm{mM}$ Tris/ $\mathrm{HCl} \mathrm{pH} 7.5,10 \mathrm{mM} \mathrm{MgCl}$, $100 \mathrm{mM} \mathrm{NaCl}, 0.02 \%$ Triton $\mathrm{X}-100,0.1 \mathrm{mg} / \mathrm{ml}$ BSA

\section{Buffers for restriction endonucleases (1x, New England Biolabs, Ipswich, MA):}

NEB 1

NEB 2

NEB 3
10 mM Bis-Tris Propane/HCl pH 7.0, 10 mM

$$
\mathrm{MgCl}_{2}, 1 \mathrm{mM} \text { DTT }
$$

$10 \mathrm{mM}$ Tris/ $\mathrm{HCl} \mathrm{pH}$ 7.9, $10 \mathrm{mM} \mathrm{MgCl}$,

$50 \mathrm{mM} \mathrm{NaCl}, 1 \mathrm{mM}$ DTT

$50 \mathrm{mM}$ Tris/ $\mathrm{HCl} \mathrm{pH} 7.9,10 \mathrm{mM} \mathrm{MgCl}_{2}$, $100 \mathrm{mM} \mathrm{NaCl}, 1 \mathrm{mM}$ DTT 
NEB 4

Activity assay buffer:

Endonuclease buffer (1x)

\section{Sucrose Gradient Buffers:}

$10 \%$ Sucrose Buffer

$30 \%$ Sucrose Buffer

$40 \%$ Sucrose Buffer

\section{SDS-PAGE buffers:}

Loading dye (or sample buffer)

Laemmli buffer (1x)

SDS

Stacking gel buffer

Separating gel

\section{Buffers for Western Blot analysis}

AP detection buffer

BCIP stock solution

Blocking Buffer

NBT stock solution

Semi-dry Transfer Buffer

TBS-Tween Buffer
Coomassie R250 dye solution

$20 \mathrm{mM}$ Tris/Acetate $\mathrm{pH}$ 7.9, 10mM Magnesium acetate, $50 \mathrm{mM}$ Potassium acetate, $1 \mathrm{mM}$ DTT

$20 \mathrm{mM} \mathrm{H}_{2} \mathrm{KPO}_{4} / \mathrm{HK}_{2} \mathrm{PO}_{4}$ buffer $\mathrm{pH}$ 6.2, $50 \mathrm{mM} \mathrm{KCl}, 1 \mathrm{mM} \mathrm{MgCl} 2,0.1 \mathrm{mg} / \mathrm{ml} \mathrm{BSA}$

$100 \mathrm{mM}$ Tris/HCl pH 8.0, 10mM EDTA, $10 \mathrm{mM}$ $\mathrm{NaCl}, 10 \%(\mathrm{w} / \mathrm{v})$ Sucrose, autoclaved $100 \mathrm{mM}$ Tris $/ \mathrm{HCl} \mathrm{pH} 8.0,10 \mathrm{mM}$ EDTA, $10 \mathrm{mM}$ $\mathrm{NaCl}, 30 \%(\mathrm{w} / \mathrm{v})$ Sucrose, autoclaved $100 \mathrm{mM}$ Tris $/ \mathrm{HCl} \mathrm{pH} 8.0,10 \mathrm{mM}$ EDTA, $10 \mathrm{mM}$ $\mathrm{NaCl}, 40 \%$ (w/v) Sucrose, autoclaved

$0.7 \%(\mathrm{w} / \mathrm{v})$ Coomassie R-250 in Methanol, $20 \%$ Acetic acid, mixed at 1:1 before use 200 mM Tris/HCl, 8M Urea, 200 mM DTT, 2\% (w/v) SDS, 0.05\% Bromphenol blue 25 mM Tris/HCl pH 8.4, 200 mM Glycin, $0,1 \%(\mathrm{w} / \mathrm{v}) \mathrm{SDS}$ $10 \%(\mathrm{w} / \mathrm{v}) \mathrm{SDS}$ in $\mathrm{H}_{2} \mathrm{O}$ $1.25 \mathrm{M}$ Tris/ $/ \mathrm{HCl} \mathrm{pH} 6.8$ $1.875 \mathrm{M}$ Tris/ $\mathrm{HCl} \mathrm{pH} 8.8$

$100 \mathrm{mM}$ Tris $\mathrm{pH} 9.5,5 \mathrm{mM} \mathrm{MgCl} 2,100 \mathrm{mM} \mathrm{NaCl}$ $50 \mu \mathrm{g} / \mathrm{ml}$ in $100 \% \mathrm{DMF}$

5\% BSA in TBS-Tween Buffer

$75 \mu \mathrm{g} / \mathrm{ml}$ in $70 \% \mathrm{DMF}$

$25 \mathrm{mM}$ Tris, $150 \mathrm{mM}$ Glycine, 10\% Methanol $20 \mathrm{mM}$ Tris/ $\mathrm{HCl} \mathrm{pH} 7.5,500 \mathrm{mM} \mathrm{NaCl}, 0.05 \%$

Tween 20

Buffers for preparation of $E$. coli competent cells
$30 \mathrm{mM}$ KOAc, $100 \mathrm{mM} \mathrm{RbCl}, 10 \mathrm{mM} \mathrm{CaCl}_{2}$, $50 \mathrm{mM} \mathrm{MnCl} 2,15 \%$ Glycerin, $\mathrm{pH} 8.5$ with Acidic acid, sterile filtrated 
TFBII

10mM MOPS, $75 \mathrm{mM} \mathrm{CaCl}_{2}, 10 \mathrm{mM} \mathrm{RbCl}, 15 \%$

Glycerin $\mathrm{pH} 6$ with $\mathrm{KOH}$, sterile filtrated

Buffers and solutions for $B$. subtilis transformation

$1 \mathrm{mM}$ HEPES, $\mathrm{pH} 7$

PEB-Buffer

272mM Sucrose, $1 \mathrm{mM} \mathrm{MgCl}$, $7 \mathrm{mM}$ Potassium phosphate, $\mathrm{pH} 7.4$

2xSMM

$342 \mathrm{~g}$ sucrose, $4.72 \mathrm{~g}$ Sodium maleate, $8.12 \mathrm{~g}$

$\mathrm{MgCl}_{2} \times 6 \mathrm{H}_{2} \mathrm{O}$, adjust $\mathrm{pH}$ to 6.5 with $\mathrm{NaOH}$, add

$\mathrm{H}_{2} \mathrm{O}$ to $1 \mathrm{~L}$, autoclaved $10 \mathrm{~min}$ at $109^{\circ} \mathrm{C}$

SMMP

equal volume of 2xSMM and 4XPAB-Medium

PEG

$10 \mathrm{~g}$ of Polyethylene glycol 8000 in $2 \mathrm{ml}$ of

$1 \mathrm{xSMM}$, autoclaved $10 \mathrm{~min}$ at $109^{\circ} \mathrm{C}$

G-P. Xue growth medium

LB medium containing $0.5 \mathrm{M}$ Sorbitol

G-P. Xue recovery medium

LB containing o.5M Sorbitol, 0.38M Mannitol,

G-P. Xue electroporation medium

0.5M Sorbitol, 0.5M Mannitol, 10\% Glycerol

Buffers and solutions for working with bacteriophages

PBS1 bacteriophage

Y-medium

$10 \mathrm{mM} \mathrm{K}_{2} \mathrm{HPO}_{4}, 20 \mathrm{mM} \mathrm{NaH} \mathrm{PO}_{4}, 0.1 \%$ (w/v)

yeast extract, $100 \mathrm{mM} \mathrm{NaCl}, 30 \mathrm{mM} \mathrm{K}_{2} \mathrm{SO}_{4}$,

$0.5 \mathrm{mM} \mathrm{MgSO}_{4}, 0,1 \mathrm{mM} \mathrm{CaCl}_{2}, 0.04 \mathrm{mM}$

$\mathrm{FeCl}_{3} \times 6 \mathrm{H}_{2} \mathrm{O}$ in $\mathrm{H}_{2} \mathrm{O}$, autoclaved

PBS1-Buffer

$100 \mathrm{mM} \mathrm{NaCl}^{3} 3 \mathrm{mM} \mathrm{K}_{2} \mathrm{HPO}_{4}, 20 \mathrm{mM} \mathrm{NaH}_{2} \mathrm{PO}_{4}$,

$0.5 \mathrm{mM} \mathrm{MgSO}_{4}, 0,1 \mathrm{mM} \mathrm{CaCl}_{2}, 0.04 \mathrm{mM}$

$\mathrm{FeCl}_{3} \times 6 \mathrm{H}_{2} \mathrm{O}, 0.1 \%$ (w/v) yeast extract in $\mathrm{H}_{2} \mathrm{O}$,

autoclaved

\section{P2 bacteriophage}

P2 bacteriophage growth medium

LB containing $0.1 \%$ Glucose, $2 \mathrm{mM} \mathrm{MgCl}_{2}$

P2 Buffer

$10 \mathrm{mM}$ Tris, $\mathrm{pH} 7.5,10 \mathrm{mM} \mathrm{MgCl} 2,1 \%$ (w/v)

Ammonium acetate

P1 bacteriophage

MC-Buffer

$100 \mathrm{mM} \mathrm{MgS}_{4}, 5 \mathrm{mM} \mathrm{CaCl}_{2}$

1M Sodium Citrate

$1 \mathrm{M} \mathrm{MgSO}_{4}$

$1 \mathrm{M} \mathrm{CaCl}_{2}$ 


\subsubsection{Bacterial Growth Media}

dYT- (double Yeast Tryptone)

LB (Luria Bertani) medium

LB-Agar

LB-Topagar

SP-Agar

SOC-Medium

PAB (Pennassay Broth) Medium

DM3 Medium
$1.6 \%(\mathrm{w} / \mathrm{v})$ Trypton, $1 \%(\mathrm{w} / \mathrm{v})$ yeast extract, $0.5 \%$ (w/v) $\mathrm{NaCl}$ in $\mathrm{H}_{2} \mathrm{O}$, autoclaved $1 \%(\mathrm{w} / \mathrm{v})$ Trypton, $0.5 \%(\mathrm{w} / \mathrm{v})$ yeast extract, $1 \%(\mathrm{w} / \mathrm{v}) \mathrm{NaCl}$ in $\mathrm{H}_{2} \mathrm{O}$, autoclaved $1 \%(\mathrm{w} / \mathrm{v})$ Trypton, $1.5 \%(\mathrm{w} / \mathrm{v})$ Agar, $0.5 \%$ (w/v) yeast extract, $1 \%(\mathrm{w} / \mathrm{v}) \mathrm{NaCl}$ in $\mathrm{H}_{2} \mathrm{O}$, autoclaved $1 \%(\mathrm{w} / \mathrm{v})$ Trypton, $0.7 \%(\mathrm{w} / \mathrm{v})$ Agar, $0.5 \%$ (w/v) yeast extract, $1 \%(\mathrm{w} / \mathrm{v}) \mathrm{NaCl}$ in $\mathrm{H}_{2} \mathrm{O}$, autoclaved

$0.8 \%(\mathrm{w} / \mathrm{v})$ Nutrient Broth, 0.02\% (w/v) $\mathrm{MgSO}_{4} \times 7 \mathrm{H}_{2} \mathrm{O}, 1 \%$ (w/v) KCl; autoclaved, then $1 \mathrm{ml} \mathrm{CaCl} 2(100 \mathrm{mM}), 1 \mathrm{ml} \mathrm{MnCl}_{2}(10 \mathrm{mM})$, $2 \mathrm{ml}$ Ammonium iron(II)citrate $(2.2 \mathrm{mg} / \mathrm{ml})$ into $1 \mathrm{~L}$ of medium added $2 \%(\mathrm{w} / \mathrm{v})$ Tryptone, $0.5 \%(\mathrm{w} / \mathrm{v})$ yeast extract, $10 \mathrm{mM} \mathrm{NaCl}, 2.5 \mathrm{mM} \mathrm{KCl}, 10 \mathrm{mM} \mathrm{MgCl}_{2}$, $10 \mathrm{mM} \mathrm{MgSO}_{4}, 20 \mathrm{mM}$ Glucose, autoclaved 1.75\% (w/v) Difco Antibiotic Medium No. 3 $250 \mathrm{ml} 1 \mathrm{M}$ Sodium succinate (adjusted to $\mathrm{pH}$ 7.3 with $\mathrm{NaOH}$ ), 50ml 5\% (w/v) Casamino acids, $25 \mathrm{ml} 10 \%(\mathrm{w} / \mathrm{v})$ yeast extract, $50 \mathrm{ml}$ Phosphate buffer, $15 \mathrm{ml} 20 \%$ (w/v) Glucose, $10 \mathrm{ml} 1 \mathrm{M} \mathrm{MgCl}_{2}, 2.5 \mathrm{ml} \%$ (w/v) BSA, $100 \mathrm{ml}$ $4 \%(\mathrm{w} / \mathrm{v})$ molten agar. All solutions were sterilized either by autoclaving or sterile filtering.

Antibiotics were added after media were autoclaved and cooled to below $60^{\circ} \mathrm{C}$.

\subsubsection{Equipment and hardware}

Automated Laser Fluorescence

DNA Sequencer (A.L.F.-sequencer) Incubator
GE Healthcare, Uppsala, Sweden W. C. Heraeus GmbH, Hanau 
Constant Cell Disruption System

Electrophoresis unit

Midget

Gel Jet Imager

Gene Pulsar ${ }^{\circledR}$ and Pulse Controller

Metal block thermostat

NovaBlot 2117-250

Milli-Q ${ }^{\circledR}$ Water Purification System

Pipetman ${ }^{\circledR}$ Model P1000, P200, P20

pH-Meter-526

Rotary shaker

Thermocycler Primus 96plus

Branson Sonifier W-250

UV-VIS Spectrophotometer

UVT2035 UV transilluminators

UV-Lamp $254 \mathrm{~nm}$

Envico sterile hood

Precision Balances L 420 P

Precision Balances U $4800 \mathrm{P}$

Vision Workstation, BioCad ${ }^{\circledR}$ Family

Vortex Genie $2^{\mathrm{TM}}$

\section{Electrophoresis power supplies:}

ECPS 3000/150

LNGs 350-06

\section{Centrifuges:}

Centrikon T-1055

Mikroliter

Mikro Rapid/K

Rotanta/RPC

Roto Silenta/RP

Sorvall ${ }^{\circledR}$ RC5C (Rotor SS34)
Constant Systems Ltd, Northants, England model 2050

GE Healthcare, Uppsala, Sweden

Intas, Göttingen

BioRad, Munich

Institute of Microbiology and Genetics,

University of Göttingen

Pharmacia LKB, Bromma

MILLIPORE, Eschborn

Gilson, Bad Camberg

Schütt Labortechnik, Göttingen

Infors AG, Bottmingen, Switzerland

MWG Biotech, Ebersberg

Heinemann, Schwäb. Gmünd

UV-1601 SHIMADZU Corporation, Kyoto, Japan

Herolab, Wiesloch

Schütt Laborthechnik, Göttingen

CEAG Slurp Reinraumtechnik

Sartorius, Göttingen

Sartorius, Göttingen

Applied Biosystems, Foster City, CA

Bender \& Hobein AG, Zurich, Switzerland

GE Healthcare, Uppsala, Sweden

Heinzinger, Rosenheim

Kendro, Langenselbold

Hettich, Tuttlingen

Hettich, Tuttlingen

Hettich, Tuttlingen

Hettich, Tuttlingen

Kendro, Langenselbold 


\subsubsection{Other materials}

Baktolin 5.5 (Disinfection solution)

Dialysis tubes VISKING ${ }^{\circledR}$

Disposable Syringes

Glass flasks and test tubes

Glass pipettes

Glass plates for SDS gels

Heparin column, Poros ${ }^{\circledR}$ HE 20

Meliseptol (disinfection solution)

Parafilm

$\mathrm{pH}$-Indicator stick

PCR cups

Petri dishes

Pipette tips

Protran BA85 Nitrocellulose

Precision Cells-Quartz glass cuvettes

Reaction Vessels (1,5 ml, $2 \mathrm{ml}, 50 \mathrm{ml}$ )

Scalpel blades

Ultrafiltration tubes
Bode Chemie, Hamburg

SERVA, Heidelberg

Perumo ${ }^{\circledR S}$ Syringe, Leuven, Belgium

Schott, Mainz

Brand, Wertheim

GE Healthcare, Uppsala, Sweden

Applied Biosystems, Foster City, CA

Braun Melsungen AG, Melsungen

American National Can., Chicago, USA

Merck, Darmstadt

Biozym, Hess.-Oldendorf

Greiner, Nürtingen

Sarstedt, Nümbrecht

Whatman ${ }^{\circledR} \mathrm{GmbH}$, Dassel

Hellma, Mühlheim/Baden

Sarstedt, Nümbrecht

Bayha $\mathrm{GmbH}$, Tuttlingen

Vivaspin Vivascience ${ }^{\circledR}$, Hannover

\subsubsection{Software}

ALF-Manager

BOXSHADE

Chromas $^{\circledR}$

CLUSTAL W

CorelDRAW $^{\circledR}$ Graphic Suite 12

Fragment Manager

MultAlin (by Florence Corpet)

PyMOL $^{\text {TM }}$

ProtParam
Version 3.02 (1995), GE Healthcare, Uppsala, Sweden Version 3.21, K. Hofmann and M. Baron

(www.ch.embnet.org/software/BOX_form.html)

Version 1.45 (32 bit), Version 2.01 and Version 2.31

Technelysium Pty. Ltd.

Service of European Bioinformatics Institute (EBI)

http://www.ebi.ac.uk/Tools/clustalw/

Corel Corporations, Ottawa, Canada

Version 1.2 (1995), GE Healthcare, Uppsala, Sweden

http://bioinfo.genotoul.fr/multalin/multalin.html

Version 0.98 (2005), DeLano Scientific LLC,

San Carlos, CA

ExPaSy Proteomics Server (http://expasy.org), Swiss 
Institute of Bioinformatics, Lausanne, Switzerland

Vision Workstation Perfusion

Chromatography

Version 2.0, Applied Biosystems, Foster City, CA

Microsoft ${ }^{\circledR}$ Office Word

Version 2007, Microsoft GmbH, Unterschleißheim

Vector NTI

Version 11.5, Invitrogen, Carlsbad, CA

\subsubsection{Databanks}

NCBI-Databank for protein, nucleotide, and genomic sequences:

http://www.ncbi.nlm.nih.gov/

RCSB Protein Data Bank (PDB) archive

http://www.rcsb.org/pdb/home/home.do

\subsection{Methods}

\subsubsection{Microbiological methods}

\subsubsection{Bacterial growth}

E. coli and B. subtilis cell cultures were grown in LB-Medium or dYT-Medium at $37^{\circ} \mathrm{C}$ and $200 \mathrm{rpm}$, if not stated otherwise. E. coli inoculations were made from either fresh overnight cultures or $-20^{\circ} \mathrm{C}$ glycerin stock. E.coli glycerine culture stocks were made by re-suspending of $1 \mathrm{ml}$ over night culture in glycerine at $1: 1$ ratio $(\mathrm{v} / \mathrm{v})$ and stored at $-20^{\circ} \mathrm{C}$. Alternatively, $9 \%$ DMSO culture stock was made and stored at $-80^{\circ} \mathrm{C}$. B. subtilis inoculations were made from bacterial spores, stored on SP-Agar (sporulating) plates Bacterial growth was monitored by determining optical density of the culture at $600 \mathrm{~nm}$ $\left(\mathrm{OD}_{600}\right)$.

\subsubsection{Bacteriophage growth}

\subsection{PBS1 bacteriophage}

\section{Preparation of PBS1 bacteriophage lysate (plate lysate method)}

$100 \mu 1$ of bacteriophage lysate obtained from BGSC (2.1.2) was diluted 1:10, 1:100 and 1:1000 in $1 \mathrm{ml}$ of Y-Medium and transferred to glass tubes containing $3 \mathrm{ml}$ of Y-medium. $500 \mu 1$ of mid-log phase B. subtilis W168 cells were added to phage suspensions and incubated for $15 \mathrm{~min}$ at RT. $4 \mathrm{ml}$ of melted LB-topagar was given to each glass tube, mixed and the suspension was immediately poured onto two fresh LB-agar plates. Plates 
were incubated overnight at $30^{\circ} \mathrm{C}$. On the next day top-agar layer was scraped off the plates and passed several times through syringe (without needle) to crush the agar. $20 \mathrm{ml}$ of Y-Medium and few drops of chloroform were then added to this suspension and incubated overnight at $4^{\circ} \mathrm{C}$. Lysate was centrifuged 3 times for $15 \mathrm{~min}$ at $4000 \mathrm{rpm}$ at RT to pellet the agar and rest of bacterial cells and the supernatant was stored at $4{ }^{\circ} \mathrm{C}$.

\section{Determination of the bacteriophage lysate titer}

$100 \mu \mathrm{l}$ of bacteriophage lysate was serially diluted $\left(10^{-1}\right.$ to $\left.10^{-10}\right)$ in $1 \mathrm{ml}$ of Y-Medium and transferred to glass tubes containing $2 \mathrm{ml}$ of Y-Medium. $500 \mu 1$ of $500 \mu 1$ of mid-log phase B. subtilis was added to each tube and incubated $15 \mathrm{~min}$ at RT. $2.5 \mathrm{ml}$ of melted LBtopagar was given to each suspension, mixed and poured onto fresh LB-agar plates. Plates were incubated at $30^{\circ} \mathrm{C}$ overnight. Plaques on plates containing from 100-500 plaques were counted on the next day and the bacteriophage titer in $1 \mathrm{ml}$ was calculated. Titer of the lysate prepared according to above described method was $\sim 5^{*} 10^{9} \mathrm{pfu} / \mathrm{ml}$.

\section{Mutagenesis of PBS1 bacteriophage}

Approximately $1 * 10^{8}$ pfu of PBS1 bacteriophage were suspended in $6 \mathrm{ml}$ of PBS1-Buffer and subjected to UV-irradiation for $2.5 \mathrm{~min}$ or $5 \mathrm{~min}$. UV-irradiation was achieved using UV-Lamp at $254 \mathrm{~nm}$ and $0.5 \mathrm{~J} \mathrm{sec}^{-1} \mathrm{~m}^{-2}$. Whole suspension was aliquoted in $200 \mu \mathrm{l}$ of irradiated phage suspension and transferred to glass tubes containing $2 \mathrm{ml}$ Y-Medium and mixed with $500 \mu 1$ of mid-log phase B. subtilis cells followed by incubation for $15 \mathrm{~min}$ at RT. $2.5 \mathrm{ml}$ of melted LB-topagar was given to each suspension, mixed and poured onto fresh LB-agar plates. Plates were incubated over night at $30^{\circ} \mathrm{C}$ and clear plaques were seeked.

\subsection{P2vir1Ram3 bacteriophage}

\section{Preparation of P2vir1Ram3 bacteriophage lysate (Kahn et al., 1991)}

$500 \mu 1$ of overnight culture of $E$. coli cells grown in P2 bacteriophage growth medium was inoculated in $50 \mathrm{ml}$ of $\mathrm{P} 2$ bacteriophage growth medium supplemented with $2 \mathrm{mM} \mathrm{CaCl} 2$ and grown to mid-log phase $\left(\mathrm{OD}_{600} \sim 0.6\right)$. P2vir1Ram3 bacteriophage plaque was picked from the plate, given to $E$. coli culture and incubated for $7 \mathrm{~min}$ at $37^{\circ} \mathrm{C}$ without shaking. The culture was then incubated at $37^{\circ} \mathrm{C}$ with shaking for approximately 2 hours until cell lysis occurred. When lysis began $200 \mu 1$ of $0.5 \mathrm{M}$ EDTA, $500 \mu 1$ of $1 \mathrm{M} \mathrm{MgCl}_{2}$ were added to chelate calcium for preventing adsorption of bacteriophage particles into cellular debris 
and to stabilize bacteriophage particles, respectively. $0.8 \mathrm{~g}$ of $\mathrm{NaCl}$ was added and when dissolved 10g of PEG6000 was given. The suspension was incubated for $15 \mathrm{~min}$ at $4^{\circ} \mathrm{C}$ with shaking at 200rpm and 1 hour on ice. Afterwards the lysate was centrifuged for 10 min at $10000 \mathrm{rpm}$ and $4^{\circ} \mathrm{C}$. The pellet was dissolved in $2 \mathrm{ml}$ of $\mathrm{P} 2$ Buffer, few drops of chloroform were added and the bacteriophage stock solution was stored at $4{ }^{\circ} \mathrm{C}$.

\section{Determination of the P2vir1Ram3 bacteriophage lysate titer}

$100 \mu 1$ of a standing overnight culture of E. coli strain that will permit growth of bacteriophage was mixed with $100 \mu 1$ of serial dilutions $\left(1: 10\right.$ to $\left.1: 10^{-8}\right)$ of the bacteriophage lysate incubated for $7 \mathrm{~min}$ at RT and $2.5 \mathrm{ml}$ of melted LB-topagar was given. Suspension was plated out on LB-agar plates and incubated overnight at $37^{\circ} \mathrm{C}$. Plaques on plates containing from 100-500 plaques were counted on the next day and the bacteriophage titer in $1 \mathrm{ml}$ was calculated. Titer of the lysate prepared according to above described method was $\sim 10^{9} \mathrm{pfu} / \mathrm{ml}$.

\subsection{Preparation of P1 bacteriophage lysate and P1 transduction}

E. coli bacteriophage $\mathrm{P} 1$ was used for transduction of kanamycine cassette for disruption of ung gene. Therefore the donor strain for lysate of P1 preparation was E. coli BL21_UXX (2.1.1.1). E. coli cells were grown to mid-log phase in LB Medium containing $5 \mathrm{mM} \mathrm{CaCl}_{2}$, $0.2 \%$ glucose. $100 \mu 1$ of $\mathrm{P} 1$ bacteriophage lysate (own laboratory collection, propagated on E. coli $\mathrm{K} 12$ ) was added and incubation was continued at $37^{\circ} \mathrm{C}$ with shaking. After $\sim 3$ hours lysis of the culture was completed. Several drops of chloroform was added and vortexed followed by centrifugation for $30 \mathrm{~min}$ at $4000 \mathrm{rpm}$ and RT. Few drops of chloroform was added and the lysate was stored at $4^{\circ} \mathrm{C}$.

For transduction, $2 \mathrm{ml}$ of overnight culture of the recipient strain grown in LB medium was centrifuged (6000rpm, $2 \mathrm{~min}, \mathrm{RT}$ ) and the pellet was resuspended in $2 \mathrm{ml}$ of LB medium

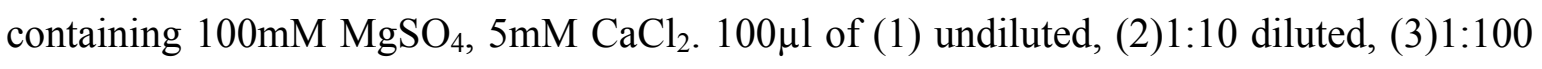
diluted, (4) 1:1000 diluted in MC-Buffer P1 lysate was given to $100 \mu 1$ of bacterial cells and incubated for $30 \mathrm{~min}$ at $37^{\circ} \mathrm{C}$ (cells without P1 lysate and P1 lysate without cells were taken for control). $200 \mu \mathrm{l}$ of $1 \mathrm{M}$ sodium citrate, $\mathrm{pH} 5.5$ was added followed by $1 \mathrm{ml}$ of LB Medium and the mixture was incubated at $37^{\circ} \mathrm{C}$ for 1 hour. Cells were pelleted at $7000 \mathrm{rpm}$ for $3 \mathrm{~min}$ and resuspended in $100 \mu \mathrm{l}$ of LB Medium containing 100mM sodium citrate, pH5.5. Finally, cells were plated onto LB-agar plates with kanamycin. On next day bacterial colonies were re-streaked on LB-agar plates with kanamycine spreaded with 
$100 \mu 1$ of $100 \mathrm{mM}$ sodium citrate, $\mathrm{pH} 5.5$. Next, colony-PCR was performed to test the transduction effectiveness.

\subsubsection{Transformation of bacteria}

\subsection{Transformation of $E$. coli}

Transformation of $E$. coli cells made competent by RbCl method (Hanahan, 1985)

$500 \mu \mathrm{l}$ of overnight culture was inoculated into $50 \mathrm{ml} \mathrm{LB}-\mathrm{Medium}$ and was grown to midlog phase $\left(\mathrm{OD}_{600} \sim 0.6\right)$ at $37^{\circ} \mathrm{C}$ with agitation. Culture was then incubated 10 min on ice followed by 10 min centrifugation at 4.000 r.p.m. and $4^{\circ} \mathrm{C}$ (Rotanta/RPK, Hettich). Cells were resuspended in $10 \mathrm{ml}$ of ice-cold TFBI Buffer, incubated $10 \mathrm{~min}$ on ice and centrifuged again. Thereafter, cells were resuspended in $2 \mathrm{ml}$ ice-cold TFBII Buffer and incubated $10 \mathrm{~min}$ on ice. Cells were then aliquoted $(100 \mu \mathrm{l})$ and frozen at $-80^{\circ} \mathrm{C}$. For transformation, plasmid DNA was incubated with cells $30 \mathrm{~min}$ on ice. Transformation mixture was subjected to heat shock at $42^{\circ} \mathrm{C}$ for 1 min followed by incubation on ice for 2 min. $1 \mathrm{ml}$ of SOC-Medium was added and cells were incubated at $37^{\circ} \mathrm{C}$ for 1 hour with gentle rolling. Cells were then diluted and plated on LB-agar plates containing antibiotic.

\section{Transformation of competent $E$. coli by electroporation (Dower et al., 1988)}

$500 \mu \mathrm{l}$ of overnight E.coli culture was inoculated into $50 \mathrm{ml}$ of dYT medium (2.1.10) and grown to mid-log phase $\left(\mathrm{OD}_{600} \sim 0,6\right)$ at $37^{\circ} \mathrm{C}$ on a shaker. Cells were harvested by centrifugation in $50 \mathrm{ml}$ falcon tubes for $10 \mathrm{~min}$ at $4.000 \mathrm{rpm}$. and $4^{\circ} \mathrm{C}$ (Rotanta/RPK, Hettich), resuspended in $50 \mathrm{ml}$ of ice-cold $\mathrm{H}_{2} \mathrm{O}$ and incubated on ice for $20 \mathrm{~min}$. Then cell suspension was centrifuged and cell pellet was washed 4 times by resuspention in ice-cold $\mathrm{H} 2 \mathrm{O}(40 \mathrm{ml}, 30 \mathrm{ml}, 20 \mathrm{ml}$ and $10 \mathrm{ml})$, followed by centrifugation after each wash. Finally, pellet was dissolved in 1-2 $\mathrm{ml}$ of $\mathrm{H}_{2} \mathrm{O}$ and left on ice. For the transformation, 1-2 $\mu \mathrm{l}$ of DNA solution $(2 \mu \mathrm{g})$ were mixed with $75 \mu \mathrm{l}$ of electrocompetent cells and incubated on ice for $5 \mathrm{~min}$. DNA-cell mixture was transferred into a chilled electroporation cuvette and subjected to the pulse at $2.5 \mathrm{kV}, 200 \Omega$ and $25 \mu \mathrm{F}$. Transformants were immediately resuspended in $1 \mathrm{ml}$ of SOC medium, incubated for $1 \mathrm{~h}$ at $37^{\circ} \mathrm{C}$ on a roller and $100 \mu \mathrm{l}$ aliquots (with or without dilution) were plated on LB agar plates containing appropriate antibiotics. Competent cells were plated on antibiotic containing agar plates as negative control. 


\subsection{Transformation of $B$. subtilis}

\section{Transformation of B. subtilis cells by electroporation (Brigidi et al., 1990)}

$500 \mu 1$ of overnight culture of B. subtilis was inoculated in 50ml LB-Medium and grown to an $\mathrm{OD}_{600}$ of $\sim 0.6$ corresponding to mid.log phase. Cells were chilled on ice for $30 \mathrm{~min}$, harvested by centrifugation (10 min at $4.000 \mathrm{rpm}$. and $4^{\circ} \mathrm{C}$ (Rotanta/RPK, Hettich)), rinsed once in 1mM HEPES pH 7, twice in PEB-Buffer and resuspended in $800 \mu 1$ of PEB-Buffer. For electroporation, plasmid DNA diluted in $10 \mu 1$ of PEB-Buffer was added to cells and followed by incubation on ice for $30 \mathrm{~min}$. Cells were then transferred to a cold $0.1 \mathrm{~cm}$ electroporation cuvette and subjected to a high-votlage electric pulse $(2.5 \mathrm{kV}, 200 \Omega$ and $25 \mu \mathrm{F}$ ). Immediately after pulse $1 \mathrm{ml}$ of SOC-Medium was added and the cell suspension was incubated at $37^{\circ} \mathrm{C}$ for one before plating onto selective media.

\section{B. subtilis protoplast transformation (Chang and Cohen, 1979)}

$200 \mu 1$ of $B$. subtilis overnight culture grown in PAB-Medium was inoculated in 10ml warm PAB-Medium and incubated at $37^{\circ} \mathrm{C}$ with shaking (200rpm). When the culture reached an $\mathrm{OD}_{600}$ of $\sim 0.5$, cells were pelleted $(10 \mathrm{~min}$ at $4000 \mathrm{rpm}$ at RT) and resuspended in $5 \mathrm{ml}$ of warm SMMP. $5 \mathrm{mg}$ of lysozyme were added and mixed by gentle inverting of the tube several times. After 2 hours of incubation at $37^{\circ} \mathrm{C}$ in a roller drum conversion of cells into protoplasts was checked under microscope (protoplasts have a spherical appearance). Protoplasts were harvested by centrifugation (10 min at $4000 \mathrm{rpm}$ at RT) and the pellet was resuspended in $5 \mathrm{ml}$ of SMMP. For transformation, plasmid DNA was gently mixed with $150 \mu 1$ of protoplasts and the mixture was added to the tube containing $450 \mu 1$ of PEG and gently mixed. Mixture was incubated at RT for $2 \mathrm{~min}$ and $1.5 \mathrm{ml}$ of SMMP was then added, mixed and centrifuged ( $7 \mathrm{~min}$ at $8000 \mathrm{rpm}$ at RT). Whole supernatant was removed and the $300 \mu 1$ of SMMP was added to the pellet without mixing. Mixture was incubated $90 \mathrm{~min}$ at $37^{\circ} \mathrm{C}$ with gentle rolling and dilutions were then plated on DM3 plates without antibiotica. Plates were incubated at $37^{\circ} \mathrm{C}$ for 2 days. After regeneration, transformants were identified by replica-plating onto selective media. As a control protoplasts were plated onto LB-agar plates: only cells that were not converted to protoplasts will grow.

\section{B.subtilis electroporation in high osmolarity solutions (Xue et al., 1999)}

Overnight culture of B. subtilis was diluted 16-fold in growth medium and was grown at $37^{\circ} \mathrm{C}$ to $\mathrm{OD}_{600}$ of $\sim 0.85-0.95$. The cells were chilled on ice for $10 \mathrm{~min}$ and harvested by 
centrifugation for $5 \mathrm{~min}$ at $4000 \mathrm{rpm}$ and $4^{\circ} \mathrm{C}$ ). Following 4 washes in ice-cold electroporation medium, the cells were suspended in $1.25 \mathrm{ml}$ of the electroporation medium with a cell concentration of $\sim 10^{10} \mathrm{cfu} / \mathrm{ml}$. Competent cells can be stored at $-80^{\circ} \mathrm{C}$. For transformation, $60 \mu 1$ of competent cells were mixed with $1 \mu 1$ DNA and then transferred to an ice-cold electroporation cuvette (1mm electrode gap). After incubation dor 1 min cells were exposed to a single electrical pulse using a Gene Pulser (BioRad Laboratories, Richmond, CA) set at $25 \mu \mathrm{F}$ and $200 \Omega$, resulting in time constants of 4.5$5.0 \mathrm{~ms}$. Immediately following electrical discharge, $1 \mathrm{ml}$ of recovery medium was added to the cells. After incubation at $37^{\circ} \mathrm{C}$ for $3 \mathrm{~h}$ cells were plated on $\mathrm{LB}$-agar plates containing antibiotic. Plates were incubated at $37^{\circ} \mathrm{C}$ overnight.

\subsubsection{Molecular biological methods}

\subsubsection{DNA extraction}

\section{Bacterial genomic DNA extraction}

Overnight culture of bacterial cells $(2 \mathrm{ml})$ was pelleted and resuspended in $300 \mu 1250 \mathrm{mM}$ Tris $\left(\mathrm{pH} 8.0\right.$ ) containing $10 \mathrm{mg} / \mathrm{ml}$ lysozyme and incubated $30 \mathrm{~min}$ at $37^{\circ} \mathrm{C}$. Afterwards $300 \mu 1$ of $0.5 \%$ SDS, $50 \mathrm{mM}$ Tris ( $\mathrm{pH} 7.5$ ), $0.4 \mathrm{M}$ EDTA, $1 \mathrm{mg} / \mathrm{ml}$ proteinase $\mathrm{K}$ was added and incubated at $50^{\circ} \mathrm{C}$ for $30 \mathrm{~min}$. The suspension was mixed with $600 \mu \mathrm{l}$ of trisequilibtrated phenol, centrifuged $10 \mathrm{~min}$ at $13000 \mathrm{rpm}$ and RT; supernatant was mixed with $300 \mu 1$ phenol and $300 \mu 1$ chloroform and centrifuged; supernatant was mixed with $600 \mu 1$ chloroform and centrifuged. Finally, genomic DNA was precipitated with ethanol.

\section{Ethanol precipitation of DNA}

$1 / 10$ vol. of $7 \mathrm{M}$ ammonium acetate and 3 vol. of $96 \%$ ethanol were added to DNA samples followed by incubation at $-20^{\circ} \mathrm{C}$ for 1 hour. DNA was pelleted by centrifugation for 30 min at $15000 \mathrm{rpm}$ and $4^{\circ} \mathrm{C}$ (Mikro Rapid/K Hettich). DNA pellets were washed with 70\% ethanol, centrifuged for $15 \mathrm{~min}$ at $4^{\circ} \mathrm{C}$, and dried at $37^{\circ} \mathrm{C}$. Finally, dried DNA pellets were dissolved in double distilled water $(\mathrm{ddH} 2 \mathrm{O})$ and stored at $-20{ }^{\circ} \mathrm{C}$.

\section{Bacteriophage DNA extraction}

$50 \mathrm{ml}$ of bacterial culture grown to mid-log phase was infected with $\sim 10^{9}$ bacteriophage particles and incubated for 3 hours at $37^{\circ} \mathrm{C}$ with shaking. $1 \mathrm{ml}$ of chloroform was added to complete the lysis. Suspension was incubated overnight at $4{ }^{\circ} \mathrm{C}$ without shaking and on the 
next day DNAseI and RNAseA were added $(1 \mu \mathrm{g} / \mathrm{ml})$ and incubated for $30 \mathrm{~min}$ at RT. Cell debris were pelleted by centrifugation for $20 \mathrm{~min}$ at $4000 \mathrm{rpm}$ and RT.1M NaCl, 10\% (w/v) PEG6000 were added to the supernatant, dissolved by slow stirring and incubated on ice for 1 hour. Bacteriophage particles were precipitated by centrifugation for $30 \mathrm{~min}$ at $10000 \mathrm{rpm}$ and $4^{\circ} \mathrm{C}$. The pellet was dissolved in $500 \mu \mathrm{l}$ of PBS buffer and $500 \mu \mathrm{l}$ of chloroform was then added. Suspension was thoroughly vortexed and then centrifuged for $15 \mathrm{~min}$ at $8000 \mathrm{rpm}$ and $4^{\circ} \mathrm{C}$. The aqueous phase was subjected to phenol/chloroform extraction followed by ethanol precipitation of DNA as described above.

\section{Small scale plasmid DNA extraction (mini-prep) by alkaline lysis}

$2 \mathrm{ml}$ of bacterial culture grown over night at $37^{\circ} \mathrm{C}$ were used to prepare plasmid DNA by modified alkaline/SDS lysis method using JetStar E1, E2, E3-solutions (Birnboim and Doly, 1979). E.coli cells were pelleted by centrifugation for $1 \mathrm{~min}$ at $13000 \mathrm{rpm}$ and RT. Pellet was resuspended in $150 \mu \mathrm{l}$ of E1 solution by vortexing and $150 \mu \mathrm{l}$ of E2 lysis solution was added followed by incubation for $5 \mathrm{~min}$ at RT. After neutralization with 150 $\mu 1$ of E3 solution, samples were incubated for $10 \mathrm{~min}$ on ice, and centrifuged for $15 \mathrm{~min}$ at $15000 \mathrm{rpm}$ and $4^{\circ} \mathrm{C}$. RNase A solution $(10 \mu \mathrm{g} / \mathrm{ml}$ final concentration) was added to the supernatant followed by incubation for $30 \mathrm{~min}$ at $37^{\circ} \mathrm{C}$. Finally, plasmid DNA was phenol/chlorophorm extracted and precipitated with ethanol as described above.

\section{Large scale plasmid DNA extraction (midi-prep)}

JETstar ${ }^{\circledR}$ Kit was used for plasmid DNA preparation from $50 \mathrm{ml}$ of overnight E.coli culture. Cells were pelleted by centrifugation ( $4000 \mathrm{rpm}, 10 \mathrm{~min}, 4^{\circ} \mathrm{C}$ ) and resuspended in $4 \mathrm{ml}$ of E1 solution until homogeneity. Then E2 solution was added with gentle mixing and samples were incubated for $5 \mathrm{~min}$ at RT. After addition of E3 solution, samples were mixed by multiple inversions and cell debris were removed by centrifugation for $10 \mathrm{~min}$ at $4000 \mathrm{rpm}$ and RT. Cleared supernatant was applied to a JETstar column equilibrated with E4 solution followed by washing twice with $10 \mathrm{ml}$ of E5 solution. DNA was eluted with 5 $\mathrm{ml}$ of E6 solution, precipitated with 0.7 volume of isopropanol and pelleted by centrifugation for $15 \mathrm{~min}$ at $15000 \mathrm{rpm}$ and $4^{\circ} \mathrm{C}$. Finally, DNA pellet was washed with $70 \%$ ethanol, dried at $37^{\circ} \mathrm{C}$, and redissolved in $10 \mu \mathrm{l}$ of double distilled water (ddH2O). 


\subsubsection{Polymerase Chain Reaction (PCR)}

\subsection{Standard PCR}

\begin{tabular}{lc}
\hline \multicolumn{1}{c}{ Reaction mix } \\
\hline Template DNA & 100ng \\
Primer, forward & 10pmoles \\
Primer, reverse & 10pmoles \\
Pfu -Polymerase & $1 \mathrm{U}$ \\
10x Pfu- Polymerase buffer & $2.5 \mu \mathrm{l}$ \\
dNTPs & $0.2 \mathrm{mM}$ each \\
dd $\mathrm{H}_{2} \mathrm{O}$ & up to $25 \mu \mathrm{l}$ \\
\hline
\end{tabular}

\begin{tabular}{ccc}
\hline Step & Temperature & Time \\
\hline 1 & $95^{\circ} \mathrm{C}$ & $5 \mathrm{~min}$ \\
2 & $94^{\circ} \mathrm{C}$ & $1 \mathrm{~min}$ \\
3 & $\mathrm{TA}^{*}$ & $1 \mathrm{~min}$ \\
4 & $72^{\circ} \mathrm{C}$ & $1 \mathrm{~min}$ \\
5 & $72^{\circ} \mathrm{C}$ & $10 \mathrm{~min}$ \\
\hline \multicolumn{3}{c}{ Step $2-4: 25 \times$ repeat cycles } \\
\hline
\end{tabular}

Table 2.1: (Left) Common PCR mixture used for amplification of DNA fragments from plasmid and genomic DNA templates. (Right) Thermocycler program used with modifications of annealing temperature, elongation time, and/or elongation temperature depending on the primer pair used and on the length of PCR fragment.* $\mathrm{T}_{\mathrm{A}}$ : Optimal primer annealing temperature calculated by following equation:

$\mathrm{T}_{\mathrm{A}}=\left(\mathrm{T}_{\mathrm{m} 1}+\mathrm{T}_{\mathrm{m} 2}\right) / 2-3^{\circ} \mathrm{C}$, where $\mathrm{T}_{\mathrm{m} 1}$ and $\mathrm{T}_{\mathrm{m} 2}$ are melting temperatures of Primer 1 and Primer 2, accordingly; $\mathrm{T}_{\mathrm{m}}$ of PCR primers were calculated using the following equation: $\mathrm{T}_{\mathrm{m}}\left[{ }^{\circ} \mathrm{C}\right]=69.3+0.41(\% \mathrm{G}+\mathrm{C})-650 / \mathrm{N}$ (Chester and Marshak, 1993)

\subsection{Error-Prone PCR (Cadwell and Joyce, 1992)}

Mutagenic PCR protocols employ several modifications relative to standard PCR that might be considered mutagenic, including: (1) increased concentration of Taq polymerase;

(2) increased extension time; (3) increased concentration of $\mathrm{MgCl}_{2}$; (4) addition of $\mathrm{MnCl}_{2}$;

(5) dNTP concentration bias. Several error-prone PCR conditions were tested (refer to Results and Discussion 3.2.3 Section) and Table 2.2 shows conditions of error-prone PCR that were used after all optimizations.

\begin{tabular}{|c|c|c|c|c|}
\hline \multicolumn{2}{|l|}{ Reaction mix } & & & \\
\hline Template DNA & $100 \mathrm{ng}$ & Step & Temperature & Time \\
\hline Primer, foward & 50 pmoles & 1 & $95^{\circ} \mathrm{C}$ & $5 \mathrm{~min}$ \\
\hline Primer, reverse & 50 pmoles & 2 & $94^{\circ} \mathrm{C}$ & $1 \mathrm{~min}$ \\
\hline dATP, dGTP & $0.2 \mathrm{mM}$ each & 3 & $\mathrm{TA}^{*}$ & $1 \mathrm{~min}$ \\
\hline dTTP, dCTP & $0.2 \mathrm{mM}$ each & 4 & $72^{\circ} \mathrm{C}$ & $2 \mathrm{~min}$ \\
\hline $\mathrm{MgCl}_{2}$ & $65 \mathrm{mM}$ & 5 & $72^{\circ} \mathrm{C}$ & $10 \mathrm{~min}$ \\
\hline ThermoPol Reaction Buffer (10x) & & \multicolumn{3}{|c|}{ Step 2-4: $25 x$ repeat cycles } \\
\hline $\begin{array}{c}\text { ThermoPol Reaction Buffer (10x) } \\
\text { Taq-Polymerase }\end{array}$ & $10 \mu l$ & & & \\
\hline $\begin{array}{c}\text { Taq } \text {-Polymerase } \\
\text { dd } \mathrm{H}_{2} \mathrm{O}\end{array}$ & $5 \mathrm{U}$ & & & \\
\hline
\end{tabular}

Table 2.2: (Left) error-prone PCR mixture employed for mutagenesis of exoA. (Right) Thermocycler program used with modifications of annealing temperature depending on the primer pair used. $* \mathrm{~T}_{\mathrm{A}}$ : Optimal primer annealing temperature was calculated as described above in the description of Table 2.1.

Error-prone PCR product was purified by extraction from agarose gel (2.2.2.6), cloned into 
pJET1.2 cloning vector (2.2.2.8) and transformed into E. coli cells (2.2.1.3.1). Plasmid DNA was extracted (2.2.2.1) from randomly picked clones and subjected to DNA sequencing analysis (2.2.2.10). All clones were washed-out from the plates and the plasmid DNA was extracted using large-scale plasmid DNA preparation method (2.2.2.1) and stored at $-20^{\circ} \mathrm{C}$. Randomized exo $A$ was digested out from pJET1.2 vector and re-cloned into appropriate expression vector (2.2.2.8). Detailed description of the library construction is in Results and Discussion Section 3.2.2.

\subsection{Colony-PCR}

This protocol is used to quickly screen for right clones carrying desired DNA fragment directly on bacterial cells. For this bacterial colony was picked from the plate and cells were suspended in $25 \mu 1$ of $1 \mathrm{x}$ ThermoPol Reaction Buffer (in case of B. subtilis cells $0.05 \mathrm{mg} / \mathrm{ml}$ of lysozyme was added as well) in the PCR reaction tube. $30 \mu \mathrm{l}$ of Chill-out $^{\mathrm{TM}}$ Wax was added on top of each suspension to prevent evaporation. Cell suspension was then incubated for $5 \mathrm{~min}$ at $98^{\circ} \mathrm{C}$. Finally, standard PCR mixture (described above) was added to the cell suspension and the PCR was carried out under conditions of the standard PCR (see above).

\subsection{Introduction of mutations into plasmid DNA using Quick-Change ${ }^{\circledR}$ site- directed mutagenesis (protocol from Stratagene)}

This PCR based mutagenesis allows introducing of site-specific mutations in doublestranded plasmid DNA. This procedure utilizes plasmid vector carrying the site of interest and a pair of complementary oligonucleotide primers containing a desired mutation. During the "cycling reaction" $P f u$ DNA polymerase extends primers annealed to the template plasmid DNA. As the result linear mutated plasmid DNA is generated. Template plasmid DNA must be isolated from Dam-methylase expressing E. coli $\mathrm{dam}^{+}$strain. In these cells template plasmid DNA is methylated at 5'-G ${ }^{(\mathrm{m}-6)} \mathrm{ATC}-3$ 'sites and this methylated or hemimethylated DNA is the target of DpnI restriction enzyme. By this means one can get rid of the parental template DNA after the "cycling reaction" and only synthetic plasmid DNA that carries desired mutations will be left. When the reaction product is introduced into E. coli XL10-Gold Kan (2.1.1.1) cells by transformation (2.2.1.3.1), newly synthesized mutated plasmid DNA is circulated via illegitimate recombination by endogenous bacterial machinery.

"Cycling reaction" was performed under conditions depicted in the Table 2.3. 


\begin{tabular}{lc}
\hline \multicolumn{1}{c}{ Reaction mix } \\
\hline Template DNA & $50 \mathrm{ng}$ \\
Primer 1 & $125 \mathrm{ng}$ \\
Primer 2 & $125 \mathrm{ng}$ \\
Pfu-Polymerase & $2.5 \mathrm{U}$ \\
$10 x$ Pfu-Polymerase buffer & $5 \mu \mathrm{l}$ \\
dNTPs & $0.2 \mathrm{mM} \mathrm{each}$ \\
dd $\mathrm{H}_{2} \mathrm{O}$ & up to $25 \mu \mathrm{l}$ \\
\hline
\end{tabular}

\begin{tabular}{ccc}
\hline Step & Temperature & Time \\
\hline 1 & $95^{\circ} \mathrm{C}$ & $5 \mathrm{~min}$ \\
2 & $94^{\circ} \mathrm{C}$ & $1 \mathrm{~min}$ \\
3 & $\mathrm{TA}^{*}$ & $1 \mathrm{~min}$ \\
4 & $72^{\circ} \mathrm{C}$ & $8 \mathrm{~min}$ \\
5 & $72^{\circ} \mathrm{C}$ & $20 \mathrm{~min}$ \\
\hline \multicolumn{3}{c}{ Step $2-4: 18 \times$ repeat cycles } \\
\hline
\end{tabular}

Table 2.3: (Left) "Cycling reaction" mixture used for Quick-change ${ }^{\circledR}$ site-directed mutagenesis (Right) Thermocycler program used for the "cycling reaction". $\mathbf{T}_{\mathbf{A}}$ "indicates an annealing temperature for mutagenic primer estimated using following formula:

$\mathbf{T}_{\mathbf{A}}=\mathrm{T}_{\mathrm{m}}-10$

$\mathbf{T}_{\mathbf{m}}=81.5+0.41(\% \mathrm{G}+\mathrm{C})-675 / \mathrm{N}-\%$ mismatch, where $\mathbf{N}$ is the primer length in bases and values for $\% \mathrm{G}+\mathrm{C}$ and $\%$ mismatch are the whole numbers.

After the "cycling reaction" $1 \mu 1$ of $D p n I$ was added to the reaction and incubated for 1 hour at $37^{\circ} \mathrm{C}$. Finally, $2.5 \mu \mathrm{l}$ of the reaction was used for the transformation of E. coli XL10 Gold Kan (2.1.1.1) cells.

10-20 single colonies were used for plasmid DNA preparation (2.2.2.1) and the DNA was verified for desired mutations by DNA sequencing analysis (2.2.2.10).

\subsection{Site-directed mutagenesis by overlap-extension using PCR (Jansohn, 2006)}

Site-directed mutagenesis by overlap-extension was used when two sites within a DNA fragment in relative distance from each other were to be mutated. Specific alterations in the nucleotide sequence are introduced by incorporating nucleotide changes into two overlapping primers. Complementary oligonucleotide primers (overlap primer 1 and 2), 5' and 3' flanking primers ("forward" and "reverse" respectively) and the PCR are used to generate two DNA fragments having overlapping ends. These fragments are combined in a subsequent "fusion" reaction in which the overlapping ends anneal, allowing the 3' overlap of each strand to serve as a primer for the $3^{\prime}$ extension of the complementary strand. The resulting fusion product is amplified further by PCR using "forward" and "reverse" primers.

Preliminary two fragments were amplified following conditions depicted in Table 2.4. 


\begin{tabular}{|c|c|c|c|c|}
\hline \multicolumn{2}{|l|}{ Reaction mix 1} & \multicolumn{3}{|c|}{ Reaction mix 2} \\
\hline Template DNA & 100ng & & Template DNA & 100ng \\
\hline Primer overlap 1 & 25pmoles & & Primer overlap 2 & 25pmoles \\
\hline Primer reverse & 25pmoles & & Primer forward & 25pmoles \\
\hline Pfu-Polymerase & $2 U$ & & Pfu-Polymerase & $2 U$ \\
\hline 10x Pfu-Polymerase buffer & $5 \mu l$ & & 10x Pfu-Polymerase buffer & $5 \mu l$ \\
\hline dNTPs & $0.2 \mathrm{mM}$ each & & dNTPs & $0.2 \mathrm{mM}$ each \\
\hline \multirow[t]{8}{*}{ dd $\mathrm{H}_{2} \mathrm{O}$} & up to $50 \mu \mathrm{l}$ & & dd $\mathrm{H}_{2} \mathrm{O}$ & up to $50 \mu \mathrm{l}$ \\
\hline & Step & Temperature & Time & \\
\hline & 1 & $95^{\circ} \mathrm{C}$ & $5 \mathrm{~min}$ & \\
\hline & 2 & $94^{\circ} \mathrm{C}$ & $40 \mathrm{sec}$ & \\
\hline & 3 & $60^{\circ} \mathrm{C}$ & $40 \mathrm{sec}$ & \\
\hline & 4 & $72^{\circ} \mathrm{C}$ & $50 \mathrm{sec}$ & \\
\hline & 5 & $72^{\circ} \mathrm{C}$ & $10 \mathrm{~min}$ & \\
\hline & \multicolumn{3}{|c|}{ Step 2-4: $28 x$ repeat cycles } & \\
\hline
\end{tabular}

Table 2.4: PCR conditions used for amplification of 2 preliminary fragments of overlap extension. (Left) PCR 1, (Right) PCR 2, (Below) Thermocycler program used for both PCRs.

Next, both PCR products were purified by extraction from agarose gel (2.2.2.6) and the overlap extension PCR was carried out under conditions depicted in Table 2.5.

\begin{tabular}{lc}
\hline \multicolumn{1}{c}{ Reaction mix } \\
\hline PCR product 1 & 50ng \\
PCR product 2 & $50 \mathrm{ng}$ \\
Primer reverse & 25 pmoles \\
Primer forward & 25 pmoles \\
Pfu -Polymerase & $2 \mathrm{U}$ \\
10x Pfu- Polymerase buffer & $5 \mu \mathrm{l}$ \\
dNTPs & $0.2 \mathrm{mM} \mathrm{each}$ \\
dd $\mathrm{H}_{2} \mathrm{O}$ & up to $50 \mu \mathrm{l}$ \\
\hline
\end{tabular}

\begin{tabular}{ccc}
\hline Step & Temperature & Time \\
\hline 1 & $95^{\circ} \mathrm{C}$ & $5 \mathrm{~min}$ \\
2 & $94^{\circ} \mathrm{C}$ & $45 \mathrm{sec}$ \\
3 & $55^{\circ} \mathrm{C}$ & $45 \mathrm{sec}$ \\
4 & $72^{\circ} \mathrm{C}$ & $1 \mathrm{~min}$ \\
5 & $72^{\circ} \mathrm{C}$ & $10 \mathrm{~min}$ \\
\hline \multicolumn{3}{c}{ Step 2-4: $30 \times$ repeat cycles } \\
\hline
\end{tabular}

Table 2.5: (Left) Overlap extension PCR conditions; (Right) Thermocycler program used for PCR

Final PCR product was purified by extraction from agarose gel (2.2.2.6) and cloned into cloning pJET1.2 vector (2.2.2.8). Once the DNA sequencing analysis (2.2.2.10) confirmed the presence of mutations, DNA fragment was re-cloned into appropriate expression vector (2.2.2.8).

\subsubsection{Spectrophotometric determination of DNA concentration}

Absorption of ultraviolet (UV) light by the ring structure of purines and pyrimidines is the basis of the spectrophotometric DNA analysis. DNA samples were diluted in $\mathrm{ddH}_{2} \mathrm{O}(1: 10$ or 1:100) depending on estimated concentrations. DNA concentration were determined by measuring the absorbance at $\lambda=260 \mathrm{~nm}\left(\mathrm{~A}_{260}\right)$ using a spectrophotometer and a quartz 
cuvette. The concentration was calculated based on the assumption that $A_{260}=1.0$ is equal to $50 \mu \mathrm{g} / \mathrm{ml}$ of double-stranded DNA, to $40 \mu \mathrm{g} / \mathrm{ml}$ of single-stranded DNA and RNA and to $20 \mu \mathrm{g} / \mathrm{ml}$ of oligonucleotides. The purity of DNA was assessed by the $A_{260} / A_{280}$ ratio. Ratios between 1.8 and 2.0 are indicatives of pure, protein-free DNA.

\subsubsection{Agarose gel electrophoresis}

DNA molecules can be separated according to their size by electrophoretic migration. For preparative and analytical DNA analysis 1\% agarose gel electrophoresis was used. The agarose was dissolved in 1xTAE buffer in a microwave. Then $0.5 \mu \mathrm{g} / \mathrm{ml}$ of ethidium bromide was added and the gel was poured into a horizontal gel-forming chamber. DNA samples were mixed with 0.5 vol. of loading buffer and loaded onto gel. Gels were run in 1xTAE buffer at the constant electric field power of 5-10 V/cm. DNA in the gel was visualized under UV light at $305 \mathrm{~nm}$ using UV transilluminator.

\subsubsection{Denaturing polyacrylamide gel electrophoresis (A.L.F-PAGE)}

Automated Laser Fluorescence DNA Sequencer (A.L.F.-DNA sequencer) allows direct detection of fluorescently labeled DNA. During electrophoresis DNA fragments migrate downwards through the gel. The laser beam excites fluorescently labeled DNA and the emitted light is detected by fluorescent detection system. Collected photo-detector signals are then digitized and sent to a computer for further processing. Results are represented in the form of intensity peaks plotted against the running time scale. Reaction products of activity assays performed with DNA modifying enzymes were analyzed by A.L.F.sequencer. DNA samples were mixed with A.L.F.-marker (2.1.9) and applied onto 11\% denaturing polyacrylamide/urea gel $(30 \times 28 \times 0.5 \mathrm{~cm})$. Gels were prepared as described below.

$11 \%$ A.L.F.-PAGE gel recipe:

\begin{tabular}{ll}
\hline Reagent & Amount \\
\hline Urea & $29.43 \mathrm{~g} \mathrm{(7M)}$ \\
Acrylamide (30\%) & $24.84 \mathrm{ml}(10.65 \%)$ \\
Bisacrylamide (2\%) & $12.42 \mathrm{ml}(0.35 \%)$ \\
10XTBE & $8.40 \mathrm{ml}$ \\
APS (10\%) & $700 \mu \mathrm{l}$ \\
TEMED & $70 \mu \mathrm{l}$ \\
$\mathrm{ddH}_{2} \mathrm{O}$ & up to $70 \mathrm{ml}$ \\
\hline
\end{tabular}

Sterile filtered A.L.F.-PAGE gel was poured in between two cleaned (in succession with with water, ethanol and isopropanol) thermostable glass plates and a plastic comb was 
inserted to form wells. Gel was polymerized for approximately $30 \mathrm{~min}$ at RT. The comb was then removed, wells were rinsed with water, gel was placed into electrophoresis chamber, and buffer reservoirs were filled with 1XTBE buffer. Before applying samples, the gel was preheated for $20 \mathrm{~min}$. DNA samples were mixed with A.L.F. marker $(1 / 2$ sample volume), preheated for $5 \mathrm{~min}$ at $95^{\circ} \mathrm{C}$, and applied onto the gel loading up to $15 \mu$ into each well. The gel was run for $250 \mathrm{~min}$ at a constant power of $52 \mathrm{~W}, 52^{\circ} \mathrm{C}$, a laser power of $4 \mathrm{~mW}$, and a sampling power of $2 \mathrm{~s}$. Electrophoresis data were processed using Fragment Manager (GE Healthcare, 2.1.13).

\subsubsection{Purification of DNA fragments}

\section{DNA extraction from agarose gel}

To extract DNA from agarose gel, the desired DNA fragment was excised from the gel with a sterile scalpel under UV light (305 nm). DNA was eluted from the gel using either NucleoTrap ${ }^{\circledR}$ (Macherey \& Nagel, Düren) or High Pure PCR Cleanup Micro Kit (Roche Diagnostics, Mannheim) purification kits according to „Protocol for DNA extraction from agarose gels using the NucleoTrap ${ }^{\circledR}$ kit” or „,Purification of DNA fragments from Agarose Gel" from manuals of the each kit.

\section{Sucrose gradient purification of DNA fragments}

In order to achieve better cloning efficiencies linear plasmid DNA required for the construction of mutant gene library was subjected to sucrose gradient purification after digestion with restriction endonucleases (2.2.2.7). DNA fragments migrate through a sucrose gradient at a rate that is dependent on their size.

$500 \mu 1$ of $40 \%$ Sucrose solution was pipetted into ultra-centrifuge tube. This solution was carefully overlaid with $9.5 \mathrm{ml}$ of mixture of $30 \%$ - and 10\%- Sucrose solutions which was prior to that prepared in the gradient mixer. Digested DNA sample was pipetted onto the gradient and the whole was overlaid with paraffin. Centrifugation of the gradient was achieved at $30000 \mathrm{rpm}$ and $15^{\circ} \mathrm{C}$ for 21 hours. Afterwards, bottom of the centrifuge tube was stabbed with a needle and $\sim 500 \mu 1$ aliquots of the solution were made. $10 \mu 1$ from each aliquot was analyzed by agarose gel electrophoresis. Desired DNA fragment was isolated from the solution by ethanol precipitation (2.2.2.1).

\subsubsection{DNA cleavage by restriction endonucleases}

For effective DNA cleavage optimal temperatures and buffers recommended by 
manufacturer were used (2.1.6). $50 \mathrm{U}$ of enzyme was used for preparative DNA cleavage (minimum $5 \mu \mathrm{g}$ ) in $100 \mu \mathrm{l}$ assay volume for $1 \mathrm{~h}$ or maximal $16 \mathrm{~h}$. For analytical DNA cleavage (300-500 ng), $5 \mathrm{U}$ of restriction enzyme in $20 \mu \mathrm{l}$ assay volume were used. In case of double digestion, if no united buffer could be found where both enzymes would show $50-100 \%$ activity, two subsequent digestion reactions were performed. After first digestion, DNA was precipitated with ethanol (2.2.2.1).

\subsubsection{Cloning of DNA fragment into vector DNA}

\section{Cloning of DNA fragment into pJET1.2 cloning vector}

Cloning of the PCR products into pJET1.2 cloning vector (2.1.3.2) was achieved using CloneJET ${ }^{\mathrm{TM}}$ PCR Cloning Kit (2.1.8) according to the BluntEnd Cloning Protocol and StickyEnd Cloning Protocol provided with manual of the kit. pJET1.2/blunt is a linearized cloning vector. The 5'-ends of the vector contain phosphoryl groups. Recirculized pJET1.2/blunt vector expresses a lethal eco47IR restriction enzyme after transformation and is not propagated. As a result, only recombinant clones containing the insert appear on culture plates.

PCR-products were purified by extraction from agarose gel (2.2.2.6) and subjected to ligation reactions according to following protocols.

BluntEnd Cloning Protocol:

For cloning blunt-end PCR products generated by proofreading DNA polymerases such as $P f u$ DNA polymerase.

First, ligation reaction was set up on ice according to following recipe:

\begin{tabular}{|c|c|}
\hline Component & Volume \\
\hline 2XReaction Buffer * & $10 \mu l$ \\
\hline blunt-end PCR product, purified & $2 \mu \mathrm{l}(\sim 0.15 \mathrm{pmol}$ ends) \\
\hline pJET1.2/blunt cloning vector (50ng/ $\mu \mathrm{l})$ & $1 \mu \mathrm{l}(\sim 0.05 \mathrm{pmol}$ ends) \\
\hline Water, nuclease-free & up to $19 \mu l$ \\
\hline T4 DNA Ligase & $1 \mu l$ \\
\hline Total volume & $20 \mu l$ \\
\hline
\end{tabular}

Ligation mixture was incubated for $30 \mathrm{~min}$ at RT. $2 \mu 1$ of the ligation reaction was used directly for transformation of $E$. coli (2.2.1.3.1).

StickyEnd Cloning Protocol:

For cloning PCR products with 3'-dA overhangs generated by Taq DNA Polymerase. 
First, ligation reaction was set up on ice according to following recipe.

\begin{tabular}{lc}
\hline \multicolumn{1}{c}{ Component } & Volume \\
\hline 2XReaction Buffer & $10 \mu \mathrm{l}$ \\
PCR product, purified & $2 \mu \mathrm{l}(\sim 0.15 \mathrm{pmol}$ ends) \\
Water, nuclease-free & up to $19 \mu \mathrm{l}$ \\
DNA Blunting Enzyme* & $1 \mu \mathrm{l}$ \\
\multicolumn{1}{c}{ Total volume } & $18 \mu \mathrm{l}$ \\
\hline
\end{tabular}

* The DNA Blunting Enzyme is a proprietary thermostable DNA polymerase with proofreading activity. It removes 3'overhangs and fill-in 5'-overhangs. Nucleotides for the blunting reaction are included in the 2xReaction Buffer.

The mixture was incubated for $10 \mathrm{~min}$ at $70^{\circ} \mathrm{C}$, chilled on ice and subjected to following reaction.

\begin{tabular}{|c|c|}
\hline Component & Volume \\
\hline PCR-product after blunting reaction & $18 \mu \mathrm{l}$ \\
\hline pJET1.2/blunt Cloning vector $(50 \mathrm{ng} / \mu \mathrm{l})$ & $1 \mu l$ \\
\hline T4 DNA Ligase & $1 \mu l$ \\
\hline Total volume & $20 \mu l$ \\
\hline
\end{tabular}

Ligation mixture was incubated for $30 \mathrm{~min}$ at RT. $2 \mu 1$ of the ligation reaction was used directly for transformation of E. coli (2.2.1.3.1).

\section{Cloning of DNA fragment into expression vector}

Linear DNA fragments obtained after digestion with restriction endonucleases (2.2.2.7) were purified prior to ligation either by extraction from agarose gel or via sucrose gradient (2.2.2.6). To prevent the re-circulization of the majority of vector DNA during the ligation, linearized vector was subjected to deposphorylation of DNA ends by treating with Calf Intestine Alkaline Phospatase (CAP) directly after digestion with restriction endonucleases. For this, $2 \mu 1$ of CAP was given to $20 \mu \mathrm{l}$ of digestion reaction and the mixture was incubated for 1 hour at $37^{\circ} \mathrm{C}$. Afterwards CAP was heat-deactivated by incubating at $80^{\circ} \mathrm{C}$ for $20 \mathrm{~min}$.

Ligation mixture contained purified linear vector and insert DNA in 1:3 molar ratio, T4 DNA ligase and 1x T4 Ligase Buffer. T4 DNA ligase catalyzes the formation of a phosphodiester bond between juxtaposed 5' phosphate and 3' hydroxyl termini in duplex DNA. Amounts of DNA in the reaction were calculated according to formula:

$$
\text { Insert Mass in } \mathrm{ng}=3 \times \frac{\text { Insert Length in } \mathrm{bp}}{\text { Vector Length in } \mathrm{bp}} \times \text { Vector Mass in } \mathrm{ng}
$$

Ligation mixture was incubated overnight at $37^{\circ} \mathrm{C}$ and on the next day transformed into $E$. coli (2.2.1.3.1). As a control, self-ligation of the vector DNA was tested each time when 
ligation reaction was performed.

\subsubsection{Preparation of oligonucleotide substrates for activity assays}

For endonuclease assays, $0.01 \mathrm{pmol} / \mu \mathrm{l}$ substrate stocks were prepared by hybridization of 5 pmol of a fluorescein-labelled oligonucleotide with 25 pmol of an opposite strand oligonucleotide in $100 \mu \mathrm{l}$ of 1XSSC buffer (2.1.9) using an automated thermocycler (Program: $90^{\circ} \mathrm{C}, 15 \mathrm{sec} ; 80^{\circ} \mathrm{C}, 3 \mathrm{~min} ; 50^{\circ} \mathrm{C}, 15 \mathrm{~min} ; 20^{\circ} \mathrm{C}, 15 \mathrm{~min}$ ), followed by a $1: 5$ dilution with water. In case of a single-stranded (ss) substrate preparation, 5 pmol of fluorescein-labelled oligonucleotides were mixed with $100 \mu \mathrm{l}$ of 1XSSC buffer and $400 \mu 1$ of water subsequently.

\subsubsection{DNA sequencing analysis}

DNA sequencing analysis was made by Goettingen Genomics Laboratory (G2L) using chain termination method by Sanger (Sanger et al., 1977). DNA samples were prepared by mixing a template DNA, a sequencing primer (2.1.4.4) and $\mathrm{ddH}_{2} \mathrm{O}$ to a final volume and concentrations recommended by G2L. Sequence data were analyzed using Chromas ${ }^{\circledR}$.

\subsubsection{Protein biochemical methods}

\subsubsection{Sodium dodecyl sulphate polyacrylamide gel electrophoresis (SDS-PAGE)}

Gel electrophoresis provides a means of separating molecules that migrate through a porous matrix in response to an electric field. In denaturing sodium dodecyl sulphate polyacrylamide gel electrophoresis (SDS-PAGE) (Laemmli, 1970), sodium dodecyl sulphate (SDS) - an anionic detergent - confers a negative charge to polypeptides in proportion to their length and ß-mercaptoethanol - a reducing agent - reduces disulfide bridges in proteins. Consequently, proteins are separated based on their molecular mass. Laemmli gels are composed of two different gels (stacker and running gel). SDS-PAGE gels $(7.5 \mathrm{~cm} \times 8 \mathrm{~cm} \times 0.75 \mathrm{~cm})$ were prepared as shown below.

15\% SDS-PAGE recipe:

\begin{tabular}{|c|c|c|}
\hline Components & $15 \%$ Resolving gel $(60 \mathrm{ml})$ & $5 \%$ Stacking gel $(35 \mathrm{ml})$ \\
\hline Acriylamid/Bisacrylamid 30\% (37.5:1) & $30 \mathrm{ml}$ & $5.9 \mathrm{ml}$ \\
\hline $1.875 \mathrm{M}$ Tris- $\mathrm{HCl}, \mathrm{pH} 8.8$ & $12 \mathrm{ml}$ & - \\
\hline $1.25 \mathrm{M}$ Tris- $\mathrm{HCl}, \mathrm{pH} 6.8$ & - & $3.5 \mathrm{ml}$ \\
\hline $10 \%$ sodium dodecyl sulphate (SDS) & $600 \mu \mathrm{l}(1 \%$ final $)$ & $350 \mu \mathrm{l}(1 \%$ final) \\
\hline $\mathrm{dH} 2 \mathrm{O}$ & $17.2 \mathrm{ml}$ & - \\
\hline $10 \%$ ammonium persulfate (APS)* & $200 \mu \mathrm{l}$ & $120 \mu \mathrm{l}$ \\
\hline TEMED* & $30 \mu \mathrm{l}$ & $35 \mu l$ \\
\hline
\end{tabular}

* Added just before pouring the gel 
$15 \%$ resolving gels were poured between two glass plates, overlaid with isopropanol to compose the flat gel surface and polymerized for $30 \mathrm{~min}$ at room temperature (RT). Then $5 \%$ stacking gel mix was made, poured onto top of the resolving gel, a comb was inserted and gel was polymerized for $30 \mathrm{~min}$ at RT. Protein samples were mixed with $1 / 5$ volume of loading buffer (2.1.9) and denatured by heating for $5 \mathrm{~min}$ at $95^{\circ} \mathrm{C}$ just before loading onto the gel. Gels were run in $1 \mathrm{x}$ Laemmli buffer (2.1.9) at $20 \mathrm{~mA}$ constant current. For staining, the gel was removed from glass plate and put into Coomassie staining solution (equal volumes of Coomassie brilliant blue R-250 in methanol (0,7 \%) and 20\% Acetic acid) and incubated at RT for 30 min with slow shaking. For de-staining, the gel was cooked in water in the microwave.

\subsubsection{Western Blot Anaylsis}

Following electrophoresis, proteins in a polyacrylamide gel can be transferred to a positively charged nitrocellulose membrane by semi-dry electroblotting, where the gel and membrane are sandwiched between two stacks of filter paper that have been pre-wet with transfer buffer. The membrane is placed near the anode, and the gel is placed near the cathode. SDS-coated, negatively charged proteins are transferred to the membrane when an electric current is applied. Once transferred to the membrane, the proteins can be probed with epitope-specific antibodies. In this study proteins that carry polyhistidine tag (6xHis) were investigated by Western Blot analysis and Anti-Penta-His antibody (Qiagen, Hilden (2.1.6.)) was used. The position of the anti-His antibody bound to immobilized 6xHistagged protein is visualized using secondary anti-mouse IgG antibody (Sigma, Steinheim (2.1.6)) conjugated to alkaline phosphatase together with enzyme substrate BCIP in combination with NBT (chromogenic method). All Western blot analyses in this study were performed according to the protocols described in QIAexpress Detection and Assay Handbook provided together with Anti-Penta-His antibody.

\subsubsection{Crude cell extract preparation}

To test the expression of recombinant proteins, test expressions were performed in $50 \mathrm{ml}$ of bacterial culture. Induced and non-induced E.coli cells or B. subtilis cells were harvested by centrifugation for $10 \mathrm{~min}$ at $4000 \mathrm{rpm}$ and $4{ }^{\circ} \mathrm{C}$, resuspended in $500 \mu 1$ of $1 \mathrm{x} \mathrm{Laemmli}$ buffer (2.1.9) and sonicated on ice for 3x1 min using Branson Sonifier 250 (output level 5, duty cycle $50 \%$ ). Cell debris was pelleted by centrifugation for $15 \mathrm{~min}$ at $8000 \mathrm{rpm}$ and 
$4^{\circ} \mathrm{C}$ and $15 \mu 1$ of the supernatant was analyzed by $15 \%$ SDS-PAGE $(2.2 .3 .1)$.

\subsubsection{Whole protein extract preparation of $B$. subtilis cells}

$200 \mathrm{ml}$ of $B$. subtilis mid-log phase culture was centrifuged for $30 \mathrm{~min}$ at $4000 \mathrm{rpm}$ and $4^{\circ} \mathrm{C}$, the pellet was resuspended in $2 \mathrm{ml}$ of PBS-Buffer and sonicated on ice for $2 \mathrm{X} 3 \mathrm{~min}$ using Branson Sonifier 250 (output level 5, duty cycle 50\%). Cell debris was pelleted by centrifugation for $20 \mathrm{~min}$ at $8000 \mathrm{rpm}$ and $4^{\circ} \mathrm{C}$. Proteins in the supernatant were concentrated by ammonium sulphate precipitation (to $80 \%$ saturation; centrifugation for 15 min at $15000 \mathrm{rpm}$ and $4^{\circ} \mathrm{C}$ ). The protein pellet was re-suspended in $1 \mathrm{ml}$ of PBS-Buffer followed by the dialysis against $3 \mathrm{~L}$ of PBS-Buffer. The molecular-weight cutoff (MWCO) of the dialysis membrane was 14000 . Whole protein extract was used further for activity assays (2.2.3.11).

\subsubsection{Heterologous protein expression}

For overexpression and further purification of the protein exo $A$ gene was cloned into expression vectors pET28a (2.1.3.1) and pASK-08 (2.1.3.4). In pET expression system (pET28a vector and E. coli BL21_UXX strain (2.1.1.1)) expression of the target gene is regulated by strong $\mathrm{T} 7$ promoter (of bacteriophage origin), which is selectively recognised only by T7 RNA polymerase. BL21 (DE3) expression host possesses T7 RNA polymerase gene, lac promoter and lac operator incorporated in its genome. Expression of T7 RNA polymerase and consequently of the target gene can be activated by addition of lactose or its analogue isopropyl- $\beta$-D-thiogalactopyranosid (IPTG) to a cell culture. In pASK-08 vector pASK- 08 vector works with the tightly regulated tet promoter. The tet repressor is encoded on the pASK- 08 vector and is constitutively expressed from the promoter of $\beta$ lactamase (bla) gene. Expression of the recombinant protein is stringently repressed until efficient chemical induction with a low concentration of anhydrotetracycline (AHT). Special E. coli strain is not required.

$20 \mathrm{ml}$ of overnight culture of E.coli expression strain carrying respective expression vector was used to inoculate 1L of dYT selective medium (2.1.10) in 3L Erlenmeyer flasks. Culture was grown at $37^{\circ} \mathrm{C}$ with shaking to an $\mathrm{OD}_{600}$ of 0.6 . Gene expression was induced by addition of IPTG to a final concentration of $1 \mathrm{mM}$ or AHT (anhydrotetracycline) to final concentration of $200 \mathrm{ng} / \mu \mathrm{l}$ and cell culture was further incubated for $3 \mathrm{~h}$ at $30^{\circ} \mathrm{C}$ if not indicated otherwise. Cells were harvested by centrifugation for $30 \mathrm{~min}$ at $4000 \mathrm{rpm}$ and $4^{\circ}$, resuspended in $25 \mathrm{ml}$ of IMAC-washing buffer (2.1.9) and centrifuged for $30 \mathrm{~min}$ at 9000 
rpm and $4^{\circ} \mathrm{C}$. Cell pellet was frozen and stored at $-80^{\circ} \mathrm{C}$. After thawing and resuspension in $20 \mathrm{ml}$ of IMAC-washing buffer (2.1.9), cells were homogenized by sonication on ice for 2X3 min using Branson Sonifier 250 (output level 5, duty cycle 50\%) and disrupted by passage through a Constant Systems Ltd (Daventry, England) cell disruptor at $180 \mathrm{MPa}$ and $14^{\circ} \mathrm{C}$. Cell debris was precipitated by centrifugation for $1 \mathrm{~h}$ at $15.000 \mathrm{rpm}$ and $4^{\circ} \mathrm{C}$. Clear cell lysate was subjected to Immobilized Metal Ion Affinity Chromatography (IMAC) (2.2.3.6). Cell pellets were also analysed by SDS-PAGE (2.2.3.1) to check for possible aggregation of target protein.

\subsubsection{Immobilized Metal Ion Affinity Chromatography}

Immobilized Metal Ion Affinity Chromatography (IMAC) is based on highly specific coordinate binding of amino acids to immobilized metal ions. Recombinant proteins used in this study were fusioned with a polyhistidine-tag at their $\mathrm{C}$ - or N-terminus. Imidazole ring of histidine residue possess high affinity to $\mathrm{Ni}^{2+}$ ions that in case of IMAC are immobilized on a sepharose matrix. During IMAC purification, cell lysate is incubated with affinity matrix, washed with buffer and the target protein is then eluted with imidazole gradient.

IMAC column was prepared by pouring $5 \mathrm{ml}$ of $50 \%$ slurry of Chelating Sepharose ${ }^{\mathrm{TM}}$ Fast Flow (2.1.7), previously equilibrated in IMAC buffer, into $5 \mathrm{ml}$ plastic syringe and let it settle down by gravity force. Then the column was equilibrated with 1 column volume $(5 \mathrm{ml})$ of $100 \mathrm{mM} \mathrm{NiCl}$, washed with 5 column volumes of water, and equilibrated with 3 column volumes of IMAC washing buffer (2.1.9). Clear bacterial cell lysate, prepared as described in 2.2.3.5, was applied onto the IMAC column followed by $2 \mathrm{x}$ washing each time with two column volumes of IMAC-washing buffer (2.1.9). Target protein was eluted from the column by passing two column volumes of IMAC elution buffer (2.1.9), one at a time (imidazole concentration: 30, 40, 50, 60, 70, 80, 90, 100, 300 and $500 \mathrm{mM}$ ). Collected IMAC fractions were analyzed by $15 \%$ SDS-PAGE (2.2.3.1). Fractions containing protein of interest were combined and concentrated to a final volume of $5 \mathrm{ml}$.

\subsubsection{Heparin affinity chromatography}

Heparin affinity chromatography was performed on a pre-packed POROS $^{\circledR}$ HE20 (Perfusion chromatography, PerSeptive Biosistems) column using Vision Workstation $\left(\right.$ BioCad $^{\circledR}$ Family, Applied Biosistems, 2.1.11) designed for automated control of essential chromatographic parameters such as: flow-rate, pressure, $\mathrm{pH}$, elution volume, fraction 
volume etc., and sophisticated computerized data analysis. Heparin coupled with a high number of anionic sulphate groups is a high-capacity cation exchanger that allows specific purification of positively charged DNA binding enzymes from protein mix. Specific proteins can be then selectively dissociated from heparin with a salt gradient. Heparin column was equilibrated with heparin washing buffer (2.1.9) at a flow rate of $4 \mathrm{ml} / \mathrm{min}$. Then $5 \mathrm{ml}$ of concentrated protein solution obtained after IMAC (2.2.3.6) was diluted 1:10 with heparin washing buffer (up to $50 \mathrm{ml}$ final volume) and applied onto heparin column at same flow rate. The column was washed with $30 \mathrm{ml}$ of heparin washing buffer. Proteins retained in the column were eluted with 15 column volumes of a continuous $0-1.5 \mathrm{M} \mathrm{NaCl}$ salt gradient and collected in $1 \mathrm{ml}$ fractions. Protein elution was monitored at 260 and $280 \mathrm{~nm}$ by a computer-controlled spectrophotometer and results were displayed as a dual line chromatogram. Peak heparin fractions were analyzed by SDS-PAGE (2.2.3.1). Fractions containing protein of interest were pooled and concentrated (2.2.3.9).

\subsubsection{Spectrophotometric determination of protein concentration}

Concentration of purified proteins was determined by measuring the absorbance at 250300nm (UV-Region). Aromatic amino acids (tyrosine, phenylalanine and tryptophan) exhibit a strong UV-light absorbance. Consequently, proteins absorb UV-light in proportion to their aromatic amino acids content and total concentration. The molar concentration of protein solutions were estimated using Lambert-Beer low and following equation:

$$
A=\varepsilon \cdot c \cdot d \quad \Leftrightarrow \quad c=\frac{A}{\varepsilon \cdot d} \quad ; \text { Where } \quad \begin{aligned}
& \mathrm{C}=\text { molar concentration } \\
& \mathrm{d}=\text { light path }(\mathrm{cm})
\end{aligned}
$$

*The molar extinction coefficient $\left(\varepsilon_{280}\right)$ was calculated for each particular protein from its amino acid sequence using following equation (Pace et al., 1995):

$\varepsilon_{280}\left(M^{-1} \mathrm{~cm}^{-1}\right)=\sum \operatorname{Trp} \cdot 5500+\sum \operatorname{Tyr} \cdot 1490+\sum$ Cystine $\cdot 125$

\subsubsection{Protein samples concentration and storage}

Purified proteins were concentrated up to 0.5 - $1 \mathrm{ml}$ final volume using $20 \mathrm{ml}$ centrifugal concentrators (Vivaspine, Vivascience ${ }^{\circledR}$ ) with appropriate Molecular Weight Cut Off (MWCO) at $3000 \mathrm{rpm}$ and $4^{\circ} \mathrm{C}$ (Rotanata/RPC, Hettich). The protein concentration was determined measuring absorbance at $280 \mathrm{~nm}$ using a spectrophotometer (2.2.3.8). Concentrated protein solutions were mixed with glycerol at a $1: 1$ ratio and stored at $-20^{\circ} \mathrm{C}$ or $-80^{\circ} \mathrm{C}$. 


\subsubsection{Endonuclease assay}

0.12 pmoles of appropriate substrate (2.2.2.9) was pre-incubated in Endonuclease Buffer (2.1.9) for $10 \mathrm{~min} 37^{\circ} \mathrm{C}$. Then an appropriate amount of enzyme was added to a final volume of $50 \mu \mathrm{l}$ and reaction mix was incubated for $20 \mathrm{~min}$ unless otherwise specified. To stop the reaction, $25 \mu 1$ of A.L.F.-marker (2.1.9) was added and the samples were heated for $5 \mathrm{~min}$ at $95^{\circ} \mathrm{C} .7 \mu \mathrm{l}$ of the assay was applied onto $11 \%$ A.L.F.-PAGE (2.2.2.5) which is $\sim 17$ fmol of fluorescein-labelled material.

\subsubsection{Activity assay with $B$. subtilis protein extract}

$0.12 \mathrm{pmol}$ of $\mathrm{U} / \mathrm{G}$ mismatch containing substrate (2.2.2.9) was pre-incubated in Endonuclease Buffer (2.1.9) with or without UGI (100 pmoles) at $37^{\circ} \mathrm{C}$ or $65^{\circ} \mathrm{C}$ for 10 min. $10 \mu \mathrm{l}$ of $B$. subtilis protein extract was added (final volume of the reaction: $50 \mu 1$ ) and the assay was incubated for $20 \mathrm{~min}$ at $37^{\circ} \mathrm{C}$ or $65^{\circ} \mathrm{C} .100$ pmoles of purified Mth2 12 was added into some assays concomitantly with the protein extract. To stop the reaction, $25 \mu 1$ of A.L.F.-marker (2.1.9) was added and the samples were heated for $5 \mathrm{~min}$ at $95^{\circ} \mathrm{C} .7 \mu 1$ of the assay was applied onto 11\% A.L.F.-PAGE (2.2.2.5) which is $\sim 17 \mathrm{fmol}$ of fluoresceinlabelled material.

\subsubsection{Treatment of PBS1 bacteriophage DNA with tUDGa}

$2.5 \mu \mathrm{g}$ of PBS1 DNA was pre-incubated in $20 \mathrm{mM}$ Phosphate Buffer with $50 \mathrm{mM} \mathrm{KCl}$ at $37^{\circ} \mathrm{C}$ for $10 \mathrm{~min}$. In reaction with uracil DNA glycosylase, 400 pmoles of tUDGa was added to final volume of $25 \mu \mathrm{l}$ and the reaction was incubated at $37^{\circ} \mathrm{C} 30 \mathrm{~min}$. In all reactions $\mathrm{NaOH}$ was added $\left(100 \mathrm{mM}\right.$ final concentration) and incubated at $95^{\circ} \mathrm{C}$ for $5 \mathrm{~min}$. Finally, $\mathrm{HCl}$ was added (100mM final concentration) and $10 \mu \mathrm{l}$ of assay was subjected to agarose gel electrophoresis (2.2.2.4). Untreated PBS1 DNA used as a control was suspended in $35 \mu 1$ of $20 \mathrm{mM}$ Phosphate Buffer with $50 \mathrm{mM} \mathrm{KCl}$ and $10 \mu 1$ was taken for agarose gel electrophoresis as well.

\subsubsection{Treatment of PBS1 bacteriophage DNA with Mth212}

2.5 $\mu \mathrm{g}$ of PBS1 DNA was pre-incubated in Endonuclease Buffer (2.1.9) at $37^{\circ} \mathrm{C}$ for $10 \mathrm{~min}$. 1, 10, 100 or 1000 pmoles of Mth212 was added to the final volume of $25 \mu 1$ and the reaction was incubated at $37^{\circ} \mathrm{C}$ or $65^{\circ} \mathrm{C}$ for $20 \mathrm{~min} .10 \mu \mathrm{l}$ of assay was subjected to agarose gel electrophoresis (2.2.2.4). 


\section{Results and Discussion}

\subsection{Production and characterization of ExoA from Bacillus subtilis}

With the purpose of elucidation of structural roots lying underneath the unique uridine endonuclease activity of Mth212, directed evolution of an exonuclease III homolog without this specific activity into Mth212-like enzyme was attempted during this work. ExoA protein from B. subtilis was chosen as an object for randomization (Introduction, 1.2.2). As Mth212, ExoA is an exonuclease III homolog and these enzymes are most likely having similar tertiary structure. Crystal structure of ExoA was not solved to date; however, multiple sequence alignment of exonuclease III homologs showed that ExoA differs from Mth212 to the same extent as it differs from other exonuclease III homologs (Figure 3.1). Mth212 shares 46\% identical and 64\% similar amino acid residues with ExoA, whereas human HAP1 has 41\% identity and 60\% similarity with Mth212.

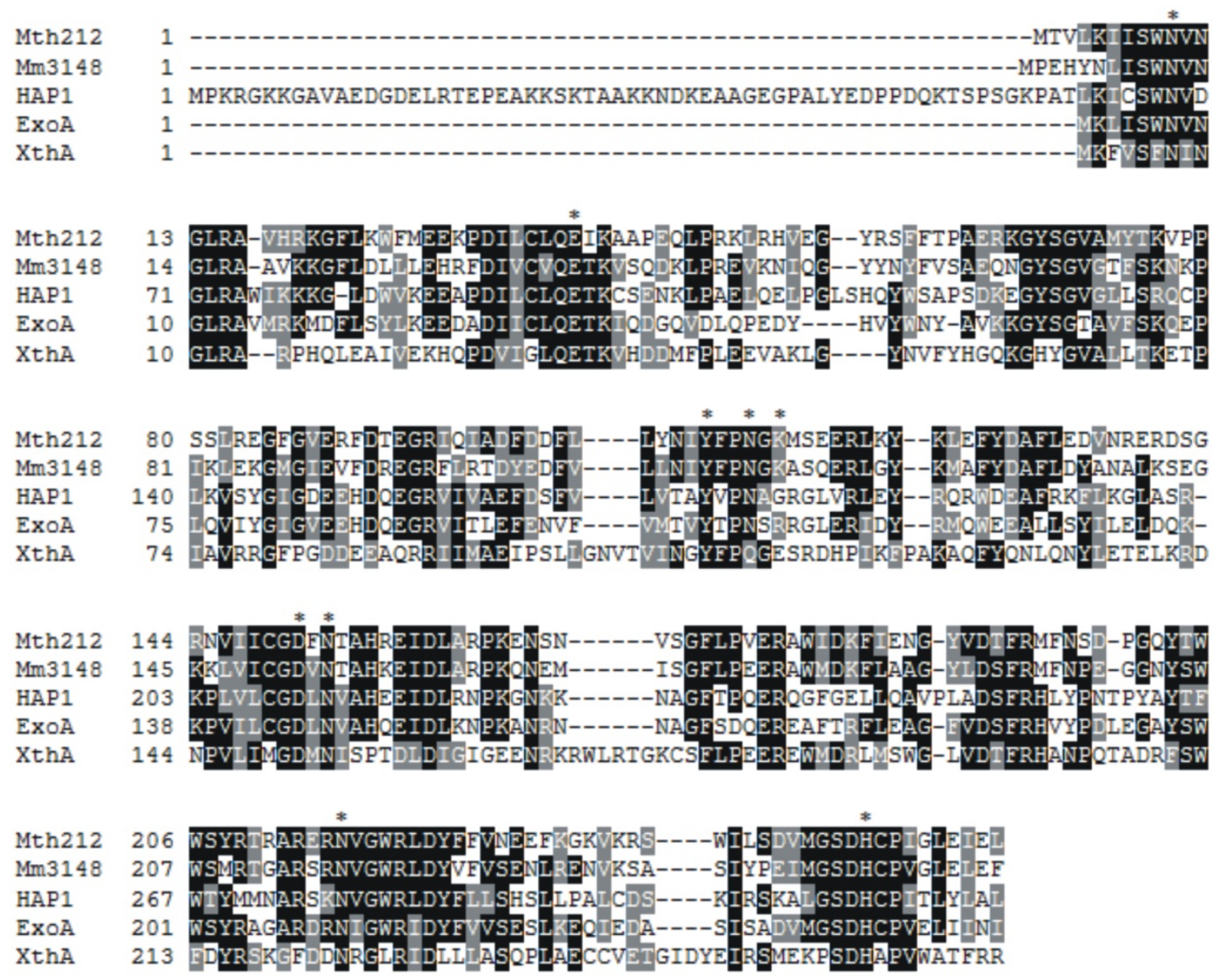

Figure 3.1: Multiple sequence alignment of B. subtilis ExoA with exonuclease III homologs such as Mm3148 (M. mazei), Mth212 (M. thermoautotrophicus), XthA (E. coli) and APE1 (HAPI (H. sapiens). Identical and similar amino acid residues are highlighted in black and grey, respectively. Amino acid residues involved in the catalysis by APE1 according to (Mol et al., 2000) and (Rothwell et al., 2000) are marked with asterisks. Alignment was performed using the CLUSTAL W2.0.12 algorithm and arranged by BOXSHADE 3.21 software (2.1.13). 


\subsubsection{Production and purification of ExoA}

In order to provide ExoA with DNA uridine endonuclease activity, the most essential step is to ensure that ExoA do not possess activity against uracil in DNA. ExoA has not been tested for this activity when it was characterized by Shida et al. (1999), and therefore biochemical characterization of ExoA, in particular the status of specific activity against uracil in DNA, was carried out. For this, ExoA was produced in an E.coli BL21_UXX ungstrain (2.1.1.1) as a N-terminal 6xHis-tagged recombinant protein using a pET_28a expression vector (2.1.3.1; cloning of exoA into pET_28a was performed by $\mathrm{N}$. Krietenstein). Protein extract was prepared as described in 2.2.3.5 and the recombinant ExoA protein (ExoA henceforth) was purified using an immobilized-metal-ion affinity chromatography (IMAC, refer 2.2.3.6 for methods).

A

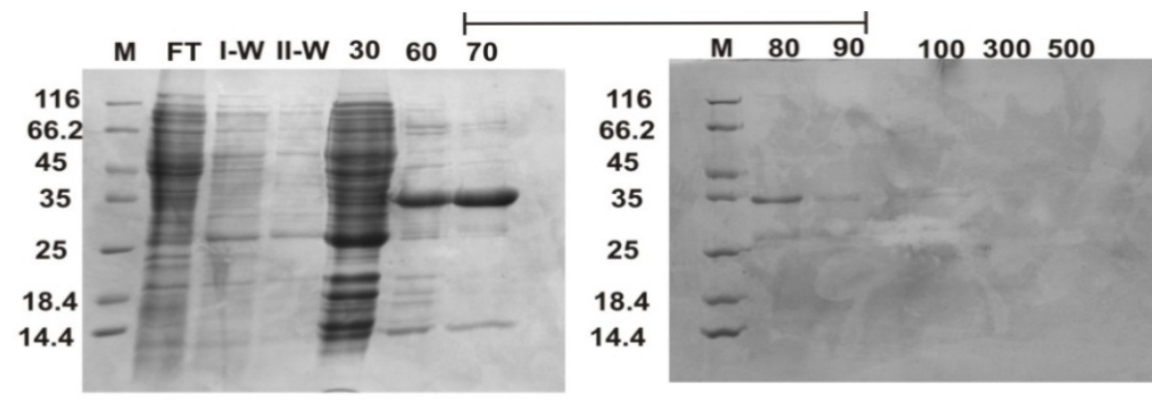

B

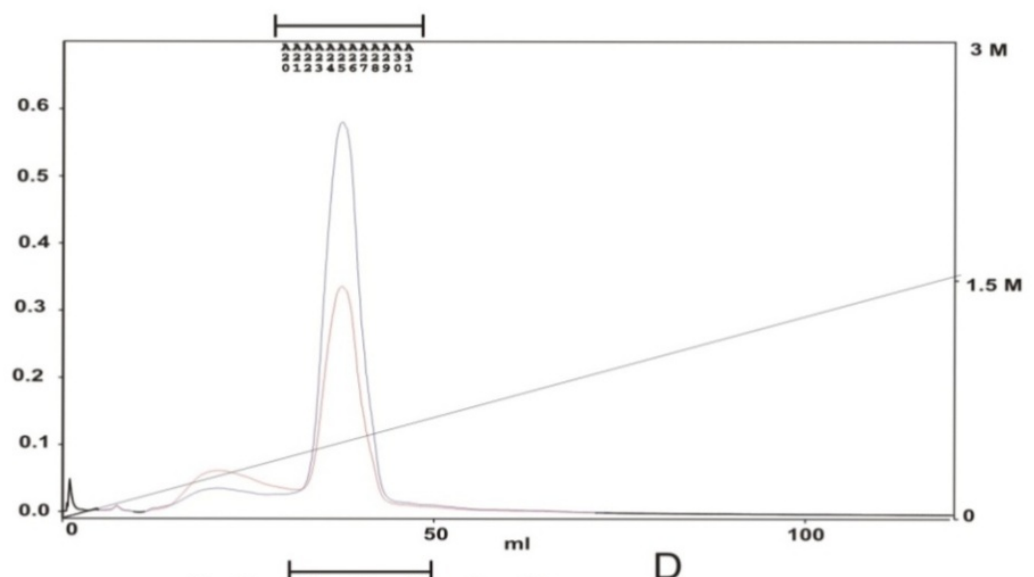

C

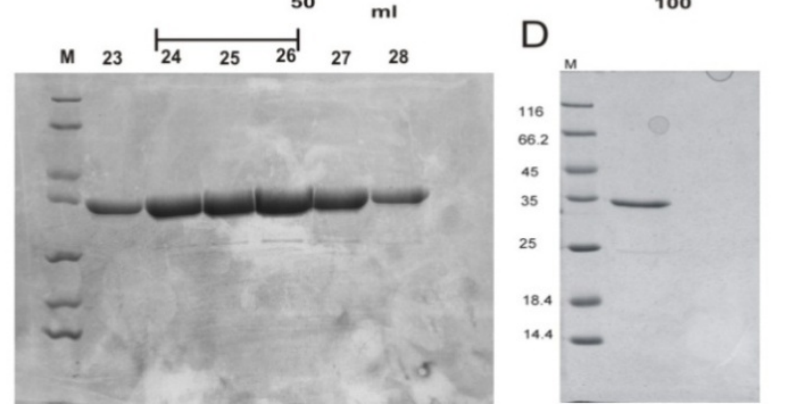

Figure 3.2: Purification of ExoA. A: Immobilized-metal-ion affinity chromatography (IMAC) fractions on $15 \%$ SDSPAGE. (M) Molecular weight marker, (FT) Flow-through fraction (cell lysate eluted from IMAC column). (I-W and IIW) Column wash fractions. 30-500: Protein fractions eluted with 30-500 mM imidazole in IMAC wash buffer. Brackets indicate fractions pooled for subsequent purification. B: Elution profile of the ExoA purification by Heparin affinity chromatography. Left ordinate: absorption at $260 \mathrm{~nm}$ (red) and $280 \mathrm{~nm}$ (blue); right ordinate: concentration of $\mathrm{NaCl}$ in $\mathrm{mol}[\mathrm{M}]$; abscissa: elution volume in ml. Numbers above the chromatogram indicate fractions that were analysed by $15 \%$ SDS-PAGE shown in panel C. Brackets indicate fractions pooled and concentrated for subsequent enzymatic characterization. D: 15\% SDS-PAGE of purified ExoA. 
Analysis of protein fractions by SDS-PAGE revealed an enriched, partly purified protein with the expected molecular weight of $\sim 34 \mathrm{kDa}$ that was eluted by $70-90 \mathrm{mM}$ imidazole containing buffer (Figure 3.2A). These fractions were further purified by a Heparin affinity chromatography (2.2.3.7). Proteins were eluted from the column using a linear gradient of $\mathrm{NaCl}(0-1.5 \mathrm{M})$ and the main peak of elution was analyzed by SDS PAGE (Figure 3.2B and C). Elution fractions containing the purified ExoA were then concentrated (2.2.3.9) to the final volume of $1 \mathrm{ml}$. The protein concentration was determined (2.2.3.8); the protein yield was approximately $3 \mathrm{mg}$ (obtained from $1 \mathrm{~L}$ of culture medium). Eventually, protein was analyzed by SDS-PAGE for purity (Figure 3.2D).

\subsubsection{Biochemical characterization of ExoA}

ExoA was produced to test whether it is devoid of DNA uridine endonuclease activity. Activity assays were performed as described in 2.2.3.10 using 40-mer double-stranded DNA oligonucleotide substrates containing a mismatch at position 24. One of the DNA strands in substrate duplex was labelled with fluorescein on its 5 'end. A schematic representation of assay substrate is shown in Figure 3.3A. Reaction products obtained during endonuclease assays were analysed under denaturing conditions by $11 \%$ A.L.F.polyacrylamid gel electrophoresis (2.2.2.5) (Figure 3.3B).

A
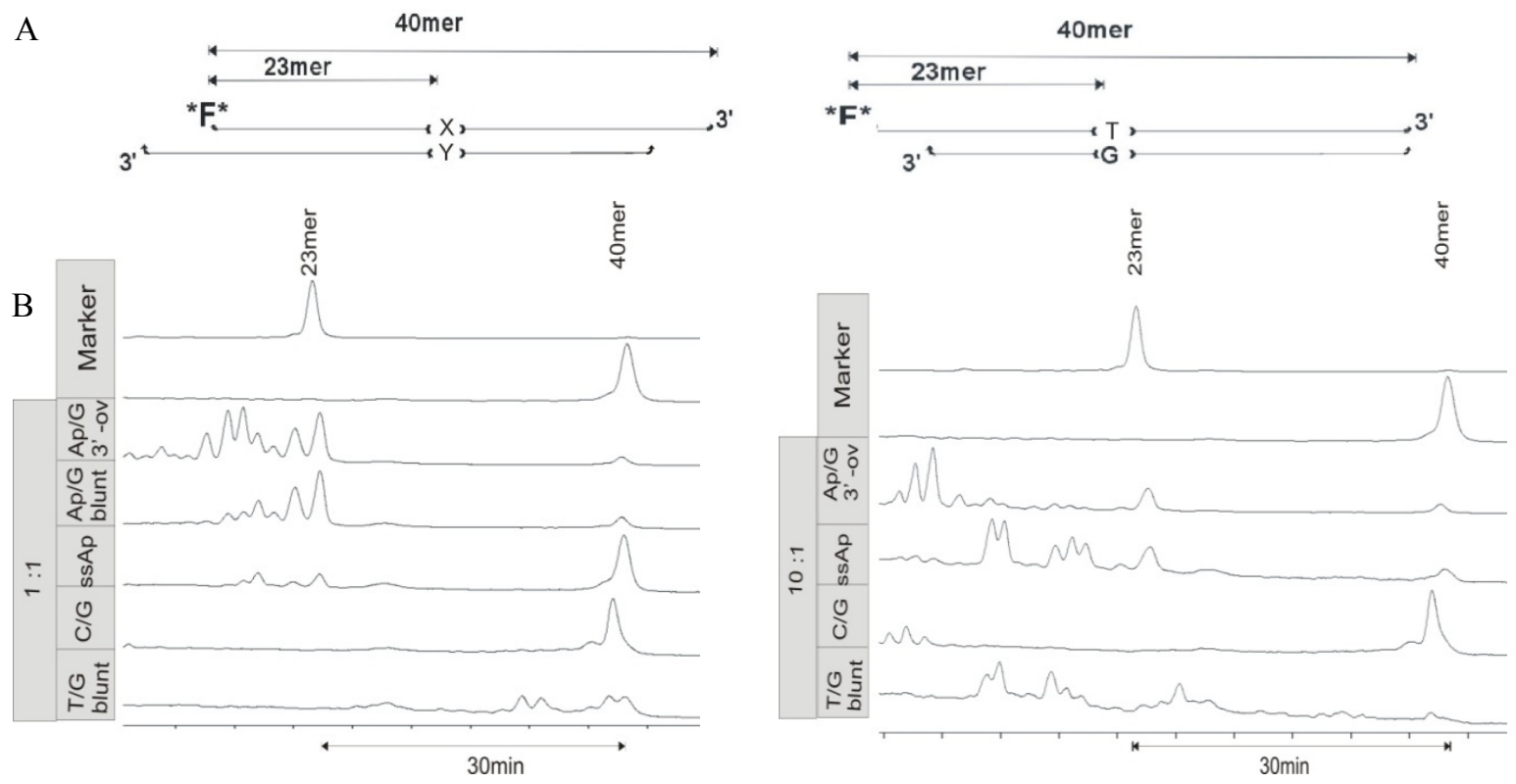

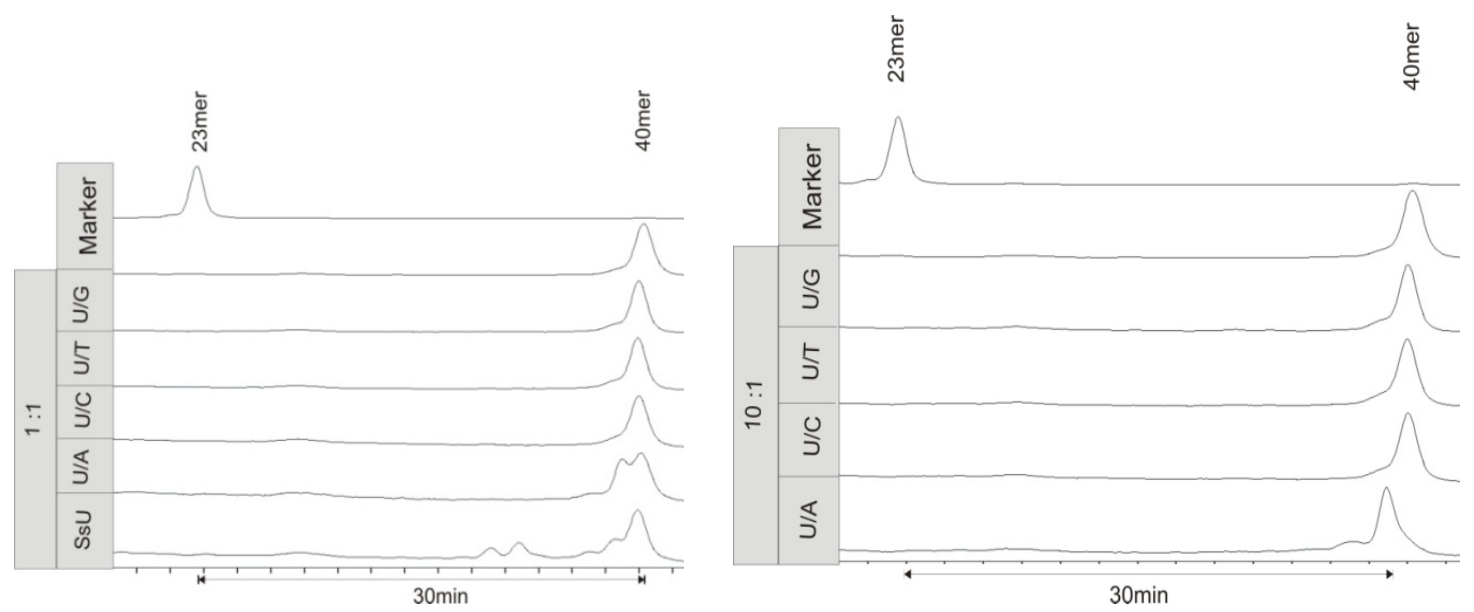

Figure 3.3: ExoA activity assay. A: schematic representation of substrate; $X=A P, C, U ; Y=G, T, C, A$; $\mathrm{F}=$ fluoroscein. Substrate containing $\mathrm{T} / \mathrm{G}$ mismatch is blunt-ended. B: A.L.F.-PAGE analysis of ExoA activity assay with different substrates. $0.12 \mathrm{pmol}$ of substrate was used at enzyme:substrate ratio of 1:1 or 1:10 in Endonuclease Buffer (2.19), incubated $10 \mathrm{~min}$ at $37^{\circ} \mathrm{C}$ without enzyme pripor to enzymatic reaction for 30 $\min$ at $37^{\circ} \mathrm{C}$.

An AP-site containing substrate resulted in a product migrating with the same electrophoretic mobility as the 23-mer marker, confirming that ExoA is an APendonuclease. Series of shorter products were also generated as a result of further degradation of the main 23 -mer product due to $3^{\prime} \rightarrow 5^{\prime}$ exonuclease activity of ExoA. Same products of $3^{\prime} \rightarrow 5$ exonuclease activity were also observed when blunt-ended $\mathrm{T} / \mathrm{G}$ mismatch containing substrate was used for the assay. However, reaction with a substrate containing single stranded 3' overhang did not yield in degradation products, confirming the $3^{\prime} \rightarrow 5$ exonuclease activity of ExoA to be active only on double stranded DNA. These results are in agreement with findings of T. Shida et al. showing that ExoA exhibits same activities as members of the exonuclease III family, such as AP-endonuclease and $3^{\prime} \rightarrow 5$ exonuclease activities (Shida et al., 1999). Activity assays (Figure 3.3) further demonstrated that ExoA, also when in excess, do not process uracil in U/G, U/C, U/T, U/A mismatches as well as uracil in ssDNA indicating that this protein does not possess DNA uridine endonuclease activity and therefore ExoA can be used in the directed evolution of an enzyme with DNA uridine endonuclease activity.

To conclude this sub-section, it was demonstrated that overproduced ExoA can be maintained in E. coli $\Delta u n g$ strain. In connection with attempts to overproduce ExoA in $E$. coli $\Delta x t h A$ strain (Section 3.5) these results are of considerable importance. 


\subsection{Attempted genetic selection of an ExoA mutant carrying DNA uridine endonuclease activity with the use of PBS1 bacteriophage}

\subsubsection{Design of a selection procedure}

For genetic selection to work, an ExoA mutant must contribute to a growth advantage for the cell. The arising question in this study is how ExoA with acquired DNA urdine endonuclease activity can contribute to this? In this approach PBS1 bacteriophage from $B$. subtilis fulfilled the requirement. PBS1 bacteriophage contains uracil instead of thymine in its DNA (Takahashi, 1963) and, in order to protect its DNA from the attack of BER, it produces UGI, a small protein that inhibits the uracil-DNA glycosylase (family 1 UDG) of the host (Wang and Mosbaugh, 1989). UGI cannot inhibit exonuclease III homologs (Schomacher, 2007). Thus, any ExoA with acquired DNA uridine endonuclease activity should be able to initiate DNA uracil repair and, due to the exceedingly numerous uridine sites in PBS1 DNA, scores of single-strand breaks will be produced which will lead to consequent fragmentation of bacteriophage DNA. In any other cells that do not possess additional activity, PBS1 will successfully finish its reproduction and kill cells by lysis. This would provide a possibility to directly select cells resistant to bacteriophage infection due to acquired DNA U-Endo activity.

However, PBS1 belongs to the group of so called pseudolysogenic bacteriophages (Slepecky and Hemphill, 2006). Pseudolysogeny is a phenomenon in which an association between bacteriophage and its host mimics lysogeny in that host cell lysis is delayed or does not occur (Singleton and Sainsbury, 2006). Unlike true lysogeny, in this case bacteriophage genome does not integrate into the host chromosome (Abedon, 2008). The genome may be carried, but not expressed or replicated, within a cell in a susceptible population of bacteria, and the genome is passed to only one of the daughter cells at each cell division; a culture containing a proportion of such 'carrier cells' is known as a carrier culture. After several successive transits from cell to daughter cell, the bacteriophage genome enters the lytic cycle and progeny bacteriophages are released by cell lysis. These may infect other cells which may in turn become carrier cells (Singleton and Sainsbury, 2006). Presumably, PBS1 was included into this group of bacteriophages because of the instability of the lysogenic state (Takahashi, 1963). In any case, such interaction of PBS1 with its host interferes with its use in the selection approach. It will be impossible to select cells that survived bacteriophage infection due to the acquired DNA uridine endonuclease activity from those that survive due to established pseudolysogeny. Therefore, a clear 
plaque mutant of PBS1 was required to select cells exhibiting DNA uridine endonuclease activity among other cells. This mutant, named PBS2, has been described in the literature by different groups (Takahashi, 1963; Katz et al., 1976; Lauer and Klotz, 1976; Duncan and Warner, 1977), but it is no longer available in the scientific community. Since mutagenesis of a bacteriophage into a clear-plaque variant is well described for other bacteriophages (Dowding and Hopwood, 1973; Walker, 1978; Calsou et al., 1987), it was decided to mutagenize PBS1 bacteriophage into its clear-plaque variant in our laboratory. Figure 3.4 gives an overview to this approach.

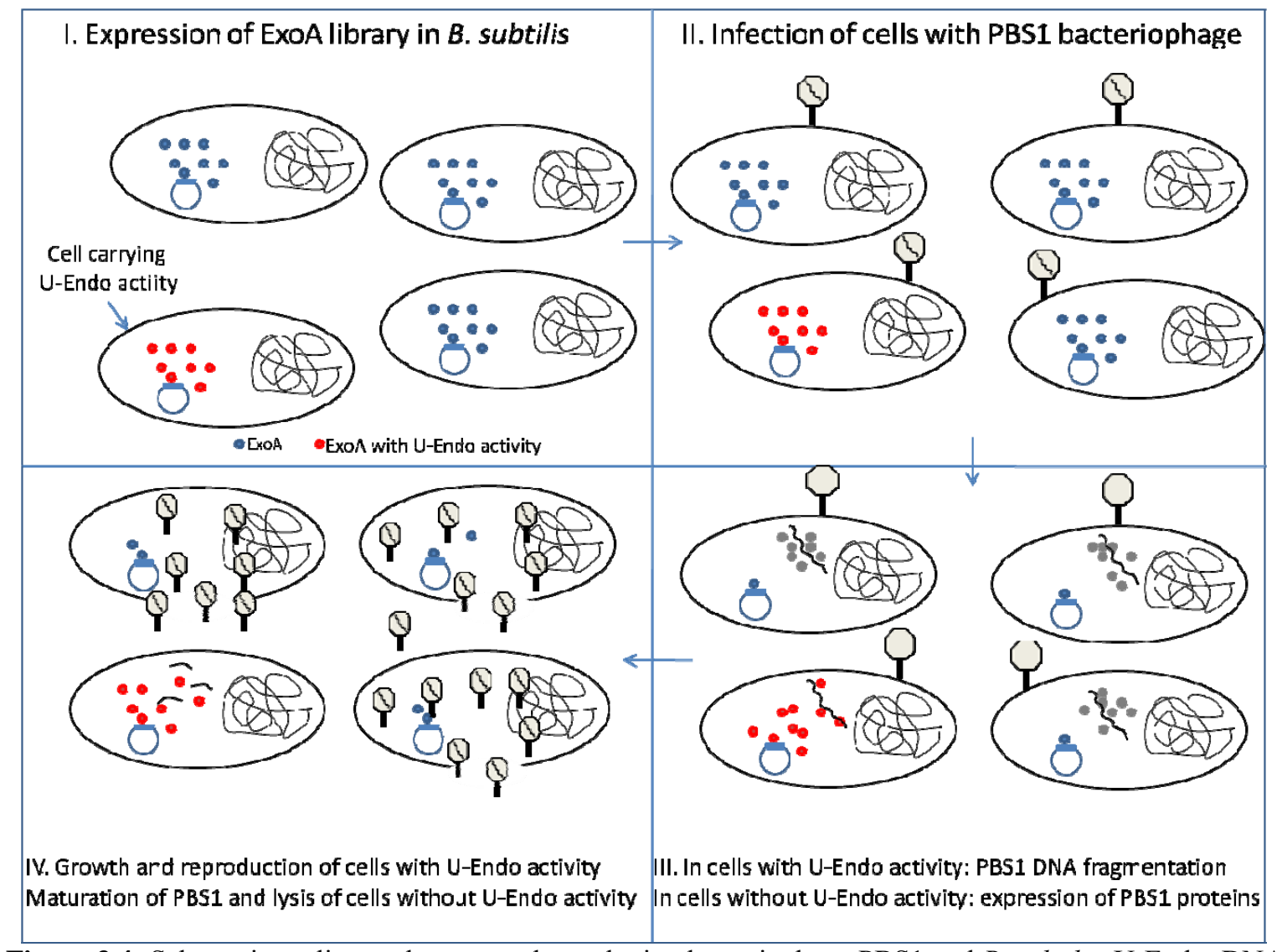

Figure 3.4: Schematic outline to the approach employing bacteriophage PBS1 and B. subtilis. U-Endo: DNA uridine endonuclease activity.

According to this design of selection procedure, experiments during this part of the work were grouped into two groups: construction of a mutant exo $A$ library (Section 3.2.2) and investigations on PBS1 bacteriophage and attempts to obtain a clear-plaque mutant of PBS1 (Section 3.2.3) and were performed in parallel.

\subsubsection{Construction of a mutant gene library}

Series of experimental strategies have been developed to generate mutant gene libraries that differ significantly from each other. Random mutagenesis which targets whole genes 
may be achieved by passing cloned genes through mutator strains, by treating DNA or whole bacteria with various chemical mutagens, or using error-prone PCR. There are also other random mutagenesis strategies which target single or few selected amino acids or regions of a protein that might be important for a certain function (Brakmann and Lindemann, 2004). Sequence diversity can also be generated by DNA shuffling (Suenaga et al., 2004), hypermutagenesis (Vartanian et al., 1996) or cassette mutagenesis (Black et al., 1996).

The error-prone PCR method is one of the most popular approaches to generate libraries in directed evolution experiments because of its simplicity and versatility. In addition, the rate of mutation in error-prone PCR can be altered by modifying PCR conditions (Wang et al., 2006). Variations in error rates can be obtained in a number of ways. One of the most straightforward methods is the combination of introducing small amount of $\mathrm{Mn}^{2+}$ (in place of the natural $\mathrm{Mg}^{2+}$ cofactor) to reduce the base pairing specificity (Beckman et al., 1985) and including unbalanced dNTP stoichiometry to force misincorporation (Cadwell and Joyce, 1994; Cirino et al., 2003). Mutagenic PCR conditions also include increased $\mathrm{Mg}^{2+}$ concentration to stabilze noncomplementary base pairs and increased polymerase concentration to enhance the probability of elongation of misprimed termini (Gelfand and White, 1990). Construction of mutant exoA library using error-prone PCR was performed according to the scheme shown in Figure 3.5.

\begin{tabular}{|l|}
\hline 1 Error-prone PCR of exoA \\
\hline 2 Transformation of \\
E. coli cells
\end{tabular}

Figure 3.5: Scheme of library construction strategy. exo $A$ served as a template for error-prone PCR (1), the PCR product was inserted into the cloning vector and transformed into $E$. coli cells (2). Thereafter, vector DNA containing the mutant gene library was isolated, the randomized exo $A$ fragment was detached from the vector by restriction endonuclease digestion, re-cloned into shuttle vector and introduced into E. coli cells by transformation (3). Next, shuttle vector containing the mutant exo $A$ library was isolated and the library was established in B. subtilis cells (4) by means of transformation.

Mutagenesis of exoA by passage through a mutator strain was abandoned due to unfavourable ratio of substitutions over frameshift mutations and considerably low mutation frequencies (data not shown). 


\subsubsection{Optimisation of error-prone PCR conditions}

According to Cadwell and Joyce, error-prone PCR protocols employ several modifications relative to standard PCR that might be considered mutagenic, including: (1) increased concentration of Taq polymerase; (2) increased extension time; (3) increased concentration of $\mathrm{MgCl}_{2}$; (4) addition of $\mathrm{MnCl}_{2}$ and (5) dNTP concentration bias. The last two modifications are expected to have the greatest impact on the error-rate (Cadwell and Joyce, 1992). Different error-prone PCR (2.2.2.2.2) conditions were tested to find the optimal PCR condition suitable for the purpose of generating mutant exoA library. All reaction mixtures contained 100ng of template DNA, 50 pmoles of each primer, $6.5 \mathrm{mM}$ $\mathrm{MgCl}_{2}$ and 5 Units of Taq polymerase. ThermoPol Reaction Buffer was used in all reactions. The mutagenic reaction mixtures contained varying concentrations of $\mathrm{MnCl}_{2}$ and dNTPs; the effect of different sets of conditions on the number and type of mutations is summarized in Table 3.1.

\begin{tabular}{|c|c|c|c|c|}
\hline $\begin{array}{l}\mathrm{MnCl}_{2} \text { concentration, } \\
\text { dNTP bias }\end{array}$ & $\begin{array}{c}\text { Number of } \\
\text { sequenced clones }\end{array}$ & $\begin{array}{c}\text { Number of deletions } \\
\text { /insertions }\end{array}$ & $\begin{array}{c}\text { Average mutation } \\
\text { number per gene }\end{array}$ & $\begin{array}{l}\text { Mutation frequency } \\
\text { per position }\end{array}$ \\
\hline $\begin{array}{c}0 \mathrm{mM} \\
\text { dATP, dGTP } 0.2 \mathrm{mM} \text { each } \\
\text { dTTP, dCTP } 0.2 \mathrm{mM} \text { each }\end{array}$ & 12 & - & 0.25 & $3.3 * 10^{-4}$ \\
\hline $\begin{array}{c}0.5 \mathrm{mM} \\
\text { dATP, dGTP } 0.2 \mathrm{mM} \text { each } \\
\text { dTTP, dCTP } 1 \mathrm{mM} \text { each }\end{array}$ & 16 & 14 deletions & 14.08 & $1.9 * 10^{-2}$ \\
\hline $\begin{array}{l}0.5 \mathrm{mM} \\
\text { dATP, dGTP } 1 \mathrm{mM} \text { each } \\
\text { dTTP, dCTP } 1 \mathrm{mM} \text { each }\end{array}$ & 14 & 6 deletions & 5.1 & $6.8 * 10^{-3}$ \\
\hline $\begin{array}{c}0.25 \mathrm{mM} \\
\text { dATP, dGTP } 1 \mathrm{mM} \text { each } \\
\text { dTTP, dCTP } 0.2 \mathrm{mM} \text { each }\end{array}$ & 8 & 4 deletions & 9.6 & $1.2 * 10^{-3}$ \\
\hline $\begin{array}{c}0.25 \mathrm{mM} \\
\mathrm{dATP}, \mathrm{dGTP} 0.4 \mathrm{mM} \text { each } \\
\text { dTTP, dCTP } 1 \mathrm{mM} \text { each } \\
0.1 \mathrm{mM}\end{array}$ & 18 & 8 deletions & 5.8 & $7.7 * 10^{-3}$ \\
\hline $\begin{array}{l}\text { dATP, dGTP } 1 \mathrm{mM} \text { each } \\
\text { dTTP, dCTP } 0.2 \mathrm{mM} \text { each }\end{array}$ & 25 & 9 deletions & 1.4 & $1.8^{*} 10^{-3}$ \\
\hline $\begin{array}{c}\text { OmM } \\
\text { dATP, dGTP } 1 \mathrm{mM} \text { each } \\
\text { dTTP, dCTP 0.1mM each }\end{array}$ & 15 & $\begin{array}{c}8 \text { deletions } \\
\text { (1 trinucleotide) }\end{array}$ & 3.26 & $4.3 * 10^{-3}$ \\
\hline $\begin{array}{c}0 \mathrm{mM} \\
\text { dATP, dGTP } 1 \mathrm{mM} \text { each } \\
\text { dTTP, dCTP } 0.2 \mathrm{mM} \text { each }\end{array}$ & 21 & 2 deletions & 1.2 & $1.5 * 10^{-3}$ \\
\hline $\begin{array}{c}\text { OmM } \\
\text { dATP, dGTP } 0.2 \mathrm{mM} \text { each } \\
\text { dTTP, dCTP } 1 \mathrm{mM} \text { each }\end{array}$ & 31 & 2 deletions & 2 & $2.6 * 10^{-3}$ \\
\hline
\end{tabular}

Table 3.1: Effects of various PCR conditions on mutation frequency and number of deletions or insertions. The average mutation number includes all mutation types. Mutation frequency was calculated as total number of mutations/total number of nucleotides sequenced (756 nucleotide positions between the two sequencing primers). For sequences refer to Appendix 7.2.1.

PCR with standard dNTP concentration $\left(0.2 \mathrm{mM}\right.$ each) and without $\mathrm{MnCl}_{2}$ resulted in only 3 mutations within 9072 nucleotides that were sequenced (first row in Table 3.1). Including of $\mathrm{MnCl}_{2}$ in the PCR reaction leads to higher number of mutations: average mutation 
number per gene being 5.1 when $0.5 \mathrm{mM} \mathrm{MnCl}_{2}$ was added to reaction and no dNTP bias was implied. However, number of deletion mutations was also considerably high: 14 single nucleotide deletions in 16 clones were obtained when $\mathrm{MnCl}_{2}$ was added to the PCR reaction compared to 2 deletions in 31 clones without $\mathrm{MnCl}_{2}$ (sequences can be found in Appendix 7.2.1). Mutagenic role of $\mathrm{Mn}^{2+}$ is suggested to be due to its interaction with the enzyme-template complex, possibly altering the conformation at the active site of the polymerase (El-Deiry et al., 1984). Frameshift mutations such as deletions and/or insertions of 1 or 2 nucleotides within the reading frame of a gene will lead to expression of novel and/or truncated polypeptides. Therefore this type of mutations should be avoided when a gene library is being constructed. The appropriate mutation frequency depends theoretically on the length of the gene, the average number of random mutations that the protein can accept without unfolding and the mutation bias. Error-prone PCR with dATP, dGTP (0.2mM each), dTTP, dCTP ( $1 \mathrm{mM}$ each) and without $\mathrm{MnCl}_{2}$ yields 2 substitutions in average and 0.064 deletions per gene (highlighted in blue, Table 3.1). Due to this favourable ratio of substitutions over frameshift mutations this set of error-prone PCR condition was selected for further use. Mutation types and their frequencies obtained by error-prone PCR under this optimized condition are summarized in Table 3.2.

\begin{tabular}{ccc}
\hline \multicolumn{2}{c}{ Total mutations in 31 clones } & 62 in 23405 nt \\
\hline \multirow{4}{*}{ Transitions } & $\mathrm{A} \rightarrow \mathrm{G}$ & $26.6 \%$ \\
& $\mathrm{G} \rightarrow \mathrm{A}$ & $3.3 \%$ \\
& $\mathrm{~T} \rightarrow \mathrm{C}$ & $30 \%$ \\
& $\mathrm{C} \rightarrow \mathrm{T}$ & $10 \%$ \\
\hline \multirow{4}{*}{ Transversion } & $\mathrm{A} \rightarrow \mathrm{T}$ & $8.3 \%$ \\
& $\mathrm{~T} \rightarrow \mathrm{A}$ & $15 \%$ \\
& $\mathrm{G} \rightarrow \mathrm{C}$ & - \\
& $\mathrm{C} \rightarrow \mathrm{G}$ & - \\
& $\mathrm{A} \rightarrow \mathrm{C}$ & $1.66 \%$ \\
& $\mathrm{C} \rightarrow \mathrm{A}$ & $1.66 \%$ \\
& $\mathrm{G} \rightarrow \mathrm{T}$ & - \\
\hline 1 deletions & $\mathrm{T} \rightarrow \mathrm{G}$ & $3.3 \%$ \\
\hline Insertions & & 2 \\
\hline
\end{tabular}

Table 3.2: Sequence context of mutation types and their frequencies obtained by the optimized error-prone PCR.

As shown in Table 3.2, this PCR condition did not result in $\mathrm{G} \rightarrow \mathrm{C}$ and $\mathrm{C} \rightarrow \mathrm{G}$ transversion mutations, which is in agreement with the results of Shafikhani et al (Shafikhani et al., 1997). Because of difference in experimental conditions employed in our study, a comparison of mutation frequencies during mutagenic PCRs with published data was difficult. For instance, some reaction buffers may be more mutagenic than the others (Eckert and Kunkel, 1990); different AT content of the template may introduce biases, 
caused by the fact that the $\mathrm{A} \rightarrow \mathrm{G}$ and $\mathrm{T} \rightarrow \mathrm{C}$ transitions are the most frequent substitution under standard PCR conditions (Fromant et al., 1995).

\subsubsection{Cloning of the library and transformation of $E$. coli}

The exoA randomized by means of error-prone PCR was inserted into different E. coli cloning vectors with considerably high cloning efficiencies (3.2.2., Figure 3.4). Direct cloning of the PCR product into shuttle vector was inefficient for the library construction (data not shown).

pJET1.2 (2.1.3.2) cloning vector was then chosen over pCR II-TOPO and pCR ${ }^{\circledR}$-Blunt IITOPO vectors because of (1) better cloning efficiency and (2) availability of a negative selection against non-recombinant clones. The latter was achieved due to expression of a lethal restriction enzyme when the vector is self-ligated. E. coli cells were transformed with the pJET1.2 cloning vector after insertion of randomized exoA. To achieve sufficient high transformation efficiency, different E. coli strains and two transformation techniques were used (2.2.1.3.1). Results are summarized in Table 3.3.

\begin{tabular}{cccc}
\hline $\begin{array}{c}\text { Transformation } \\
\text { method }\end{array}$ & E. coli strain & $\begin{array}{c}\text { Number of clones } \\
\text { (pJET_exoA) }\end{array}$ & $\begin{array}{c}\text { Number of } \\
\text { transformants / } / \text { g pUC19 }\end{array}$ \\
\hline $\mathrm{RbCl}_{2}$ method & $\mathrm{DH} 5 \alpha$ & 1600 & $5.6^{*} 10^{7}$ \\
& $\mathrm{TOP} 10$ & 35000 & $7 * 10^{6}$ \\
\hline Electroporation & $\mathrm{DH} 5 \alpha$ & 900 & $2 * 10^{7}$ \\
& TOP10 & 1150 & $8.6^{*} 10^{6}$ \\
\hline
\end{tabular}

Table 3.3: Transformation efficiency of $E$. coli with pJET1.2 vector containing mutant exoA library. Table shows results of single experiment for each transformation (method descriptions: 2.2.1.3.1). Covalently closed, circular, supercoiled DNA of pUC19 vector was used as a control.

Maximal number of clones was obtained with chemically $\left(\mathrm{RbCl}_{2}\right)$ competent One Shot TOP10 E. coli cells (2.1.1.2) and was used therefore for library generation.

Approximately $9 * 10^{5}$ colonies with randomized exo $A$ in pJET1.2 vector were collected and used for plasmid DNA isolation (2.2.2.1). For protein expression in B. subtilis, the exoA library was then cut out from the pJET1.2 vector re-cloned into linearized and purified pBQ200 shuttle vector (2.2.2.8) that was modified previously into pBQ200_BpiI (2.1.3.4) using site-directed Quick-change ${ }^{\circledR}$ mutagenesis (2.2.2.2.4) to introduce two BpiI recognition sites. BpiI cleaves downstream of its recognition site and generates any desired 4 base 5'-overhangs. This feature makes this enzyme more efficient in respect of library generation than other conventional restriction endonucleases that cleave palindrome sites. Routinely, $3^{*} 10^{5}$ clones were obtained from each transformation. Colonies were then collected and used for isolation of the mutant exoA library in pBQ200_BpiI shuttle vector. 
Expression of ExoA when cloned into pBQ200_BpiI shuttle vector was under regulation of a strong DegQ36 promoter (Msadek et al., 1991); ribosome binding site of the B. subtilis gapA gene was upstream of the translational start of exoA gene (Meinken et al., 2003).

\subsubsection{Investigation of transformation efficiencies of different $B$. subtilis strains}

It is well known that $B$. subtilis cells exhibit transformation efficiencies few orders of magnitude lower than gram-negative E. coli cells (Trevors et al., 1992). Nonetheless, three major options exist for the introduction of DNA into B. subtilis by transformation: (1) transformation of naturally competent bacteria, (2) polyethylene glycol (PEG)-mediated transformation of protoplasts and (3) electroporation. During DNA transfer into naturally competent B. subtilis cells, the DNA suffers double-strand cleavage at the cell surface and one of the two strands is stripped away during the actual entry into the cell (Cutting and Youngman, 1994). For that reason this method is inappropriate for establishing the mutant exoA library in B. subtilis. Therefore, the other two methods were used and transformation efficiencies were determined for several B. subtilis strains (Table 3.5).

\begin{tabular}{|c|c|c|c|}
\hline Transformation method & $\begin{array}{c}\text { Expected max. transformation } \\
\text { efficiency }(/ \mu \mathrm{g} D N A)\end{array}$ & B. subtilis strain & $\begin{array}{c}\text { Transformation efficiency / } \mu \mathrm{g} \\
\text { pBQ200_exoA }\end{array}$ \\
\hline \multirow{3}{*}{ Protoplast transformation } & \multirow{3}{*}{$2 * 10^{7}$ (S. Chang and N. Cohen, 1979) } & W168 & 28 \\
\hline & & SB19E & 18 \\
\hline & & IG-20 & 35 \\
\hline \multirow{4}{*}{ Electroporation } & \multirow{4}{*}{$10^{4}$ (P. Brigidi et al, 1990) } & W168 & $1.6^{*} 10^{2}$ \\
\hline & & SB19E & 59 \\
\hline & & IG-20 & $5 * 10^{2}$ \\
\hline & & ISW1214 & $8.9 * 10^{2}$ \\
\hline \multirow{4}{*}{$\begin{array}{l}\text { Electroporation in high } \\
\text { osmolarity solution }\end{array}$} & \multirow{4}{*}{$1.4^{*} 10^{6}$ (G-P. Xue et al., 1999) } & W168 & $6 * 10^{3}$ \\
\hline & & SB19E & $1.2 * 10^{2}$ \\
\hline & & IH6140 & $7 * 10^{4}$ \\
\hline & & ISW1214 & $8 * 10^{2}$ \\
\hline
\end{tabular}

Table 3.5: Transformation efficiencies of B. subtilis strains. Second column of the table shows highest transformation efficiencies described in the literature to the time of study. For genotypes of B. subtilis strains and methods used, refer to Material and Methods section 2.1.1.2 and 2.2.1.3.2, respectively.

The protoplast transformation method in our study did not work as efficient as it was described in the literature. Poor regeneration of protoplasts on DM3 stabilizing agar medium (2.1.10) and incomplete conversion of intact cells into protoplasts were the main problems faced during the experiments (data not shown). Electroporation of B. subtilis cells also delivered low transformation efficiency, even with restriction and modification deficient strains ISW1214 and IG-20.

Maximal transformation efficiency reached during this study was $7 * 10^{4}$ transformants $/ \mu \mathrm{g}$ DNA with B. subtilis IH6140 strain (kindly provided by Dr. V. Kontinen, National Institute 
for Health and Welfare, Finland) by means of "Electroporation in high osmolarity solutions" (2.2.1.3.2). This transformation efficiency was lower compared to that obtained by Xue et al. $\left(1.4 * 10^{6}\right.$ transformants/ $\mu \mathrm{g}$ DNA) who used same $B$. subtilis strain as well as the same method (Xue et al., 1999). This difference is likely due to the use of different plasmid DNA. pUBxynA vector used by Xue et al. is a $5.9 \mathrm{~kb}$ Gram-positive vector carrying kanamycine resistance gene and expresses xylanase at high levels upon establishment within the cell which may lead to increased cell survival. In contrast, pBQ200_exo $A$ vector used in this study is a $7.5 \mathrm{~kb}$ shuttle vector carrying erythromycin resistance gene.

To conclude this sub-section: (1) mutant exo $A$ library of approximately $9 * 10^{5}$ variants was constructed after optimization; (2) methods for transformation of B. subtilis cells were tested and the most efficient method was selected for this study.

\subsubsection{Investigation of PBS1 bacteriophage}

\subsubsection{Verification of presence of uridine residues in PBS1 bacteriophage genome}

As previously described, due to its unique DNA, PBS1 bacteriophage (2.1.2) was to be used in the selection of the ExoA protein variant which has acquired the DNA uridine endonuclease activity. Uridine in the PBS1 DNA is the target for this novel activity and it was important to ensure the presence of uridine residues in the DNA of bacteriophage. PBS1 bacteriophage was obtained from Bacillus Genetic Stock Center (BGSC), The Ohio State University, USA (2.1.2).

DNA was extracted from PBS1 bacteriophage particles (2.2.2.1), treated with DNA uracil glycosylase (2.2.3.12) and analysed by agarose gel electrophoresis (Figure 3.6).

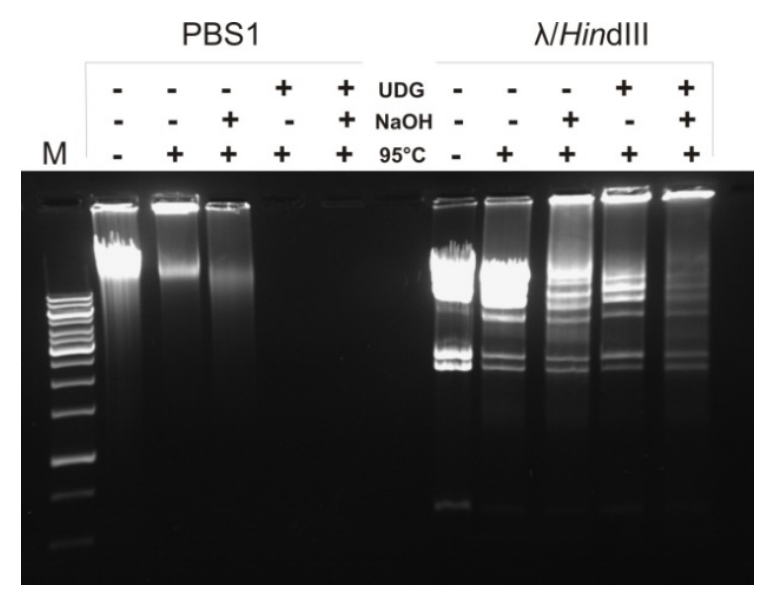

Figure 3.6: Analysis of PBS1 DNA processing by uracil-DNA glycosylase tUDGa by agarose gel electrophoresis. $2.5 \mu \mathrm{g}$ PBS1 DNA was used for analysis. HindIII disgested $\lambda$ bacteriophage DNA was used as a control. Assay conditions $(25 \mu \mathrm{l})$ : $400 \mathrm{pmol} \mathrm{tUDGa}$ in $20 \mathrm{mM}$ Phosphate Buffer with $50 \mathrm{mM} \mathrm{KCl}$, incubation at $37^{\circ} \mathrm{C}$ for $30 \mathrm{~min}$; at $95^{\circ} \mathrm{C}$ for $5 \mathrm{~min}$ with $\mathrm{NaOH}(100 \mathrm{mM}$ end concentration). $\mathrm{HCl}$ was added to neutralize the reaction. $10 \mu \mathrm{l}$ of assay was loaded onto gel. M: DNA size Marker GeneRuler ${ }^{\mathrm{TM}} 1 \mathrm{~kb}(2.1 .5 .1)$ 
The tUDGa homolog from M. mazei (Mm0486) that excises uracil base from $\mathrm{U} / \mathrm{G}, \mathrm{U} / \mathrm{C}$, U/T mismatches and U/A base pair was used for this assay (preparation by S. Ber, Ber 2009). Addition of $\mathrm{NaOH}$ to the reaction and incubation at $95^{\circ} \mathrm{C}$ drives strand cleavage at the base-free DNA site by $\beta$-elimination.

As shown in Figure 3.6, PBS1 DNA was completely degraded when tUDGa was added to the reaction; in contrast, HindIII disgested $\lambda$ DNA, which does not contain uracil residues, remains intact, indicating that PBS1 DNA is susceptible to the action of tUDGa due to the uracil presence.

To test the susceptibility of PBS1 DNA to the action of a DNA uridine endonuclease, bacteriophage DNA was treated with Mth212 (Figure 3.7, for method refer to section 2.2.3.13). Mth212 incises DNA strand 5' to the uridine residue and only when incisions are made on both DNA strands in near proximity it will lead to dsDNA break.

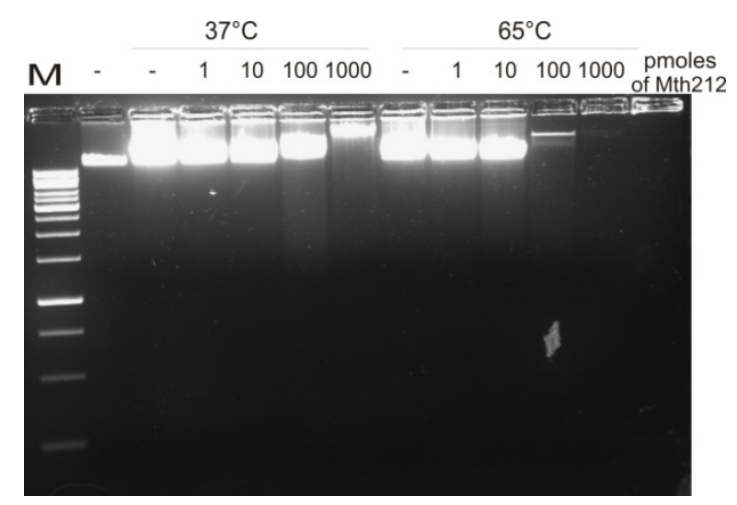

Figure 3.7: Agarose gel analysis of PBS1 DNA processing of by Mth212. Assay conditions (25 $\mu 1): 2.5 \mu \mathrm{g}$ PBS1 DNA in Endonuclease Buffer (2.1.9), incubation at $37^{\circ} \mathrm{C}$ or $65^{\circ} \mathrm{C}$ for $20 \mathrm{~min}$; amount of Mth212 in the reaction: upper bar of the figure. $10 \mu 1$ of assay was used for agarose gel electrophoresis. M: DNA size Marker GeneRuler ${ }^{\mathrm{TM}} 1 \mathrm{~kb}(2.1 .5 .1)$

Incubation of PBS1 DNA with Mth2 12 at $65^{\circ} \mathrm{C}$, a temperature for maximal activity for Mth212, (Georg et al., 2006, Schomacher et al., 2009) resulted in PBS1 DNA degradation in an Mth212 concentration-dependent manner, with a maximum degradation at 1000 pmoles of Mth212, indicating that PBS1 DNA is susceptible to the action of DNA uridine endonuclease.

\subsection{Processing of PBS1 DNA in vivo}

Biochemical analysis of PBS1 DNA showed that it can be processed by Mth212 in vitro. To test whether PBS1 DNA will be attacked by Mth212 in vivo, Mth212 was expressed in B. subtilis after successful cloning of mth212 gene into pBQ200 shuttle vector. As a control, inactive mutant of Mth212 mth212_D151N (Georg et al., 2006) was used. Cells expressing the Mth212 or its inactive mutant were then infected with PBS1 bacteriophage and the plating efficiencies were measured (2.2.1.2.1) (Figure 3.8). 


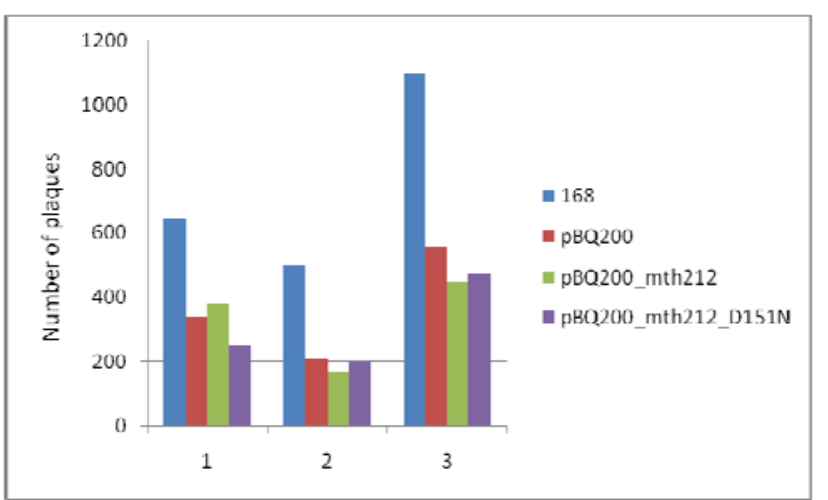

Figure 3.8: Number of PBS1 plaques when B. subtilis cells containing different vectors are infected. 168: wild-type (WT) strain of $B$. subtilis, pBQ200: empty vector, pBQ200_mth212: expression vector for WT Mth212, pBQ200_mth212_D151N: expression vector for inactive Mth212. 1, 2, and 3: ordinal number of experiments. For material and methods refer to Section 2.2.1.2.1..

It was expected that PBS1 DNA will be attacked by Mth212 soon after infection, leading to its degradation and thus bacteriophage death. However, no significant difference in plating efficinecy was observed between cells harbouring pBQ200_mth212, pBQ200_mth212_D151N and the empty vector pBQ200 after infection with PBS1. The difference in plating efficiency between wild-type cells and cells carrying the shuttle vector is most probably due to the presence of antibiotics in the medium, since some antibiotics have been found to negatively affect bacteriophage growth (Santos et al., 2009).

Observed lack of bacteriophage growth inhibition can be explained with following: (1) Mth212 is not expressed in B. subtilis; (2) Mth212 cannot properly fold in B. subtilis; (3) the temperature of $37^{\circ} \mathrm{C}$ used for bacterial and bacteriophage growth is not optimal for Mth212 activity. The optimal temperature for Mth2 12 is $65^{\circ} \mathrm{C}$ (J. Georg et al., 2006).

To address the question whether Mth212 is expressed and can properly fold in B. subtilis, a Western blot analysis was performed with the cytosolic fraction of crude cell extracts (2.2.3.2).

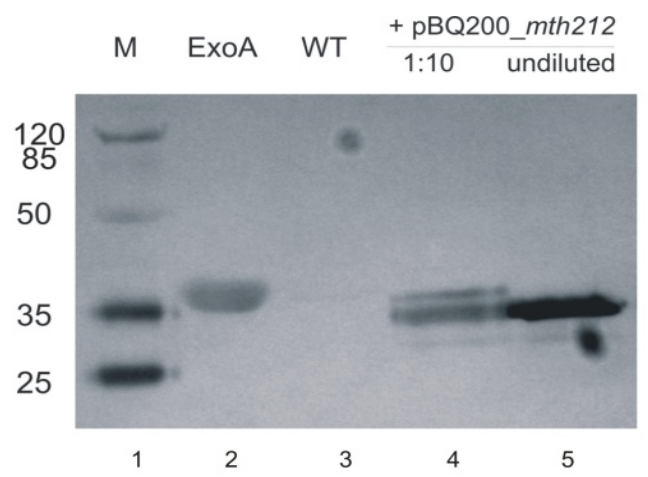

Figure 3.9: Western blot (2.2.3.2) analysis of the cytosolic fraction of crude cell extracts of B. subtilis using anti-Penta-His antibody (2.1.6) 1: (M) Protein Molecular Weight Marker (2.1.5.2); 2: Purified ExoA Protein, 100 pmoles, used as a positive control; 3: cell extract of B. subtilis strain W168; 4 and 5: cytosolic protein extract of $B$. subtilis strain W168 carrying pBQ200_mth212 vector, 1:10 diluted and undiluted, respectively. 
A protein band of approximately $30 \mathrm{kDa}$ size was detected in the cytosolic fraction of crude cell extract of $B$. subtilis carrying pBQ200_mth212 vector by (Figure 3.9). This was similar to the expected molecular weight of 6xHis-tagged Mth212 (31.17 kDa) indicating the expression of Mth212 and its proper folding in B. subtilis. Next, we analyzed enzymatic activity of this protein.

Because of the thermal instability of $B$. subtilis proteins at $65^{\circ} \mathrm{C}$ (optimal temperature for Mth212), it is impossible to infect B. subtilis cells with PBS1 bacteriophage at this temperature to see the influence of Mth212. Therefore, enzymatic activity tests were performed with the protein extracts of B. subtilis expressing Mth212 (Figure 3.10, for methods refer to section 2.2.3.11).

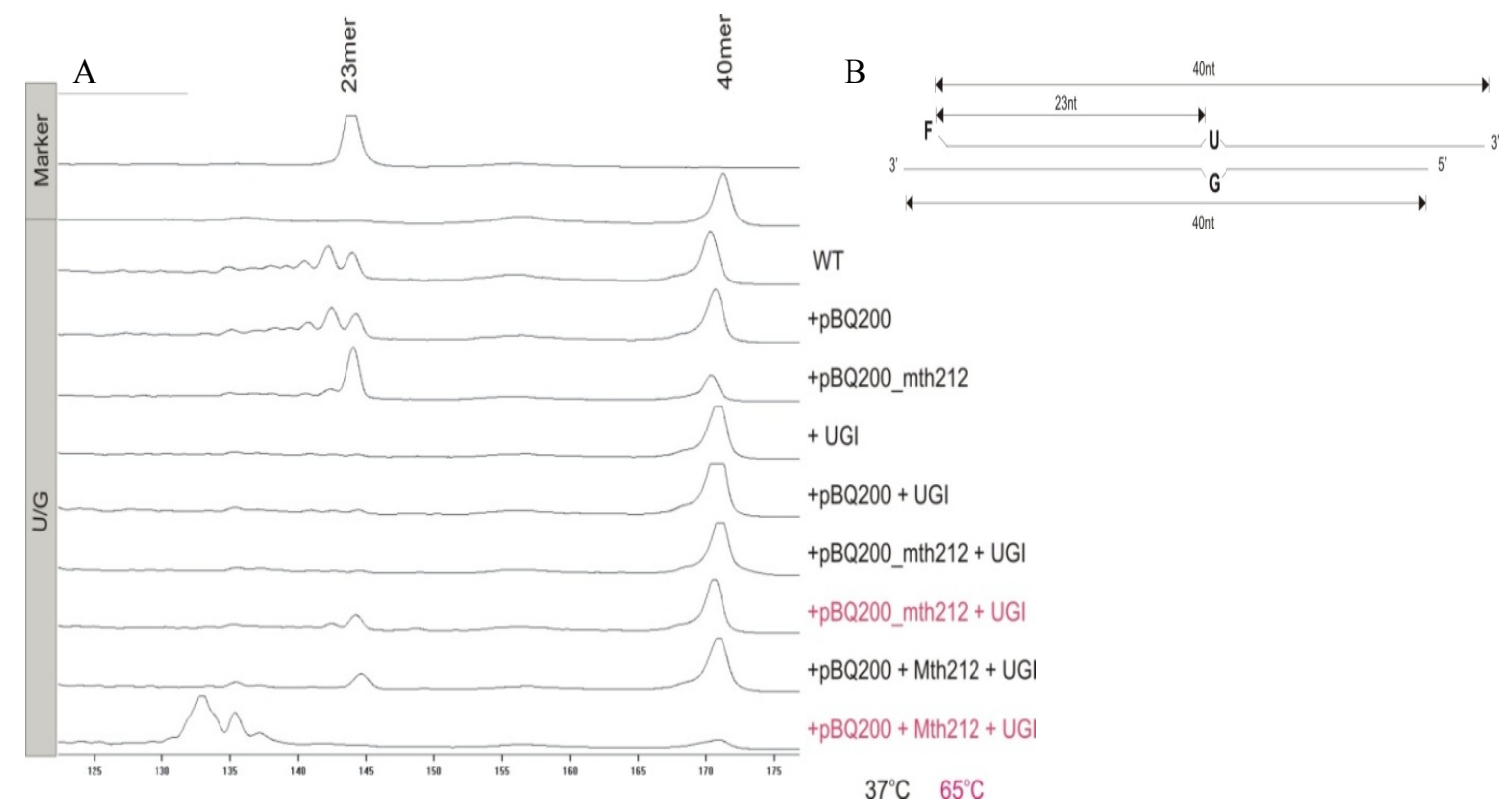

Figure 3.10: Activity assay of $B$. subtilis protein extracts. A: A.L.F. PAGE analysis of the assay. Assay conditions: $0.12 \mathrm{pmol}$ substrate, $10 \mu \mathrm{l}$ protein extract in Endonuclease Buffer (2.1.9); incubation at $37^{\circ} \mathrm{C}$ or $65^{\circ} \mathrm{C}$ (labeled with red) for $20 \mathrm{~min}$; WT: WT strain protein extract; protein extract from cells transformed with empty vector (pBQ200),or pBQ200_mth212 vector (2.2.3.4). UGI: uracil-DNA glycosylase Inhibitor (100 pmoles); for inhibition, UGI was added $10 \mathrm{~min}$ prior to substrate addition; 100 pmoles of purified Mth212 protein was used as positive control. B: Schematic representation of the substrate used in the assay.

As shown in Figure 3.10, all three types of cell extract; wild-type, cells containing pBQ200, and cells containing pBQ200_mth212, produced a 23-mer and one or few shorter fragments from the oligonucleotide substrate with $U / G$ mismatch. However, uracil-DNA glycosylase inhibitor protein, UGI, was able to completely inhibit this reaction, suggesting that (1) the 23-mer product is a result of activity of endogenous uracil-DNA glycosylases and AP-endonucleases of B. subtilis, (2) activity of Mth212 is too low at $37^{\circ} \mathrm{C}$. In contrast, when the assay mixture was incubated at $65^{\circ} \mathrm{C}$ a 23 -mer product peak was observed, 
indicating the activation of Mth212, which cannot be inhibited by UGI. These results support the use of ExoA: since it is originated from B. subtilis, this protein will work at $37^{\circ} \mathrm{C}$ without any complication regarding the temperature optimum. Once it is converted to DNA uridine endonuclease, it would attack PBS1 bacteriophage DNA in B. subtilis cells.

\subsubsection{Experiments to obtain clear-plaque mutant of PBS1 bacteriophage}

As described in Section 3.2.1. a clear plaque mutant of PBS1, named PBS2, was required was for the genetic selection of cells exhibiting DNA uridine endonuclease activity. Since this mutant bacteriophage could not be found in the scientific community, it was decided to mutagenize PBS1 bacteriophage into its clear-plaque variant in our laboratory.

UV-irradiation was employed for mutagenesis of PBS1 to obtain a clear-plaque mutant. At first, a photokilling curve of PBS1 was made to optimize UV irradiation dose (Figure 3.11). Approximately $1 * 10^{7}$ plaque forming units (pfu) of PBS1 bacteriophage were suspended in $6 \mathrm{ml}$ of PBS1-Buffer (2.1.9) and subjected to UV-irradiation (254 nm, $0.5 \mathrm{~J}$ $\left.\sec ^{-1} \mathrm{~m}^{-2} ; 2.2 .1 .2 .1\right) .100 \mu 1$ of irradiated bacteriophage suspension was serially diluted and the dilutions were plated with $500 \mu l$ of log-phase B. subtilis cells as described in Materials and Methods (2.2.1.2.1). Cells were incubated overnight at $30^{\circ} \mathrm{C}$ and plaques were counted.

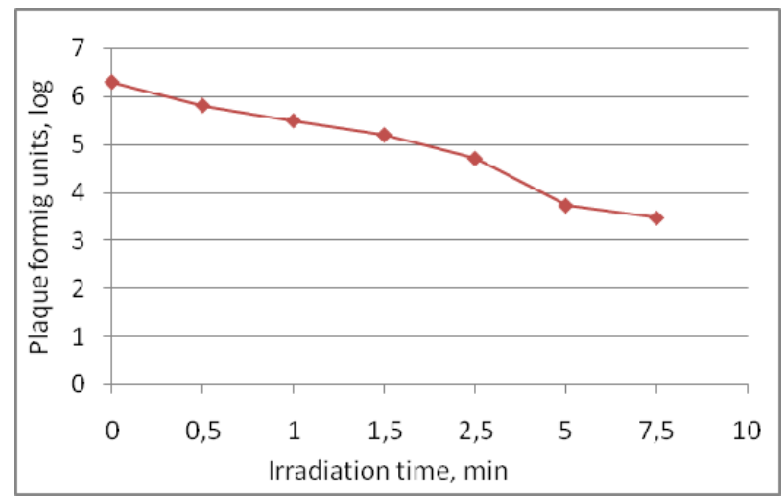

Figure 3.11: Semi-log curve of bacteriophage numbers after irradiation. UV irradiation dose: $254 \mathrm{~nm}, 0.5 \mathrm{~J}$ $\sec ^{-1} \mathrm{~m}^{-2}$

No plaque was detected after 10 minutes of irradiation of bacteriophage. However, after 2.5 and 5 minutes of UV irradiation bacteriophage number decreased by approximately 2 and 3 orders of magnitude, respectively and killed more than $99 \%$ of the bacteriophage population. Higher dose of UV would decrease the number of viable bacteriophage particles drastically, whereas lower dose would induce insufficient damage to DNA. Therefore, UV irradiation dose of $2.5-5 \mathrm{~min}$ at $254 \mathrm{~nm}$ and $0.5 \mathrm{~J} \mathrm{sec}^{-1} \mathrm{~m}^{-2}$ was established for consequent experiments to generate clear-plaque mutants (for detailed description of 
PBS1 bacteriophage mutagenesis experiment refer to Material and Methods section 2.2.1.2.1). However, despite of high number of screened plaques, a bacteriophage with desired clear-plaque phenotype could not be obtained.

It is known that DNA damages caused by UV-irradiation induce SOS response in E. coli cells, resulting in error-prone translesion synthesis (Friedberg et al., 2006). Jean Weigle was the first to observe that the UV-irradiation of the host cells $(i . e$. induction of SOSresponse) lead to increased survival rate and number of mutant bacteriophages (Weigle, 1953). These phenomena were termed later as Weigle reactivation and Weigle mutagenesis, respectively. In this study, it was attempted to make use of Weigle mutagenesis phenomenon to increase the likelihood of clear-plaque mutation in PBS1 bacteriophage.

In order to determine whether Weigle reactivation of PBS1 bacteriophage occurs in $B$. subtilis, non-irradiated or irradiated (1 minute at $254 \mathrm{~nm}$ and $0.5 \mathrm{~J} \mathrm{sec}^{-1} \mathrm{~m}^{-2}$ ) B. subtilis cells were plated with irradiated PBS1 bacteriophage and plaques were counted (Figure $3.12)$.

\section{A} $\begin{gathered}\text { Weigle reactivation value } \\ (\text { P. E. Love and R. E. Yasbin, 1984) }\end{gathered}=\frac{\text { surviving fraction of irradiated bacteriophage incubated on irradiated cells }}{\text { surviving fraction of the irradiated bacteriophage incubated on non-irradiated cells }}$

B

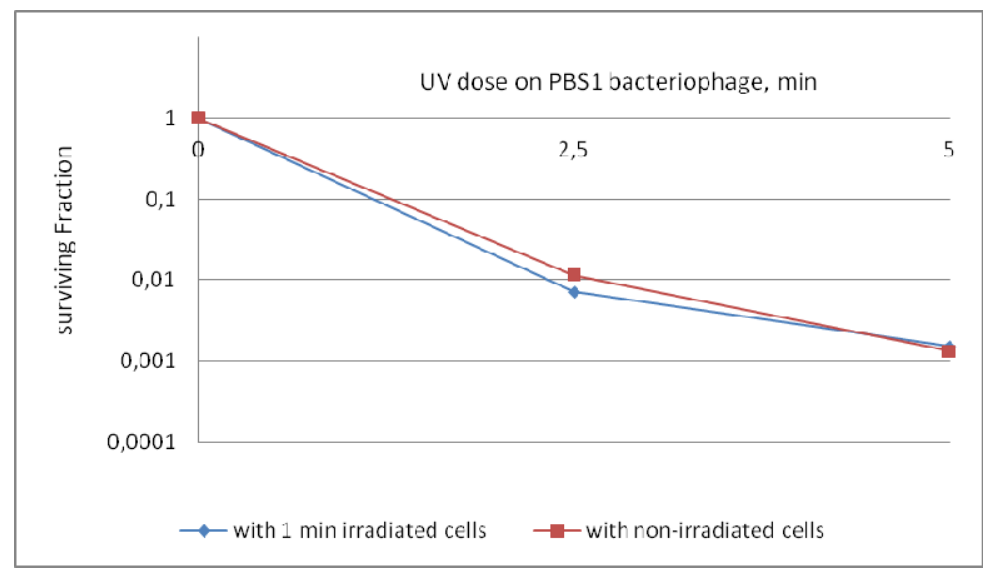

Figure 3.12: Determination of Weigle reactivation for PBS1 bacteriophage. A: Formula for calculating Weigle reactivation value. B: Semi-log plots of the surviving fraction of PBS1 bacteriophage plated with $B$. subtilis cells that were either non-irradiated or irradiated for $1 \mathrm{~min}$. Abscissa: UV-irradiation (at $254 \mathrm{~nm}$ and $0.5 \mathrm{~J} \mathrm{sec}^{-1} \mathrm{~m}^{-2}$ ) in minutes; ordinate: surviving fraction of bacteriophage.

Weigle reactivation value for PBS1 bacteriophage irradiated for 2.5 minutes was $0.592 \pm$ $0,297(\mathrm{n}=3)$. Weigle reactivation value for bacteriophage $\lambda$ irradiated for 2.5 minutes, for instance, was approximately 100 (Weigle, 1953), leading to a conclusion that no Weigle reactivation occurred for PBS1. One can suggest that Weigle reactivation and mutagenesis effects might be bacteriophage specific. It is known that Weigle reactivation and mutagenesis are based on error-prone bypass of DNA lesions of SOS-induced cells 
(Friedberg et al., 2006). PBS1 bacteriophage utilizes its own virally encoded DNA polymerase which incorporates uracil instead of thymine during the viral DNA replication (Hitzeman and Price, 1978). If PBS1 DNA polymerase is not able to do translesion synthesis of bacteriophage DNA, it may explain the lack of Weigle reactivation for PBS1 bacteriophage. This result precluded the making use of Weigle mutagenesis to obtain a clear plaque mutant of PBS1.

To conclude this sub-section: in this study, UV mutagenesis was employed to generate lytic mutant of PBS1. However, no clear-plaque mutant was found even though approximately $2 * 10^{6}$ plaques were screened. In the study of Takahashi, spontaneous clearplaque mutant of PBS1, termed as PBS2, was found by plating of a large number of bacteriophage particles with B. subtilis (Takahashi, 1963), and, unfortunately, no quantitative data regarding this mutation was published. Spontaneous clear-plaque mutation frequency of $E$. coli $\lambda \mathrm{h}$ bacteriophage, for instance, is $0,025 \%$ which is 1 clearplaque mutant in around 4000 and the clear-plaque mutation frequency increases when UV-irradiation is employed (Miura and Tomizawa, 1970).

Taken together, it can be suggested that mutations that lead to a clear-plaque phenotype in PBS1 occur extremely rare and the desired mutant cannot be obtained under experimental conditions employed in this study. Perhaps, complex lysis-lysogeny regulation mechanism exists for PBS1 and only several distinct mutations occurring simultaneously can result in a lytic mutant.

The employment of lytic mutant of PBS1 bacteriophage in the selection of ExoA with acquired DNA uridine endonuclease activity was the most straightforward way due to its intrinsic feature to contain uracil in the DNA. Given that this bacteriophage cannot be utilized for the selection another approach was designed. 


\subsection{Attempted genetic selection of an ExoA mutant carrying U-Endo activity with the use $E$. coli bacteriophage}

\subsubsection{Design of a selection procedure}

This approach is similar to previous selection method that was envisioned for B. subtilis, but it utilizes E. coli as a host cell. Selection pressure is achieved here through the use of bacteriophage as well. However, since there are no known E. coli bacteriophages that have uracils in their DNA, like PBS1 bacteriophage does, this approach is not as straightforward as the approach implementing B. subtilis and PBS1.

In other words, uracils must be intoduced into bacteriophage DNA. This can be achieved by growing bacteriophages on E. coli cells deficient of both uracil-DNA glycosylase and dUTPase activities $\left(d u t^{-}, u n g^{-}\right)$. Thereby, up to $30 \%$ of all thymines in bacteriophage DNA can be replaced by uracil (Duncan and Weiss, 1982). On the other hand, once these bacteriophage particles infect cells that are not $d u t_{-}, u n g-$, their DNA will not contain uracil anymore. This means that cells carrying DNA uridine endonuclease activity are not resistant to bacteriophage as soon as the first round of infection is completed. In order to protect the cells that survived the primary infection due to the acquired DNA uridine endonuclease activity from the second infection, secondary infection must be hindered. This can be achieved by using bacteriophages mutated in one of the genes expressed late in the bacteriophage development. This bacteriophage can be propagated in amber-suppressor dut-, ung- cells, where uracils will be introduced in its DNA. Subsequently, cells carrying the mutant gene library will be infected with these bacteriophages. In cells that carry DNA uridine endonuclease activity bacteriophage DNA will be fragmented due to uridine sites in DNA, whereas in other cells bacteriophage encoded proteins will be expressed. However, due to the mutation in late gene no mature bacteriophage will be released and at the same time the host cell will be overburden with production of defect bacteriophage particles which leads to the cell death. In this way, selection of cells expressing ExoA with desired activity can be achieved. Figure 3.13 gives an overview to this approach. 


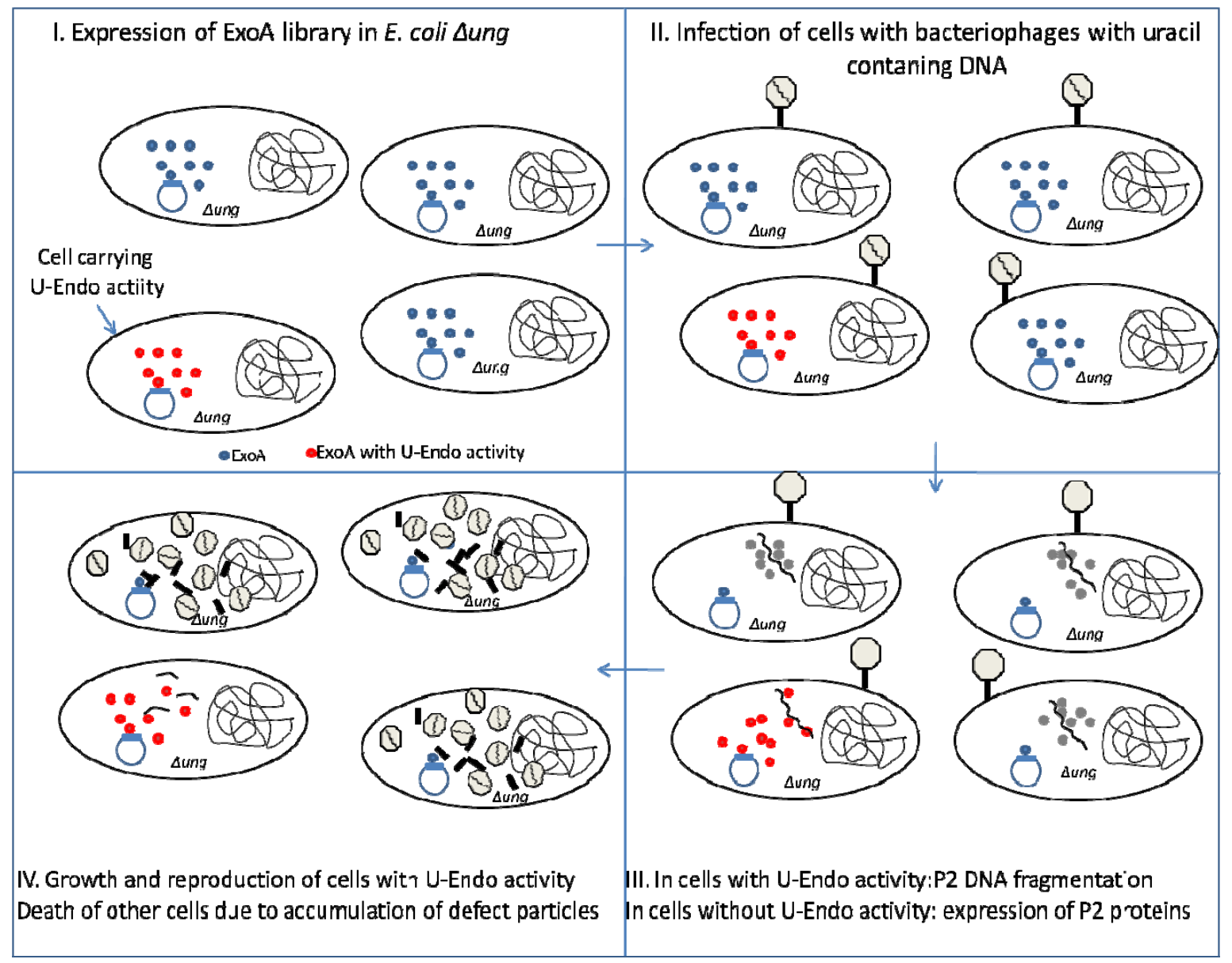

Figure 3.13: Schematic outline to the approach employing E. coli bacteriophage. U-Endo: DNA uridine endonuclease activity.

\subsubsection{Construction of a mutant gene library}

Error-prone PCR for randomization of exo $A$ and cloning of exo $A$ library into pJET1.2 vector were performed as before (Sections 3.2.2 and 3.2.4). Mutation frequencies, ratio of total mutation number to deletion and insertion number, as well as mutation types were determined after sequencing of clones. No significant differences were observed from results of previous library generation (3.2.3) (sequences can be found in Appendix 7.2.2). For protein expression in E. coli, mutant exoA library was re-cloned (2.2.2.8) into expression vectors pASK-08 (2.1.3.5) and pTNA (2.1.3.6). pASK-08 vector provides with inducible, high-level expression of protein, whereas pTNA vector provides with constitutive, low-level expression of protein. For cloning into pTNA vector SphI restriction endonuclease site was removed from exo $A$ using site-directed Quick-change ${ }^{\circledR}$ mutagenesis (2.2.2.2.4) without affecting the protein sequence (for sequence refer to Appendix 7.3.1). Table 3.6 summarizes the construction of new mutant exo $A$ libraries. 


\begin{tabular}{ccccc}
\hline & exOA_pJET1.2 for pASK-08 & exoA_pASK-08 & exOA_pJET1.2 for pTNA & exoA_pTNA \\
\hline $\begin{array}{c}\text { Number of } \\
\text { sequenced clones }\end{array}$ & 48 & 48 & 48 & 48 \\
\hline $\begin{array}{c}\text { Total number of } \\
\text { tranformants* }\end{array}$ & $8,1 * 10^{5}$ & $3 * 10^{6}$ & $4 * 10^{5}$ & $6,7 * 10^{5}$ \\
\hline
\end{tabular}

Table 3.6: Number of clones obtained during the generation of mutant libraries. *-clones from several transformations were pooled together.

\subsubsection{Construction of E. coli mutant strains C1a Aung and C520 Aung}

PBS1 bacteriophage expresses uracil-DNA glycosylase Inhibitor protein (UGI), which blocks the activity of uracil-DNA glycosylases of the host (Wang and Mosbaugh, 1989) to protect its DNA from the attack of BER. This gives "natural" possibility to select the protein with DNA uridine endonuclease activity. In this approach, however, gene of the uracil-DNA glycosylase (ung) must be knocked out in P2 bacteriophage indicator E. coli strains C1a (non-permissive strain, 2.1.1.1) and C520 (amber-suppressor strain, 2.1.1.1) to enable selection of DNA uridine endonuclease. The ung gene was knocked out by replacing it with a kanamycine cassette using P1 bacteriophage transduction (2.2.1.2.3). E. coli BL21_UX strain (Georg et al., 2006) was used as a donor strain for transduction. Absence of complete ORF of ung was verified by PCR (2.2.2.2.1) (Figure 3.14).

A

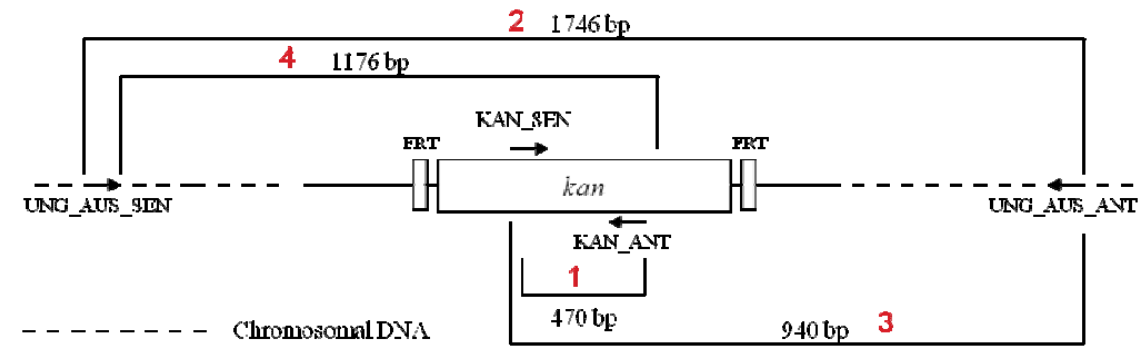

B

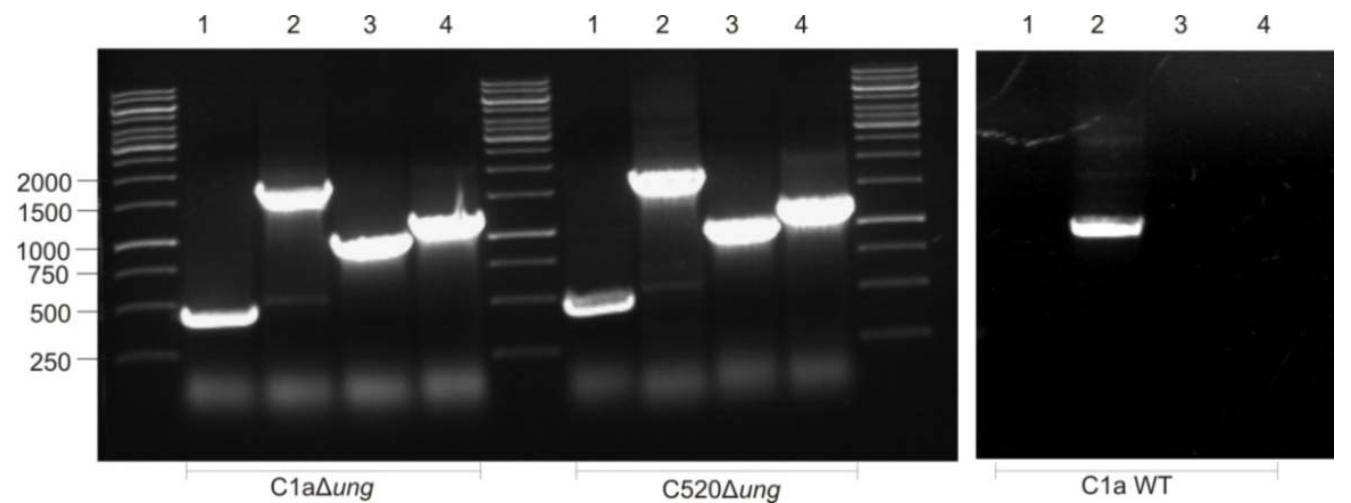

Figure 3.14: Deletion of ung gene in E. coli C1a and C520 strains. A: Scheme of Kanamycine cassette insertion into E. coli chromosome. Primer positions are shown by arrows, expected PCR-product $(1,2,3$, and 4) lengths are given in base pairs (bp). B: PCR-Analysis. 1, 2, 3, 4: PCR products using the primer combination shown on the scheme. DNA from E. coli Cla WT was used as a control, expected PCR product with the primer set 2 is $910 \mathrm{bp}$, and no product was expected with other primer sets. 


\subsubsection{Cloning of an amber-suppressor tRNA gene}

For successful propagation of P2vir1Ram3 bacteriophage (2.1.2) on E. coli CJ236 dut-, ung- strain (2.1.1.1) presence of an amber-suppressor tRNA was necessary. Ambersuppressor tRNA gene serU132 (Steege and Horabin, 1983) (Figure 3.15) was amplified by PCR (2.2.2.2.1) from E. coli C520 DNA, cloned into pBR322 vector using EcoRI and PstI and then re-cloned into pACYC177 vector using BamHI and PstI (2.2.2.8). The serU132 insert was verified by sequencing (Appendix 7.3.2). pACYC177 is a low copy plasmid with a p15A origin of replication which makes it compatible with vectors containing ColE1 origin of replication such as expression vectors pASK-08 and pTNA.

\section{GGGACTGTIAAAATGCCAAATTTCCTGGCATCATGGGCAACCATCTGAACGGAGAGATGCCGGAGCGGCTGAACGGACCGG ICTCTAAAACCGGAGTAGGGGCAACTCTACCGGGGGTTCAAATCCCCCTCTCTCCGCCATTTATCAATG}

Figure 3.15: Sequence of the serU132 structural gene in pACYC177. The region corresponding to mature

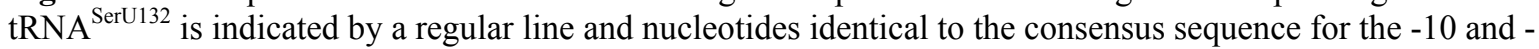
35 regions of $E$. coli are indicated by dashed lines. The position of SerU132 mutation which corresponds to the middle nucleotide of the tRNA anticodon is shown in red $(\mathrm{G} \rightarrow \mathrm{T})$. The adenine residue which serves as the tRNA start is indicated with an arrow (adapted from D. A. Steege and J. I. Horabin, 1983).

To test whether the presence of pACYC177_serU132 vector in E. coli enables the growth of P2vir1Ram3 in a non-permissive strain plating efficiencies of P2vir1Ram3 on different strains were measured. High-titer lysate of pure P2vir1Ram3 was made (2.2.1.1.2), bacteriophage DNA was isolated (2.2.2.1) and the presence of Ram3 mutation was confirmed by sequencing of the $R$ gene (see Appendix 7.3.3 for the sequence; $R$ gene sequence reference: Linderoth et al., 1994). 100 $\mu 1$ of the P2vir1Ram3 bacteriophage lysate was diluted and the dilutions were plated with $100 \mu 1$ of $E$. coli cells as described in section 2.2.1.1.2. Plaques were counted on the next day and the titer was determined.

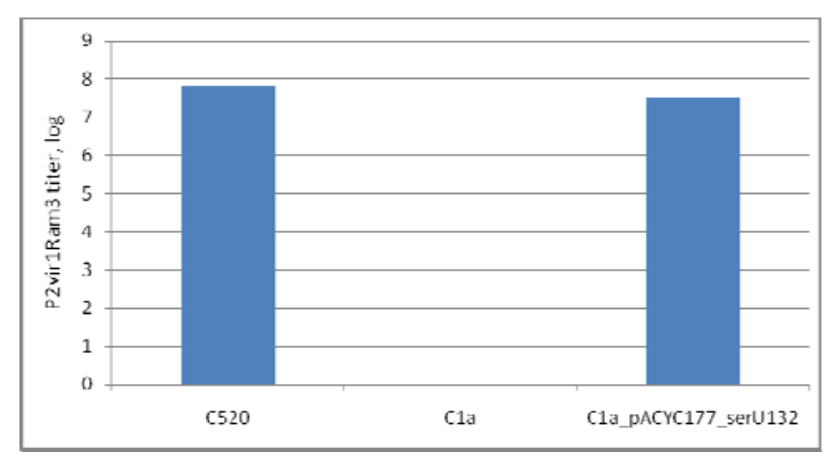

Figure 3.16: Titer of P2vir1Ram3 bacteriophage propagated on an amber-supressor strain C520, nonpermisive wild-type strain C1a (2.1.1.1) and C1a strain carrying pACY177_serU132. 
Wild-type cells lacking amber-suppressor tRNA did not support bacteriophage growth (Figure 3.16). In contrast, E. coli C1a strain transformed by pACYC177_serU132 vector permit the growth of P2vir1Ram3 bacteriophage, suggesting that $\operatorname{tRNA}^{\mathrm{SerU} 132}$ is synthesized in E. coli and the expression level is sufficient to suppress Ram3 amber mutation of the bacteriophage. Consequently, pACYC177_serU132 vector was employed in following experiments.

\subsubsection{Cultivation of bacteriophage P2vir1Ram3 on dut- ung- strain}

pACYC177_serU132 vector was introduced into E. coli dut-, ung- strain CJ236 cells by transformation (2.2.1.3.1) and cells were then infected with P2vir1Ram3 bacteriophage. Bacteriophage lysate was prepared (2.2.1.1.2) and, in order to see whether propagation on $d u t$, ung- strain resulted on the incorporation of uracil into bacteriophage DNA, lysate titers on E. coli strains C520 and C5204ung (2.1.1.1) were determined (2.2.1.2.2).
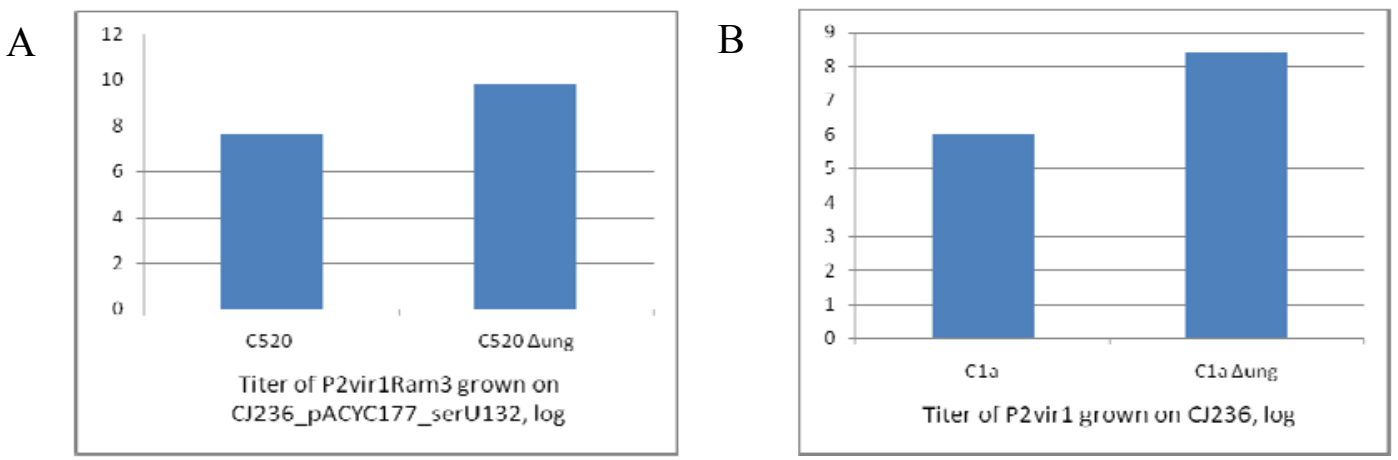

Figure 3.17: Titers of $\mathrm{P} 2$ vir1Ram3 (A) and $\mathrm{P} 2 \mathrm{vir}(\mathrm{B})$ bacteriophages propagated on E. coli dut-, ung- strain.

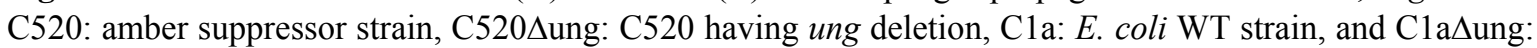
Cla having ung deletion.

The titer of P2vir1Ram3 passaged through CJ236/pACYC177_serU132 cells (designated as P2vir1Ram3-U henceforth) on C520 strain differs from the titer on C520Aung strain (Figure 3.17A). Approximately $99.3 \%$ of all bacteriophages did not grow in cells where DNA uracil glycosylase (Ung) was present. As a control, titer of P2vir1 bacteriophage lysate grown on E. coli CJ236 (designated as P2vir1-U henceforth) strain was determined (Figure 3.17B). P2 vir1 bacteriophage (2.1.2) was obtained after plating P2vir1Ram3 on $E$. coli C1a. Reversion of Ram3 mutation was verified by sequencing of $R$ gene (see Appendix 7.3.4 for sequence). $1 \%$ of the P2vir1-U bacteriophages was able to grow on C1a strain.

Taken together, these results suggest that uracil is incorporated into bacteriophage DNA upon propagating on E. coli dut-, ung- strain. The reduced ability of P2vir1Ram3 to grow 
on E. coli $\mathrm{C} 520$ indicates that the genome of P2vir2Ram3-U is fragmented due to high number of DNA double-strand breaks. Double-strand breaks occur when uracil molecules incorporated nearly opposite each other in both DNA strands attract action of uracil-DNA glycosylase working together with AP-endonucleases.

Small percentage of P2vir1Ram3-U bacteriophages was able to grow on C520 cells. This may be due to the (1) low incorporation of uracil into DNA, in which case, uracils will be repaired without fragmentation of viral DNA, and (2) relatively low level of uracil-DNA glycosylase in wild-type cells (Olsen et al., 1991). The latter will be overcome in our study by the use of pASK-08 expression vector which provides with the high level expression of the cloned gene.

\subsubsection{Survey of inability of P2vir1Ram3 bacteriophage to finish infection}

Inability to successfully finish infection with simultaneous inhibition of cell growth when bacteriophage is propagated on non-permissive strain was the major prerequisite of this approach. It was expected that when P2vir1Ram3 infects $\mathrm{C} 1$ a cells overproduction of defective bacteriophage particles due to the lack of the $R$ gene product takes place and as a consequence cell growth ceases because infected cells are not able to live as long or reproduce as fast as uninfected cells. This phenomenon was observed for P2vir1Kam12 bacteriophage infection in liquid culture; Kam12 is a lysis deficient mutant of P2vir1 and $\mathrm{C} 1$ a cells stopped growing about 30 minutes post-infection but did not lyse (Zierman et al., 1994) (Figure 3.18C).

To test whether infection of $E$. coli C1a with P2vir1Ram3 will trigger cell death, $10^{8}$ of $E$. coli $\mathrm{Cla}$ cells in log-phase were suspended in dYT medium (10ml end volume), mixed with $10^{9}$ of bacteriophage, incubated at $37^{\circ} \mathrm{C}$ with rotation and the optical density was measured over a time course (Figure 3.18A-B).
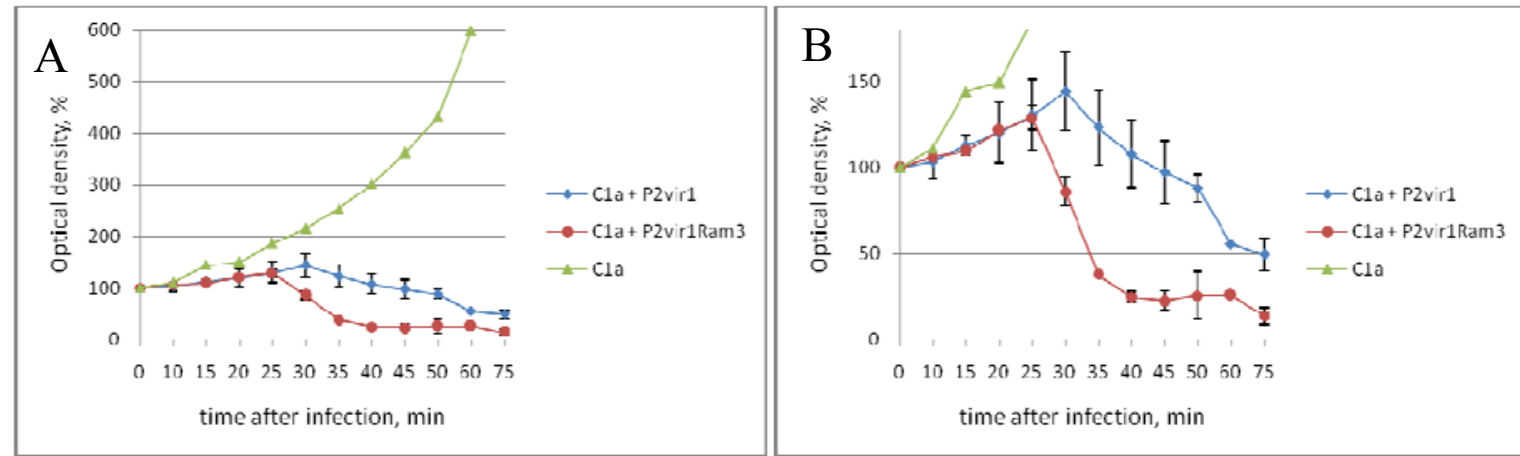


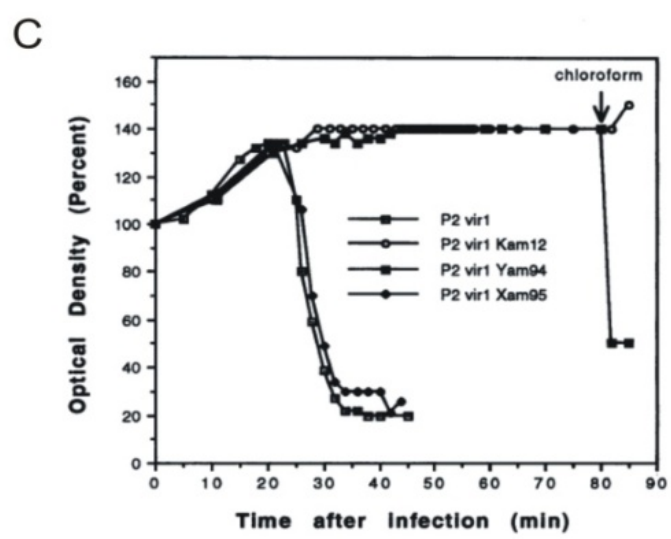

FIG. 5. Lysis of C-1a. Samples $(9 \mathrm{ml})$ of cells in early-log phase (which is defined as $100 \%$ ) were infected with the phage strains indicated at a multiplicity of infection of 10 . (A) Infection with $P 2$ vir1 and $\mathrm{P} 2$ vir 1 amber mutants in genes $K, Y$, and $X$. Eighty minutes after infection, $300 \mu \mathrm{l}$ of chloroform was

Figure 3.18: E. coli $\mathrm{Cla}$ cell growth upon bacteriophage infection. A: Measurements of the optical densities. B: Cell density plot (A) is magnified by decreasing $y$-axis maximum for a better interpretation. $\mathrm{N}$ $=3$ for $\mathrm{C} 1 \mathrm{a}+\mathrm{P} 2$ virl and $\mathrm{C} 1 \mathrm{a}+\mathrm{P} 2$ vir1Ram3. $\mathrm{C}$ : Infection of $\mathrm{C} 1 \mathrm{a}$ cells with Kam12 mutant of P2vir1 bacteriophage, adapted from Zierman et al., 1994.

Optical densities of E. coli C1a cells decreased after 30 or 25 min when infected with P2vir1 or P2vir1Ram3 bacteriophage, respectively (Figure 3.18A-B). Normally, when cells stop to grow optical density remains unchanged. Infection of $E$. coli $\mathrm{C} 1 \mathrm{a}$ cells by either P2vir1 or P2vir1Ram3 decreased optical density indicating cell lysis. However, in comparison to results of Zierman et al., (1994) a delay of roughly 10 minutes was observed (Figure 3.18C).

Remarkably, infection with P2vir1Ram3 bacteriophage lead to lysis of non-suppressor cells. Mechanism of cell lysis regulation of P2 bacteriophage places it in the lambdoid group exemplified by $\lambda, \mathrm{P} 22, \mathrm{~Pa}-2$ and 21 bacteriophages (Ziermann et al., 1994). The timing of lysis in these bacteriophages has been fine-tuned by involving a "holin" and an "endolysin" (a murein hydrolase) that are both necessary to induce precisely timed and rapid cell lysis (Rice and Bayles, 2008). It can be suggested that because functions involved in host cell lysis in P2vir1Ram3 bacteriophage are not affected (genes $K$ and $\mathrm{Y}$, endolysin and holin, respectively) cell lysis occurs despite of incomplete assembly of bateriophage particles.

Next, E. coli C1a cell lysate obtained after infection of P2vir1Ram3 was tested whether it contains infectious bacteriophage particles (2.2.1.2.2). For this, $100 \mu 1$ of E. coli C1a cell lysate was diluted and dilutions were plated with $500 \mu \mathrm{L}$. coli $\mathrm{C} 1 \mathrm{a}$ and $\mathrm{C} 520$ cells. 


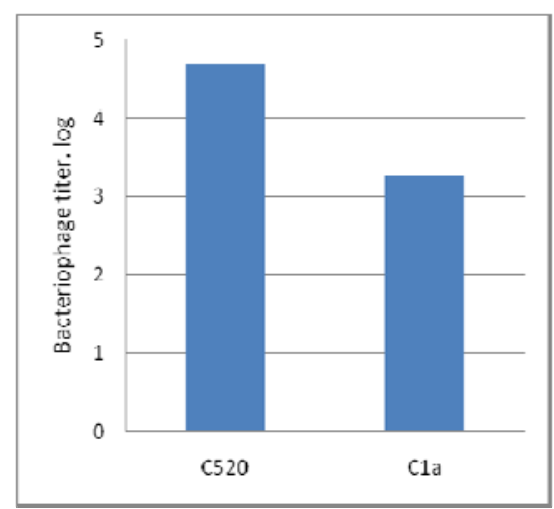

Figure 3.19: Bacteriophage titer of a lysate obtained after infecting E. coli C1a with P2vir1Ram3 on E. coli strains C1a and C520 (2.2.1.2.2).

The results from Figure 3.17 show that lysate obtained upon infection of E. coli C1a cells with P2vir1Ram3 contains bacteriophage particles of which some are capable of infecting C1a cells (180 plaques). These plaques are most likely arisen from bacteriophages that underwent reversion mutation of Ram3. Bacteriophage titer on E. coli C520 cells was $5 * 10^{4} \mathrm{pfu} / \mathrm{ml}$, these bacteriophages are probably P2vir1Ram3 that did not infect C1a cells. Considering that $10^{9} \mathrm{pfu}$ was used for infection in liquid culture, nearly $10^{5}$ fold decrease in bacteriophage titer stands for the expected lack of bacteriophage reproduction in E. coli C1a cells.

Infection in liquid culture, however, brings along the major obstacle when the selection of a protein with uridine DNA endonclease activity with the help of uracil containing bacteriophage DNA will be carried on. Small percentage of P2vir1Ram3 bacteriophage grown on dut-, ung- strain was able to grow in C520 cells (3.3.5, Figure 3.17A). The progeny of these bacteriophages in liquid culture will rapidly spread and infect cells including those carrying desired activity. Therefore, after infection cells must be plated onto agar medium plates to provide with spatial separation of cells.

To test if the infection with P2vir1Ram3 bacteriophage will lead to E. coli C1a cell lysis on agar medium, the following experiment was done.

$10^{6}$ of E. coli C1a cells were infected with P2vir1Ram3 bacteriophage at MOI $1\left(10^{6} \mathrm{pfu}\right.$ added), MOI 0.1 ( $10^{5} \mathrm{pfu}$ added $)$ and MOI $5\left(5^{*} 10^{6} \mathrm{pfu}\right.$ added $)$ and the serial dilutions were plated and colonies were counted next day. 


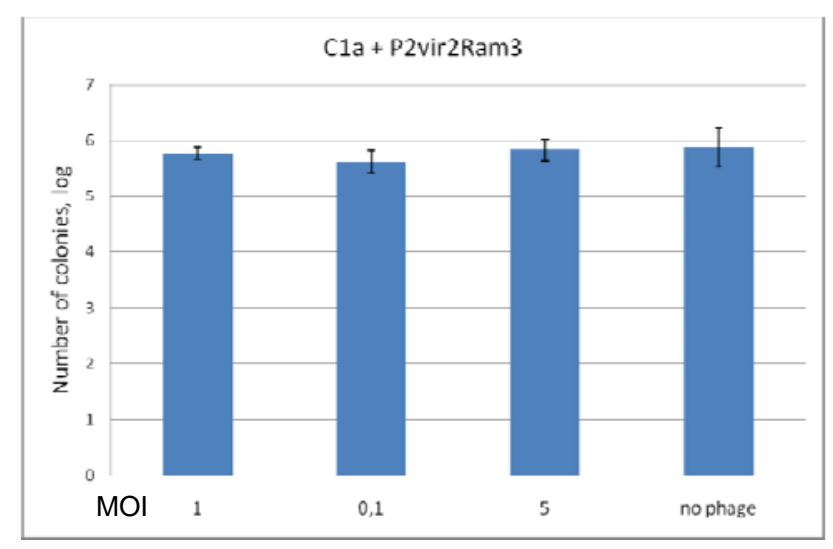

Figure 3.20: Plating efficiency of $E$. coli $\mathrm{C} 1$ a cells when infected with P2vir1Ram3 bacteriophage at MOI 1, 0.1 and 5. $\mathrm{n}=3$ (for method protocol: 2.2.1.2.2).

The number of E. coli C1a cells infected with P2vir1Ram3 at MOI 1, 0.1 and 5 was not significantly different from the number of uninfected cells (Figure 3.20), which suggests that C1a cells do not die upon infection with P2vir1Ram3. This result contradicts with results obtained with infection in liquid culture (Figure 3.18A-B) where E. coli C1a cells lysed upon infection with P2vir1Ram3. This means that accumulation of immature particles of P2vir1Ram3 bacteriophage in cells does not impair with the metabolism of infected cells, thus cells grow and reproduce relatively normal, however, when agitated these cells are prone to rapid lysis due to weakened cell wall caused by bacteriophage enzymes. At the same time, accumulation of defective bacteriophage particles in cells growing on agar medium has no influence on cell viability.

This result does not support the employment of P2vir1Ram3 bacteriophage in the selection of a protein with DNA uridine endonuclease activity. P2vir1Kam12 bacteriophage was the next candidate for this approach because of its ability to inhibit the cell growth without lysis as demonstrated by Zierman et al. (Figure 3.18C, Zierman et al., 1994). Unfortunately, neither P2vir1Kam12 nor P2vir22Kam12 bacteriophages were available in the scientific community. Therefore, another approach for the selection of a protein with DNA uridine endonuclease activity was designed. 


\subsection{Attempted genetic selection based on heteroduplex DNA of phagemid pBluescriptII with uracil containing mismatch}

This approach differs from above discussed strategies since it does not employ bacteriophages. Instead, ability of DNA uridine endonuclease to initiate repair of uracil containing mismatch is utilized. The principle underlying this approach is: a heteroduplex DNA with a mismatched uridine residue $(\mathrm{U} / \mathrm{T})$ introduced within E. coli lethal gene is generated. Thymine in this mismatch is a part of a stop codon, which is placed on purpose to truncate the lethal protein information, whereas uracil in complementary strand, if not repaired, will lead to restoration of the wild-type protein information when DNA replication proceeds. When cells carrying mutant exo $A$ library will be transfected with this heteroduplex DNA, uracil-thymine mismatch within lethal gene will be repaired in cells with additional DNA uridine endonuclease activity, leading to expression of a truncated protein, which in turn enables the cell survival, and in all other cells with no DNA uracil repair repair lethal gene product will kill those, thus enabling the selection. E. coli host cells for this experiment must be devoid of both UDG and MutS that initiate BER and methyl-directed mismatch repair (MMR), respectively. For heteroduplex DNA construction pBluescript II SK $(+)$ phagemid vector and $E$. coli $c c d B$ gene, product of which is an inhibitor of DNA gyrase, were chosen. Figure 3.21 gives an overview to the use of heteroduplex DNA in selection.

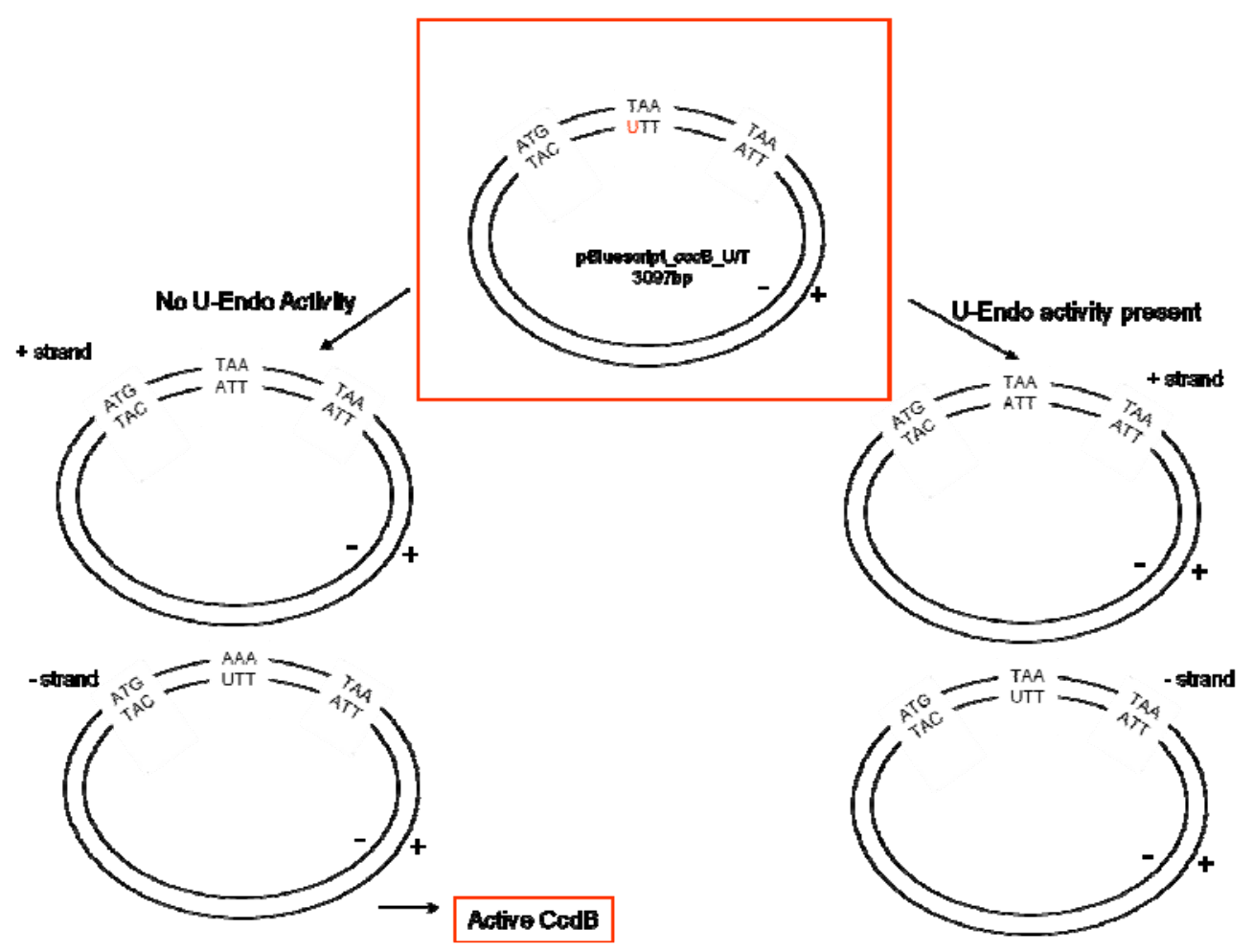


Figure 3.21: Schematic outline to the approach employing heteroduplex DNA. When E. coli $\Delta u n g, \Delta m u t S$ cells are transformed with pBluescript_ccdB_U/T construct there are 2 possible ways. (Left panel) If no DNA uridine endonuclease is present in the cell, $\mathrm{U} / \mathrm{T}$ mismatch will not be repaired and after first round of replication information encoded on the -strand of pBluescript_ccdB_U/T will lead to expression of active CcdB protein thus killing the host cell. (Right panel) If uridine DNA endonuclease is expressed in the cell U/T mismatch will be repaired and after first round of replication information encoded on both strands of pBluescript_ccdB_U/T vector will lead to expression of truncated CcdB thus enabling the cell growth and reproduction

\subsubsection{Construction of mutant gene library}

Error-prone PCR for randomization of exo $A$ and cloning of exoA library into pJET1.2 vector were performed as described before (Sections 3.2.2 and 3.2.4). Mutation frequencies, ratio of total mutation number to deletions and insertions, as well as number and mutation types were determined after sequencing of clones. No significant differences were observed from previous results of library generation (3.2.3) (sequences can be found in Appendix 7.2.3). For protein expression in E. coli, mutant exoA library was re-cloned into the expression vector pACYC177 (2.1.3.7) because of its compatibility with vectors containing ColE1 origin of replication. SphI restriction endonuclease site was introduced into the vector sequence by site-directed Quick-change ${ }^{\circledR}$ mutagenesis (2.2.2.2.4) to enable the cloning of randomised exo $A$ with concomitant disruption of ampicillin resistance gene sequence.

\subsubsection{Construction of heteroduplex DNA}

Heteroduplex DNA containing base/base mismatches, ssDNA gaps or multibase loops have been extensively used for genetic analysis of DNA repair mechanisms in vivo (Kramer et al., 1984, Shenoy et al., 1987, Campbell et al., 1989, Aprelikova and Jiricny, 1991). In this study, we used $E$. coli lethal gene $c c d B$ to generate a heteroduplex DNA containing U/T mismatch for a selection of an enzyme capable of repairing this mismatch. Preparation of covalently closed circular heteroduplex DNA was intended to be done according to the scheme envisaged in Figure 3.22. 


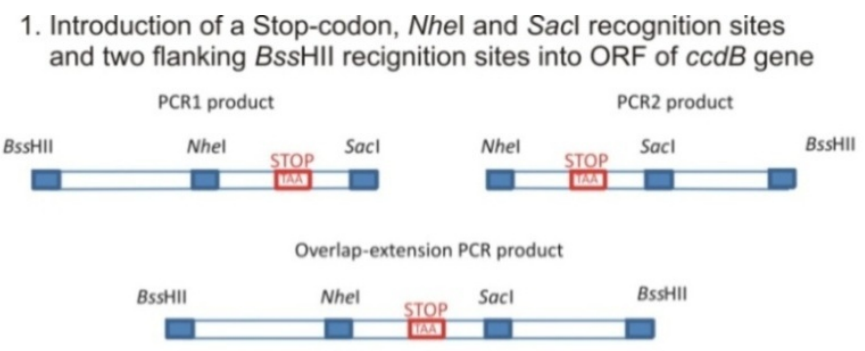

2. Cloning of $c c d B$ construct into pBluescript II SK (+) phagemid vector

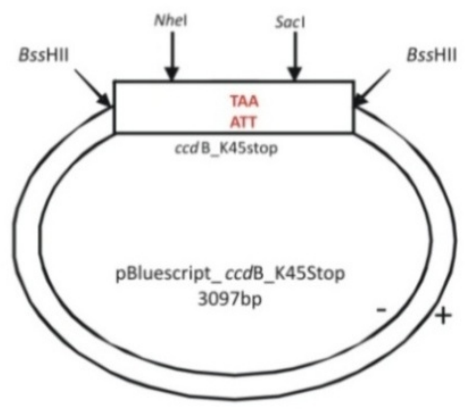

3. Digestion of pBluescript_ccdB_K45Stop with Nhel and Sacl

4. ssDNA preparation of pBluescript_ccdB_K45Stop (sense strand)
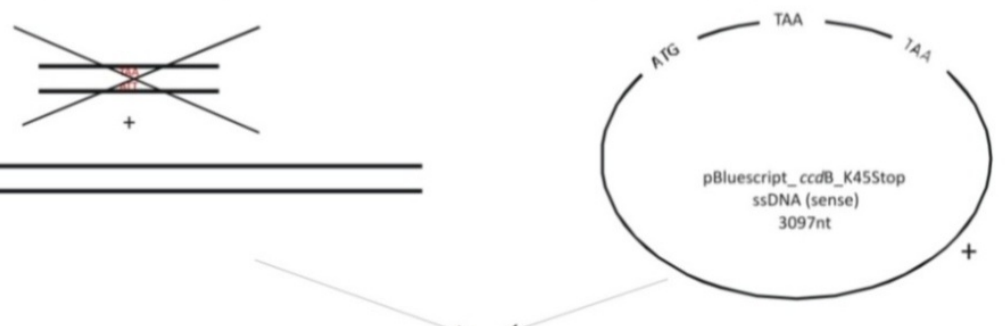

5. Generation of gapped duplex DNA

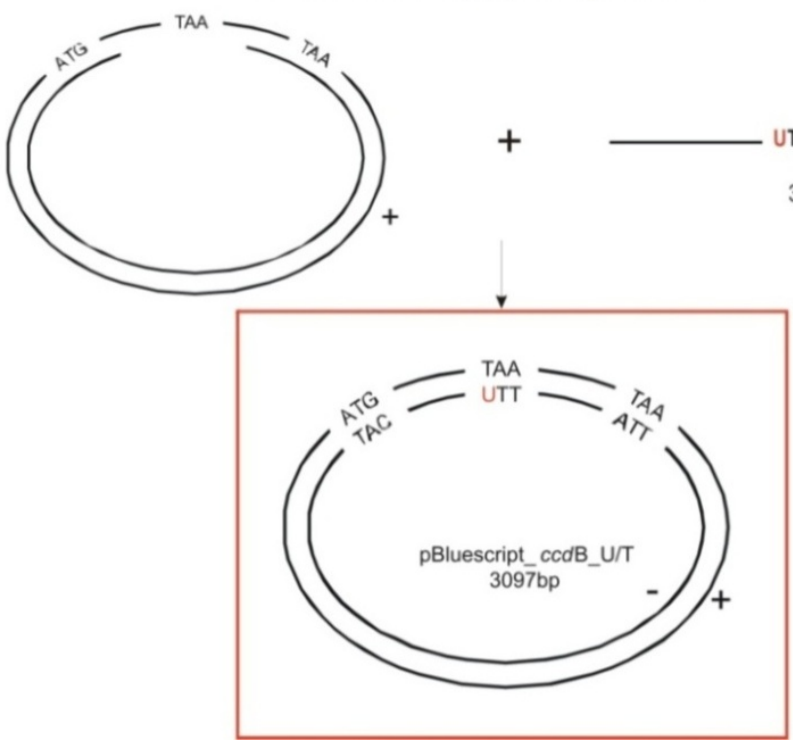

Figure 3.22: Schematic representation of heteroduplex DNA construction steps.

Site-directed mutagenesis by overlap extension using PCR (2.2.2.2.5) was employed to obtain $c c d B$ gene with two restriction endonuclease sites and stop codon introduced within the gene sequence (Figure 3.22 (1)). $c c d B$ is encoded by the F-plasmid of E. coli, therefore 
E. coli NM522 (2.1.1.1.12) DNA was used as template for the amplification of $c c d B$ gene. Overlap extension mutagenesis involved 2 mutagenic primers containing NheI and SacI restriction sites and the stop codon. Each primer was used in a separate PCR reaction with an outer flanking primer carrying $B s s \mathrm{HII}$ restriction site. In this manner two halves of $c c d B$ containing 62 bp long complementary to each other region were generated. Next, 2 PCR product were put together where they anneal in the $62 \mathrm{bp}$ region of complementarity and prime off each other. After the final PCR on this template with 2 outer flanking primers containing BssHII restriction sites the full length $c c d B$ with the stop codon, NheI, SacI and 2 flanking BssHII restriction sites was obtained. Stop codon (TAA) was introduced into $c c d B$ by replacing the lysine 45 (K45) codon (AAA). Both NheI and SacI restriction sites were introduced into $c c d B$ without affecting the amino acid sequence of CcdB protein. This construct is designated as $\boldsymbol{c} \boldsymbol{c d B} \boldsymbol{B} \_$K45Stop henceforth.

As next, PCR product was inserted into the pJET1.2 cloning vector and the insert sequence was verified (for sequence see Appendix 7.3.5). Then, the $c c d B \_K 45$ Stop construct recloned into the BssHII site of pBluescript II SK (+) vector (Figure 3.22 (2), for method refer to 2.1.3.8). pBluescipt II SK $(+)$ is a phagemid vector; the sense strand (ssDNA) of this vector can be rescued using the helper phage M13K07 (2.1.2.4). The sense strand of the vector is also the sense-strand of the $\beta$-galactosidase gene (lacZ). This feature makes this vector useful for the purpose of heteroduplex DNA construction. When $c c d B \_$K45Stop is successfully cloned, $\mathrm{CcdB}$ protein will be fused with the $\mathrm{N}$-terminal 8 amino acids of LacZ protein and the expression of fusion protein will be regulated under the control of lac promoter.

Cloning of $c c d B \_$K45Stop into BssHII restriction sites of the pBluescript II SK $(+)$(Figure $3.23 \mathrm{~A}$ ), provides ligation of the insert in both directions. It was expected that approximately $50 \%$ of transformants will contain the vector with insert ligated in desired orientation that will enable expression of the inserted gene. However, none of the 24 clones that were sequenced, contained the insert in desired orientation (for sequences see Appendix 7.4.1) (Figure 3.23B).

A

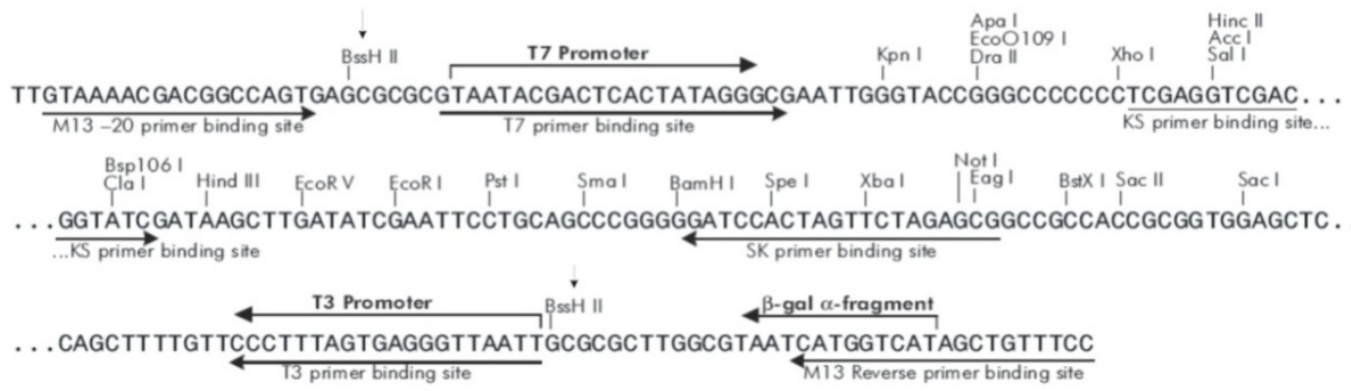


B

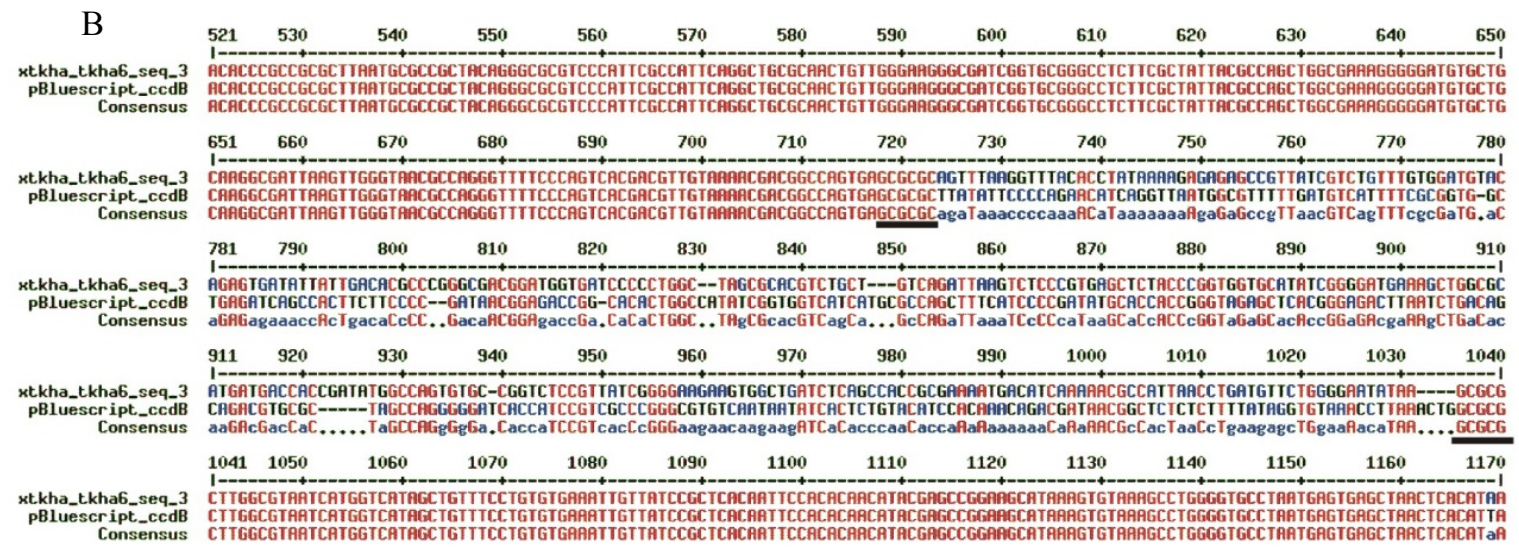

Figure 3.23: A: Multiple cloning site of pBluescript II SK $(+)$ vector (adapted from pBluescript II Phagemid vectors; Instruction Manual, Stratagene, USA). 2 BssHII sites are marked with arrows. B: Alignment of the obtained sequence to the expected sequence. $c c d B \_$K45Stop is cloned in undesired orientation. 2 BssHII sites are underlined. Sequence alignment was done with MultAlin online software (2.1.13).

In addition, the ligation mixture of $c c d B \_$K45Stop and pBluescript II SK (+) was introduced into E. coli DH5 $\alpha$ and TOP10 strains (2.1.1.1) by transformation and colonyPCRs (2.2.2.2.1) were performed. Several colony-PCRs also confirmed that all clones contained $c c d B \_$K4Stop ligated in undesired orientation. One of these colony-PCRs is shown in Figure 3.24.
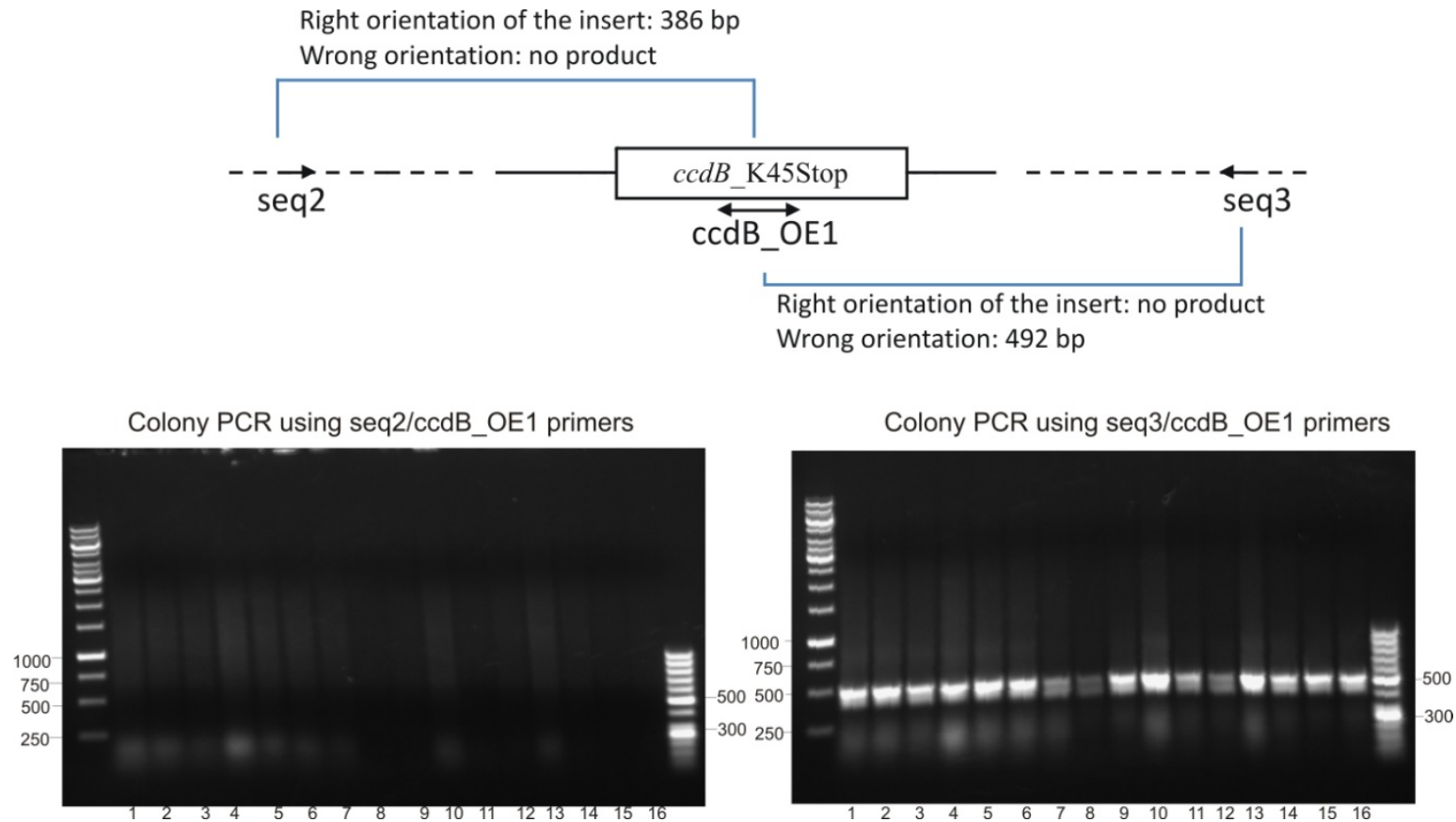

Figure 3.24: Colony PCR with $E$. coli colonies carrying $c c d B$ K45Stop ligated into pBluescript II SK (+) vector. Above is the schematic representation of primer combinations used for PCR and expected product sizes. 1-16: numbers given to colonies used for PCR. Colony-PCR was performed as described in section 2.2.2.2.1 and applied onto the agarose gel (2.2.2.4).

These results (Figure 3.21) suggest that the pBluescript II SK (+) with $c c d B$ K45Stop insert in the desired orientation expresses a short peptide that is possibly lethal for the cell 
and only those clones that contain pBluescript II SK (+) with $c c d B \_$K45Stop insert in wrong orientation survived. To verify this suggestion, E. coli lacl ${ }^{Q}$ strain TOP10F' (2.1.1.1.4) was transformed with $c c d B \_K 45$ Stop and pBluescript II SK (+) after ligation. The $l a c I^{Q}$ mutation leads to continuously expressed repressor of the lac promoter causing inhibition of protein expression controlled under this promoter.

Colony-PCR with transformants revealed that 9 colonies, out of 16 , contain the ccdB_K45Stop construct inserted in the desired orientation (Figure 3.25).
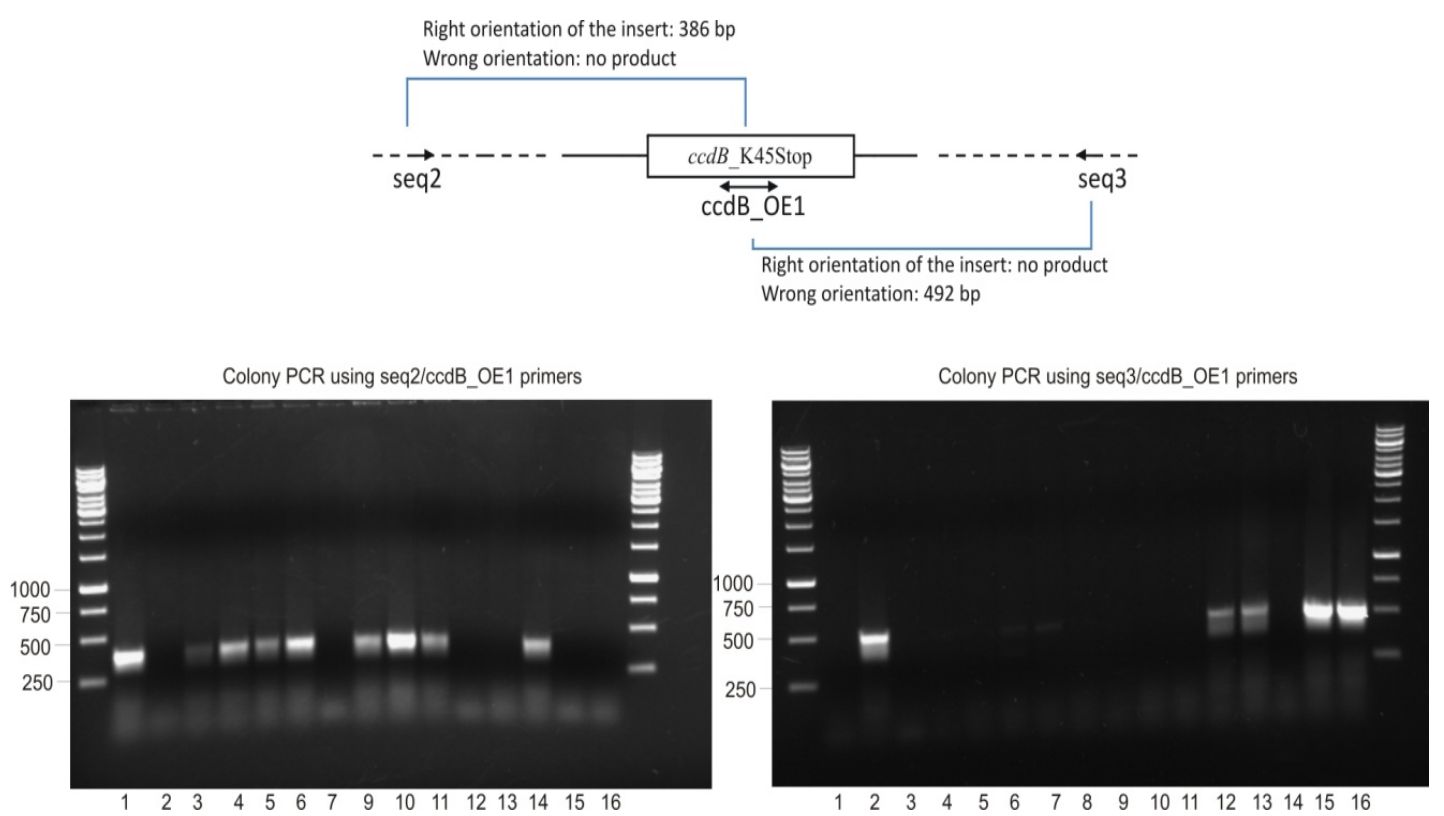

Figure 3.25: Colony PCR with E. coli TOP10F' colonies carrying $c c d B \_$K45Stop ligated into pBluescript II SK $(+)$ vector. Above is the schematic representation of primer combinations used for the PCR and explanation of product sizes. 1-16: numbers given to colonies used for the PCR. Colony-PCR was performed as described in section 2.2.2.2.1 and applied onto the agarose gel (2.2.2.4).

Sequencing of the clones that were positive in colony-PCR confirmed the right orientation of $c c d B \_$K45Stop in pBluescript II SK $(+)$vector (Figure 3.23) (for sequences: Appendix 7.4.2).

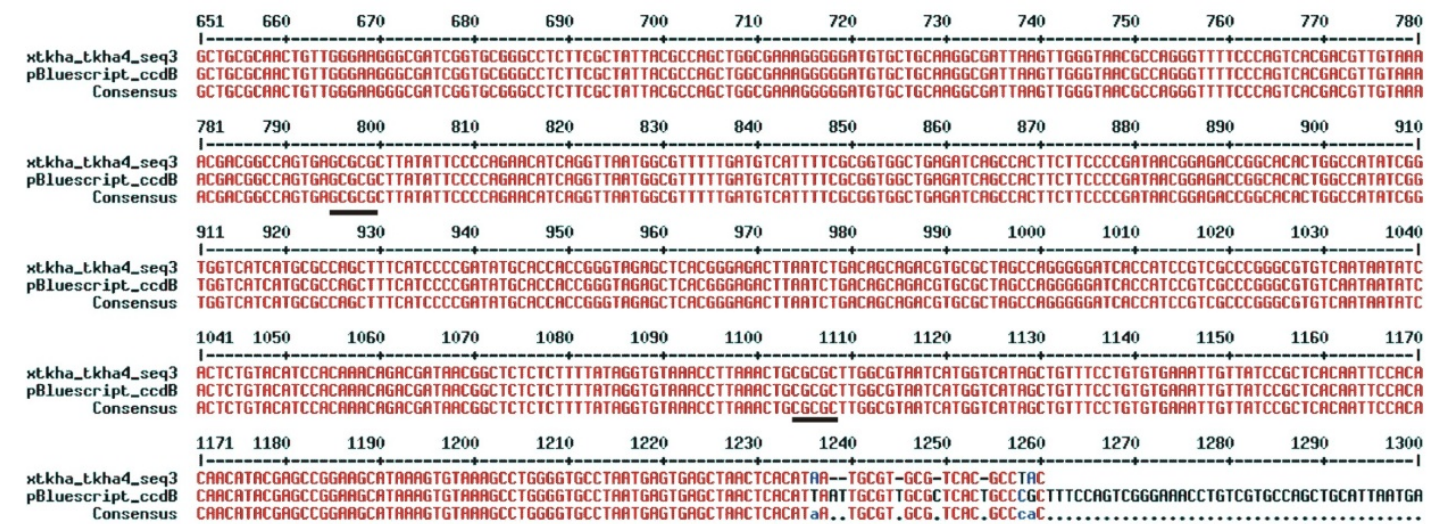

Figure 3.26: Alignment of the obtained sequence to the expected sequence. $c c d B \_$K45Stop is cloned in desired orientation. 2 BssHII sites are underlined. Sequence alignment was done with MultAlin online software (3.1.13). 
Taken together these results imply that there is a negative selection in E. coli non-lacI ${ }^{Q}$ cells against the clones with desired orientation of the insert. Re-transformation of $E$. coli DH5 $\alpha$ and TOP10 cells (2.1.1.1) with the plasmid DNA obtained from $l a c I^{Q}$ strain did not yield in any colonies (Table 3.7). This confirmed previously obtained results that the presence of the vector containing $c c d B \_$K45Stop in desired orientation is lethal for bacteria.

\begin{tabular}{ccc}
\hline DH5 $\alpha$ & TOP10 & TOP10 F' \\
\hline 0 & 0 & $1.3 * 10^{6}$ \\
\hline
\end{tabular}

Table 3.7: Re-transformation efficiency of $E$. coli strains (number of transformants per $1 \mu \mathrm{g}$ DNA). pBluescript II SK (+) vector with $c c d B_{-}$K45Stop cloned in desired orientation isolated from the E. coli TOP10F' cells was used for re-transformation.

Native CcdB is an $11.7 \mathrm{kDa}$ protein (101 amino acids long) which is a part of $c c d$ (control of cell death) system encoded by F plasmid in E. coli. Ccd system is one of the three systems that guarantee preferential growth of F-plasmid carrying cells in a bacterial population by killing newborn bacteria that have not inherited a copy of F-plasmid at cell division (post-segregational killing) (Afif et al., 2001). If the action of CcdB is not prevented by CcdA protein, another part of $c c d$ system, it traps and poisons the DNAgyrase cleavable complex (Bernard et al., 1993) by forming tight non-covalent complex and thus blocking the passage of E. coli and bacteriophage T7 polymerases (Chritchlow et al., 1997). This suggests that CcdB converts gyrase into a DNA poison and kills bacteria by causing DNA lesions leading to double-strand breaks in the DNA (Loris et al., 1999).

Numerous publications describe that only the C-terminal 3 amino acids of CcdB (W99, G100, I101) are responsible for the "killer function" of this protein (Bahassi et al., 1995; Bahassi et al., 1999; Loris et al., 1999; Critchlow et al., 1997). More recently it was shown that the tryptophan 99 (W99) makes the actual contact with arginine 462 (R462) of GyrA protein (Dao-Thi et al., 2005).

\section{MTMITPSAQFKVYTYKRESRYRLFVDVQSDIIDTPGRRMVIPLASARLLSD}

Figure 3.27: Amino acid sequence encoded by $c c d B \_$K45Stop. N-Terminal 8 amino acids of LacZ are shown in red. CcdB_K45Stop poplypeptide has a theoretical pI of 9.81 (calculated on ProtParam software, 2.1.13), with 8 positively charged (in green) and 5 negatively charged (in blue) amino acids.

Bahassi et al. (1995) showed that the expression of the first 20 or 60 amino acids of CcdB (CcdB_Q21Amber mutant or CcdB_W61-Amber mutant, respectively) have no cytotoxic 
effect on E. coli (Bahassi et al., 1995). The question, however, why $44 \mathrm{~N}$-terminal amino acids of CcdB expressed in E. coli are being toxic remains open.

It is known that $\mathrm{CcdB}$ in complex with CcdA participates in autoregulation of $c c d$ operon by binding to a DNA segment in the promoter region and $\mathrm{CcdB}$ may contain a partial DNA-binding motif (De Feyter et al., 1989). The secondary structure and surface charge distribution of CcdB_K45Stop polypeptide possibly provide it with the increased DNA binding ability. Thus, unspecific but very tight binding of CcdB_K45Stop to the DNA may result in blockage of replication or transcription processes leading to cell death. Comprehensive elucidation of CcdB_K45Stop toxicity effect on E. coli cells requires further investigations that are beyond the purpose of this study.

Because of toxicity of the truncated $\mathrm{CcdB}$ protein, its use as selection tool for ExoA with acquired DNA uridine endonuclease activity was disapproved. On the other hand, this selection approach may work if other $E$. coli lethal genes will be engaged. 


\subsection{ExoA triple mutant and selection of its stable variant by genetic complementation}

Structural basis of uridine recognition mechanism of Mth212 was not clarified when this project started. The directed evolution is a powerful tool for the modification of enzyme activities with no requirement of comprehensive understanding of structure-function relationship and as such this method was chosen to study uridine recognition by providing ExoA with DNA uridine endonuclease activity. Unfortunately, the use of this method met little success due to inability to select the particular protein from the library (Sections 3.2 3.4). Therefore, it was attempted to provide ExoA with the DNA uridine endonuclease activity by means of directed mutagenesis.

Rational design to obtain DNA uridine endonuclease activity was based on recent results of crystallographic studies of Mth212 (Lakomek, 2009; Lakomek et al., 2010) and Mth212mutants (Smolorz, 2009). These studies proposed a model of potential uridine recognition and/-or discrimination mechanism where an additional pocket close to active centre is responsible for uridine recognition. Amino acid residues asparagine-114, glycine-115, lysine-116, lysine-125, asparagine-153, serine-171 and glycine-172 of Mth212 build the surface of this additional pocket (Figure 3.28).
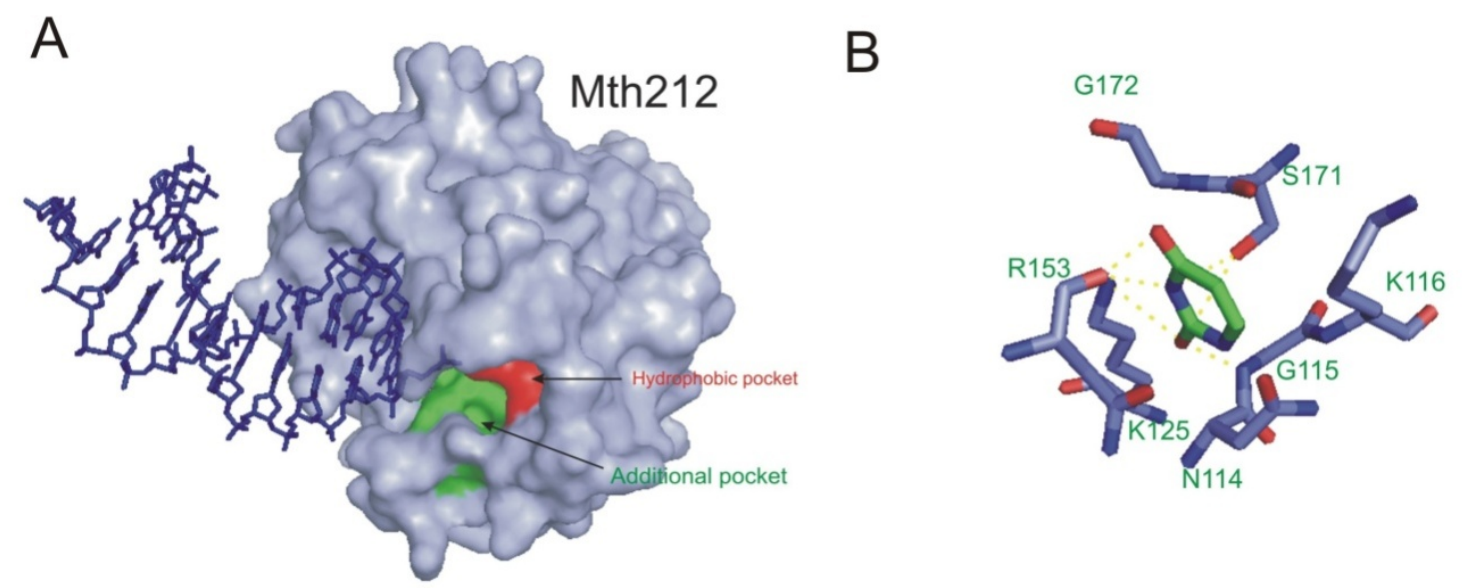

Figure 3.28: A: A surface representation of Mth212 molecule (protein A, 3GA6) with hydrophobic pocket outlined with W205, W219 and L221 residues (colored in red) and additional pocket outlined with N114, G115, K116, K125, N153, S171 and G172 residues (colored in green). B: A close-up view of Mth212 amino acids constituting additional pocket and their possible hydrogen bondings with uracil base. Pictures were generated using PyMol software and PDB-file 3GA6 (Lakomek et al., 2010).

In order to determine ExoA amino acid residues homologous to amino acid residues that constitute the additional pocket of Mth212 multiple alignment of ExoA with other exonuclease III homologs including Mth212 was carried out and respective amino acids were then engrafted into Table 3.8. 


\begin{tabular}{cccccc}
\hline Mth212 & Mma3148 & Af_ExoIII & ExoIII & ExoA & APE1 \\
\hline N114 & N115 & Q108 & Q112 & N109 & N174 \\
G115 & G116 & G109 & G113 & S110 & A175 \\
K116 & K117 & F110 & E114 & R111 & G176 \\
K125 & K126 & K120 & K125 & R120 & R185 \\
N153 & N154 & N148 & N153 & N147 & N212 \\
S171 & S172 & C167 & C177 & A165 & A230 \\
G172 & G173 & - & S178 & G166 & G231 \\
\hline
\end{tabular}

Table 3.8: Amino acids of exonuclease III homologs (Mma3148 from M. mazei, Af_ExoIII from A. fulgidus, ExoIII from E. coli, APE1 from H. sapiens and ExoA from B. subtilis) homologous to amino acid residues constituting additional pocket of Mth212 from M. thermautotrophicus. Residues that are conserved in respect of Mth212 residues are highlighted in blue; ExoA residues that were mutated are in red. Multiple sequence alignment was performed with CLUSTAL W2.0.12 software (2.1.13).

Table 3.8 shows that ExoA differs from Mth212 in respect of uridine recognition pocket constituting amino acids in residues serine-110, arginine-111 and arginine-120 (designated as S110, R111 and R120 henceforth) and alanine-165. Directed mutagenesis of S110, R111 and R120 residues of ExoA into G110, K111 and K120 respectively was found rational. ExoA alanine-165 was not targeted for mutagenesis since Mth212/S171T and Mth212/S171A mutant studies revealed relatively low contribution of this amino acid residue to uridine recognition (Smolorz, 2009).

\subsubsection{Generation and purification of the ExoA S110G_R111K_R120K triple and R120K single mutants}

In order to test whether S110G, R111K, R120K amino acid exchanges in ExoA will provide it with DNA uridine endonuclease activity exoA_S110G_R111K_R120K mutant (designated as ExoA triple mutant henceforth) was constructed by Site-directed mutagenesis by overlap extension using PCR (2.2.2.2.5) and the construct was then cloned into pASK-08 expression vector (2.1.3.5).

Lysine-125 in Mth212 which corresponds to arginine-120 in ExoA was shown to have important role in uracil recognition, explicitly taking part in discrimination against cytosine (S. Smolorz, 2009). To test whether exchanging arginine-120 into lysine can alone result in DNA uridine endonuclease activity R120K single mutant of ExoA was generated by sitedirected Quick-change ${ }^{\circledR}$ mutagenesis $(2.2 .2 .2 .4)$. This mutation as well as all other sitespecific mutations was verified by DNA sequence analysis (Appendix 7.5.1). For protein production WT exoA, R120K single and triple mutants were cloned as C-terminal 6xHistagged proteins into pASK-08 vector and introduced into E. coli NM522Aung (2.1.1.1) cells. 
As shown in Figure 3.29, wild-type ExoA (30 kDa) was detected in the supernatant of the crude extract and relative small amount of this protein was in the pellet. Compared to this, a large amount of R120K single mutant was detected in the pellet and only a small amount of this protein remained in the supernatant indicating that this protein can be isolated and purified from a large scaled culture. In contrast, the triple mutant was only detected in the pellet containing insoluble proteins, but not in the supernatant, or the amount of this protein in the supernatant is too small to be detected on the SDS-PAGE (2.2.3.1).

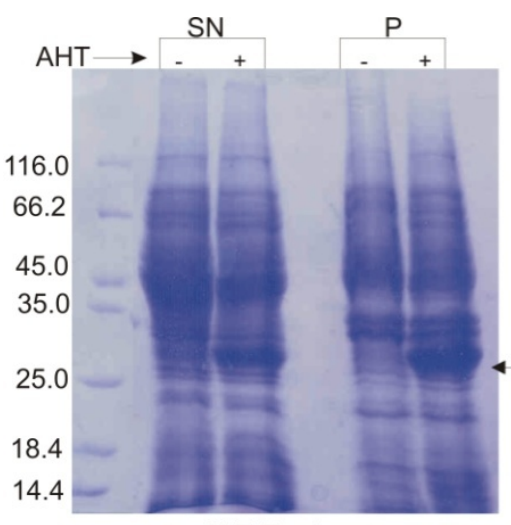

WT ExoA

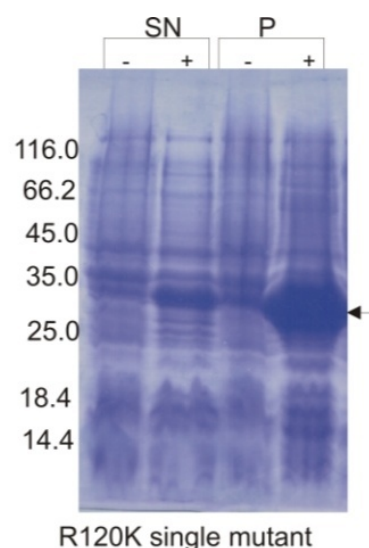

R120K single mutant

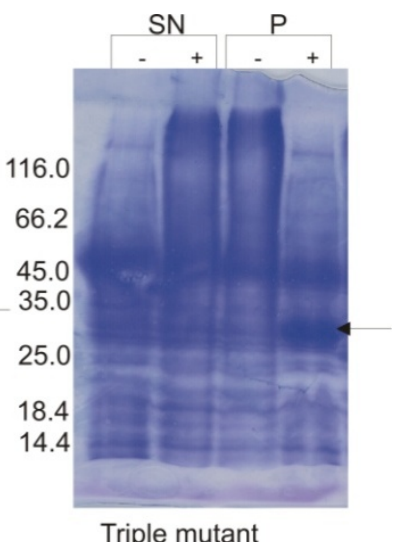

Triple mutant

Figure 3.29: SDS-PAGE analysis of protein test expressions. Crude cell extracts of E. coli NM522 $\Delta u n g$ overexpressing wild-type ExoA, ExoA R120K and ExoA triple mutant on 15\% SDS-PAGE. SN: supernatant, P: pellet; +/- with or without induction with anhydrotetracycline (AHT); ExoA protein band (30kDa) is indicated with arrow. Crude cell extracts were isolated as described in section 2.2.3.3.

It is believed that stabilizing mutations tend to deactivate, whereas activating mutations tend to destabilize (Arnold, 1998). It can be suggested that the mutations introduced into ExoA sequence contributed to come extent to catalytic activity of enzymes, however enhanced activity came along with less stability and/or low solubility.

As next, it was tried to improve the solubility of the triple mutant during protein expression. Occasionally, induction of protein expression for a long time can result in misfolding and subsequent aggregation into inclusion bodies. Therefore, duration of the induction time was decreased. This attempt did not improve solubility of the triple mutant in a small-scale expression experiment, even after 4 hours of induction the protein was not present in the supernatant (Figure 3.30).
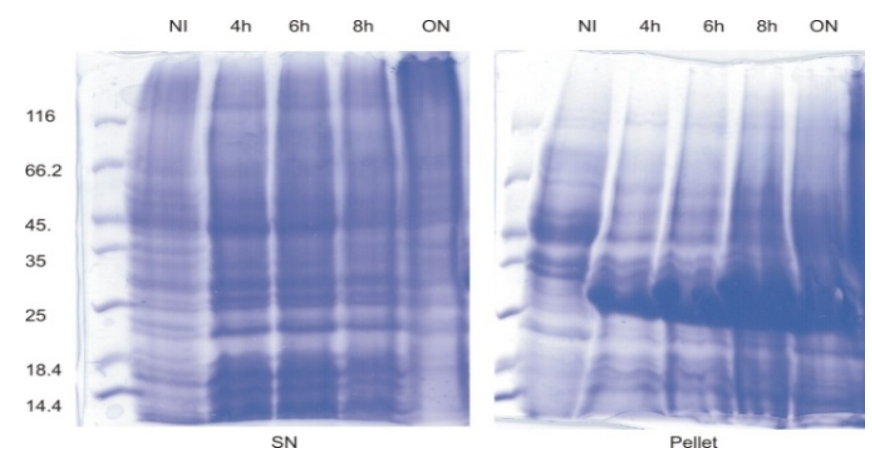

Figure 3.30: $15 \%$ SDS-PAGE analysis of E. coli NM522 $\Delta$ ung cell extracts overexpressing ExoA triple mutant. SN: supernatant; NI-not induced; 4h, 6h, 8h: 4, 6, 8 hours of induction with AHT, respectively; $\mathrm{ON}$-overnight incubation with inducer. Crude cell extracts were done as described in section 2.2.3.3. 
With the hope that the supernatant contains a small amount of the triple mutant that cannot be resolved by Coomassi stain, it was tried to isolate this protein from the supernatant of cells in a large-scale purification (2.1.1.1.13).

ExoA triple mutant protein extracts was made as described in 2.2.3.5 and the protein was purified using IMAC (2.2.3.6; Figure 3.31), followed by Heparin affinity chromatography (2.2.3.7; Figure 3.32). Purification of wild-type ExoA and R120K single mutant was performed by same way. At the end, purified proteins were concentrated to a final volume of $500 \mu 1$ and analyzed by SDS-PAGE (Figure 3.33).

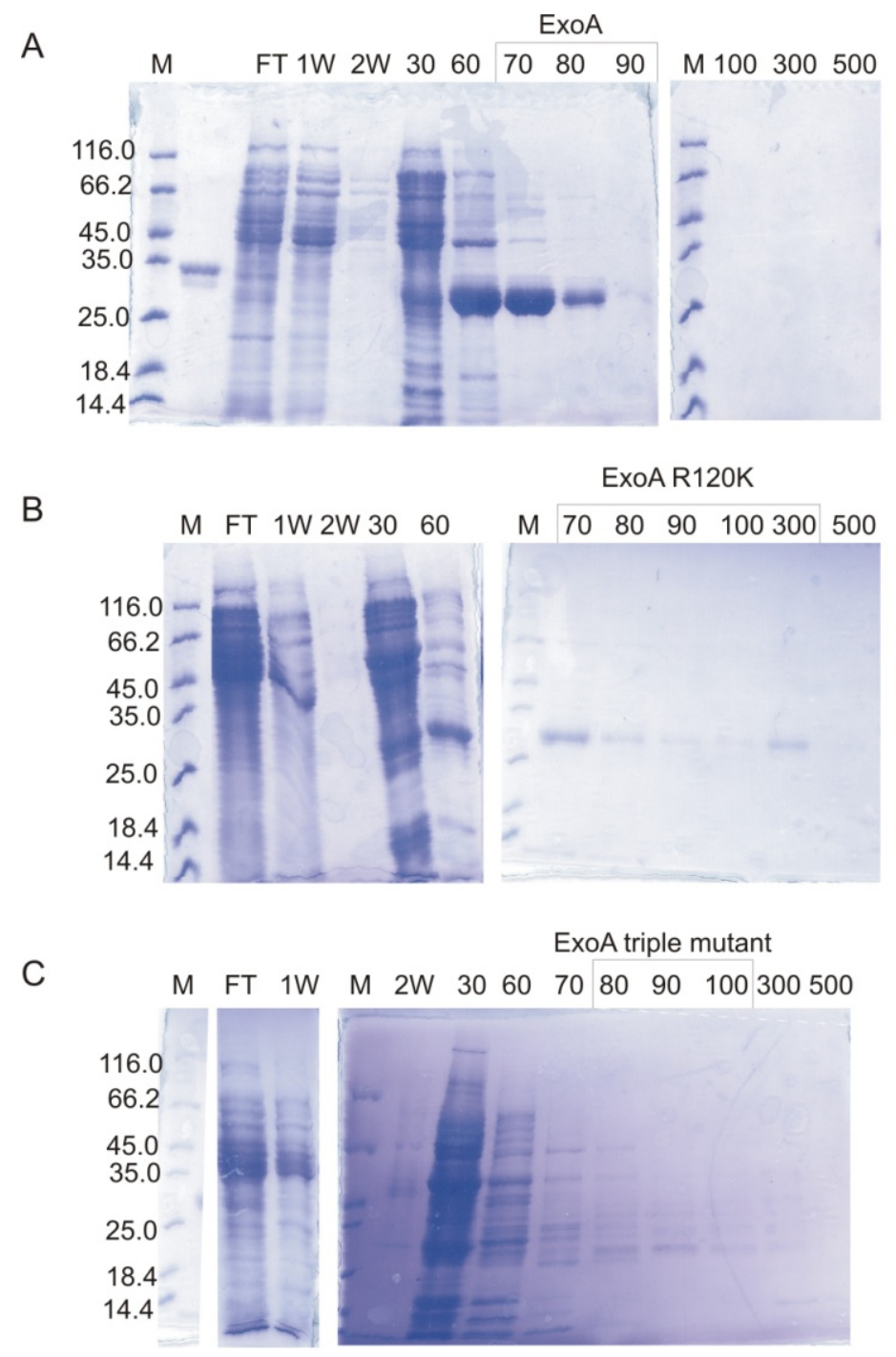

Figure 3.31: 15\% SDS-PAGE analysis of IMAC fractions. A: WT ExoA, B: ExoA R120K single mutant, C: ExoA triple mutant. IMAC was carried out using $5 \mathrm{ml}$ columns packed with Chelating Sepharose ${ }^{\mathrm{TM}}$ Fast Flow as described in section 2.2.3.6.

M: Protein Molecular Weight Marker (2.1.5.2); FT: Flow-through fraction. 1W and 2W: Column wash fractions. 30-500: Protein fractions eluted with 30-500 mM imidazole in IMAC wash buffer (2.1.9). Brackets indicate fractions pooled for subsequent purification.

As expected, a large amount of wild-type ExoA protein (Figure 3.28A) and a relative small 
amount of R120K single mutant (Figure 3.31B) were obtained after purification by IMAC. IMAC elution fractions of ExoA triple mutant (Figure 3.31C) contained several proteins, including an almost invisible protein band of expected molecular weight $(\sim 30 \mathrm{kDa})$ that could be concentrated by next step of purification. Therefore, either of the IMAC fractions that contain partly purified proteins, WT ExoA, R120K single mutant, and the triple mutant were subjected to a Heparin affinity chromatography.

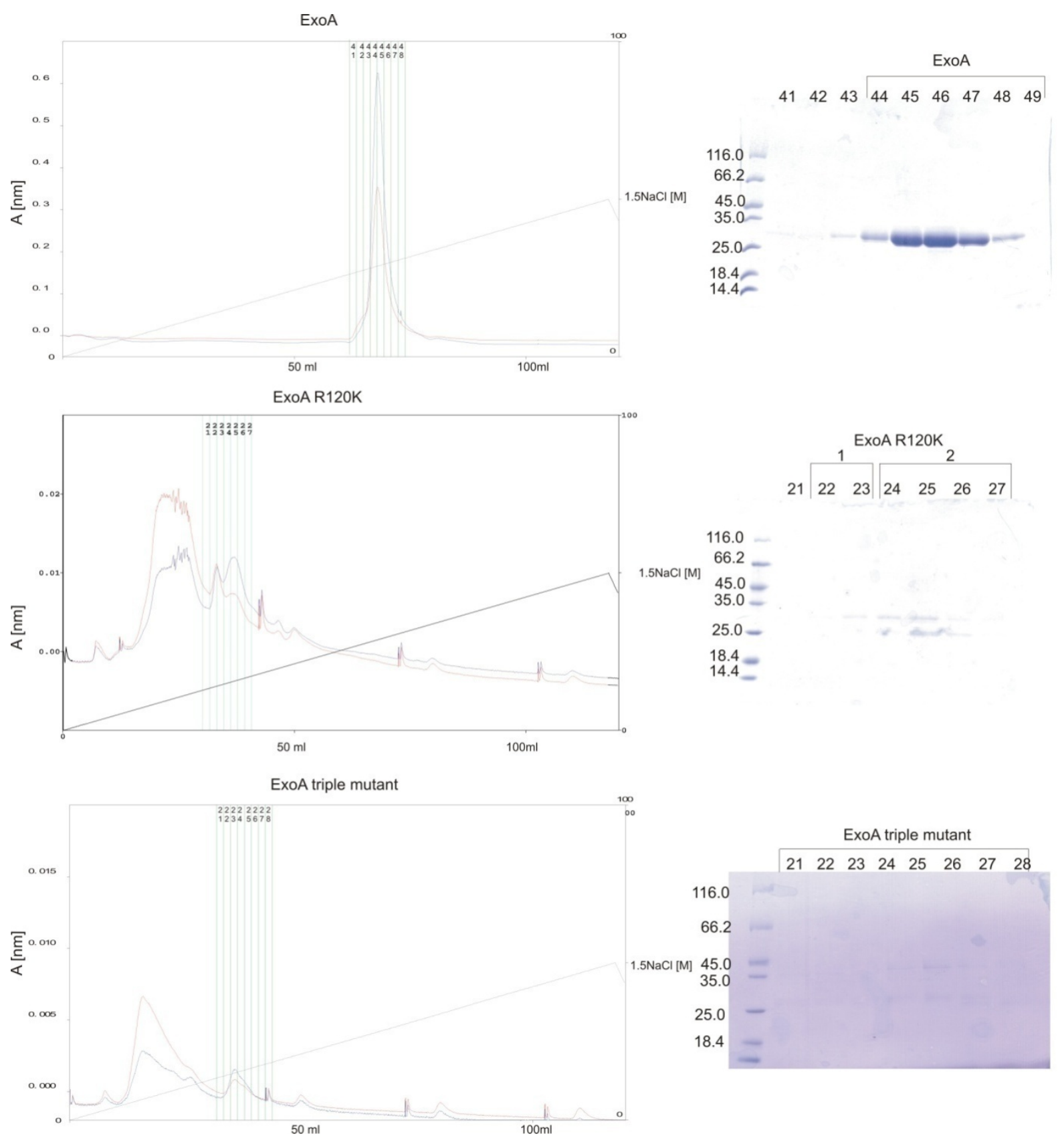

Figure 3.32: Elution profiles of ExoA, ExoA R120K single and ExoA triple mutants purification by Heparin affinity chromatography are shown on the left. Heparin chromatography was performed on BioCAD ${ }^{\mathrm{TM}}$ Workstation (Appied Biosystems) using POROS ${ }^{\circledR} \mathrm{HS} 20 \mu \mathrm{m}$ column $(10 \mathrm{~mm} \times 100 \mathrm{~mm}, 7.89 \mathrm{ml})$ at a $4 \mathrm{ml} / \mathrm{min}$ flow rate. Left ordinate: absorption at $260 \mathrm{~nm}$ (red) and $280 \mathrm{~nm}$ (blue); Right ordinate: concentration of $\mathrm{NaCl}$ in mol [M]; Abscissa: elution volume in ml. Green lines and numbers above the chromatogram indicate fractions that were analysed by $15 \%$ SDS-PAGE shown on the right. Brackets above the gel indicate fractions pooled and concentrated (Figure 3.33). 


$$
\begin{array}{l|rr|l}
\text { WT } & \multicolumn{2}{|r|}{\text { R120K }} & \text { Triple } \\
\cline { 2 - 3 } & 1 & 2 & \text { mitant }
\end{array}
$$

116.0

66.2

45.0

35.0

25.0

18.4

14.4

Figure 3.33: 15\% SDS-PAGE analysis of purified and concentrated proteins purification. Wild-type ExoA (WT), 2 fractions of ExoA R120K single mutant (R120K) and ExoA triple mutant were concentrated to final volume of $500 \mu \mathrm{l} .5 \mu \mathrm{l}$ of wild-type ExoA, $20 \mu \mathrm{l}$ of each single and triple mutant solutions is applied onto gel.

At the end, the fractions of Heparin affinity chromatography representing the main peak of elution profile (Figure 3.32) were concentrated and analyzed by SDS-PAGE. As shown in Figure 3.33, highly purified WT ExoA, two protein solutions of partly purified R120K single mutant, and a triple mutant solution containing a protein band of $25 \mathrm{kDa}$ and $20 \mathrm{kDa}$ that differed from the expected size were obtained. Interestingly, one the two protein solutions of R120K single mutant (2. fraction of R120K in Figure 3.30) contains same sized protein bands indicating that they may be resulted from $\mathrm{N}$-terminal degradation of ExoA mutants that possibly did not alter the activity of the mutants.

\subsubsection{Activity assays with ExoA variants}

In order to study the effect of R120K and S110G_R111K_R120K substitutions on the enzymatic activity of ExoA single mutant and ExoA triple mutant, purified protein solutions (Figure 3.33) were analysed by endonuclease assay. The assay was performed as described in 2.2.2.9 using 40-mer double-stranded DNA oligonucleotide substrates containing an AP/G (where AP is an abasic site analogue), U/G, U/C and U/T mismatches as well as U/A natural base pair at position 24. Reaction products obtained during endonuclease assays were analysed under denaturing conditions by $11 \%$ A.L.F.polyacrylamid gel electrophoresis (A.L.F.-PAGE, see section 2.2.2.5) (Figure 3.34C-F). 
A

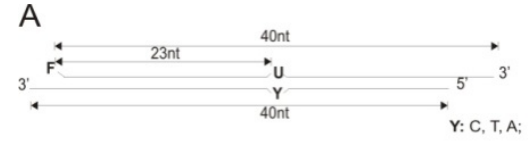

B

C

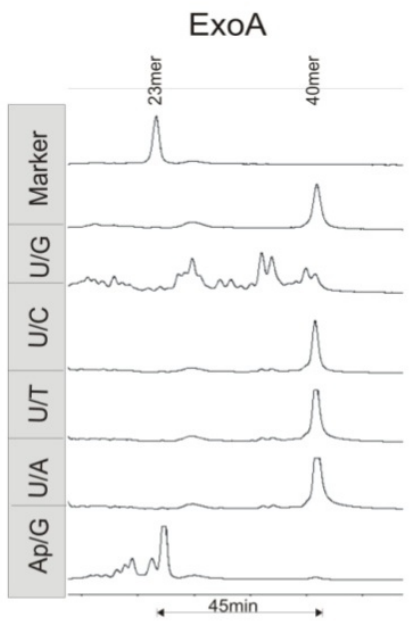

$\mathrm{D}$

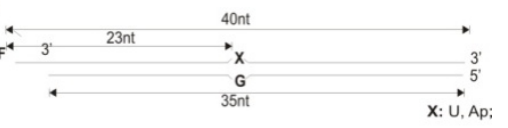

C

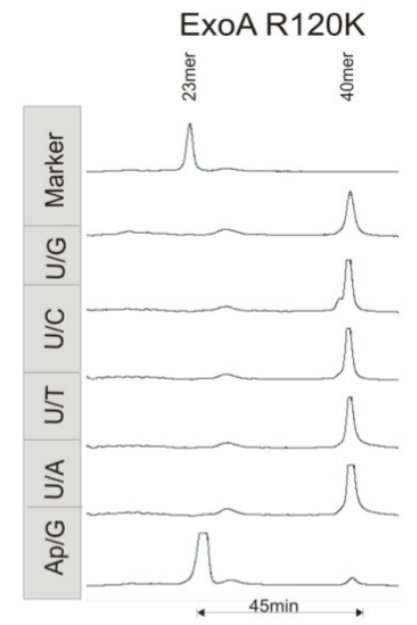

$E$

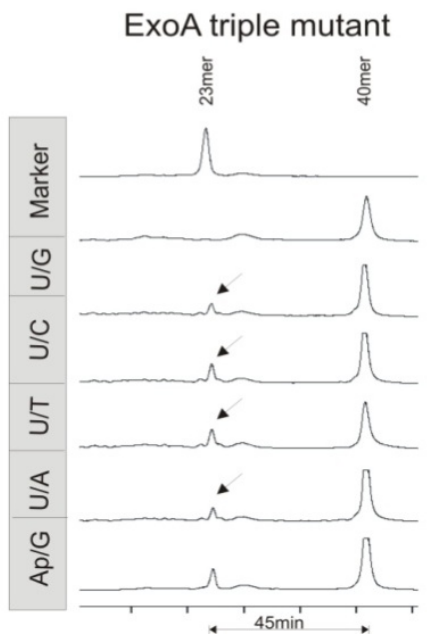

$\mathrm{F}$

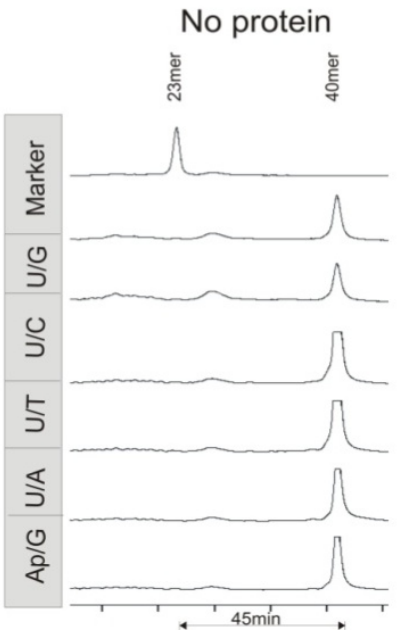

Figure 3.34: A.L.F.-PAGE of endonuclease assays with ExoA, ExoA R120K single and ExoA triple mutants. A-B: Schematic representation of substrates used in the assay. Ap/G and $U / G$ containing substrates are blunt-ended, whereas U/C, U/T and U/A containing substrates have 5 nucleotides long 3' overhang. C-F: A.L.F.-PAGE analysis of endonuclease assays with ExoA (C), ExoA R120K single mutant (D) and ExoA triple mutant (F). D: Endonuclease assay in absence of protein. 0.24 pmol of substrate was incubated with purified protein (Figure 3.33, amount of enzyme used for assay: 0.24 pmol of ExoA, $1 \mu 1$ of R120K and $5 \mu 1$ of triple mutant) for $15 \mathrm{~min}$ at $37^{\circ} \mathrm{C}$ in $50 \mu \mathrm{l}$ of endonuclease buffer (2.1.9).

Wild-type ExoA showed strong AP-endonuclease (with Ap/G substrate) and 3'-5' exonuclease (with blunt-ended $\mathrm{Ap} / \mathrm{G}$ and $\mathrm{U} / \mathrm{G}$ substrates) activites. No 23-mer product was observed with uracil containing substrates (Figure 3.34C). This result is in agreement with results of ExoA activity assays made in the beginning of present study (Sections 3.1.1 and 3.1.2). ExoA R120K single mutant exhibited AP-endonuclease activity similar to wild type ExoA, however, its 3'-5'exonuclease activity was severely decreased. No 23-mer product was observed with uracil containing substrates as well (Figure 3.34D).

Activity assay with ExoA triple mutant revealed 23-mer product product with all 4 uracil containing substrates (indicated with arrows on Figure 3.34E). Processing of uracil in all 4 
substrates was of similar rate and was comparable with the processing of AP-site analog in $\mathrm{Ap} / \mathrm{G}$ substrate. Substrate containing hypoxanthine mispaired with guanine was not processed by ExoA triple mutant (data not shown).

This asks the question whether this uracil specific activity can be assigned to ExoA triple mutant. On the SDS-PAGE (Figure 3.33) of purified ExoA triple mutant protein solution showed 2 protein bands of approximately 20 and $25 \mathrm{kDa}$, but not a band of the expected size $(30 \mathrm{kDa})$. The origin of these 2 proteins is unclear. Whether these 2 proteins were responsible for the uracil specific activity is equivocal as well, since ExoA R120K single mutant protein solution also showed the presence of these 2 bands in addition to the $30 \mathrm{kDa}$ ExoA band. To test if these 2 protein bands may be variants of ExoA which underwent Nterminal processing, Western Blot analysis (2.2.3.2) was done.

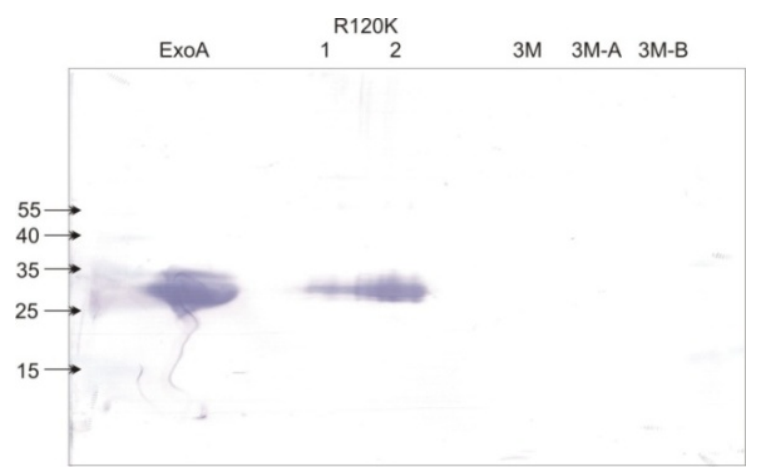

Figure 3.35: Western Blot analysis with ExoA, ExoA R120K single and ExoA triple mutants. All ExoA variants carry C-terminal 6xHis-tag; antibodies used for Western Blot were Penta-His antibody and antimouse AP-conjugated IgG. 3M, 3M-A, 3M-B: different preparations of ExoA triple mutant. $2 \mu 1$ of wild-type ExoA and $20 \mu \mathrm{l}$ of all other protein solutions were loaded onto gel. PageRuler ${ }^{\mathrm{TM}}$ Prestained Protein Ladder (2.1.5.2) was used as protein molecular weight standard.

The 20 and $25 \mathrm{kDa}$ protein bands were not detectable in both ExoA single and triple mutant solutions by Western blot (Figure 3.35), indicating that probably non of these two bands originate from ExoA or that ExoA mutant was degraded from the C-terminus containing the $6 \mathrm{xHis}-$ tag.

\subsubsection{Attempts to optimize production of ExoA triple mutant protein}

To improve the yield of ExoA triple mutant experimental conditions were modified and tested. (1) Incubating E. coli cells during protein overexpression at low temperature can reduce the rate of protein synthesis thus giving the cells more time for proper folding of proteins. (2) Decreasing incubation time after induction can reduce protein loss due to degradation by proteases. (3) Addition of protease inhibitors can prevent degradation of proteins thereby improving the yield of overexpressed protein. (4) Heat shock of a cell 
culture prior to induction can increase expression of chaperones that is needed for proper folding of protein molecules (Chen et al., 2002).

Unfortunately, all above mentioned modifications did not improve the yield of ExoA triple mutant. As illustrated in Figure 3.36, neither decrease of incubation temperature to $25^{\circ} \mathrm{C}$ (A) nor heat shock of cells at $42^{\circ} \mathrm{C}$ prior to induction of protein expression (B) had any effect on the yield of the triple mutant as a soluble protein. Effect of other conditions on protein expression are not presented here, as they exhibited similar pattern as in Figures 3.24, 3.25, namely no ExoA triple mutant appearance in the supernatant of cell extracts.

A

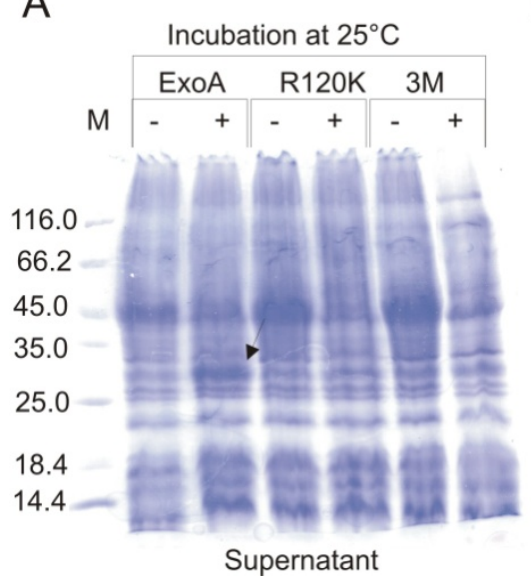

B

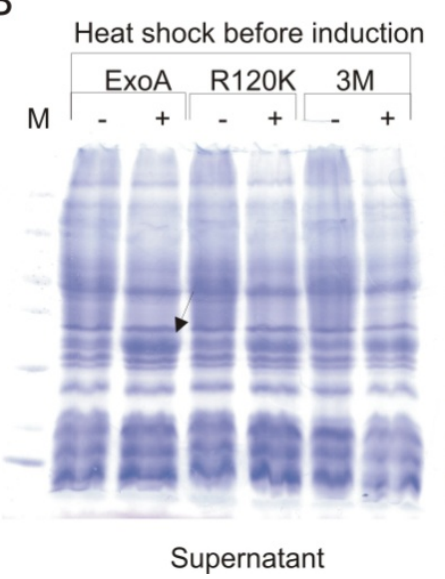

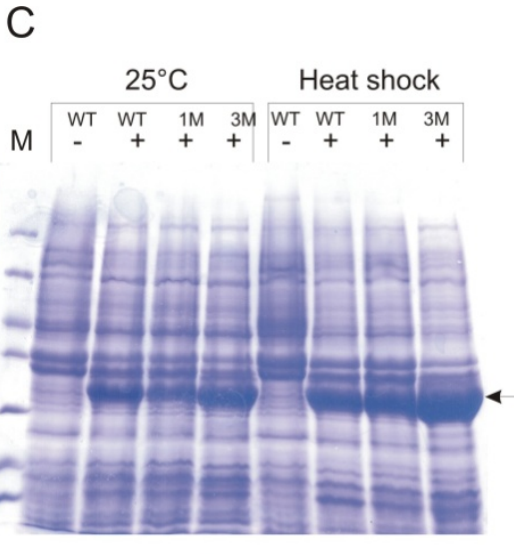

PELLETS

Figure 3.36: Effect of low incubation temperatue (A) and heat shock prior to induction (B) on the yield of ExoA triple mutant. Crude cell extracts of E. coli NM522 4 ung overexpressing ExoA (WT), ExoA R120K and ExoA triple mutant (3M) were analyzed by $15 \%$ SDS-PAGE. M: Protein Molecular Weight Marker; +/-: with or without induction with anhydrotetracycline (AHT); ExoA protein band $(30 \mathrm{kDa})$ is indicated with an arrow. Crude cell extracts were done as described in section 2.2.3.3.

\subsubsection{ExoA quadruple (S110G_R111K_D145N_R120K) mutant production, purification and activity assays}

ExoA triple mutant protein solution exhibited uracil specific activity. In order to assign this activity to ExoA triple mutant and exclude the possibility of contamination with E. coli enzymes an inactive variant of ExoA triple mutant (ExoA_S110G_R111K_R120K_D145N, designated as quadruple mutant henceforth) can be produced under the same conditions as ExoA triple mutant (Section 3.5.1). If uracil specific activity is abolished in the protein solution of ExoA quadruple mutant, it will support the proposition that ExoA triple mutant has acquired DNA uridine endonuclease activity.

Conserved amino acid residues aspartate-210 in APE1 and aspartate-151 in Mth212 are known to be essential residues for the catalytic function of these enzymes (Rothwell et al., 
2000; Georg et al., 2006). Substitution of this aspartate into asparagine leads to the loss of all catalytic activities in these proteins. Amino acid sequence alignment of human APE1, Mth212 and ExoA (Figure 3.1, Section 3.1.1) revealed aspartate-145 in ExoA to be the equivalent residue.

The replacement of aspartate at 145 by asparagines (D145N), an inactivating mutation, was introduced into exoA_S110G_R111K_R120K by site-directed Quick-change ${ }^{\circledR}$ mutagenesis (2.2.2.2.4) and the presence of mutation was verified by DNA sequence analysis (for sequence Appendix 7.5.2). ExoA quadruple mutant protein was produced under same conditions as that used for the triple mutant (Section 3.5.1). Figure 3.37 summarizes the purification steps of ExoA quadruple mutant.
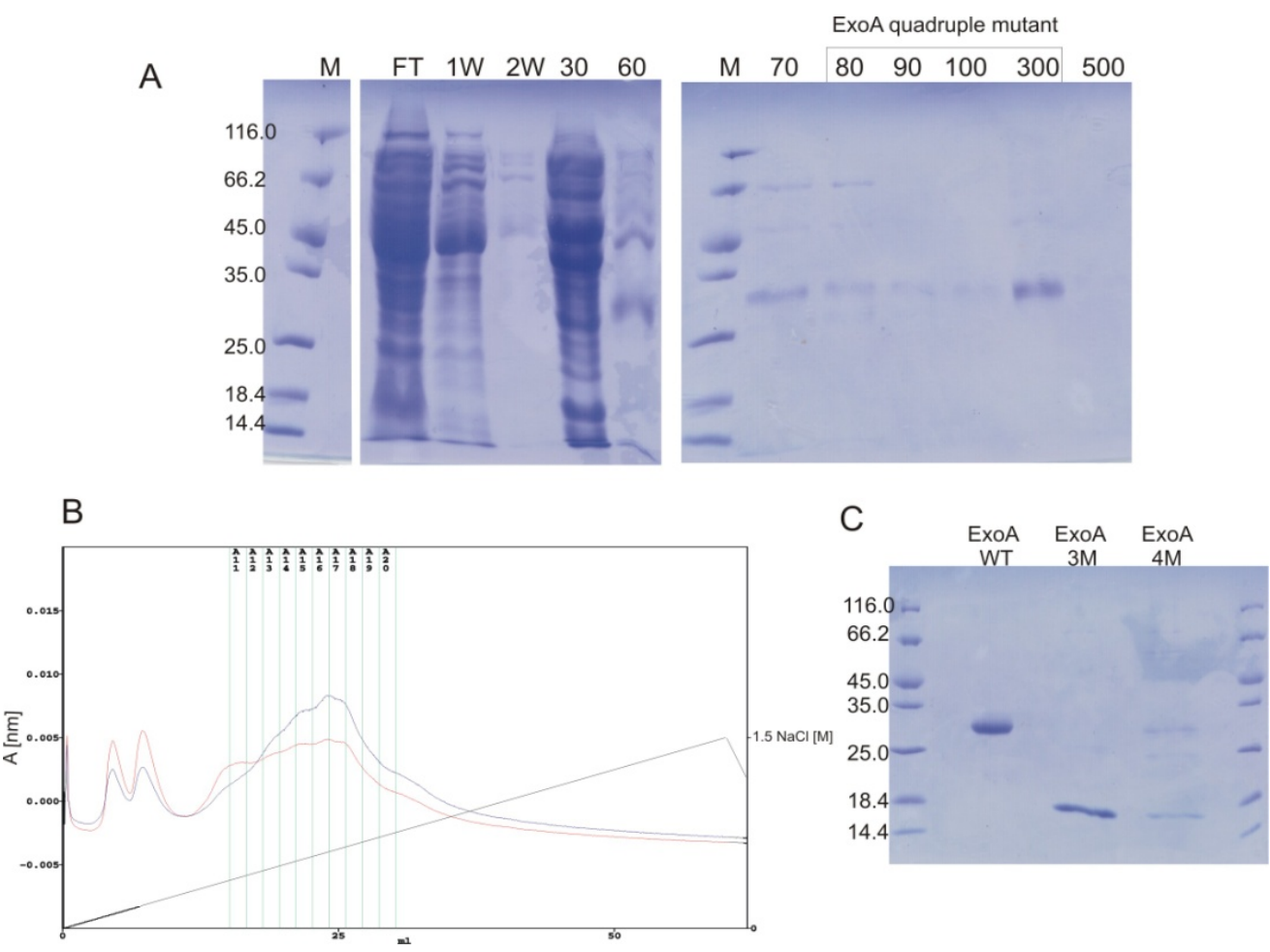

Figure 3.37: Purification of ExoA quadruple mutant. A: 15\% SDS-PAGE of IMAC fractions. M: Molecular weight marker, FT: Flow-through fraction. 1W and 2W: Column wash fractions. 30-500: Protein fractions eluted with 30-500 $\mathrm{mM}$ imidazole in wash buffer (2.1.9). Brackets indicate fractions pooled for subsequent purification B: Elution profile of the ExoA quadruple mutant purification by Heparin affinity chromatography. Left ordinate: absorption at 260nm (red) and $280 \mathrm{~nm}$ (blue); right ordinate: concentration of $\mathrm{NaCl}$ in mol [M]; abscissa: elution volume in ml. Numbers above the chromatogram indicate fractions that were pooled and concentrated to final volume of $350 \mu 1$. C: $15 \%$ SDS-PAGE of purified wild type ExoA, ExoA triple mutant (3M) and ExoA quadruple mutant (4M).

As shown on Figure 3.37C, D145N mutation had modest influence on the yield of the protein as faint band of 30kDA size was present on SDS-PAGE. This may be a result of a subtle stabilization of the protein structure thus making it more soluble in comparison to ExoA triple mutant.

Endonuclease activity assays (2.2.3.10) were performed to test the ExoA quadruple mutant 
protein solution for activity against uracil in DNA (Figure 3.38).
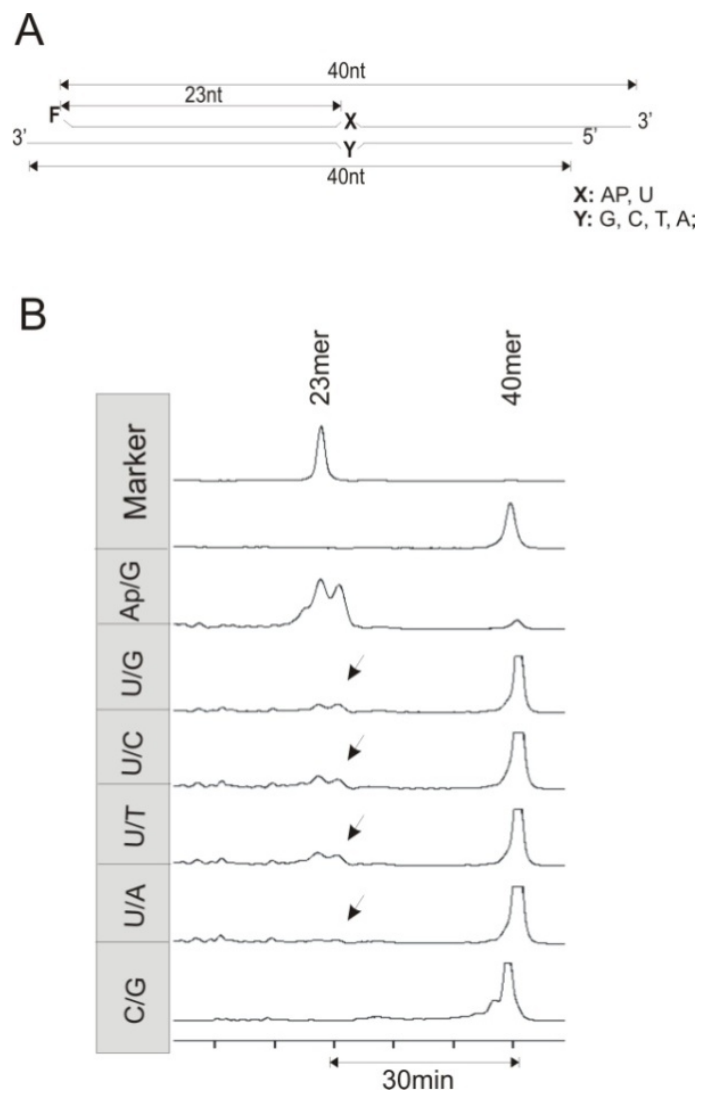

Figure 3.38: A.L.F.-PAGE of endonuclease assays with ExoA quadruple mutant. A: Schematic representation of substrate used in the assay. B: A.L.F.-PAGE analysis of endonuclease assays quadruple mutant. $0.24 \mathrm{pmol}$ of substrate was incubated with $2.5 \mu \mathrm{l}$ ofprotein solution (Figure $3.37 \mathrm{C}$ ) for $20 \mathrm{~min}$ at $37^{\circ} \mathrm{C}$ in $50 \mu 1$ of endonuclease buffer (2.1.9).

A.L.F.-PAGE analysis showed the presence of 23-mer product peak with ExoA quadruple mutant protein solution incubated with uracil containing substrates (indicated with arrows on Figure 3.38). In addition to the 23-mer product, a 22-mer product and series of shorter products were observed which can be considered as the product of 3 ' -5 ' exonucleolytic degradation of the main 23-mer product. Significantly large product peak with AP/G substrate indicates the presence of an enzyme with AP-endonuclease activity in the protein solution. Since D145N mutation must have abolished all catalytic activities of ExoA, this result suggests possible contamination with an AP-endonuclease of E. coli and its notably strong activity excludes the possibility of spontaneous revertants of ExoA.

Taken together these results suggest that the uracil specific activity detected in ExoA triple mutant protein solution may originate from contamination with E. coli enzymes: uracilDNA glycosylase other that UNG (uracil N-glycosylase, E. coli Family 1 UDG) and APendonuclease. However, it does not inevitably imply that ExoA triple mutant does not exhibit DNA uridine endonuclease activity. 


\subsubsection{Design of selection procedure of a stable variant of ExoA triple mutant}

The assumption is that ExoA has acquired DNA uridine endonuclease activity due to S110G, R111K, and R120K mutations. However, this activity of ExoA cannot be demonstrated, because these mutations concurrently contributed to conformational destabilization of the protein leading to its aggregation in inclusion bodies.

The goal is to improve conformational stability of ExoA triple mutant through introduction of additional mutations and thus obtain pure protein to ascertain whether ExoA triple mutant exhibits DNA uridine endonuclease activity. Library of randomized ExoA triple mutant variants and a selection approach to identify the stable protein are required.

The idea for genetic selection of a stable ExoA triple mutant was based on increased sensitivity of E. coli $\triangle x t h A$ cells to Mitomycin C than wild-type cells (Cunningham et al., 1986). Overexpression of an AP-endonuclease, Mma3148 from M. mazei in particular, in those cells contributes to the resistance to this antibioticum (S. Ber, 2009). Thus, ExoA triple mutant variants that have acquired mutations that compensate the destabilizing effect of the three mutations can be selected by growing on Mytomycin C. Expression of a stable variant of ExoA triple mutant in E. coli $\triangle x t h A$ cell will lead to the cell growth on Mitomycin $\mathrm{C}$, whereas other cells do not grow. This approach rests on an assumption that the three mutations did not affect AP-endonuclease activity of ExoA.

A critical prerequisite to this approach is an evidence that overexpression of wild-type ExoA leads to the resistance of E. coli $\triangle x t h A$ cells to Mitomycin C. It is known that overexpression of the E. coli exonuclease III homolog, XthA, in $\triangle x t h A$ cells is toxic due to unknown reasons. It is possible that overexpressed XthA binds unspecificly to DNA leading to replication / transcription arrest and consequently to cessation of cell growth (Ber, 2009). Therefore, it must be ensured that ExoA variants can be overexpressed in $\triangle x t h A$ cells.

\subsubsection{E. coli $\triangle$ xth $A$ strain and cytotoxicity of overproduced proteins}

To test the cytotoxic effect of overexpressed ExoA, ExoA triple mutant, ExoA quadruple mutant or Mth212, corresponding genes were inserted into pASK-08 vector and introduced

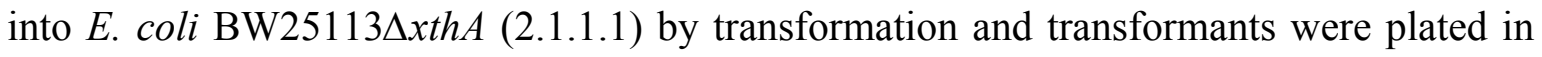
the presence or absence of anhydrotetracycline (AHT) inducer. 


\begin{tabular}{|c|c|c|c|c|c|c|c|c|c|c|c|}
\hline \multicolumn{2}{|c|}{ pASK_08 } & \multicolumn{2}{|c|}{ pASK_exoA } & \multicolumn{2}{|c|}{ pASK_exoA_D145N } & \multicolumn{2}{|c|}{ pASK_exoA_3M } & \multicolumn{2}{|c|}{ pASK_exoA_4M } & \multicolumn{2}{|c|}{ pASK_mth212 } \\
\hline- & $+\mathrm{AHT}$ & - & $+\mathrm{AHT}$ & - & $+\mathrm{AHT}$ & - & $+\mathrm{AHT}$ & - & $+\mathrm{AHT}$ & - & $+\mathrm{AHT}$ \\
\hline $8,3 * 10^{4}$ & $1.1 * 10^{5}$ & $3 * 10^{5}$ & $0\left(2,8 * 10^{5}\right)$ & $3,4 * 10^{5}$ & 70 & $7,8^{*} 10^{4}$ & 10 & $6,5^{*} 10^{4}$ & 10 & $1,9 * 10^{5}$ & 30 \\
\hline
\end{tabular}

Table 3.9: Transformation efficiency in E. coli BW25113 $\Delta x t h A$ cells (number of transformants per $\mu \mathrm{g}$ DNA). 100ng of DNA was used for transformation. -/+ AHT: transformants plated on agar medium with or without AHT inducer. Colonies of pASK_exoA in E. coli $\triangle x t h A$ (shown in red) were very small, and could be counted only after 2 days of incubation at $37^{\circ} \mathrm{C}$. pASK_exoA_3M: exoA containing S110G, R111K, R120K mutations; pASK_exoA_4M: exoA containing S110G, R111K, R120K, D145N mutations;

No transformants were obtained under conditions when wild-type ExoA, ExoA mutants as well as Mth212 were overexpressed in E. coli BW25113 $4 x t h A$ cells (Table 3.9). To rule out the possibility of reduced transformation efficiency due to the inability to establish plasmid DNA in the cell, colonies grown on agar medium without inducer were transferred into liquid medium and overnight culture was plated on agar medium with or without inducer.

\begin{tabular}{ccc}
\hline & - & + AHT \\
\hline pASK_exoA_D145N & $1,04 * 10^{7}$ & 44 \\
pASK_exoA_3M & $9.5 * 10^{3}$ & 9 \\
\hline
\end{tabular}

Table 3.10: Number of colonies of $E$. coli $\triangle x t h A$ cells carrying pASK_exoA_D145N and pASK_exoA_3M (exoA containing S110G, R111K, R120K mutations) vectors. Overnight cell culture was diluted and plated on agar medium with and without AHT inducer.

When the same number of cells containing pASK_exoA_D145N vector is plated on agar medium with or without inducer, only 44 cells $(=0.0004 \%$ of cells $)$ were grown on medium with inducer, indicating that overexpression of inactive ExoA in E. coli $\Delta x t h A$ cells in fact leads to cessation of cell growth (Table 3.10). Number of cells overexpressing ExoA triple mutant on agar medium with inducer is only 9 , however, it makes $0.1 \%$ of cells grown on agar medium without inducer. This shows that a relative high number of cells survived overexpression of the ExoA triple mutant compared to overexpression of the inactive ExoA, which supports our previous result demonstrating that the ExoA triple mutant is very unstable: E. coli $\triangle x t h A$ cells survive the overexpression of this protein because the protein is rapidly aggregated into inclusion bodies.

From experiments of E. coli BW25113 $\Delta x t h A$ transformation it could be seen that overexpression constructs of wild-type ExoA as well as of ExoA mutants and Mth212 cannot be established in those cells (Table 3.9). Same observation was made when E. coli XthA was attempted to be expressed in the same strain: expression of both wild-type and inactive mutant of XthA lead to cell death. However, cells that acquired nonsense 
mutations, frameshift mutations or mutations that lead to destabilization of the protein tertiary structure within $x t h A$ gene survived (Ber, 2009). This, per se, is surprising since XthA is a natural cell constituent. Why overexpression of an exonuclease III homolog results in cell death? It can be tentatively explained by fact that exonuclease III homologs are multifunctional nucleases and too much nuclease activity spills over into unspecific action thus lethally damaging the genome. However, observation that overexpression of inactive variant of ExoA also caused cell death (Table 3.10) along with results of Ber (2009) that inactive variant of XthA was lethal as well do not support this explanation.

Since it is known that inactivating amino acid exchange from aspartate to asparagine in exonuclease III homologs did not affect the DNA binding property of these proteins and even stabilize the substrate binding (Rothwell, 2000; Ciiradeva, 2009) it can be suggested that exonuclease III homologs when overexpressed unspecificly bind to DNA thus inhibiting binding of other essential proteins to DNA. From this, it can be assumed that this lethal effect should be observed in any kind of genetic background as long as it allows for sufficiently high gene expression.

However, contrary to this assumption, E. coli $\Delta u n g$ strain has been routinely employed for overproduction of exonuclease III homologs without any problems (this work, Sections 3.1.2 and 3.5.1; Schomacher et al., 2006; Ber, 2009; Ciirdaeva, 2009). From this it can be deduced that the possible explanation for the lethal effect lies in a phenotypic specialty of the $\triangle x t h A$ genotype. It was shown that $E$. coli $\triangle x t h A$ cells exhibit hyper-rec phenotype (Zieg et al., 1978). The question is whether the molecular reasons of this hyper-rec phenotype and the lethal effect of exonuclease III overexpression can be brought together in a plausible model. Below it was attempted to address this question.

- Crystallographic studies of Mth212 (in collaboration with department of Prof. Ficner) revealed strong binding affinity of this protein to DNA ends, since in crystal structures of Mth212 in complex with dsDNA oligonucleotide protein was invariably bound in an exonuclease-like binding mode (Lakomek et al., 2010). Furthermore, the same binding mode was reported for crystal structure of exonuclease III homolog from A. fulgidus in complex with dsDNA oligonucleotide (Schmiedel et al., 2009), thus implying that exonuclease III homologs strongly bind to DNA ends.

- The hyper-rec phenotype of E. coli $\Delta x t h A$ cells may be due to one or both of the following reasons: (1) single-strand breaks emerge when class I AP-endonuclease with associated glycosylase activity, such as Nth, MutM, or Nei remove damaged 
bases from DNA with concomitant generation of DNA breaks 3' to the AP-site. In E. coli, exonuclease III and endonuclease IV process the unusual DNA 3'-ends (3'dRp, 3'-phosphate) that emerge as a result of this glycosylase/AP-lyase pathway. Significantly, exonuclease III accounts for more than $95 \%$ of the total activity in $E$. coli crude extracts for removal of 3'-blocking ends (Demple et al., 1986). In the absence of exonuclease III, endonuclease IV is alone responsible for removing DNA 3'-blocking ends otherwise the single-strand break will be converted to a double-strand break by an encounter with a replication fork or by the generation of a nearby nick on the opposite strand. This would induce recombinational repair by the RecBCD pathway. (2) in RecBCD recombination pathway, RecBCD binds specifically to DNA double-strand end (Kowalczykowski, 2000). In wild-type cells, such ends may be targets of competition between RecBCD and exonuclease III (Centore et al., 2008). In such case, exonuclease III suppresses, to some extent, recombination and the deletion of the $x t h A$ gene would relief this suppression.

- By the time cells of a $\Delta x t h A$ strain are prepared for transformation, their genomes are laced with single strand breaks of the nature outlined above. After transformation, replication resumes and expression of the plasimd-borne exonuclease III gene starts. The single strand breaks are converted to double strand breaks which are in need of recombinational repair. This however, is frustrated by the large amounts of exonuclease III now present and competing with RecBCD for the DNA ends. This renders the double strand breaks lethal.

This model is in accord with all known facts of biochemistry of exonuclease III homologs and of genetics of $\Delta x t h A$ mutants. It makes the following specific prediction: The lethal effect of exoA (or homolog) overproduction on $\triangle x t h A$ cells is transient in nature and confined to the time window immediately following transformation. In other words, it should be possible to stably establish overproduction constructs of exoA (or homologs) with no expression of host $x t h A$ in the production phase of the transgene under any of the following regimes: (1) instead of employing a $\Delta x t h A$ host, use gene regulation and bring down expression of the host $x$ thA gene to (near) zero only after transformation. (2) introduce the $x$ thA deletion into a wild type strain already transformed with the overproduction construct. (3) use a $\triangle x t h A$ host that overproduces the RecBCD functions. (4) Repress $\operatorname{exo} A$ ( $x t h A)$ transgene expression during transformation of a $\Delta x t h A$ host and tune up expression only later and slowly. For lack of time, however, none of these predictions could be tested. 
Remarkably, Hadi and Wilson III (2000) observed same extreme cytotoxicity of Ape2, a human AP-endonuclease with high sequence homology to $E$. coli XthA, when overexpressed in E. coli cells. Site-specific mutagenesis of catalytic residues as well as depletion of unique $\mathrm{C}$-terminal domain of this protein provided little alleviation from the observed cytotoxicity. However, since they did not specify whether this effect was observed in $\triangle x t h A$ cells it is difficult to discuss about their results in connection with this work.

To conclude this sub-section, generation of a stable variant of the ExoA triple mutant by selection of E. coli $\triangle x t h A$ cells carrying the random library is impossible under utilized experimental conditions due to cytotoxic effect of protein overexpression on these cells. 


\section{Summary}

Mth212, an exonuclease III homolog from the archaeon Methanothermobacter thermoautotrophicus, compensates the lack of a DNA uracil glycosylase (UDG) in this organism by catalyzing direct strand incision next to a uridine residue in the DNA, a reaction substituting in a single step the consecutive action of a UDG and an apurinic/apyrimidinic (AP)-endonuclease in base excision repair (BER). What structural solution was found for Mth212 to possess this unique activity was unknown. To elucidate this question, an approach to convert ExoA from B. subtilis, an exonuclease III homolog without specific activity against uridine in DNA, into DNA uridine endonuclease was taken. Prior to this study, directed mutagenesis of amino acid residues of another exonuclease III based on the apo structure of Mth212 was met with limited success, and, therefore, a particular approach employing directed evolution was proposed. Directed evolution of enzymes requires efficient selection procedure. The exo $A$ mutant libraries in E. coli and B. subtilis were generated and different selection strategies to identify the ExoA with acquired DNA-U activity were developed and tested.

1. Selection in B. subtilis using PBS2 bacteriophage. Because of the unique feature of bacteriophage PBS1 to inherently possess uracil in its DNA, this bacteriophage was the foremost candidate for creating selection pressure on bacterial cells carrying the library of mutated proteins. For this approach, lytic derivative of PBS1 (named PBS2) was required. Although intensely studied in the last decades, PBS2 bacteriophage is no longer available in the scientific community. Therefore, it was attempted to mutagenize PBS1 into a variant exhibiting same lytic activity as PBS2 by means of UV-irradiation. Approximately $2 * 10^{6}$ plaques were screened for a clear-plaque mutant, yet the desired mutant was not found. Although all other prerequisites for the selection of a protein with acquired activity were fulfilled, without lytic mutant of PBS1 this selection approach could not be utilized.

2. Selection in E. coli using virulent P2virlRam3 bacteriophage with uracils introduced into DNA. In this approach Ram3 mutation in the late gene of P2vir1Ram3 bacteriophage was used to protect cells carrying desired activity from the secondary infection with newly produced bacteriophages. It was believed that due to this mutation bacterial cells die without releasing new bacteriophages. However, the P2vir1Ram3 did not fulfill this requirement and therefore could not be employed in this selection approach.

3. Selection in E. coli using heteroduplex DNA. This approach was based on the ability of DNA uridine endonuclease to initiate repair of uracil containing mismatch. The 
$E$. coli lethal gene $c c d B$ was used in the generation of a heteroduplex DNA with a mismatched uridine residue (U/T) as a part of stop codon. In contrast to our expectations, cloning of $c c d B$ gene containing the mismatch into the phagemid vector was lethal for $E$. coli despite of the stop codon present within the gene. This makes the use of this construct in this selection approach impossible.

Due to the problems that emerged during the development of above-discussed selection strategies, directed evolution of ExoA into DNA uridine endonuclease was not accomplished. Utilization of different E. coli bacteriophage (approach 2) and or construction of the heteroduplex DNA with a lethal gene other than $c c d B$ (approach 3) may lead to successful selection approach for directed evolution. However, due to limited time these possible modifications were not attempted.

Rationally designed S110D, R111K and R120K exchanges in the protein sequence lead to insolubility of ExoA, thus the protein could not be produced and characterized and attempts to improve the solubility of triple mutant protein met no success. Genetic selection of a stable variant of this triple mutant protein in E. coli $\triangle x t h A$ cells was attempted, yet cytotoxic effect of protein overexpression precluded accomplishing this task. Projecting these amino acid exchanges onto another exonuclease III homolog from a thermostable organism is likely to answer the question whether these amino acids contribute to DNA uridine endonuclease activity.

The question what makes Mth212 to a DNA uridine endonuclease remains open. Directed evolution, however, is one of the straightforward methods that can indeed clarify the mechanism of uridine recognition by Mth212. Further modifications such as use of different bacteriophages and or genes will improve the methods utilized in this work and will result in a successful selection ultimately leading to the elucidation of the structural roots lying underneath the unique activity. 


\section{Abbreviations}

Amp ampicillin

AP- apyrimidinic/apurinic site

APS ammoniumperoxodisulfat

bp base pair

BSA bovine serum albumin

${ }^{\circ} \mathrm{C} \quad$ degree Celsius

C-terminal carboxy-terminal

DNA deoxyribonucleic acid

dNTP deoxyribonucleoside triphosphate

dsDNA double stranded DNA

DTT dithiothreitol

$\mathrm{dYT}$ double yeast tryptone

EDTA ethylenediaminetetraacetate

e.g. exempli graciā (for example)

EP error-prone

g gramm

h hours

HEPES 4-(2-Hydroxyethyl)-1-piperazin-ethan-sulfonic acid

IMAC immobilized metal ion affinity chromatography

IPTG isopropyl- $\beta$-D-thiogalactopyranosid

$\mathrm{kb} \quad$ kilo-base pair

$1 \quad$ liter

LB Luria Bertani

M molar

$\mathrm{Mr} \quad$ relative molecular mass

$\mathrm{ml}, \mu \mathrm{l}$ milli- $\left(10^{-3}\right)$, micro- $\left(10^{-6}\right)$ liter

min minutes 
$\mu \mathrm{m}, \mathrm{nm}$ micro- $\left(10^{-6}\right)$, nano- $\left(10^{-9}\right)$ meter

$\mathrm{N}$-terminal amino-terminal

OD optical density $\mathrm{x} \mathrm{nm}$

ori origin of replication

p $\quad \operatorname{pico}\left(10^{-12}\right)$

PAGE polyacrylamide gel electrophoresis

PCR polymerase chain reaction

PEG polyethylenglycol

Pfu-Polymerase, DNA-Polymerase B from Pyrococcus furiosus

RT room temperature

rpm rotation per minute

sec second

SDS sodiumdodecylsulfat

ssDNA single stranded DNA

$\mathrm{T}$ temperature

t time

Taq-Polymerase, DNA-Polymerase from Thermus aquaticus

TEMED N,N,N',N'-Tetramethylethylenamin

Tris tris(hydroxymethyl)aminomethan

$\mathrm{U} \quad$ enzymatic activity unit

U-Endo DNA-uridine-endonuclease

UDG Uracil-DNA-Glycosylase

Ugi Uracil-DNA-Glycosylase Inhibitor

Ung Uracil-N-Glycosylase from E.coli

UV ultraviolet

Vol. volume

$\mathrm{v} / \mathrm{v} \quad$ volume/volume

w/v weight/volume 
3D three-dimensional

DNA/RNA-Bases:

A Adenine

C Cytosine

G Guanine

T Thymine

U Uracil

\section{Amino acids:}

A / Ala Alanine

C / Cys Cysteine

D / Asp Aspartic Acid

E / Glu Glutamic Acid

F / Phe Phenylalanine

G / Gly Glycine

$\mathrm{H}$ / His Histidine

I / Ile Isoleucine

K / Lys Lysine

L / Leu Leucine

M / Met Methionine

$\mathrm{N} /$ Asn Asparagine

P / Pro Proline

Q / Gln Glutamine

R / Arg Arginine

S / Ser Serine

$\mathrm{T} /$ Thr Threonine

V / Val Valine

W /Trp Tryptophan

Y / Tyr Tyrosine 


\section{Literature}

Abedon, S. T. (2008). Bacteriophage Ecology: population growth, evolution, and impact of bacterial viruses (Advances in Molecular and Cellular Microbiology). Cambridge: Cambridge University Press.

Afif H., N. Allali, M. Couturier and L. Van Melderen (2001). The ratio between CcdA and CcdB modulates the transcriptional repression of the $c c d$ poison-antidote system. Molecular Microbiology, 41 (1), 73-82.

Aharoni A., A. D. Griffiths and D. S. Tawfik (2005). High-throughput screens and selections of enzyme-encoding genes. Current Opinion in Chemical Biology, 9, 210-216.

An Q., P. Robins, T. Lindahl, D. E. Barnes (2005). C $\rightarrow$ T mutagenesis and gammaradiation sensitivity due to deficiency in the Smug1 and Ung DNA glycosylases. The EMBO Journal, 24, 2205-2213.

Aprelikova O. and J. Jiricny (1991). Effect of uracil situated in the vicinity of a mispair on the directionality of mismatch correction in Escherichia coli. Nucleic Acids Research, 19 (7), 1443-1447.

Arnold, F. H (1998). Design by Directed evolution. Accounts of Chemical Research, 31, 125-131.

Bahassi E. M., M. H. O'Dea, N. Allali, J. Messens, M. Gellert and M. Couturier (1999). Interactions of CcdB with DNA gyrase. Inactivation of GyrA, poisoning of the gyrase-DNA complex, and the antidote action of CcdA. The Journal of Biological Chemistry, 274 (16), 10936-10944.

Bahassi E. M., M. A. Salmon, L. Van Melderen, P. Bernard and M. Couturier (1995). F plasmid CcdB killer protein: ccdB gene mutants coding for non-cytotoxic proteins which retain their regulatory functions. Molecular Microbiology, 15 (6), 1031-1037.

Barret T. E., R. Savva, G. Panayotou, T. Barlow, T. Brown, J. Jiricny, L. H. Pearl (1998). Crystal structure of a G:T/U mismatch specific DNA glycosylase: mismatch recognition by complementary-strand interactions. Cell, 92, 117-129.

Beckman R. A., A. S. Mildvan and L. A. Loeb (1985). On the fidelity of DNA replication: manganese mutagenesis in vitro. Biochemistry, 24 (21), 5810-5817.

Ber, S. (2009). Biochemische, molekularbiologischeund genetische Untersuchung über strukturelle Voraussetzungen fr DNA U-Endonukleaseaktivität in der ExoIIIFamilie von DNA Reparaturenzymen. Dissertation. Georg August Universität Göttingen.

Bernard P., K. E. Kezdy, L. Van Melderen, J, Steyaert, L. Wyns, M. L. Pato, P. N. Hoggins and M. Couturier (1993). The F plasmid CcdB protein induces efficient ATP-dependent DNA cleavage by gyrase. Journal of Molecular Biology, 234, 534541. 
Bertani, L. (1957). The effect of inhibition of protein synthesis on the establishment of lysogeny. Virology, 4, 53-71.

Bichara M., J. Wagner and I. B. Lambert (2006). Mechanisms of tandem repeat instability in bacteria. Mutation Research/Fundamental and Molecular Mechanisms of Mutagenesis, 598 (1-2), 144-163.

Bhagwat A. S. and M. Lieb (2002). Cooperation and competition in mismatch repair: very short patch repair and methyl-directed mismatch repair in Escherichia coli. Molecular Microbiology, 44, 1421-1428.

Black M. E., T. G. Newcomb, H. M. Wilson and L. A. Loeb (1996). Creation of drugspecific herpes simplex virus type 1 thymidine kinase mutants for gene therapy. Proceedings of the Natural Academy of Sciences of United States of America, 93 (8), 3525-3529.

Brakmann S. and A. Schwienhorst (2004). Evolutionary Methods in Biotechnology. Weinheim: WILEY-VCH Verlag GmbH \& Co. KgaA.

Brakmann S. and B. F. Lindemann (2004). Generation of mutant libraries using random mutagenesis. In S. B. Schwienhorst, Evolutionary methods in biotechnology (S. 511). Weinheim: WILEY-VCH Verlag GmbH \& Co. KgaA.

Brigidi P., E. De Rossi, M. L. Bertani, G. Riccardi and D. Matteuzzi (1990). Genetic transformation of intact cells of Bacillus subtilis by electroporation. FEMS Microbiology, 67, 135-138.

Bron S., K. Murray, T. A. Trautner (1975). Restriction and modification in B. subtilis. Purification and general porperties of a restriction endonuclease from strain R. Molecular and General Genetics, 143 (1), 13-23.

Cadwell R. C. and G. F. Joyce (1994). Mutagenic PCR. PCR Methods and Applications, 3, 136-140.

Cadwell R. C. and G. F. Joyce (1992). Randomization of genes by PCR mutagenesis. PCR Methods and Applications, 2, 28-33.

Campbell C. R., D. Ayares, K. Watkins (1989). Single-stranded DNA gaps, tails and loops are repaired in Escherichia coli. Mutation Research/Fundamental and Molecular Mechanisms of Mutagenesis, 211 (1), 181-188.

Calsou P., A. Villaverde and M. Difais (1987). Activated RecA protein may induce expression of a gene that is not controlled by the LexA repressor and whose function is required for mutagenesis and repair of UV-irradiated bacteriophage lambda. Journal of Bacteriology, 169 (10), 4816-4821.

Centore R. C., R. Lestini and S. J. Sandler (2008). XthA (Exonuclease III) regulates loading of RecA onto DNA substrates in log phase Escherichia coli cells. Molecular Microbiology, 67 (1), 88-101. 
Chang A. C. Y. and S. N. Cohen (1978). Construction and characterization of amplifiable multicpoy DNA cloning vehicles derived from the P15A cryptic miniplasmid. Journal of Bacteriology, 134 (3), 1141-1156.

Chang S. and S. N. Cohen (1979). High frequency transformation of Bacillus subtilis protoplasts by plasmid DNA. Molecular and General Genetics, 168, 111-115.

Chen J., T. B. Acton, S. K. Basu, G. T. Montelione and M. Inouye (2002). Enhancement of the solubility of proteins overexpressed in Escherichia coli by heat shock. Journal of molecular Microbiology and Biotechnology, 4 (6), 519-524.

Chen J-C., W. M. Rideout III and P. A. Jones (1994). The rate of hydrolytic deamination of 5-methylcytosine in double-stranded DNA. Nucleic Acids Research, 22 (6), 972-976.

Chritchlow S. E., M. H. O'Dea, A. J. Howells, M. Couturier, M. Gellert and A. Maxwell (1997). The interaction of the F-plasmid killer protein, CcdB, with DNA gyrase:induction of DNA cleavage and blocking of transcription. Journal of Molecular Biology, 273, 826-839.

Cirino P. C., K. M. Mayer and D. Umeno (2003). Generating mutant libraries using error-prone PCR. Methods in Molecular Biology, 231, 3-9.

Ciirdaeva E. (2009). Investigations into the mode of action of the DNA uridine endonuclease Mth212 of Methanothermobacter thermautotrophicus $\Delta \mathrm{H}$. Dissertation. Georg August Universität Göttingen.

Cordoba-Canero D., E. Dubois, R. A. Ariza, M-P- Doutriaux and T. Roldan-Arjona (2010). Arabidopsis Uracil DNA Glycosylase (UNG) is required for base excision repair of uracil and increases plant sensitivity to 5-Fluorouracil. The Journal of Biological Chemistry, 285, 7475-7483.

Cunningham R. P., S. M. Saporito, S. G. Spitzer and B. Weiss (1986). Endonuclease IV (nfo) mutant of Escherichia coli. Journal of Bacteriology, 168 (3), 1120-1127.

Cutting S. M. and P. Youngman (1994). Gene transfer in Gram-Positive bacteria. In Methods for general and molecular bacteriology (S. 348-364). Washington, DC: American Society for Microbiology.

Dao-Thi M-H., L. Van Melderen, E. De Genst, H. Afif, L. Buts, L. Wyns. R. Loris (2005). Molecular basis of gyrase poisoning by the addiction toxin CcdB. Journal of Molecular Biology, 348 (5), 1091-1102.

Davidson J. F., J. Anderson, H. Guo, D. Landis and L. A. Loeb (2002). Applied molecular evolution of enzymes involved in synthesis and repair of DNA. In S. B. Johnson, Directed Molecular Evolution of Proeins: or How to Improve Enzymes for Biocatalysis (S. 281-307). Wiley-VCH Verlag GmbH \& Co. KGaA.

De Bont R. and N. van Larebeke (2004). Endogenous DNA damage in humans: a review of quantative data. Mutagenesis, 19 (3), 169-185. 
De Feyter R., C. Wallace, D. Lane (1989). Autoregulation of the $c c d$ operon in the F plasmid. Molecular and General Genetics, 218, 481-486.

Demple B. A., A. Johnson and D. Fung (1986). Exonuclease III and endonuclease IV remove 3' blocks from DNA synthesis primers in $\mathrm{H}_{2} \mathrm{O}_{2}$-damaged Escherichia coli. Proceedings of the Natural Academy of Sciences of United States of America, 83, 7731-7735

Di Noia J. M., C. Rada, M. S. Neuberger (2006). SMUG1 is able to excise uracil from immunoglobulin genes: insight into mutation versus repair. The EMBO Journal, 25, 585-595.

Dower W. J., J. F. Miller and C. W. Ragsdale (1988). High efficiency transformation of E. coli by high voltage electroporation. Nucleic Acids Research, 16, 6127-6145.

Dowding J. E. and D. D. Hopwood (1973). Temperate bacteriophage for Streptomyces coelicolor A2(2) isolated from soil. Journal of General Microbiology, 78, 349-359.

Duncan B. K. and J. Miller (1980). Mutagenic deamination of cytosine residues in DNA. Nature, 287, 560-561.

Duncan B. K. and B. Weiss. (1982). Specific mutator effects of ung (uracil-DNA glycosylase) mutations in Escherichia coli. Journal of Bacteriology, 151 (2), 750755.

Duncan B. K. and H. R. Warner (1977). Metabolism of uracil-containing DNA: Degradation of bacteriophage PBS2 DNA in Bacillus subtilis. Journal of Virology, 22 (3), 835-838.

Eckert K. A. and T. A. Kunkel (1990). High fidelity DNA synthesis by the Thermus aquaticus DNA polymerase. Nucleic Acids Research, 18, 3739-3744.

El-Deiry W. S., K. M. Downey and A. G. So (1984). Molecular mechanisms of manganese mutagenesis. Proceedings of the Natural Academy of Sciences of United States of America, 81, 7378-7382.

Fields P. I. and R. E. Yasbin (1980). Involvement of deoxyribonucleic acid polymerase III in W-reactivation in Bacillus subtilis. Journal of Bacteriology, 144 (1), 473-475.

Friedberg E. C., G. C. Walker, W. Siede, R. D. Wood, R. A. Schultz, T. Ellenberger (2006). DNA Repair and Mutagenesis. Second edition. Washington, D.C.: ASM Press.

Fromant M., S. Blanquet and P. Plateau (1995). Direct random mutagenesis of genesized DNA fragments using Polymerase Chain Reaction. Analytical Biochemistry, 224, 347-353.

Fromme J. C. and G. L. Verdine (2004). Base Excision Repair. In W. Yang, Advances in protein chemistry. Volume 69. DNA repair and replication (S. 1-28). San Diego: Elsevier Academic Press. 
Gabbar S., M. Wyszynski and A. S. Bhagwat (1994). A DNA repair process in Escherichia coli corrects $\mathrm{U}: \mathrm{G}$ and $\mathrm{T}: \mathrm{G}$ mismatches to $\mathrm{C}: \mathrm{G}$ at sites of cytosine methylation. Molecular and General Genetics, 243, 244-248.

Gelfand D. H. and T. H. White (1990). In PCR Protocols: A guide to methods and applications (S. 129-141). San Diego: Academic Press.

Georg J., L. Schomacher, J. P. Chong, A. I. Majernik, M. Raabe, H. Urlaub, S. Müller, E. Ciirdaeva, W. Kramer and H-J. Fritz (2006). The Methanothermobacter thermautotrophicus ExoIII homologue Mth212 is a DNA uridine endonuclease. Nucleic Acids Research, 34 (18), 5325-5336.

Gläsner W., R. Merkl, V. Schellenberger, H-J. Fritz (1995). Substrate preferences of Vsr DNA mismatch endonuclease and their consequences for the evolution of the Escherichia coli K-12 genome. Journal of Molecular Biology, 245, 1-7.

Hadi M. Z. and D. M. Wilson III (2000). Second human protein with homology to the Escherichia coli abasic endonuclease III. Environmental and Molecular Mutagenesis, 36, 312-324.

Hanahan, D. (1985). DNA Cloning I. A Practical Approach. New York: Oxford University Press/IRL Press.

Harris R. S., S. K. Petersen-Mahrt, M.S. Neuberger (2002). RNA editing enzymes APOBEC1 and some of its homologs can act as DNA mutators. Molecular Cell, 10, 1247-1253.

Hendrich B., U. Hardeland, H-H. Ng, J.Jiricny, A. Bird (1999). The thymine glycosylase MBD4 cad bind to the product of deamination at methylated CpG sites. Nature, 401, 301-304.

Hilvert D., S. V. Tayoler and P. Kast (2002). Using Evolutionary strategies to investigate the structure and function of chorismate mutases. In S. B. Johnson, Directed Molecular Evolution of Proteins: or How to Improve Enzymes for Biocatalysis (S. 29-62). Wiley-VCH Verlag GmbH \& Co. KGaA.

Hinks J. A., M. C. Evans, Y. De Miguel, A. A. Sartori, J. Jiricny and L. H. Pearl (2002). An iron-sulphur cluster in the family 4 uracil DNA glycosylases. Journal of Biological Chemistry, 277, 16936-16940.

Hitzeman R. A., and A. R. Price (1978). Bacillus subtilis bacteriophage PBS2-induced DNA polymerase, its purification and assay characteristics. The Journal of Biological Chemistry, 253 (23), 8518-8525.

Horst J-P., and H-J. Fritz (1996). Counteracting the mutagenic effect of hydrolytic deamination of DNA 5-methylcytosine residues at high temperature: DNA mismatch N-glycosylae Mig.Mth of the thermophilic archaeon Methanobacterium thermoautotrophicum THF. The EMBO Journal, 15 (19), 5459-5469. 
Hoseki J., A. Okamoto, R. Masui, T. Shibata, Y. Inoue, S. Yokoyama and S. Kuramitsu (2003). Crystal structure of a family 4 uracil-DNA glycosylases from Thermus thermophilus HB8. Journal of Molecular Biology, 333, 515-526.

Ischenko A. A. and M. K. Saparbaev (2002). Alternative nucleotide incision repair pathway fro oxidative DNA damage. Nature, 415, 183-187.

Ishiwa H. and H. Shibahara-Sone (1986). New shuttle vectors for Escherichia coli and Bacillus subtilis. IV. The nucleotide sequence of pHY300PLK and some properties in relation to transformation. Japanese Journal of Genetics, 61, 515-528.

Jackson L.A. and L. A. Loeb (2001). The contribution of endogenous sources of DNA damage to the multiple mutations in cancer. Mutation Research, 477 (1-2), 7-21.

Jaenisch R. and A. Bird (2003). Epigenetic regulation of gene expression: how the genome integrates intrinsic and environmental signals. Nature Genetics, 33 Suppl:, 245-254.

Jansohn, M. (2006). Gentechnische Methoden. Eine Sammlung von Arbeitsanleitungen für das molekularbiologische Labor. Spektrum Akademischer Verlag.

Kahn M. L., R. Ziermann, G. Deho, D. W. Ow, M. G. Sunshine and R. Calendar (1991). Bacteriophage P2 and P4. Methods in Enzymology, 204, 264-280.

Katz G. E., A. R. Price and M. J. Pomerantz (1976). Bacteriophage PBS2-induced inhibition of uracil-containing DNA degradation. Journal of Virology, 20 (2), 535538.

Kavil B., M. Otterlei, G. Slupphaug, H. E. Krokan (2007). Uracil in DNA - general mutagen, but normal intermediate in acquired immunity. DNA Repair, 6, 505-516.

Kavli B., O. Sundheim, M. Akbari, M. Otterlei, H. Nilsen, P. A. Aas, L. Hagen, H. E. Krokan, G. Slupphaug (2002). hUNG2 is the major repair enzyme for removal of uracil from U:A mismatches, and U in single-stranded DNA, with hsMUG1 as a broad specificity backup. The Journal of Biological Chemistry, 277, 39926-39936.

Kosaka H., J. Hoseki, N. Nakagawa, S. Kuramitsu, R. Masuri (2007). Crystal structure of family 5 uracil-DNA glycosylase bound to DNA. Journal of Molecular Biology, 373 (4), 839-850.

Kowalczykowsi S. C. (2000). Initiation of genetic recombination and recombinationdependent replication. Trends in Biochemical Sciences, 25, 156-165

Kramer B., W. Kramer and H-J. Fritz (1984). Different base/base mismatches are corrected with different efficiencies by the methyl-directed DNA mismatch-reoair system of E. coli. Cell, 38, 879-887.

Krokan H. E., F. Drablos and G. Slupphaug (2002). Uracil in DNA - occurence, consequences and repair. Oncogene, 21, 8935-8948. 
Kunkel, T. (1992). DNA replication fidelity. Journal of Biological Chemistry, 267, 1825118254.

Laemmli, U. K. (1970). Cleavage of structural proteins during the assembly of the head of bacteriophage T4. Nature, 227, 680-685.

Lakomek, K. (2009). Structural characterization of the lysosomal $66.3 \mathrm{kDa}$ protein and of the DNA repair enzyme Mth0212 by means of X-ray crystallography. Dissertation. Georg August University of Göttingen.

Lakomek K., A. Dickmanns, E. Ciirdaeva, L. Schomacher and R. Ficner (2010). Crystal structure analysis of DNA uridine endonuclease Mth212 bound to DNA. Journal of Molecular Biology, 399, 604-617.

Lauer G. D. and L. C. Klotz (1976). Molecular weight of bacteriophage PBS2 DNA. Journal of Virology, 18 (3), 1163-1164.

Linderoth N. A., B. Julien, K. E. Flick, R. Calendar and G. E. Christie (1994). Molecular cloning and characterization of bacteriophage P2 genes $\mathrm{R}$ and $\mathrm{S}$ involved in tail completion. Virology, 200, 347-359.

Lindahl, G. (1971). On the control of transcription of bacteriophage P2. Virology, 46, 620633.

Lindahl T. and B. Nyberg (1972). Rate of depurination of native deoxyribonucleic acid. Biochemistry, 11 (19), 3610-3618.

Lindahl, T. (1993). Instability and deacy of the primary structure of DNA. Nature, 362, 709-715.

Lindahl T. and D. E. Barnes. (2000). Repair of endogenous DNA damage. Cold Spring Harbor Symp. Quant. Biol., 65, 127-133.

Lindahl, T. (2001). Keynote: Past, present and future aspects of base excision repair. Progress in Nucleic Acid Research and Molecular Biology, 68.

Loris R., M-H. Dao-Thi, E. M. Bahassi, L. Van Melderen, F. Poortmans, R. Liddngton. M. Couturier and L. Wyns (1999). Crystal structure of CcdB, a topoisomerase poison from E. coli. Journal of Molecular Biology, 285, 1667-1677.

Love P. E. and R. E. Yasbin (1984). Characterzation of the inducble SOS-like system of Bacillus subtilis. Journal of Bacteriology, 160 (3), 910-920.

Lutz S. and S. J. Benkovic (2002). Engineering protein evolution. In S. B. Johnson, Directed Molecular Evolution of Proteins: or how to improve enzymes for biocatalysis (S. 177-208). Wiley-VCH Verlag GmbH \& Co. KGaA.

Martin-Verstraete I., M. Debarbouille, A. Klier and G. Rapoport (1994). Interactions of wild-type and truncated LevR of Bacillus subtilis with the upstream activating sequence of the levanase operon. Journal of Molecular Biology, 241, 178-192. 
Meinken C., H-M. Blencke, H. Ludwig and J. Stülke (2003). Expression of the glycolytic gapA operon in Bacillus subtilis: differential syntheses of proteins encoded by the operon. Microbiology, 149, 751-761.

Miura A. and J. Tomizawa (1970). Mutation and recombination of bacteriophage lambda: effect of ultraviolet radiation. Proceedings of the Natural Academy of Sciences of United States of America, 67 (4), 1744-1726.

Mol C. D., S. P. S. Parikh, C. D. Putnam, T. P. Lo and J. A. Tainer (1999). DNA repair mechanisms for the recognition and removal of damaged DNA bases. Annual Review of Biophysics and Biomolecular Structure, 28, 101-128.

Mol C. D., T. Izumi, S. Mitra and J. A. Tainer (2000). DNA-bound structures and mutants reveal abasic DNA binding by APE1 and DNA repair coordination (corrected). Nature, 403, 451-456.

Msadek T., F. Kunst, A. Klier and G. Rapoport (1991). DegS-DegU and ComP-ComA Modulator-Effector pairs control expression of the Bacillus subtilis pleiotropic regulatory gene degQ. Journal of Bacteriology, 173 (7), 2366-2377.

Nedderman P. and J. Jiricny (1994). Efficient removal of uracil from G-U mispairs by the mismatch-specific thymine DNA glycosylase from HeLa cells. Proceedings of the Natural Academy of Sciences of United States of America, 91, 1642-1646.

Olsen L. C., R. Aasland, H. E. Krokan and D. E. Helland (1991). Human uracil-DNA glycosylase complements E. coli ung mutants. Nucleic Acids Research, 19 (16), 4473-4478.

Pace C. N., F. Vajdos, L. Fee, G. Grimsley and T. Gray (1995). How to measure and predict the molar absorption coefficient of a protein. Protein Science, 4, 2411-2423.

Palmer B. R. and M. G. Marinus (1994). The dam and $d c m$ strains of Escherichia coli: a review. Gene, 143 (1), 1-12.

Palva I., P. Lehtovaara, L. Kääriäinen, M. Sibakov, K. Cantell, C. H. Schein, K. Kashiwagi, C. Weissmann (1983). Secretion of interferon by Bacillus subtilis. Gene, 22 (2-3), 229-235.

Parikh S. S., C. D. Mol, G. Slupphaug, S. Bharati, H. E. Krokan, J. A. Tainer (1998). Base excision repair initiation revealed by crystal structures and binding kinetics of human uracil-DNA glycosylase with DNA. The EMBO Journal, 17, 5214-5226.

Patel P. H. and L. A. Loeb (2000). DNA polymerase active site is highly mutable: evolutionary consequences. Proceedings of the NAtional Academy of Sciences of United States of America, 97 (10), 5095-5100.

Pearl, H. P. (2000). Structure and function in the uracil-DNA glycosylase superfamily. Mutation Research, 460, 165-181.

Pruss G. J. and R. Calendar (1978). Maturation of bacteriophage P2 DNA. Virology, 86 (2), 454-467. 
Rastogi R. P., Richa, A. Kumar, M: B. Tyagi and R. P. Sinha (2010). Molecular mechanisms of ultraviolet radiation-induced DNA damage and repair. Journal of Nucleic Acids, Published online 2010 December 16. doi:10.4061/2010/592980.

Rice K. C. and K. W. Bayles (2008). Molecular control of bacterial death and lysis. Microbiology and Molecular Biology Reviews, 72 (1), 85-109.

Roberts J. D. and T. A. Kunkel (1996). Chapter 7. Fidelity of DNA replication. In M. L. DePamphilis, DNA Replication in Eukaryotic Cells (S. 217-247). New York: Cold Springs Harbor Laboratory Press.

Rothwell D. G., B. Hang, M. A. Gorman, P. S. Freemont, B. Singer, I. D. Hickson (2000). Substitution of Asp-210 in HAP1 (APE/Ref-1) eliminates endonuclease activity but stabilises substrate binding. Nucleic Acids Research, 28 (11), 22072213.

Ruiz-Laguna J., M. J. Prieto-Alamo, C. Pueyo (2000). Oxidative mutagenesis in Escherichia coli strains lacking ROS-scavenging enzymes and/or 8-oxoguanine defenses. Environmental and Molecular Mutagenesis, 35 (1), 22-30.

Salas-Pacheco J. M., B. Setlow, P. Setlow and M. Pedraza-Reyes (2005). Role of the Nfo and ExoA apurinic/apyrimidinic endonucleases in protecting Bacillus subtilis spores from DNA damage. Journal of Bacteriology, 187 (21), 7374-7381.

Sandigursky M., and W. A. Franklin (1999). Thermostable uracil-DNA glycosylase from Thermotoga maritima, a member of a novel class of DNA repair enzymes. Current Biology, 9, 531-534.

Sandigursky M., and W. A. Franklin (2000). Uracil DNA glycosylase in the extreme thermophile Archaeoglobus fulgidus. Journal of Biological Chemistry, 275, 1914619149.

Sanger F., S. Nicklen, A. R. Coulson (1977). DNA sequencing with chain terminating inhibitors. Proceedings of the National Academy of Sciences of United States of America, 74, 5463-5467.

Santos S. B., C. M. Carvalho, S. Sillankorva, A. Nicolau, E. C. Ferreira and J. Azeredo (2009). The use of antibiotics to improve phage detection and enumeration by the double-layer agar technique. BMC Microbiology, 9 (148), doi:10.1186/1471-2180-9-148.

Sartori A. A., A. Fitz-Gibbon. H. Yang, H. Miller and J. Jiricny (2002). A novel uracilDNA glycosylase with broad substrate specificity and an unusual active site. The EMBO Journal, 21, 3182-3191.

Sartori A. A., P. Schär, S. Fitz-Gibbon, J. H. Miller and J. Jiricny (2001). Biochemical characterization of uracil-processing activities in the hyperthermopilic archaeon Pyrobaculum aerophilum. Journal of Biological Chemistry, 276, 29979-29986.

Sasaki I. and G. Bertani (1965). Growth abnormalities in Hfr derivatives of Escherichia coli strain C. Journal of General Microbiology, 40, 365-376. 
Savva R., K. McAuley-Hecht, T. Brown, L. H. Pearl (1995). The structural basis of specific base-excision repair by uracil-DNA glycosylase. Nature, 373, 487-493.

Schmiedel R., B. Kuettner, A. Keim, N. Sträter and T. Greiner-Stöffele (2009). Structure and function of an AP endonuclease from Archaeoglobus fulgidus. DNA Repair, 8 (2), 219-231.

Schomacher L., A. K. Schürer, E. Ciirdaeva, P. McDermott, J. P. J. Chong, W. Kramer, H-J. Fritz (2010). Archaeal DNA uracil repair via direct strand incision: A minimal system reconstituted from purified components. DNA Repair, 9, 438447.

Schomacher L., J. P. J. Chong, P. Mcdermott, W. Kramer and H-J. Fritz (2009). DNA uracil repair initiated by the archaeal ExoIII homologue Mth212 via direct strand incision. Nucleic Acids Research, 37 (7), 2283-2293.

Shafikhani S., R. A. Siegel, E. Ferrari and V. Schellenberger (1997). Generation of large libraries of random mutants in Bacillus subtilis by PCR-based plasmid multimerization. Biotechniques, 23 (2), 304-310.

Shenoy S., K. C. Ehrlich and M. Ehrlich (1987). Repair of thymine-guanine and uracilguanine mismatched bases in bacteriophage M13mp18 DNA heteroduplexes. Journal of Molecular Biology, 197 (4), 617-626.

Shida T, T. Ogawa, N. Ogasawara, and J. Sekiguchi (1999). Characterization of Bacillus subtilis ExoA protein: a multifunctiona DNA-repair enzyme similiar to the Escherichia coli exonuclease III. Bioscience, Biotechnology and Biochemistry, 63 (9), 1528-1534.

Singleton P. and D. Sainsbury (2006). Dictionary of Microbiology and Molecular Biology. Third edition, revised. West Sussex: John Wiley \& Sons Ltd.

Slepecky R. A. and H. E. Hemphill (2006). The Genus Bacillus - Nonmedical. In M. D. al., Prokaryotes, Third edition (S. 530-562). Springer Science + Business Media, LLC.

Smolorz, S. (2009). Untersuchungen zum Problem der spezifischen Erkennung des Substrat-Uracilrestes durch die zur ExoIII-Familie gehörende Uridin-Endonuklease Mth212 aus Methanothermobacter thermautotrophicus. Diplomarbeit. Georg August Universität Göttingen.

Starkuviene V., and H. J. Fritz (2002). A novel type of uracil DNA glycosylases mediating repair of hydrolytic DNA damage in the extremely thermophilic eubacterium Thermus thermophilus. Nucleic Acids Research, 30, 2097-2102.

Starkuviene, V. (2001). Identification and characterization of thermostable uracil glycosylases from the archaeon Methanobacterium thermoautotrophicum and the bacterium Thermus thermophilus. Dissertation, Georg-August Universität Göttingen. 
Steege D. A. and J. I. Horabin (1983). Temperature inducible amber suppressor: construction of plasmids containing the Escherichia coli SerU- (SupD-) gene under control of the bacteriophage labmd PL promoter. Journal of Bacteriology, 155 (3), 1417-1425.

Suenaga H., M. Goto and K. Furukawa (2004). DNA shuffling. In S. B. Schwienhorst, Evolutionary methods in biotechnology (S. 13-24). Weinheim: WILEY-VCH Verlag GmbH \& Co. KgaA.

Sunshine M. G., M. Thorn, W. Gibbs, R. Calendar and B. Kelly (1971). P2 phage amber mutants: Characterization by use of a polarity supressor. Virology, 46 (3), 691-702.

Takahashi, I. (1963). Transducing phages for Bacillus subtilis. Journal of General Microbiology, 31, 211-217.

Trevors J. T., B. M. Chassy, W. J. Dower and H. P. Blaschek (1992). Electrotransformation of bacteria by plasmid DNA. In Guide to Electroporation and Electrofusion (S. 265-290). San Diego: Academic Press.

Vartanian J-P., M. Henry and S. Wain-Hobson (1996). Hypermutagenic PCR involving all four transitions and a sizeable proportion of transversions. Nucleic Acids Research, 24 (14), 2627-2631.

Verri A., P. Mazzarello, G. Biamonti, S. Spadari and F. Focher (1990). The spicific binding of nuclear protein(s) to the cAMP responsive element (CRE) sequence (TGACGTCA) is reduced by the misincorporation of $U$ and increased by desamination of C. Nucleic Acids Research, 18, 5775-5780.

Walker, G. C. (1978). Inducible reactivation and mutagenesis of UV-irradiated bacteriophage P22 in Salmonella typhimurium LT2 containing the plasmid pKM101. Journal of Bacteriology, 135 (2), 415-421.

Wang Z. and D. W. Mosbaugh (1989). Uracil DNA glycosylase inhibitor gene of bacteriophage PBS2 encodes a binding protein specific for uracil DNA glycosylase. Journal of Biological Chemistry, 264, 1163-1171.

Wang T-W., H. Zhu, X-Y. Ma, t. Zhang, Y-S. Ma and D-Z. Wei (2006). Mutant library construction in directed molecular evolution. Molecular Biotechnology, 34, 55-68.

Wanner R. M., D. Castor, C. Güthlein, E. C: Böttger, B. Springer, J. Jiricny (2009). The uracil DNA glycosylase UdgB of Mycobacterium smegmatis protects the organism from the mutagenic effects sof cytosine and adenine deamination. Journal of Bacteriology, 191 (20), 6312-6319.

Warner H. R., B. K. Duncan, C. Garret and J. Neuhard (1981). Synthesis and metabolism of uracil-containing deoxyribonucleic acid in Escherichia coli. Journal of Bacteriology, 145 (2), 687-695.

Weigle, J. J. (1953). Induction of mutations in a bacterial virus. Proceedings of the Natural Academy of Sciences of United States of America, 39, 628-636. 
Weiss B. and L. Grossman (1987). Phosphodiesterases involved in DNA repair. Advances in Enzymology, 60, 1-34.

Xia G., L. Chen, T. Sera, M. Fa, P. G. Schulzt, F. E. Romesberg (2002). Directed evolution of novel polymerase activities: mutation of a DNA polymerase into an efficient RNA polymerase. Proceedings of the Natural Academy of Sciences of United States of America, 99 (10), 6597-6602.

Xiao G. Y., M. Tordova, J. Jagadeesh, A. C. Drohat, J. T. Stivers, G. L. Gilliland (1999). Crystal structure of Escherichia coli uracil DNA glycosylase and its complexes with uracil and glycerol: structure and glycosylase mechanism revisited. Proteins: Structure, Function and Genetics, 35, 13-24.

Xue G-P., J. S. Johnson, B. P. Dalrymple (1999). High osmolarity improves the electrotransformation efficiency of the gram-positive bacteria Baciilus subtilis and Bacillus licheniformis. Journal of Microbiological Methods, 34, 183-191.

Yang H., S- Fitz-Gibbon, E. M. Marcotte, J. H. Tai, E. C. Hyman and J. H. Miller (2000). Characterization of a thermostable DNA glycosylase specific for U/G and T/G mismatches from the hyperthermophilic archaeon Pyrobaculum aerophilum. Journal of Bacteriology, 182, 1272-1279.

Yoon J. H., C. S. Lee, T. R. O'Connor, A. Asui and G. P. Pfeifer (2000). The DNA damage spectrum produced by simulated sunlight. Journal of Molecular Biology, 299, 681-693.

Zieg J., V. F. Maples and S. R. Kushner (1978). Recombination levels of Escherichia coli K-12 mutants deficient in various replication, recombination, or repair genes. Journal of Bacteriology, 134 (3), 958-966.

Zierman R., B. Bartlett, R. Calendar and G. E. Christie (1994). Functions involved in bacteriophage P2-induced host cell lysis and identification of a new tail gene. Journal of Bacteriology, 176 (16), 4974-4984. 


\section{Appendix}

In Appendix Section original sequencing data are given (refer to the attached CD). Chromatograms are saved in .ab1 format and can be viewed by employing enclosed Chromas Lite 2.01 software. Vector sequences are given in .docx files as well as in .gb format, supported by Vector NTI software.

7.1 Vector sequences

7.2 Sequences of cloned error-prone PCR products

7.2.1 Sequences to Approach 1 (Results and Discussion, 3.2)

7.2.2 Sequences to Approach 2 (Results and Discussion, 3.3)

7.2.3 Sequences to Approach 3 (Results and Discussion, 3.4)

7.3 Verification of different clonings

7.3.1 Sequence of exoA with SphI restriction site removed

7.3.2 Sequence of cloned serU132 tRNA gene

7.3.3 Sequence of cloned $R$ gene from P2vir1Ram3 bacteriophage

7.3.4 Sequence of cloned $R$ gene from P2vir1 bacteriophage

7.3.5 Sequences of $c c d B \_K 45$ construct cloned into pJET1.2

7.4 Cloning of $c c d B \_K 45$ construct into pBluescript II SK (+) phagemid vector

7.4.1 Sequences of $c c d B \_K 45$ construct cloned into pBluescript II SK (+) in undesired orientation

7.4.2 Sequences of $c c d B \_K 45$ construct cloned into pBluescript II SK $(+)$ in desired orientation

7.5 Sequences to directed mutagenesis of ExoA

7.5.1 Sequences of ExoA single and triple mutants

7.5.2 Sequence of ExoA quadruple mutant

7.6 exoA sequences from survived $\Delta x t h A$ transformants

7.7 Nucleotide and amino acid sequences of exoA 


\section{Acknowledgements}

Prof. Dr. Hans-Joachim Fritz is the first I would like to thank to. I thank you for accepting me as a $\mathrm{PhD}$ student in your research group, for your keen supervision, motivating discussions and encouragement.

I would like to thank Dr. Wilfried Kramer. Thank you for being co-referent of the thesis, for your valuable remarks on the theoretical and practical aspects of the work, for all advices and help.

I also wish to express my gratitude to my colleagues at the department Dr. Anke Schürer, Dr. Christopher Ede, Steffen Schubert, Nils Krietenstein, Sabine Smolorz, Sabrina Lehmann, who all helped me, taught me and motivated me throughout my work. My special thanks goes to Dr. Blagovesta Popova for her continuous help, and to my lab-mates Dr. Elena Ciirdaeva and Dr. Svetlana Ber for being not only the lab-mates but very good friends. You all being so nice and friendly had a great impact on me and my work.

Many thanks to Marita Kalck, Bettina Hucke, Christiane Preiß, Angelika Löffers for their readiness to help and the warm, friendly atmosphere. I greatly appreciate the work of Olaf Waase, Patrick Regin and Jarek Sobkowiak.

I would love to extent my warmest thanks to all my friends from Göttingen. There are too many people whom I am grateful to mention all here. But thanks to you all I always felt like at home in Göttingen. My special thanks goes to Dr. Byambajav Buyandelger, Altantsetseg Tsendsuren, Khishigjargal Mookhor and Oyunsanaa Byambasuren whose help and support have been invaluable.

I wish to strongly express my thanks to the DAAD, Deutscher Akademischer Austausch Dienst, especially the Referat 423. Without the financial support from DAAD I would not be writing these words.

Last but never the least I would like to thank my family. To my beloved grandmother Sonya, who is always praying for me, I dedicate this work. I am deeply grateful to my dearest parents, my best advisers, to whom I am always their little baby. Without my Mom I would never have stepped into this fascinating field, and I can't thank her enough for that. I thank my beloved and respected grandparents, uncles and aunts, my two little sisters, whose love, support and belief in me give me the strength to go forward. 


\section{Curriculum vitae}

Name:

Date of birth:

Place of birth:

Nationality:

1990-2000

2000-2004

2004

2004-2005

2005-2006

2006-2007

2007-2011

October 2007-till date

\section{Khaliun Tseden}

11.11.1983

Greifswald, Germany

Mongolian
Primary and secondary Mongolian-Russian joint school Nr. 3

Study of Biotechnology with major in Genetics at the Faculty of Biology, National University of Mongolia.

Bachelor of Science (B.Sc.) degree in Biology. Diploma work: "Optimisation and employment of RAPD-PCR for populational genetics study of Ochotona daurica”.

Experimental work at the Institute of Human Genetics, Georg-August University of Göttingen

Study for the Master of Science (M. Sc.) degree in Biology at the Faculty of Biology, National University of Mongolia. Master thesis: "Premature translation of transition protein 2 mRNA causes sperm abnormality and male infertility."

Teaching assistant at the Faculty of Biology, National University of Mongolia

German Academic Exchange Service (DAAD) fellow

$\mathrm{PhD}$ study at the Institute of Microbiology and Genetics, Georg-August University of Göttingen under supervision of Prof. Dr. Hans-Joachim Fritz 